UNIVERSIDADE DE SÃO PAULO

FACULDADE DE ECONOMIA, ADMINISTRAÇÃO E CONTABILIDADE DEPARTAMENTO DE ADMINISTRAÇÃO PROGRAMA DE PÓS-GRADUAÇÃo EM ADMINISTRAÇÃO

THREE STUDIES ON FARMER COOPERATIVES: HETEROGENEITY, MEMBER PARTICIPATION AND DEMOCRATIC DECISION MAKING

Daniela Maria Pozzobon Orientador: Prof. Dr. Decio Zylbersztajn 
Prof. Dr. João Grandino Rodas

Reitor da Universidade de São Paulo

Prof. Dr. Reinaldo Guerreiro

Diretor da Faculdade de Economia, Administração e Contabilidade

Prof. Dr. Adalberto Américo Fischmann

Chefe do Departamento de Administração

Prof. Dr. Lindolfo Galvão de Albuquerque

Coordenador do Programa de Pós-Graduação em Administração 


\title{
THREE STUDIES ON FARMER COOPERATIVES: HETEROGENEITY, MEMBER PARTICIPATION AND DEMOCRATIC DECISION MAKING
}

\author{
Tese apresentada ao Departamento de \\ Administração da Faculdade de Economia, \\ Administração e Contabilidade da \\ Universidade de São Paulo como requisito \\ para a obtenção do título de Doutor em \\ Administração.
}

Orientador: Prof. Dr. Decio Zylbersztajn

\section{Versão Corrigida}

(versão original disponível na Unidade que aloja o Programa)

\section{SÃO PAULO}


FICHA CATALOGRÁFICA

Elaborada pela Seção de Processamento Técnico do SBD/FEA/USP

Pozzobon, Daniela Maria

Three studies on farmer cooperatives : heterogeneity, member participation and democratic decision making / Daniela Maria Pozzobon. - São Paulo, 2011.

$247 \mathrm{p}$.

Tese (Doutorado) - Universidade de São Paulo, 2011.

Orientador: Decio Zylbersztajn.

1. Governança corporativa 2. Custo de transação - Efeitos 3.

Cooperativas agrícolas I. Universidade de São Paulo. Faculdade de Economia, Administração e Contabilidade. II. Título.

CDD -658.4 
Dedico esta obra, e todo esforço que dediquei a ela, a um homem incansável que transforma a terra bruta em alimentos, e a uma mulher iluminada que transforma palavras em versos: meus queridos pais; $\mathrm{e}$ a um homem que, de tão especial, faz dezenas de milhares de quilômetros parecerem meros centímetros: meu amado e sempre presente, Mark. 
Agradeço aos meus pais, João e Onilse Noal Pozzobon, por toda força, por compreenderem minha ausência, e pelo apoio que me dedicaram em todas as minhas idas e vindas nestes 5 anos, desde os 6 primeiros meses em que passei somente como aluna especial, até os 12 meses que passei no exterior.

Agradeço ao meu amado Mark, pelo seu apoio incansável e incondicional durante as principais fases de desenvolvimento desta tese, pelas suas inúmeras leituras e discussões, por toda sua atenção e amor. Agradeço à família Wever por todo carinho e apoio.

Agradeço imensamente ao Prof. Decio Zylbersztajn, por ter acreditando na minha capacidade e me aceitado como sua orientanda, pelo respeitoso relacionamento que tivemos neste período, por ter me passando seus conhecimentos e experiências, pela oportunidade de desenvolver meu trabalho também no exterior.

Agradeço a CAPES e CAPES exterior pelo financiamento da bolsa.

Agradeço aos Professores Martinho Almeida e Cláudio Machado Filho por me receberem na FEA e em sua disciplina em 2006, e por me indicarem o Prof. Decio Zylbersztajn como provável orientador.

Agradeço a querida Nice Santana por todo seu apoio, agradeço também sua incrível família (Júnior, Léo, Aline e Felipe), por terem sido minha família em São Paulo.

Agradeço aos queridos colegas, Guilherme Monteiro, Silvia Caleman e José Paulo Souza, que sempre dedicaram um pouquinho do seu tempo para discussões sobre meu trabalho.

Agradeço ao colega Christiano Cunha pela sua ajuda na parte econométrica.

Agradeço ao Dr. Jos Bijman, por ter me recebido no Management Studies Group, e por ter dedicado seu tempo para leitura e discussões do meu trabalho, durante 12 meses.

Agradeço aos professores da FEA, Sérgio Zaccarelli, Silvio dos Santos, Maria Tereza Fleury, Afonso Carlos Fleury, Cláudio Machado Filho, Maria Aparecida Gouvêa, Decio Zylbersztajn, Maria Sylvia Saes, José Augusto da Silveira, pelos conhecimentos transmitidos nas disciplinas cursadas.

Agradeço aos colegas da FEA, mestrandos e doutorandos, pelas discussões em grupo, em especial aos colegas Marco Antonio Conejero, Sonia Decoster e Liana Peçanha

Agradeço aos alunos das turmas de graduação onde prestei a disciplina de monitoria juntamente com o Prof. Decio Zylbersztajn e com a companhia insubstituível do Dr. José Paulo. Agradeço também o apoio do colega Evandro Siqueira Francisco nesta fase.

Agradeço ao Prof. Onno Omta, por ter me aceitado no Management Studies Group Wageningen University, e aos professores, colegas e funcionários, por terem proporcionado um excelente ambiente de trabalho. Neste período, gostaria de agradecer em especial, aos colegas Jose-Jaime Coronado, Zhen Liu, e Annie Royer, pela amizade.

Agradeço ao meu "brother" Oscar Candia e a minha "sister" Ilona Grabowicz, pela convivência pacífica e divertida na Gerdestraat, 33. Um agradecimento especial a Professora Rosa Machado que freqüentemente conviveu conosco.

Agradeço ao Dr. Roldan Muradian e ao Prof. Ruerd Ruben - Centre for International Development Issues Nijmegen, e ao Prof. George Hendrikse - Erasmus University Rotterdam, pelo convite para integrar o grupo de pesquisa "cooperatives and value chains", pela atenção, pelas discussões, pelos textos enviados, enfïm, por todas as oportunidades a mim dispensadas. Agradeço especialmente às doutorandas do grupo, Qiao Liang - Center for Agricultural and Rural Development (China), e Claire University of the Free State (South Africa), pela amizade.

Agradeço ao Prof. George Hendrikse, pela oportunidade de apresentação do meu projeto de pesquisa no seminário do "eRNAC (e-Research Network for Agricultural Cooperatives) Netherlands 2009”, e pelos seus comentários sobre minha proposta de pesquisa. 
Agradeço ao Dr. Roldan Muradian pela oportunidade de apresentação do meu projeto de pesquisa no “CERES Summer School 2009 - Radboud Universiteit Nijmegen”.

Agradeço ao Prof. Rainer Kühl - Justus-Liebig-Universität Gießen, pela oportunidade de participar do "1st eRNAC International Doctorate Workshop - Perspectives on Performance of Rural and Agricultural Cooperatives in Changing Environments", e pelos seus comentários sobre a minha proposta de pesquisa.

Agradeço aos participantes da Oficina Pensa, a qual meu trabalho foi discutido, em especial aos professores Decio e Sylvia Saes, pelos seus comentários.

Agradeço ao Prof. Sigismundo Bialoskorski Neto, Dr. Fábio Chaddad, Dr. Christiane Rezende, Dr. Luciana Florêncio de Almeida, pela leitura do meu trabalho de qualificação e pelas discussões e sugestões.

Agradeço aos membros da minha banca de defesa, Prof. Silvia Caleman, Prof. Vivian Lara, Prof. Sylvia Saes, Prof. Antônio Buainain, pela leitura do meu trabalho e pelas discussões e sugestões.

Agradeço ao Sr. Rui Polidoro Pinto - FECOAGRO, ao Sr. Vergilio Perius - OCERGS, e ao Sr. André Barreto - FEARROZ e suas equipes, pela atenção dada a minha pesquisa.

Agradeço aos presidentes das cooperativas entrevistadas, Sr. Nei Cesar Mânica, Sr. Luis Eugênio dos Santos, Sr. Fernando Osório, Sr. Joel Antônio Capeletti, Sr. Walter Vontobel, Sr. Luiz Paraboni Filho, Sr. Eduino Wilkomm, Sr. Paulo Cézar Pires, Sr. Adilo Gelain, Sr. Otmar Afonso Langer, Sr. Euclides Vestena, pelo seu interesse na minha pesquisa. Agradeço também aos presidentes e vice-presidentes, Sr. Lauro Scherer, Sr. Helder Piegas, Sr. Mario José Schafër, e Sr. Darci Hartmann pela atenção.

Agradeço aos executivos das cooperativas pesquisadas, especialmente ao Rui Ficagna, Zélia Savoldi, Sadi Scaramussa, e Paulo Santos, pela sua imensa atenção e interesse na minha pesquisa.

Agradeço ao Prof. Pedro Luis Büttembender - UNIJUÍ, e ao Dr. Davi Rogério Costa EESP-FGV, pelo seu tempo e atenção na fase de coleta de dados.

Agradeço aos meus irmãos, Cristina Eliza e João Ângelo, aos meus pais, e ao Mark por compreenderem minha ausência em momentos importantes de suas vidas.

Agradeço aos meus queridos "dindos", Edione e Luiz, pelo imenso carinho e apoio.

Agradeço ao meu tio, Pe. Eugênio Pozzobon, pelo interesse constante no meu trabalho.

Agradeço a Nice Santana, Kassia Watanabe e a Camila Mourad, pela grande ajuda que me dedicaram quando eu precisei de 'teto' e carona em São Paulo.

Agradeço a Prof. Sylvia Saes e aos colegas da Sala C-14, especialmente Silvia, Kassia, Nice, Christiane, Luciana, Nádia, Guilherme, Tiago, Carla, JP, Rubia, Anders, pela grande amizade dentro e fora da universidade.

Agradeço aos funcionários da FEA-FIA, Cida, Valéria, Lucimara, Luciene, Daniela, Fabiana, Francisco e, principalmente a Eloisa, pela atenção. 


\section{RESUMO}

O principal foco desta tese é sobre como cooperativas podem minimizar tanto custos de tomada de decisões democráticas quanto de agência. Em particular, a tese examina como diferenças nos níveis de heterogeneidade e de participação dos membros afetam estes custos e o controle dos mesmos. Esta tese é um dos primeiros estudos que se propõem a examinar empiricamente como as cooperativas controlam seus custos de tomada de decisões. Os relacionamentos entre as variáveis-chave da tese são examinados em três estudos. Primeiramente, nós desenvolvemos um modelo de mensuração de heterogeneidade baseado em categorização, o qual leva em consideração a presença (ausência) de um grupo dominante e o tamanho do(s) grupo(s) minoritário(s). O modelo classifica cooperativas desde homogêneas até mais heterogêneas, com base em características tanto dos membros quanto da cooperativa. Cinco níveis de heterogeneidade são identificados. Com base nestes resultados, nós desenvolvemos um modelo que prevê um relacionamento não-linear entre heterogeneidade e nível de participação dos membros no processo de tomada de decisões da cooperativa. Em segundo lugar, este trabalho distingue os conflitos de interesse que existem em todos os níveis (horizontais, diagonais e verticais) do processo de tomada de decisões da cooperativa. Isto possibilitou o entendimento de todos os custos advindos destes conflitos. Em relação a estudos anteriores sobre custos de tomada de decisões, nós examinamos uma gama maior de custos de tomada de decisões, a qual inclui tanto os custos de tomada de decisões democráticas quanto custos de agência. Além disso, a presente tese contribui com a literatura existente, quando desenvolve o conceito de custos democráticos. Este trabalho, ainda, distingue estes custos em termos de custos diretos e custos de oportunidade. Em fazer isto, nós demonstramos que o processo de fornecer incentivos para membros para participar na governança da cooperativa envolve substanciais custos. Freqüentemente, estudos neste assunto focam principalmente nos benefícios advindos da participação dos membros na governança, porém ignoram os custos associados ao processo de fornecer incentivos. Mais do que isto, nós demonstramos que custos diretos de agência e custos de oportunidade de agência têm, relativamente, diferente importância, sendo custos diretos provavelmente menos onerosos quando comparados com o risco de exposição a custos de oportunidade. Com relação a custos de oportunidade, nós os distinguimos, ainda, em relação à sub e super representação com relação à participação dos membros no conselho de administração. Nós demonstramos também que a relação entre participação dos membros no conselho de administração e custos democráticos é mais complexa do que a freqüentemente apontada pela literatura. Isto é possível uma vez que nós temos focado nosso estudo não somente no tamanho, mas também na composição (representatividade) do conselho. Finalmente, nós demonstramos as dificuldades que as cooperativas enfrentam em tentar minimizar custos de tomada de decisões (democráticos e de agência). 


\begin{abstract}
The main focus of this thesis is on how cooperatives can minimize both democratic and agency costs. In particular, the thesis examines how differences in the level of heterogeneity and member participation amongst cooperatives affect their management of these costs. The thesis is one of the first studies to empirically examine how cooperatives manage their decision making costs. The relationships amongst the key variables of the study are examined in three studies. First, we develop a measurement of heterogeneity based on a 'grouping' method, with the aim of showing the presence (absence) of a dominant group and the size of the minority group $(s)$. Cooperatives are ranked from homogenous to more heterogeneous based on both cooperative and member characteristics. Five different types of cooperatives are identified. Based on these results, a model is developed that predicts a non-linear relation between heterogeneity and member participation. Second, we distinguish all conflicts of interests (horizontal, vertical and diagonal) which exist at the different levels of cooperative decision making. By doing so, we are able to obtain a more complete picture of the costs of cooperative decision making. We also examine a broader range of decision making costs than most studies, as both democratic and agency costs are considered. In the present thesis, we have contributed to the literature by developing the concept of democratic costs. We distinguish between both direct and opportunity costs for both types of decision making costs. In doing so, we draw attention to the fact that the mechanisms used to increase member participation are not without costs. Frequently, studies focus mainly on the benefits of increased member participation, thereby disregarding some of the costs associated with it. Moreover, the thesis indicates that there are differences in the relative importance of direct and opportunity agency costs: direct agency cost should be a smaller concern for cooperatives compared to exposure to high opportunity agency costs. With regard to opportunity costs, a further distinction is made between costs associated with over-and underrepresentation of member groups in the board of directors. We show that the relation between member participation in the board of directors and democratic costs is more complex than is often assumed in the literature. Compared to previous studies, we focus not only on board size, but also on board composition; i.e., which member groups the board represents. Finally, we show the difficulties cooperative face in minimizing (balancing) both democratic and agency costs.
\end{abstract}





\section{INDEX}

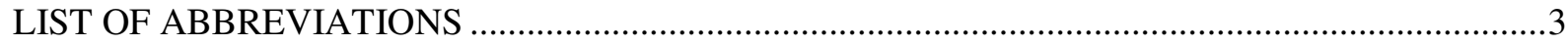

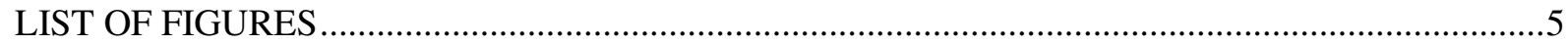

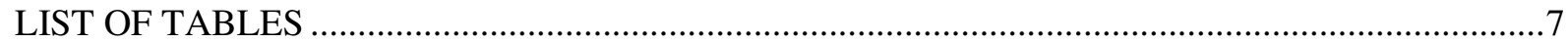

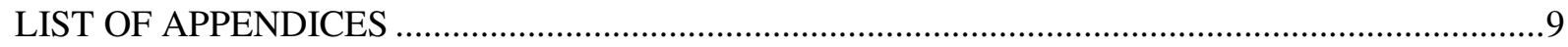

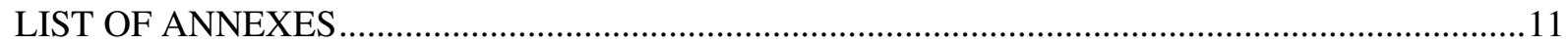

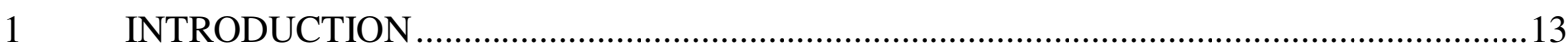

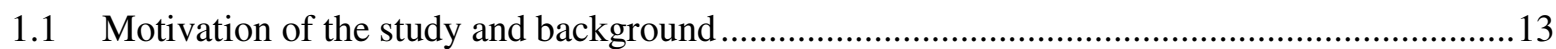

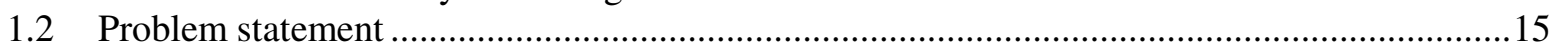

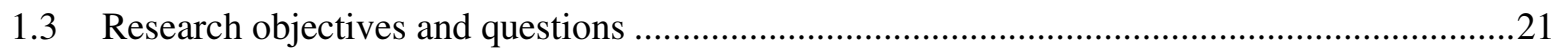

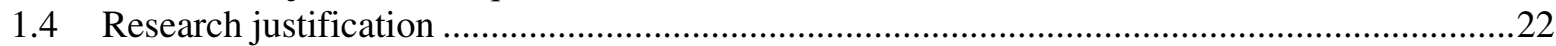

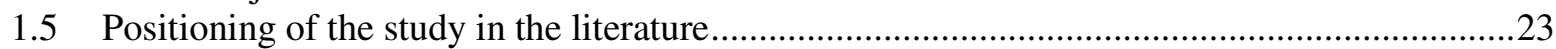

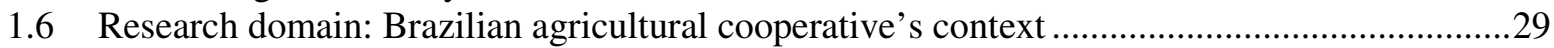

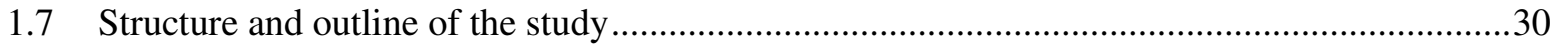

2 MEMBER PARTICIPATION IN COOPERATIVE GOVERNANCE: DOES

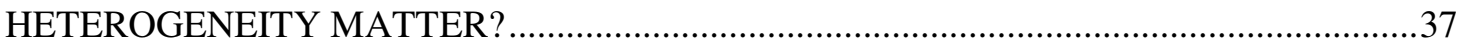

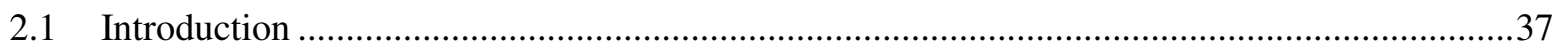

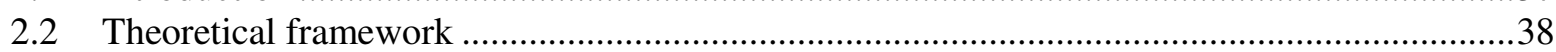

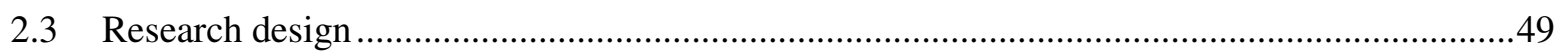

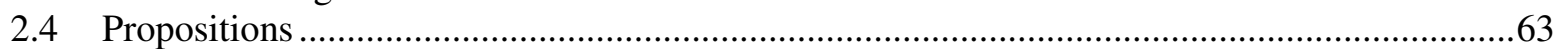

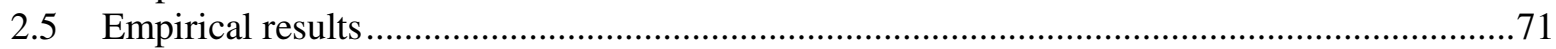

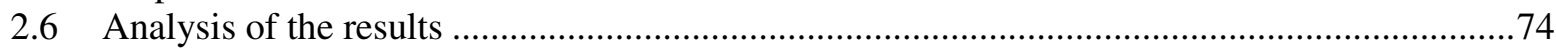

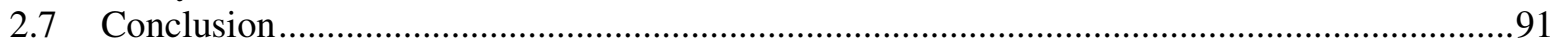

3 THE COSTS OF DEMOCRATIC CONTROL

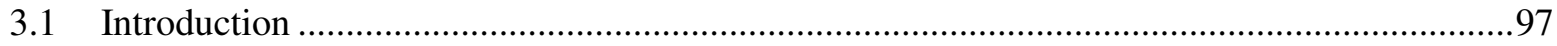

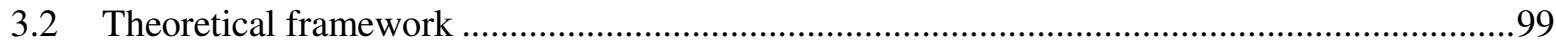

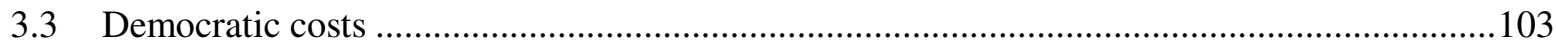

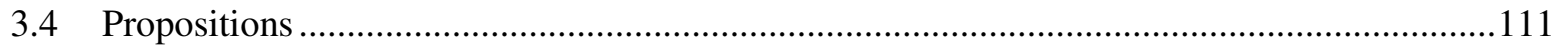

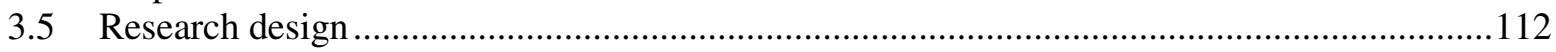

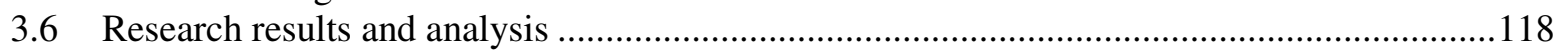

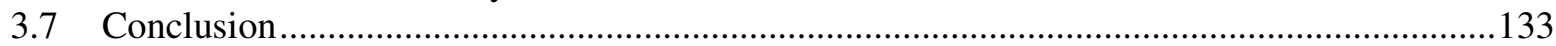

4 THE COSTS OF COOPERATIVE GOVERNANCE: DEMOCRATIC AND AGENCY

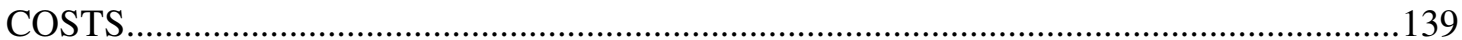

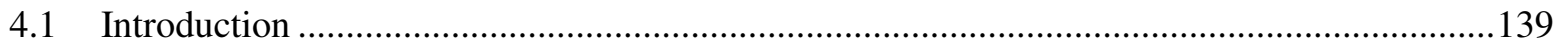

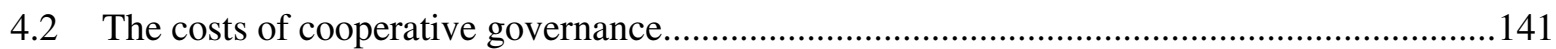

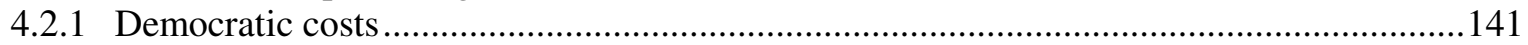

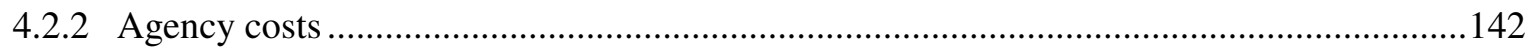

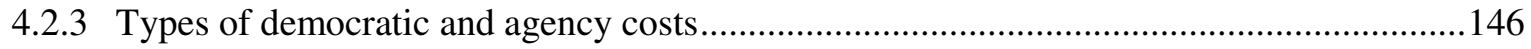

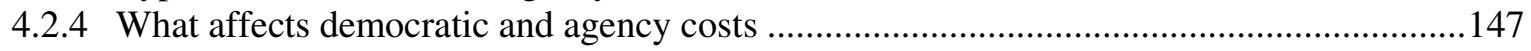

4.2.5 Balancing democratic costs and usage of agency mechanisms in the context of high (low)

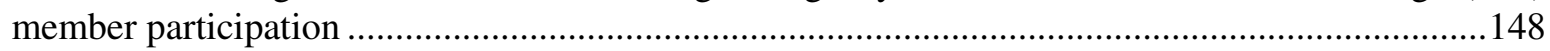

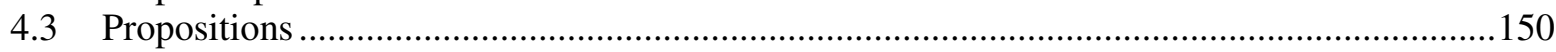

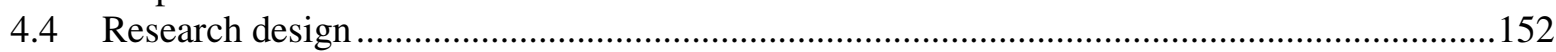

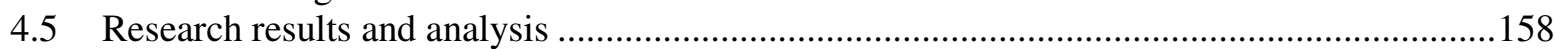

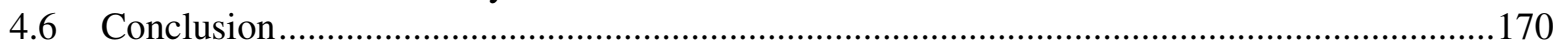




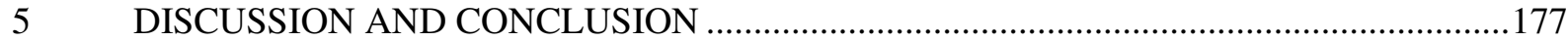

5.1 Heterogeneity and level of member participation in cooperative governance ........................178

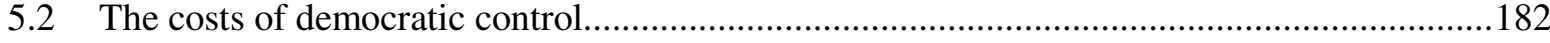

5.3 Balancing democratic and agency costs in cooperative governance ...................................185

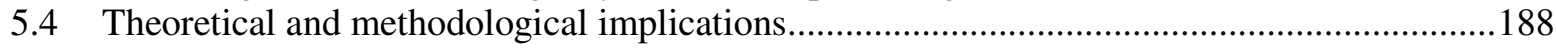

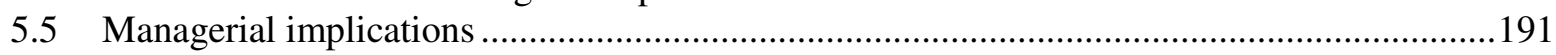

5.6 Limitations of the study and direction for further research ..............................................193

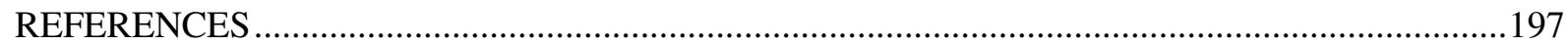




\section{LIST OF ABBREVIATIONS}

CEO - Chief Executive Officer

$\mathrm{CV}$ - Coefficient of variation

FAO - Food and Agriculture Organization

FEARROZ - Federação das Cooperativas de Arroz do Rio Grande do Sul Ltda.

FECOAGRO - Federação das Cooperativas Agropecuárias do Rio Grande do Sul

IBGE - Instituto Brasileiro de Geografia e Estatística

OCB - Organização das Cooperativas Brasileiras

OCERGS - Sindicato e Organização das Cooperativas do Estado do Rio Grande do Sul.

RS - Rio Grande do Sul

USDA - United States Department of Agriculture 


\section{LIST OF FIGURES}

Figure 1 - Agri-food largest firms in Brazil by Net Revenues in 2008 ............................................ 15

Figure 2 - Horizontal, diagonal and vertical conflicts of interests in cooperative decision makings ... 18

Figure 3 - Different levels of heterogeneity regarding cooperative's and member's characteristics .... 19

Figure 4 - Six strategies as a function of the choice to contribute and the choice to control others ..... 28

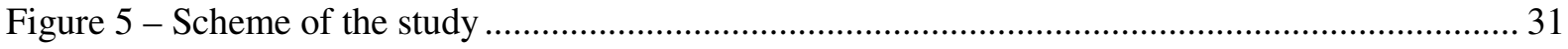

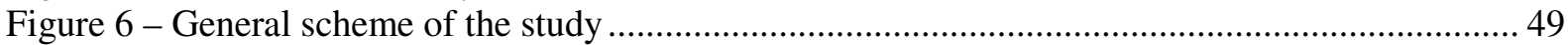

Figure 7 - Percentage of members who deliver each (quality of) product Vs. percentage that each

(quality of) product represents in the annual revenues ........................................................52

Figure 8 - Homogeneity-heterogeneity for cooperative's characteristics (CV_PERCPROD) ............. 56

Figure 9 - Homogeneity-heterogeneity for cooperative's characteristics (CV_PERCMEMB) ............ 57

Figure 10 - Homogeneity-heterogeneity for farm's members' characteristics (CV_PERCVOL)........ 58

Figure 11 - Homogeneity-heterogeneity for farm's members' and cooperatives characteristics...........58

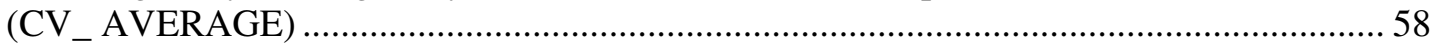

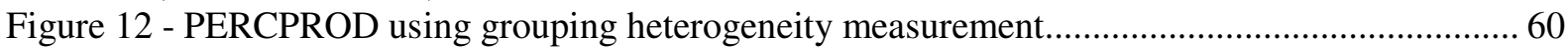

Figure 13 - PERCMEMB using grouping heterogeneity measurement ............................................... 61

Figure 14 - PERCVOL using grouping heterogeneity measurement ................................................. 62

Figure 15 - Relation between level of heterogeneity and level of member participation at the general

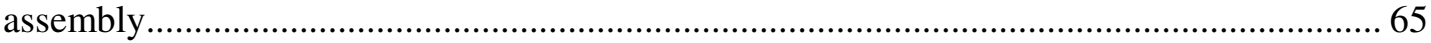

Figure 16 - Research results for the relation between level of heterogeneity (CV_PERCPROD) and level of member participation (MPATGA) ........................................................................ 75

Figure 17 - Research results for the relation between level of heterogeneity (CV_PERCMEMB) and level of member participation (MPATGA) ………............................................................ 76

Figure 18 - Research results for the relation between level of heterogeneity (CV_PERCVOL) and level of member participation (MPATGA) ............................................................................ 77

Figure 19 - Research results for the relation between level of heterogeneity (CV_AVERAGE) and

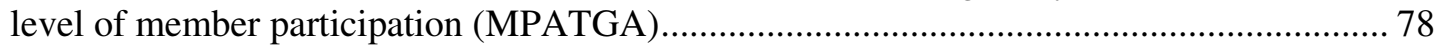

Figure 20 - Research results for the relation between level of heterogeneity (PERCPROD) and level of member participation (MPATGA) ..................................................................................... 79

Figure 21 - Research results for the relation between level of heterogeneity (PERCMEMB) and level

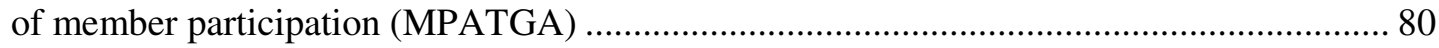

Figure 22 - Research results for the relation between level of heterogeneity (PERCVOL) and level of

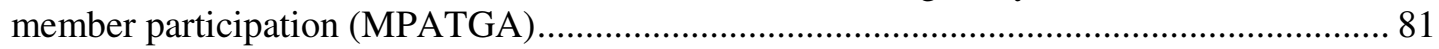

Figure 23 - Research results for the relation between level of heterogeneity (AVERAGE) and level of

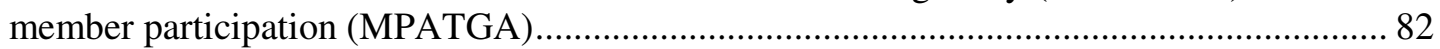

Figure 24 - Hypothetical relations between member participation and direct costs of democratic

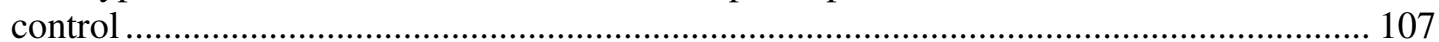

Figure 25 - Hypothetical relation between member participation and opportunity costs of democratic

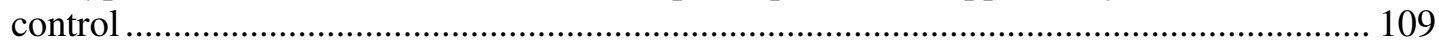

Figure 26 - Hypothetical relations between member participation and total costs of democratic control

Figure 27 - Relation between percentage of member participation at pre-general assemblies and number of members per nucleus in research cooperatives.................................................. 119

Figure 28 - Relation between percentage of member participation at pre-general assemblies and

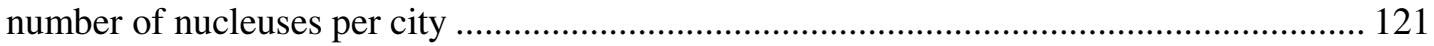

Figure 29 - Relation between board size and board total salary per year....................................... 123

Figure 30 - Two groups of cooperatives are examined: cooperatives with high member participation and high direct democratic costs Vs. cooperatives with low member participation and low

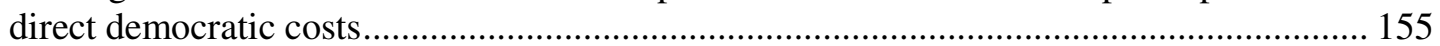

Figure 31 - Two groups of cooperatives: high member participation and high direct democratic costs Vs. low member participation and low direct democratic costs ....................................... 158

Figure 32 - Balance between direct democratic costs and usage of mechanisms (frequency of internal audits) to reduce exposure to agency problems considering high/low levels of member participation at the general assembly..... 160 
Figure 33 - Balance between direct democratic costs and usage of mechanisms (frequency of external audits) to reduce exposure to agency problems considering high/low levels of member participation at the general assembly....

Figure 34 - Two groups of cooperatives: high member participation and high direct democratic costs Vs. low member participation and low direct democratic costs 162

Figure 35 - Balance between direct democratic costs and usage of mechanisms (frequency of internal audits) to reduce exposure to agency problems considering high/low levels of member participation at the board of directors

Figure 36 - Balance between direct democratic costs and usage of mechanisms (frequency of external audits) to reduce exposure to agency problems considering high/low levels of member participation at the board of directors ....

163

Figure 37 - Two groups of cooperatives: low member participation and opportunity democratic costs Vs. high member participation and no opportunity democratic costs................................ 165

Figure 38 - Balance between opportunity democratic costs and usage of mechanisms (frequency of internal audits) to reduce agency problems considering high/low levels of member participation at the board of directors 166

Figure 39 - Balance between opportunity democratic and usage of mechanisms (frequency of external audits) to reduce agency problems considering high/low levels of member participation at the board of directors

166

Figure 40 - Two groups of cooperatives: high member participation and opportunity democratic costs Vs. low member participation and no opportunity democratic costs................................... 168

Figure 41 - Balance between opportunity democratic costs at the board of directors with regard to overrepresentation and usage of mechanisms (frequency of internal audits) to reduce exposure to agency problems considering high/low levels of member participation at the board of directors.

169

Figure 42 - Balance between opportunity democratic costs at the board of directors with regard to overrepresentation and usage of mechanisms (frequency of external audits) to reduce exposure to agency problems considering high/low levels of member participation at the board of directors

Figure 43 - Relation between level of heterogeneity and level of member participation at the general assembly.

Figure 44 - Hypothetical relation between member participation and opportunity costs of democratic control 183

Figure 45 - Horizontal, diagonal and vertical conflicts of interests in cooperative decision makings 189

Figure 46 - Hypothetical relations between member participation at the board of directors and total costs of democratic control ......

Figure 47 - Homogeneity-heterogeneity for PERCPROD using grouping heterogeneity measurement model 221

Figure 48 - Homogeneity-heterogeneity for PERCMEMB using grouping heterogeneity measurement model 223

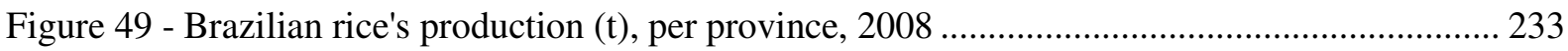

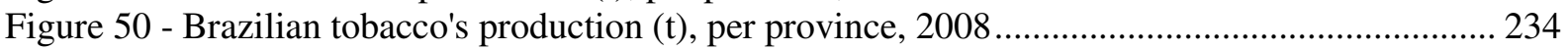

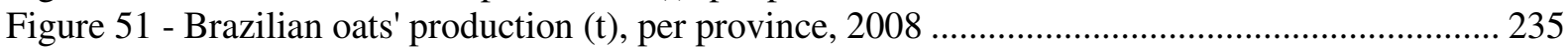

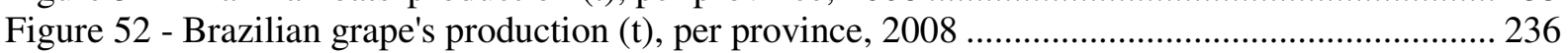

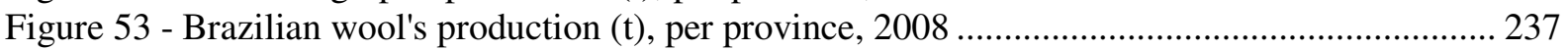

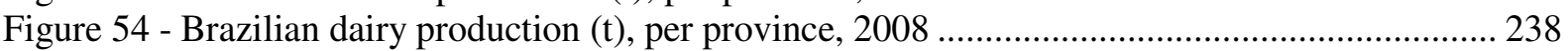

Figure 55 - Brazilian wheat's production $(\mathrm{t})$, per province, 2008.................................................... 239

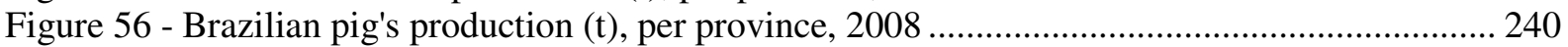

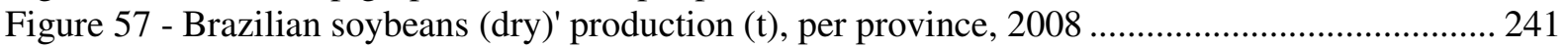

Figure 58 - Brazilian Maize (Green)'s production (t), per province, 2008 ….................................... 242

Figure 59 - Brazilian chicken's production $(\mathrm{t})$, per province, 2008 ….............................................. 243

Figure 60 - Brazilian roosters, pullets and chick's production (t), per province, 2008........................ 244

Figure 61 - Brazilian cattle's production $(\mathrm{t})$, per province, 2008 ..................................................... 245

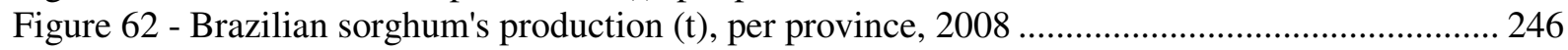

Figure 63 - Brazilian beans (dry)'s production (t), per province, 2008 ……..................................... 247 


\section{LIST OF TABLES}

Table 1 - Percentage of Brazilian agricultural production by cooperatives as a percentage of the total, in 2008, selected commodities

Table 2 - Percentage of U. S. farmer cooperatives' shares of farm marketing, 1951-1993, selected commodities

Table 3 - Percentage of European cooperative market share in the sale of agricultural products in 1991,

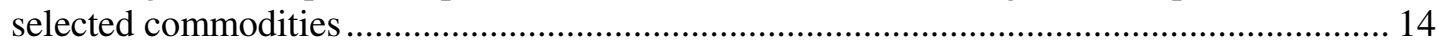

Table 4 - Evolution of the number of Brazilian agricultural cooperatives, members and employees... 15

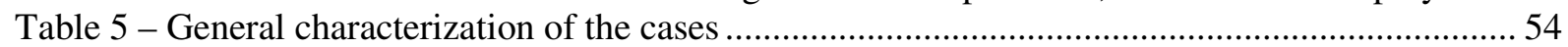

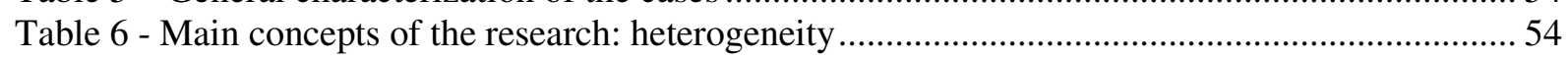

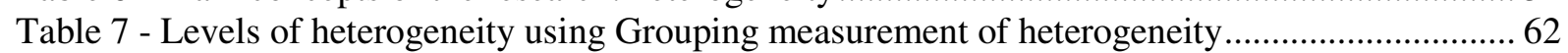

Table 8 - Measurement: level of heterogeneity and level of member participation............................... 66

Table 9 - Level of member participation at general assemblies in researched cooperatives ................ 71

Table 10 - Volume of products delivered by board members of researched cooperatives ................... 72

Table 11 - Products delivered by board members of researched cooperatives ..................................... 73

Table 12 - Percentage of each products received by researched cooperative ...................................... 73

Table 13 - Descriptive statistics for variables of the research ........................................................... 84

Table 14 - Logistic regression using data from CV heterogeneity measurement (CV_PERCPROD) 84

Table 15-Logistic regression using data from CV heterogeneity measurement (CV_PERCMEMB). 85

Table 16- Logistic regression using data from CV heterogeneity measurement (CV_PERCVOL).... 85

Table 17- Logistic regression using data from CV heterogeneity measurement (CV_AVERAGE).... 86

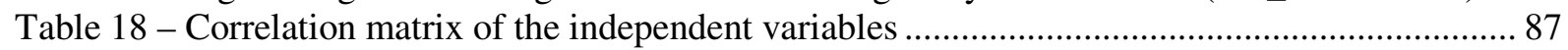

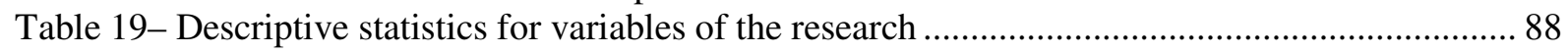

Table 20- Logistic regression using data from grouping heterogeneity measurement (PERCPROD). 89

Table 21- Logistic regression using data from grouping heterogeneity measurement (PERCMEMB) 89

Table 22- Logistic regression using data from grouping heterogeneity measurement (PERCVOL) ... 90

Table 23 - Operationalisation of the main concepts of the research................................................... 116

Table 24 - Rules for validation of propositions ............................................................................ 117

Table 25 - Level of member participation and number of members per nucleus in researched cooperatives

Table 26 - Level of member participation and number of nucleuses per city in researched cooperatives

Table 27 - Board size and salary of board members/year in researched cooperatives

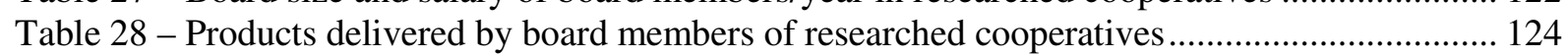

Table 29 - Percentage of each products received by researched cooperative .................................... 124

Table 30 - Opportunity democratic costs at the board of directors (underrepresentation) .................. 125

Table 31 - Opportunity democratic costs at the board of directors (overrepresentation) .................... 129

Table 32 -The costs of democratic control in researched cooperatives .......................................... 132

Table 33 - Definitions of democratic and agency costs in agricultural cooperatives and their direct and

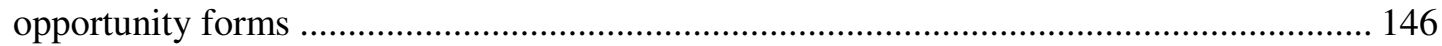

Table 34 - Relations between level of member participation and democratic and agency costs (and

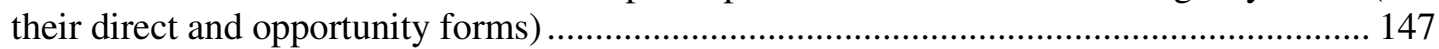

Table 35 - General characterization of the researched cooperatives ................................................. 153

Table 36 - Operationalisation of the main concepts of the research................................................. 154

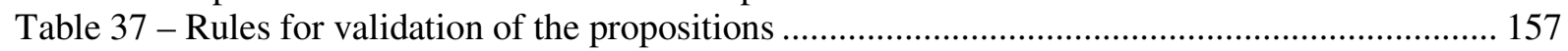

Table 38 - Direct democratic costs at the general assembly and usage of mechanisms (frequency of internal audits) to reduce exposure to agency problems of cooperatives with high/low levels of member participation at the general assembly.....

159

Table 39 - Direct democratic costs at the general assembly and usage of mechanisms (frequency of external audits) to reduce exposure to agency problems of cooperatives with high/low levels of member participation at the general assembly............................................................. 159

Table 40 - Direct democratic costs at the board of directors and usage of mechanisms (frequency of internal audits) to reduce exposure to agency problems of cooperatives with high/low levels of member participation at the board of directors. 
Table 41 - Direct democratic costs at the board of directors and usage of mechanisms (frequency of external audits) to reduce exposure to agency problems of cooperatives with high/low levels of member participation at the board of directors.

Table 42 - Opportunity democratic costs at the board of directors (underrepresentation) and usage of mechanisms (frequency of internal audits) to reduce exposure to agency problems of cooperatives with high/low levels of member participation at the board of directors ......... 165

Table 43 - Opportunity democratic costs at the board of directors (underrepresentation) and usage of mechanisms (frequency of external audits) to reduce exposure to agency problems of cooperatives with high/low levels of member participation at the board of directors ......... 165

Table 44 - Opportunity democratic costs at the board of directors (overrepresentation) and usage of mechanisms (frequency of internal audits) to reduce exposure to agency problems of cooperatives with high/low levels of member participation at the board of directors ......... 168

Table 45 - Opportunity democratic costs at the board of directors (overrepresentation) and usage of mechanisms (frequency of internal audits) to reduce exposure to agency problems of cooperatives with high/low levels of member participation at the board of directors ......... 168

Table 46 - Propositions on the relation between member participation in cooperative governance and democratic costs.

Table 47 - Propositions on the relation amongst level of member participation, democratic and agency costs in cooperative governance

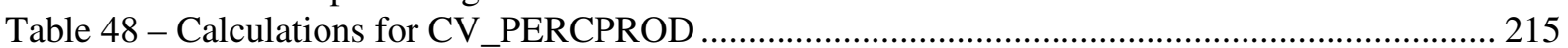

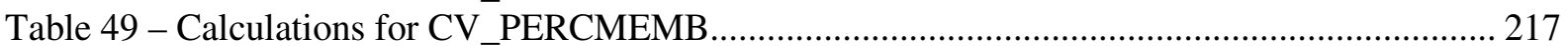

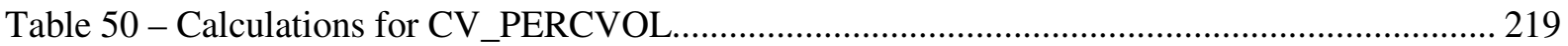

Table 51 - Homogeneity-heterogeneity for PERCVOL using grouping heterogeneity measurement

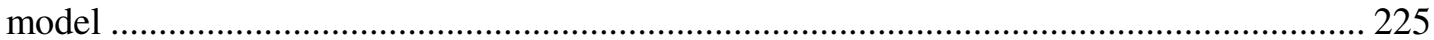

Table 52 - Negative correlation between CV_PERCPROD and level of member participation........ 227

Table 53 - Positive correlation between CV_PERCPROD and level of member participation .......... 227

Table 54 - Negative correlation between CV_PERCMEMB and level of member participation ...... 228

Table 55 - Positive correlation between CV_PERCMEMB and level of member participation........ 228

Table 56 - Negative correlation between CV_PERCVOL and level of member participation .......... 229

Table 57 - Positive correlation between CV_PERCVOL and level of member participation............ 229

Table 58 - Negative correlation between CV_AVERAGE and level of member participation ..........230

Table 59 - Positive correlation between CV_AVERAGE and level of member participation........... 230

Table 60 - Two groups of cooperatives: high member participation and high direct democratic costs Vs. low member participation and low direct democratic costs ......................................... 231

Table 61 - Two groups of cooperatives: high member participation and high direct democratic costs Vs. low member participation and low direct democratic costs ......................................... 231

Table 62 - Two groups of cooperatives: low member participation and opportunity democratic costs Vs. high member participation and no opportunity democratic costs................................. 232

Table 63 - Two groups of cooperatives: high member participation and opportunity democratic costs Vs. low member participation and no opportunity democratic costs.................................. 232

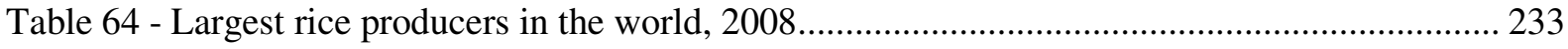

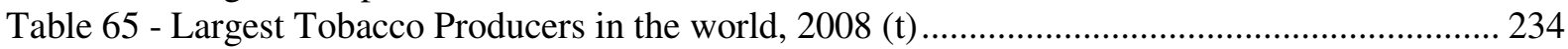

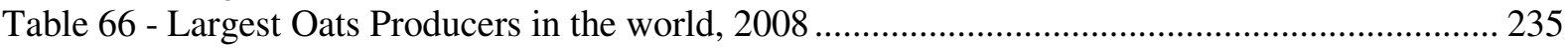

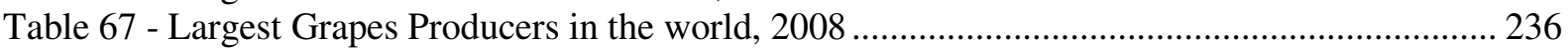

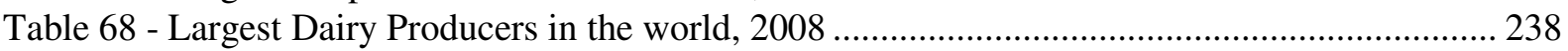

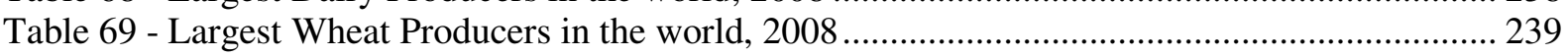

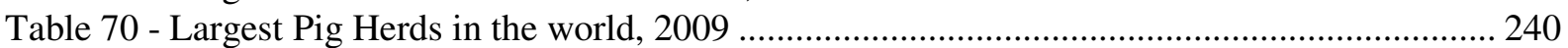

Table 71 - Largest Soybeans (dry) Producers in the world, 2008 ...................................................... 241

Table 72 - Largest Maize (Green) Producers in the world, 2008 ..................................................... 242

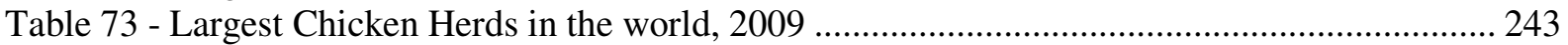

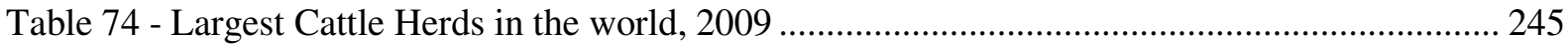

Table 75 - Largest Beans (dry) (Dry) Producers in the world, 2008 ............................................... 247 


\section{LIST OF APPENDICES}

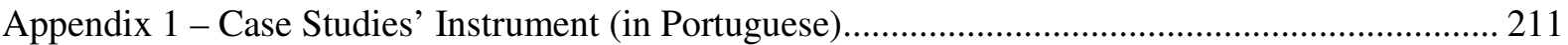

Appendix 2 - Calculations for variables of heterogeneity using CV as a measurement model.......... 215

Appendix 3 - Calculations for variables of heterogeneity using grouping as a measurement model.. 221

Appendix 4 - Transformation of the CV heterogeneity data from low to high

Appendix 5 - Placing cooperatives into groups based on two dimensions: (1), level of member participation; (2), level of (direct or opportunity) democratic cost. 


\section{LIST OF ANNEXES}

Annex 1 - The role of Rio Grande do Sul in the Brazilian's and World's agricultural production, selected commodities ............................................................233 


\section{INTRODUCTION}

\section{1}

\section{Motivation of the study and background}

The motivation for this study is the observed loss of competitiveness of cooperatives compared to investor-owned firms in terms of decision making costs (GORTON; SCHMID, 1999; HANSMANN, 1999; BIJMAN, 2002). As is explored in this study, one of the main causes of this loss of competitiveness is the cost of democratic control which cooperatives face (STAATZ, 1987b; REYNOLDS, 1997; ZYLBERSZTAJN, 1994; HENDRIKSE; VEERMAN, 2001; BIJMAN, 2002). This study aims to examine this and other causes (i.e., agency costs) which hamper cooperatives' competitiveness. We use evidences from Brazilian agricultural cooperatives to obtain insights into how cooperatives can reduce the cost of collective decision making (democratic costs), without incurring excessive agency costs.

In many agricultural markets both investor-owned firms as well as cooperatives are relevant players. The presence of cooperatives in the Brazilian market is illustrated in Table 1.

Table 1 - Percentage of Brazilian agricultural production by cooperatives as a percentage of the total, in 2008, selected commodities

\begin{tabular}{c|c|c|c|c|c|c|c|c|c|c|c|c|c}
\hline Commodity & $\begin{array}{c}\text { Beans } \\
(\text { dry })\end{array}$ & Rice & $\begin{array}{c}\text { Maize } \\
\text { (green) }\end{array}$ & Grape & Garlic & Coffee & Soybeans & Pork & Cotton & Oats & Dairy & Barley & Wheat \\
\hline$\%$ & 11 & 11 & 17 & 19 & 22 & 28 & 29 & 31 & 39 & 39 & 40 & 44 & 62 \\
\hline
\end{tabular}

SOURCE: OCB; 2009

Cook (1995) reports the participation of U. S. farmer cooperatives' shares of farm marketing in the United States (see Table 2).

Table 2 - Percentage of U. S. farmer cooperatives' shares of farm marketing, 1951-1993, selected commodities

\begin{tabular}{c|c|c|c|c|c}
\hline Year/commodity & Dairy & Cotton & Grains/oil seeds & $\begin{array}{c}\text { Fruit/ } \\
\text { vegetables }\end{array}$ & Livestock \\
\hline 1951 & 46 & 10 & 35 & 20 & 13 \\
\hline 1961 & 58 & 19 & 33 & 22 & 13 \\
\hline 1971 & 70 & 25 & 34 & 25 & 11 \\
\hline 1982 & 77 & 36 & 36 & 20 & 7 \\
\hline 1988 & 76 & 41 & 30 & 24 & 10 \\
\hline 1993 & 85 & 35 & 42 & 21 & 7 \\
\hline
\end{tabular}


Hendrikse (1998) illustrates the prominent presence of agricultural cooperatives in a number of markets in the European Union (see Table 3).

Table 3 - Percentage of European cooperative market share in the sale of agricultural products in 1991, selected commodities

\begin{tabular}{c|c|c|c|c|c|c|c|c|c}
\hline Country & Pork & Beef & Poultry & Eggs & Dairy & $\begin{array}{c}\text { Sugar } \\
\text { beet }\end{array}$ & Grain & Fruit & Vegetables \\
\hline Belgium & 15 & 1 & - & - & 65 & - & $25-30$ & $60-65$ & $70-75$ \\
\hline Denmark & 97 & 53 & - & 0 & 92 & 0 & 50 & 90 & 90 \\
\hline Germany & 23 & 25 & - & - & 56 & - & - & $20-40$ & $55-65$ \\
\hline Greece & 3 & 2 & 20 & 3 & 20 & 0 & 49 & 51 & 12 \\
\hline Spain & 5 & 6 & 8 & 18 & 16 & 20 & 16 & 30 & 15 \\
\hline France & 80 & 30 & 30 & 25 & 50 & 16 & 70 & 45 & 35 \\
\hline Ireland & 55 & 9 & 20 & 0 & 98 & 0 & 26 & 14 & 8 \\
\hline Italy & 15 & 6 & - & 5 & 32 & - & 35 & 31 & 10 \\
\hline Luxembourg & 35 & 25 & - & - & 81 & - & 79 & 10 & - \\
\hline Netherlands & 24 & 16 & 21 & 18 & 84 & 63 & 65 & 78 & 69 \\
\hline Portugal & - & - & - & - & - & - & - & - & - \\
\hline $\begin{array}{c}\text { United } \\
\text { Kingdom }\end{array}$ & 19.9 & 5.1 & 0.2 & 18.8 & 4.1 & 0.4 & 21.1 & 29.6 & 19.4 \\
\hline
\end{tabular}

SOURCE: EUROPEAN COMMISSION; 1994 apud HENDRIKSE; 1998

Even though cooperatives form an important part of world-wide agricultural markets, in both the United States and in several European countries the number of cooperatives as well as cooperative members is decreasing (BHUYAN, 2007). Part of this results from increased heterogeneity of cooperatives and their members (BIJMAN, 2002), as well as managerial inefficiencies which cooperatives face as not only democratic costs (STAATZ, 1987d; ZYLBERSZTAJN, 1994; BIJMAN, 2002) but also agency costs (GORTON; SCHMID, 1999) can be more severe in a cooperatives than in investor-owned firms.

In Brazil, overall, the number of cooperatives and cooperative members is relatively stable (see Table 4). However, there are a lot of cooperatives where the number of members is decreasing, while in other cooperatives it is increasing. Zylbersztajn and Miele (2005) and Miele and Zylbersztajn (2005), for instance, show the case of two important Brazilian wine cooperatives in Rio Grande do Sul state where specialized farmers (who are the minority in the cooperative) are leaving the cooperative in search for higher prices for their differentiated products. 
Table 4 - Evolution of the number of Brazilian agricultural cooperatives, members and employees

\begin{tabular}{c|c|c|c}
\hline Year & Cooperatives & Members & Employees \\
\hline 2006 & 1,549 & 886,076 & 123,890 \\
\hline 2007 & 1,544 & 879,649 & 139,608 \\
\hline 2008 & 1,611 & 968,767 & 134,579 \\
\hline 2009 & 1,615 & 942,147 & 138,829 \\
\hline
\end{tabular}

SOURCE: OCB; 2010

Although the number of cooperatives and cooperative members is relatively stable, amongst the largest ten organizations in the food industry, based on revenue, only one is a cooperative and five cooperatives are listed amongst the top twenty (see Figure 1).

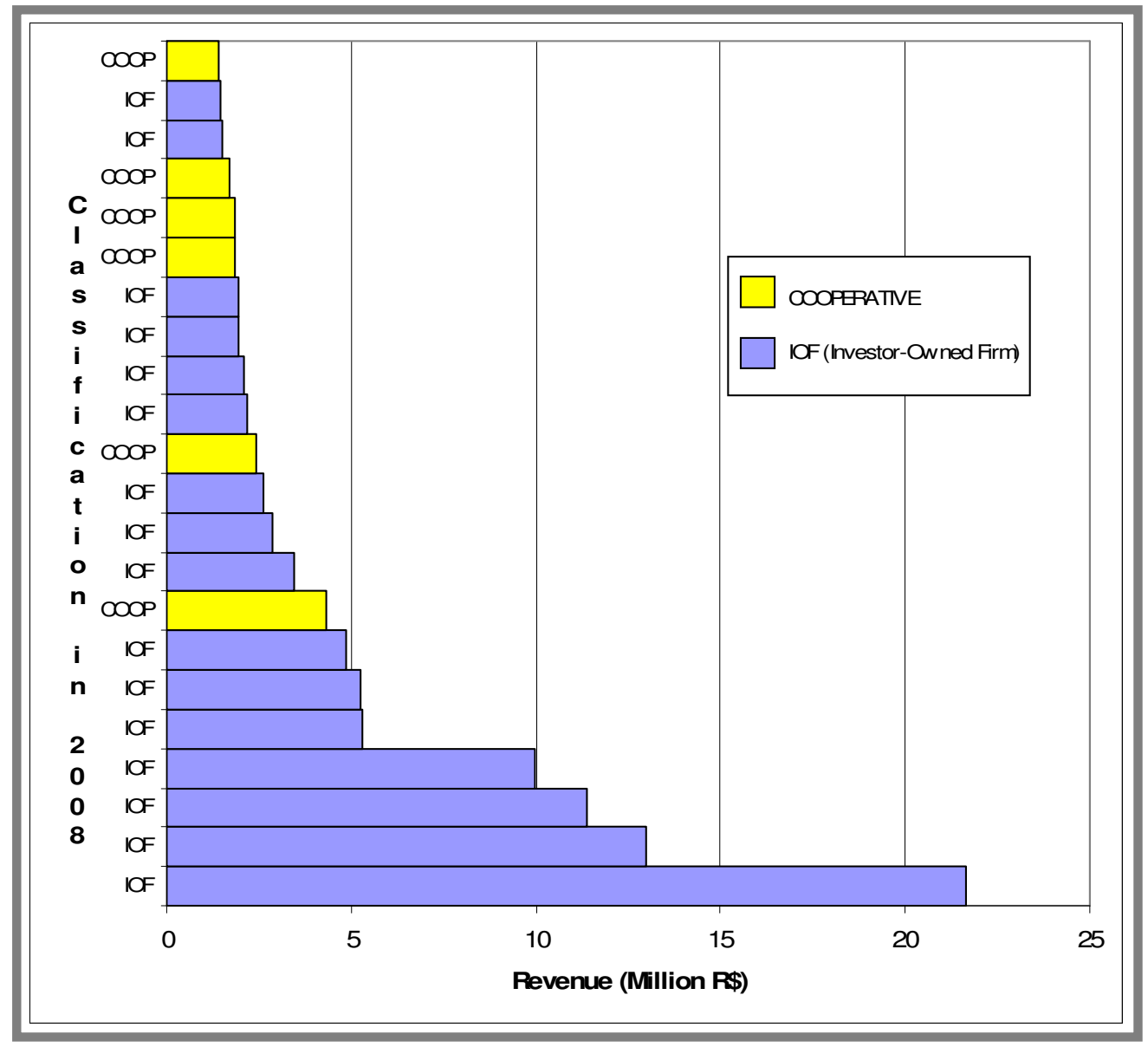

Figure 1 - Agri-food largest firms in Brazil by Net Revenues in 2008 SOURCE: Author, with data from Valor 1000; 2009

\subsection{Problem statement}

One of the causes of cooperatives' loss of competitiveness compared to investor-owned firms may be the costs of democratic control (i.e., democratic costs) which cooperatives face. This study examines these and other decision making costs (i.e., agency costs) which hamper 
cooperatives' competitiveness, and argues how this is related to the traditional organizational structure of the cooperative.

\section{Democratic costs in cooperatives}

The control of (traditional) cooperatives is structured democratically. Member-democratic control makes decision making process different (and also slower and more costly) in cooperatives in contrast to investor-owned firms (ZYLBERSZTAJN, 1994; HENDRIKSE; VEERMAN, 2001; BIJMAN, 2002; HENDRIKSE; OIJEN, 2004). This is particularly the case when the cooperative decision making process is compared to the decision making process in investor-owned firms with concentrated ownership because of at least three reasons.

First, because each member has one vote at the general assembly ${ }^{1}$ independently from the number and size of transactions carried-out with the cooperative. This contrasts with investorowned firms where voting rights are usually based on the amount of equity investment made by the investor.

Second, because a lot of cooperative decision making takes place not only in the executive board, but also in the general assembly and in the board of directors (ZYLBERSZTAJN, 1994).

Third, because cooperatives, which need to be managed by their members, spend resources on giving (uninterested) members incentives to participate in the decision making process. Members may be uninterested to participate, as individual members may perceive they have limited possibilities to influence decisions (as each member has only one vote). Furthermore, because of the democratic nature of the decision making process, cooperatives that do have a high level of member participation may incur costs related to solving conflicts of interests amongst members.

\footnotetext{
${ }^{1}$ The cooperative's general assembly is the equivalent of the investor-owned firm' shareholder meeting.
} 
Democratic $\operatorname{costs}^{2}$ are: (1), the costs resultant from the need of providing incentives for members to participate in the collective decision making process; (2), the costs resultant from either horizontal or diagonal conflicts of interests amongst members who have to make decisions about how the benefits of (using) the cooperative are distributed amongst them. Horizontal conflicts of interests (i.e., among members) arise when members attempt to collectively make decisions about the distribution of benefits and costs at the general assembly. Diagonal conflicts of interests (i.e., among members and members of the board of directors) arise either when board members do not represent all members groups or when board is overrepresented; and (3), the costs resultant from the cooperative's attempts to manage these conflicts or to prevent them.

\section{Agency costs in cooperatives}

Alternatively, agency costs result from a vertical conflict of interests between members and managers with regard to the governance of the cooperative; i.e., when members delegate control to a manager. Agency costs consist of the costs of monitoring the performance and behavior of the management (i.e., agent) as well as the opportunity costs when management makes decisions which are not in the best interest of members (owners/principals).

Agency costs are a particular problem in cooperatives because they lack some of the (internal and external) corporate governance principles and mechanisms which investor-owned firms use to control these costs. Public-listed investor-owned firms, for instance, use corporate governance principles (i.e., equitable treatment, transparency, accountability, and responsibility) and governance mechanisms (e.g., capital markets, takeover risk, market analysts, competitive agencies, external/knowledgeable board members, among others) in order to control (the performance of) management.

In unlisted investor-owned firms, ownership is generally concentrated, which means that each owner has a strong incentive to monitor management performance.

\footnotetext{
${ }^{2}$ Democratic costs are a particular type of decision making costs that cooperatives incur since they are firms democratically controlled by members-patrons. The concept of democratic costs has been largely ignored by the cooperative literature until now. We discuss democratic costs in greater detail in chapters 3 and 4.
} 
In cooperatives, there is not: (1), information generated by a secondary market (because cooperatives shares do not appreciate and there is not a secondary market for them $)^{3}$ (CONDON, 1987), nor (2), external/knowledgeable board members, for use in the evaluation and control of management behavior. Furthermore, there are not enough incentives for members to control the performance of the management because the benefits that members receive from the cooperative comes from the premium prices they get for products they deliver to the cooperative and the lower prices they pay for the inputs they purchase from the cooperative, rather than a (large) distribution of surplus (ZYLBERSZTAJN, 1994).

Figure 2 shows that democratic costs are associated to horizontal and diagonal conflicts of interest, while agency costs are associated to vertical conflicts of interests.

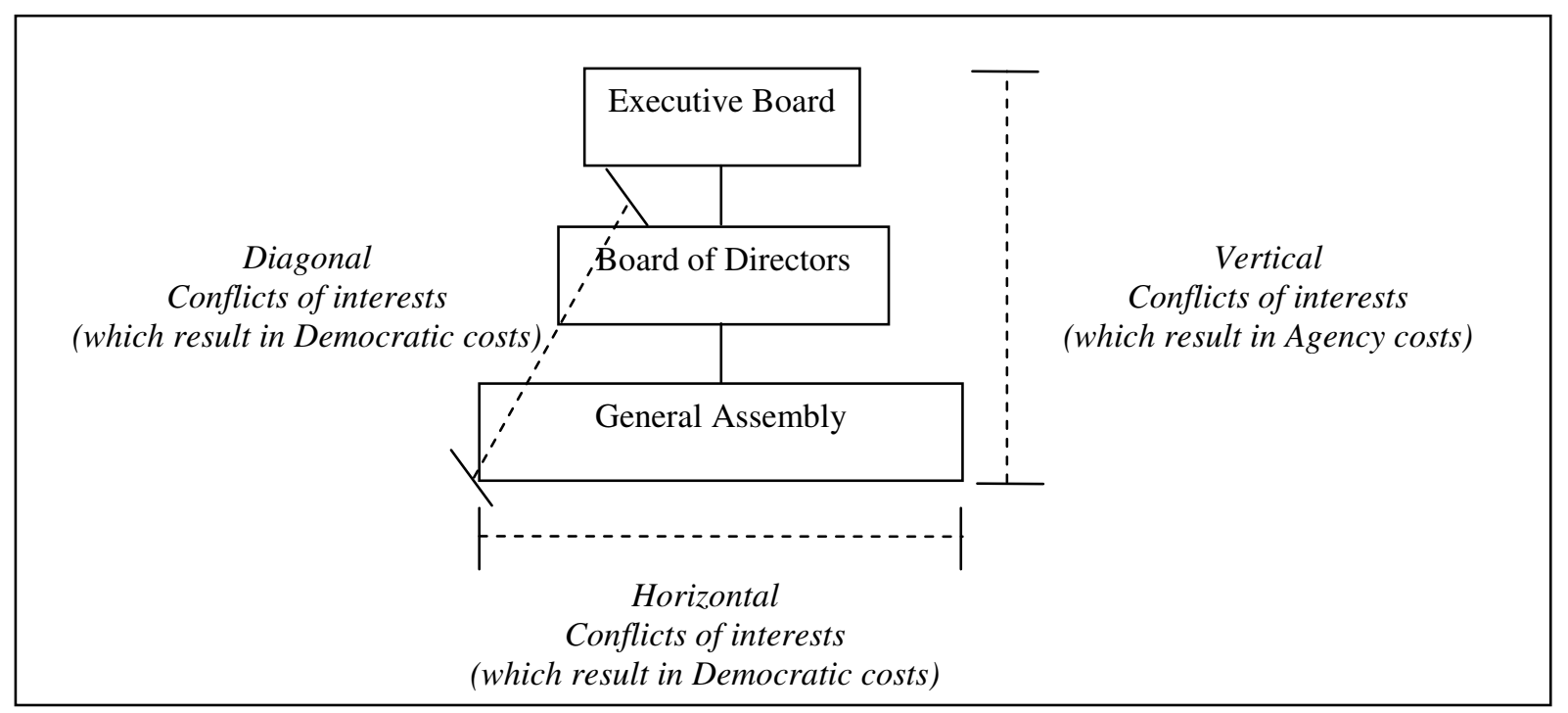

Figure 2 - Horizontal, diagonal and vertical conflicts of interests in cooperative decision makings

\section{What affects these costs?}

In particular, two aspects of cooperatives affect the ability in which they can control democratic and agency costs: the level of heterogeneity and the level of member participation. These two variables play a very relevant role in this study. The level of heterogeneity affects the level of member participation in cooperative governance, while the level of member participation in turn affects decision making costs (democratic and agency costs).

\footnotetext{
${ }^{3}$ According to Ang, Cole, and Lin (2000), the only information that is available, perhaps, are the differences in interest rate offered by banks to cooperatives demanding debt capital.
} 


\section{Heterogeneity}

According to Bogetoft and Olesen (2004), in the past, agricultural cooperatives had more homogeneous members producing the same standard product. Nowadays, due to recent trends (e.g., in consumer demand, in technology improvement, higher productivity), many cooperatives have gotten more heterogeneous members (e.g., members who still produce standard products and also members who produce differentiated product qualities). The main view of this study is that homogeneous cooperatives may have either homogeneous (see box 1, Figure 3) or heterogeneous members (see box 2, Figure 3), and heterogeneous cooperatives may have either homogeneous (see box 3, Figure 3) or heterogeneous (see box 4, Figure 3) members.

\begin{tabular}{|c|c|c|c|}
\hline & & \multicolumn{2}{|c|}{ Members' characteristics } \\
\hline & & Homogeneous & Heterogeneous \\
\hline \multirow[b]{2}{*}{$\begin{array}{r}\text { Cooperative's } \\
\text { characteristics }\end{array}$} & Homogeneous & $\begin{array}{c}\text { E.g., a honey cooperative where all } \\
\text { members deliver around the same } \\
\text { volume and quality of honey to the } \\
\text { cooperative }\end{array}$ & $\begin{array}{l}\text { E.g., a soybeans cooperative where } \\
\text { all members deliver around the } \\
\text { same volume and quality of honey } \\
\text { to the cooperative }\end{array}$ \\
\hline & Heterogeneous & $\begin{array}{l}\text { (3) } \\
\text { E.g., a cooperative that receives } \\
\text { pigs, and dairy and where pigs } \\
\text { represent } 50 \% \text { of the cooperatives } \\
\text { revenues and dairy represents } 50 \% \text { : } \\
\text { all members deliver both pigs and } \\
\text { dairy and around the same volume }\end{array}$ & $\begin{array}{l}\text { (4) } \\
\text { E.g., a cooperative that receives } \\
\text { grains, pigs, and dairy where } \\
\text { members deliver different volumes } \\
\text { and combinations of products }\end{array}$ \\
\hline
\end{tabular}

Figure 3 - Different levels of heterogeneity regarding cooperative's and member's characteristics

As a result, it can be expected that the more heterogeneous is the cooperative and its members, the more the interests of the members (or group of members) conflict with each other. These conflicts of interest are likely to adversely affect the collective decision making process in the cooperative (e.g., at the general assembly), as more heterogeneous (groups of) members have to make decisions about how the benefits of (using) the cooperative are distributed amongst them.

These conflicts of interests are likely to arise because members are heterogeneous but cooperative generated benefits are (mostly) homogeneous (because of the traditional 
cooperative principles, e.g., equally treatment, democratic nature). For example, members who produce top quality products and, as a consequence, have more production costs due to higher technology efficiency employed (e.g., minority members) receive mostly the same benefits as members who produce standard quality products (e.g., majority members). All of these levels of heterogeneity, and as a consequence, of conflicts of interests, bring potential costs to the decision making of democratic, collective actions as cooperatives are.

Heterogeneity may also affect decision making at the board of directors. With heterogeneous membership, board members are more likely to be 'captured' by interest groups (e.g., smallholders, or soybeans-supplying members) within the cooperative. Subsequently, interest groups that are underrepresented at the board need to monitor them actively, leading to higher democratic costs for the cooperative. ${ }^{4}$

\section{Member participation}

Members may participate in all of the three main cooperative governance bodies: (1) attending general assemblies; (2) holding a position in the board of directors; (3) holding a position in the executive board. Participation is highly variable amongst cooperatives, i.e., it is much higher in some cooperatives than in others.

A higher level of member participation may increase democratic costs in a cooperative, as more members participate in the collective decision making process (at the general assembly or at the board of directors). At the same time, a higher level of member participation may reduce agency costs, as more members monitor management.

\section{Balancing democratic and agency costs}

Considering the issues discussed above, a difficult challenge for cooperatives is therefore how to control both democratic and agency costs considering different levels of heterogeneity and member participation. This is the main issue addressed in the present thesis.

\footnotetext{
${ }^{4}$ This is why some authors (e.g., HANSMANN, 1996) classify cooperatives as "political institutions".
} 


\subsection{Research objectives and questions}

More specifically, the present study aims to focus on the following dimensions of this topic:

(1), to develop a heterogeneity measurement model that ranks cooperatives from homogeneous to heterogeneous, while taking into account both cooperatives and members characteristics (Chapter 2);

(2), to examine whether there are differences in level (i.e., percentage) of member participation attending general assemblies across more homogenous and more heterogeneous cooperatives (Chapter 2);

(3), to examine whether there are differences in characteristics of members holding a position in the board of directors across more homogenous and more heterogeneous cooperatives (e.g., whether large farmers participate more) (Chapter 2);

(4), to examine the relation between level of member participation (at general assemblies and at the board of directors) and democratic costs in cooperatives (Chapter 3);

(5), to examine how the ability of cooperatives to control democratic and agency costs is related to the level of member participation (Chapter 4).

The study seeks to achieve these objectives by addressing the following research questions:

RQ1: What is the relation between level of heterogeneity and level of member participation in the governance of agricultural cooperatives? (Chapter 2)

RQ2: What is the relation between level of member participation and democratic costs in agricultural cooperatives? (Chapter 3 )

RQ3: How is the ability of cooperatives to control both democratic and agency costs related to the level of member participation? (Chapter 4) 


\section{$1.4 \quad$ Research justification}

With regard to member participation in cooperative governance, it is important to study it since cooperative scholars have recognized that it has been under-researched. For instance, Cook (1994, p. 42) argues that "empirical results in most areas of cooperative management behavioral hypotheses are limited or nonexistent" and Birchall and Simmons (2004b) argue that it has become important to current public policy and to cooperatives and unions themselves. Although studies examine member participation in cooperative governance (e.g., BIRCHALL; SIMMONS, 2004a; 2004b; 2004c; BHUYAN, 2007; LAURSEN; KARANTININIS; BHUYAN, 2008 - in Europe -, GRAY; KRAENZLE, 1998 - in United States; BANERJEE et al, 2001 - in India -, and BIALOSKORSKI NETO, 2006 - in Brazil) previous research has not compared differences in member participation between homogeneous and heterogeneous cooperatives.

With regard to heterogeneity, no previous studies have been identified which have operationalized this concept. However, it is important to measure heterogeneity, because it is a significant source of conflict of interests between members. Furthermore, gaining an accurate picture of the relation between level of heterogeneity and member participation in cooperative governance is important because both heterogeneity and member participation are sources of decision making costs. In addition, it is important to examine this relation more accurately because there are conflicting views in the literature about this topic. Some studies (e.g., HANSMANN, 1996; HENDRIKSE; BIJMAN, 2002; KALOGERAS et al, 2009) assume that there is a positive linear relation between member participation and heterogeneity: when heterogeneity increases, members have more incentive to actively participate in the governance of the cooperative. However, other studies (e.g., ÖSTERBERG; NILSSON, 2009) state that member participation may decrease as heterogeneity increases, because the cooperative becomes to complex to manage.

With regard to the costs of democratic control, with few exceptions (e.g., FORCADELL, 2005), cooperative scholars have fundamentally ignored the presence of these costs in the governance of cooperatives. We found no measure on democratic costs in cooperatives. Cooperative scholars (e.g., ILIOPOULOS; COOK, 1999; GRIPSRUD; LENVIK; OLSEN, 2000) have focused their attention instead on influence costs. Furthermore, cooperative 
scholars have largely ignored how the heterogeneity and the level of member participation in cooperative governance affect these costs.

With regard to agency costs, although studies examine the issue of the separation between ownership and control in agricultural cooperatives (e.g., ZYLBERSZTAJN, 1994; POZZOBON; MACHADO FILHO, 2007; COSTA, 2010; COSTA; CHADDAD; AZEVEDO, 2010; COSTA; AZEVEDO, 2010, in Brazil), they do not examine these costs in more detail. With few important exceptions (e.g., GORTON; SCHMID, 1999 who study it in the context of Austrian cooperative banking), empirical research that identifies and measures these costs is limited. However, no previous studies have been identified which have examined: (1), the relationship between member participation and agency costs, or (2), the relationship between agency and democratic costs). Perhaps most importantly, we did not find research which has examined both democratic and agency costs across homogeneous and heterogeneous cooperatives.

\subsection{Positioning of the study in the literature}

The present thesis integrates elements from new institutional economics theory (basically the concepts of transaction costs, property rights and agency relationships) and the theory of collective action to give form and meaning to the main concepts of this study (e.g., democratic costs, agency costs, heterogeneity interests, member participation) and their relations. The sections below detail these two approaches, and explain why they are used in the study.

\section{New institutional economics theory}

\section{Transaction costs economic theory}

The main contribution of new institutional economics theory, in its microeconomic dimension, is to drawn attention to the diversity of governance structures (e.g., investorowned firms and cooperatives) in economies, and to give a transaction-cost (efficiency) based explanation for this diversity. The present study uses the new institutional economics theory to provide a framework for examining the different types of internal transaction costs which 
cooperatives face. ${ }^{5}$ As is explained subsequently, various authors (e.g., COASE; WILLIAMSON; JENSEN) and various theories (e.g., property rights, agency) form part of new institutional economic theory.

Coase (1937) observes that, under certain conditions, some market costs are saved when transactions are organized within the firm (by forming an organization and allowing some authority, i.e., an "entrepreneur" to direct the resources) instead of through the market. Furthermore, Williamson $(1986,1996)$ discusses at length under which conditions the costs of using the market are likely to be high (caused by factors such as asset specificity, uncertainty and frequency of transactions) and suggests that transactions in such cases should be carried out inside the firm. Williamson $(1975 ; 1985)$ argues that within firm transactions may be preferred over market transactions when parties must make investments in specialized resources (i.e., assets which looses value if used in alternative transactions) and when detailed long-term contracts are impossible or costly to write (or enforce). This is because some of the rents arising from these investments cannot be divided up appropriately in advance between transaction parties. Bringing transactions within the firm (integration) is seen as a way of reducing the threat of opportunistic behavior ${ }^{6}$ which can arise in such circumstances.

In this sense, Klein, Crawford and Alchian (1978, p. 299) argue that the "advantage of joint ownership of such specialized assets, namely, economizing on contracting costs necessary to insure non opportunistic behavior, must of course be weighed against the costs of administering a broader range of assets within the firm."

\section{Property rights theory}

Proponents of (new) property rights theory (e.g., GROSSMAN; HART, 1986; HART; MOORE, 1990) criticize the transaction cost-based arguments for failing to take into account the costs which arise when market transactions are internalized. Grossman and Hart (1986) argue that opportunistic behavior between parties to a transaction does not necessarily

\footnotetext{
${ }^{5}$ Other conceptual approaches can be also adopted, as seen by Anna Grandori, Nicolai Foss, amongst others. Our choice is to focus on the contribution of Oliver Williamson.

${ }^{6}$ Opportunism is the risk that the other party to the transaction will renegotiate the terms of the conditions, once investments are made (WILLIAMSON, 1986).
} 
disappear when such a transaction is internalized; i. e. also employees can behave opportunistically. Therefore, they conclude that ownership itself bears substantial costs.

\section{Agency theory}

Scholars from agency theory (e.g., JENSEN; MECKLING, 1976) focus on costs resulting from the principal-agent problem. As is explained earlier, these are the costs which members/owners (principal) incur when they delegate control to a manager (agent). These costs consist of monitoring (the performance and behavior of) the management as well as the opportunity costs when management makes decisions which are not in the best interest of members/owners.

\section{New institutional economics theory applied in the cooperative literature}

Hansmann (1988) applies the concepts of transaction costs, property rights and agency in the cooperative literature and identifies three types of ownership costs that cooperatives face: (1) the costs of collective decision making; (2), monitoring; and (3), risk bearing of the firm.

The present study extends the new institutional economics theory and the theory of cooperatives (e.g., Hansmann, 1988, 1996, amongst other authors), as it studies in depth (because it considers all conflicts of interests that may exist in the decision making process and all their resultant costs) the internal transaction costs in a different context than investorowned firms. The costs which cooperatives incur in the collective decision making process are referred to in this study as democratic costs and are discussed in greater detail in chapters 3 and 4. Monitoring and other agency costs will be discussed in greater details in chapter 4.

\section{Theory of collective action}

The theory of collective action explains that members within cooperatives have interests in common (which provide incentives for members to participate in cooperatives), as well as heterogeneous interests (that is necessary to understand the manner in which members participate, and the transaction costs which result from their participation). In summary, theory predicts that individuals will choose to explore the possibility of organizing an activity collectively when he expects that he may increase his utility (CHRISTIANO, 2003). 
According to Olson (1965), who is one of the main authors on the theory of collective action, while there is a doubt whether there is any single purpose that would be the characteristic of organizations in general, at least there is one which is characteristic of all organization with an important economic aspect: the furtherance of the interests of their members. The author observes that while political scientists believe that associations exist to fulfill purposes which a group of men has in common, social psychologists believe that the attraction of group membership is not so much in sheer belonging but rather in attaining something by means of this membership.

Then, Olson (1965) concludes that the word group is used in such a way that it means a number of individuals with a common interest, i.e. there is no group without its interests. But, in addition, those who belong to an organization or group also have purely individual interests, different from those of the others in the organization or group. He calls the attention to the fact that if there are not common but only purely personal or individual interests to be advanced, an individual and unorganized action can work most efficiently.

\section{Theory of collective action applied in the cooperative literature}

In the cooperative literature, Reynolds (1997) notes that agricultural producers have an incentive to form and support a cooperative when it provides benefits they would not obtain by acting independently. ${ }^{7}$ However, according to him, together with individual incentives in making cooperation possible, conflicting interests coexist with those of cooperation. Therefore, cooperatives would prosper if producer interests and goals are accomplished more effectively with cooperation than with more individualistic methods of transacting for services. Bogetoft and Olesen (2004)'s findings support it. They show that standard producers (e.g., majority) and differentiated producers (e.g., minority claiming for best prices) can only both stay and profit together in a cooperative if they can exploit synergies. Otherwise, the cooperative is likely to incur in higher transaction costs because of this heterogeneity.

With regard to the issue of level of heterogeneity, the literature on social sciences has two opinions about. On the one hand, it considers that heterogeneity of interests can impede collective action, polarizing a group into opposing camps rather than coalescing members

\footnotetext{
${ }^{7}$ For a literature review on this issue see, for example, Cook (1995).
} 
toward a unified collective action (HECKATHORN, 1992). On the other hand, it also considers that the presence of actors with diverse characteristics facilitates collective action because it increases the likelihood that a critical mass of highly motivated contributors will emerge to initiate action. I. e, the success of collective action is almost guaranteed if the group includes at least one actor whose benefit from collective action exceeds the entire production cost. Olson (1965) argues that such groups are said to be privileged. ${ }^{8}$

With regard to the issue of level of member participation, the literature on collective action suggests that differences in this level may incur in two kinds of costs: poor monitoring (e.g., the costs of low participation), and conflict of interests solving (e.g., the costs of high participation).

To explain the costs of low participation we can refer once more to Olson (1965). The author argues that even if members of a group have a common interest in obtaining the collective benefit, they have no common interest in paying the cost of providing that collective good. "Each would prefer that the others pay the entire cost [e.g., monitoring cost], and ordinarily would get any benefit provided whether he had borne part of the cost or not" (OLSON, 1965, p. 21).

In the cooperative literature, Österberg and Nilsson $(2009$, p. 181) note that "all the members may understand that information should be given to the management and that control of the management [monitoring] should be conducted, but each one may like 'somebody else' to do this, i.e., free-rider behavior". Birchall and Simmons (2004c) note that members are more likely to participate when the costs are lower than the benefits of participation.

Heckathorn $(1990 ; 1993)$ analyzes that when the level of member participation is low, selective incentives (e.g., punishment for free-riders or rewards for cooperators), i.e., a "second-order" free-rider problem (OLIVER, 1980) arises. It means that those who fail to bear the costs of collective action (e.g., the costs of participation) still receive its benefits (e.g., the decisions taken).

\footnotetext{
${ }^{8}$ Other conceptual approaches (e.g., political sciences) can also be adopted, as seen in De Figueiredo. Our choice is to focus on the contribution of Olson.
} 
Heckathorn (1990) shows that when collective action is organized through selective incentives, each member makes first-level choices (i.e., whether to contribute to producing the public good) and second-level choices (i.e., whether to influence others). 'First-level choices' are assumed to be dichotomous, i.e., members either contribute to the production of the public good or they choose to free-ride. 'Second-level choices', in their turn, are assumed to be three-fold: members exert no control over others; exert compliant control to increase contributions to production of public goods; or exert oppositional control to weaken compliant control.

Thus, according to Heckathorn (1990) there are six possible strategies (Figure 4). The first strategy is full cooperation. It involves contributing to public goods production and sanctioning those who fail to contribute. Thus, the individual who chooses this strategy maximizes the individual and collective contributions to the production of public goods. The second strategy is hypocritical cooperation. It occurs when a member free-rides, i.e., fails to contribute to the public good, but urges others to contribute. The third strategy occurs when a member who chooses private cooperation contributes to the public good, but does not try to prevent others from free-riding. The fourth strategy occurs when a member who chooses full defection refuses to contribute and permits others to do as they wish. The fifth strategy occurs when a member who chooses compliant opposition contributes to the public good, but defends the rights of others to refuse to contribute. Finally, the sixth strategy occurs when a member who chooses full opposition refuses to contribute and opposes norms that would compel compliance.

\begin{tabular}{|c|c|c|c|c|}
\hline & & \multicolumn{3}{|c|}{$\begin{array}{c}\text { CHOICE OF INTERPERSONAL CONTROL } \\
\text { (Second Level) }\end{array}$} \\
\hline & & $\begin{array}{l}\text { Compliant Control } \\
\text { (Cooperation) }\end{array}$ & $\begin{array}{l}\text { No Control } \\
\text { (Defection) }\end{array}$ & $\begin{array}{l}\text { Oppositional } \\
\text { Control }\end{array}$ \\
\hline \multirow{2}{*}{$\begin{array}{c}\text { CHOICE OF } \\
\text { CONTRIBUTING } \\
\text { TO THE PUBLIC } \\
\text { GOOD } \\
\text { (First Level) }\end{array}$} & $\begin{array}{l}\text { Contribute } \\
\text { (Cooperation) }\end{array}$ & $\begin{array}{c}(1) \\
\text { Full cooperation }\end{array}$ & $\begin{array}{l}\text { (3) } \\
\text { Private cooperation }\end{array}$ & $\begin{array}{c}\text { (5) } \\
\text { Compliant } \\
\text { opposition }\end{array}$ \\
\hline & $\begin{array}{l}\text { Not Contribute } \\
\text { (Defection) }\end{array}$ & $\begin{array}{c}(2) \\
\text { Hypocritical } \\
\text { Cooperation }\end{array}$ & $\begin{array}{c}\text { (4) } \\
\text { Full defection }\end{array}$ & $\begin{array}{c}\text { (6) } \\
\text { Full opposition }\end{array}$ \\
\hline
\end{tabular}

Figure 4 - Six strategies as a function of the choice to contribute and the choice to control others SOURCE: Heckathorn; 1990 
In summary, either when members choose to contribute (i.e., participate) or not (i.e., freeride), cooperatives are always likely to incur positive internal transaction costs. The costs resultant from higher level of member participation, are referred to costs of conflict of interests solving (as they bring not only common but also individual interests to the decision making process). The costs resultant from lower level of member participation, are referred to costs of poor monitoring the management, and costs of cooperative giving members incentives to participate.

\subsection{Research domain: Brazilian agricultural cooperative's context}

In this study, we address the issue of how to control both democratic and agency costs considering different levels of heterogeneity and member participation in Brazilian agricultural cooperatives. Cooperatives are a particularly prominent form of organization which is found in the Brazilian agricultural market. In 2009 there were roughly 1,615 such firms, which together accounted for 38.4 percent of the overall agricultural gross domestic product (OCB, 2009). Because of their importance in the agricultural economy (which is explained earlier in this chapter), as well as their degree of heterogeneity and their typical traditional structure, Brazilian cooperatives are of interest of this research.

More specifically, a number of cooperatives from the state of Rio Grande do Sul (RS) have been studied. Rio Grande do Sul is the selected location for this study because it has a rich variety of important aspects which are needed for this study, such as: (1), small and large memberships; (2), low and high percentages of member participation in pre and general assemblies. Furthermore, in RS one can find differences with regard to the number of different types of products received by each cooperative.

Degree of heterogeneity amongst cooperatives and cooperative members is important for this research, as it is one of the key element examined in this study. One can find both single product (e.g., grapes cooperatives) and multiple product cooperatives (with different degrees of product representation in the sales of the cooperatives). In addition, they may have members either with homogeneous characteristics (e.g., volume of products delivered) or members with large differences regarding these aspects. 
Various aspects of the traditional structure of cooperatives (e.g., one-man one-vote), as is explained above, can be expected to affect democratic and agency costs. Therefore, to understand these costs, it is interesting to do research on the governance of Brazilian cooperatives. For a large part, their governance structure is regulated by law. Brazilian cooperative law number 5,764, created in 1971 regulates the cooperatives by following the cooperative principles from the International Cooperative Alliance, namely (i), voluntary and open membership (ii), democratic member control (iii), member economic participation (iv), autonomy and independence (v), education, training and information (vi), cooperation among cooperatives (vii), concern for community.

\subsection{Structure and outline of the study}

The present thesis ${ }^{9}$ is developed in five chapters. This introductory chapter is followed by three studies and by the final conclusion chapter. The studies are concerned with relationships amongst heterogeneity, member participation and cooperative decision making costs (democratic and agency costs), in accordance with the general theme of the study. Figure 5 illustrates the scheme of the relationships amongst the studies.

\footnotetext{
${ }^{9}$ Note: this thesis is written in English, on behalf of my supervisor and of CPG FEA-USP (Comissão de PósGraduação da Faculdade de Economia, Administração e Contabilidade da Universidade de São Paulo), since I had spent one year abroad as an international guest researcher at Wageningen University, and as a guest researcher at the research group "cooperatives and value chains", where I had the opportunity to discuss many times my project and chapters with international researches on this field, from diverse universities, such as Wageningen University (The Netherlands), Haramaya University (Ethiopia), University of the Free State (South Africa), the Center for Agricultural and Rural Development (China), Rotterdam University (The Netherlands), Nijenrode University (The Netherlands), Radboud Universiteit Nijmegen (The Netherlands), Liebig-Universität Gießen (Germany).
} 


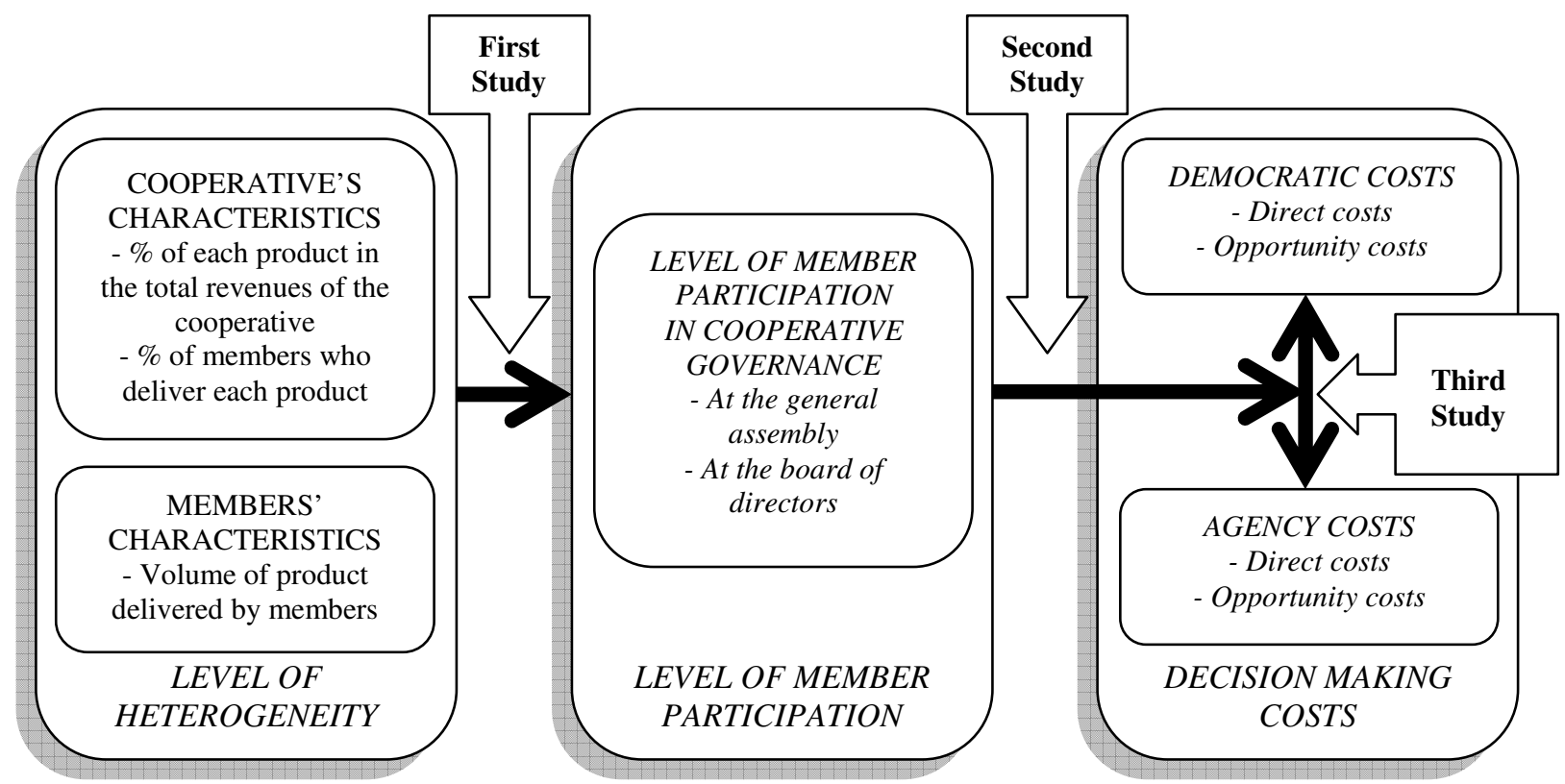

Figure 5 - Scheme of the thesis

The introduction presents the motivation of the study and background, the statement of the main research problem, the research objectives and questions, the research justification, the positioning of the study in the literature, the research domain, and the structure and outline of the thesis.

Chapter two - "Member participation in cooperative governance: does heterogeneity matter?" focuses on the relation between level of heterogeneity and level of member participation in cooperative governance since these are the two main drivers of decision making costs (i.e., democratic and agency costs) in agricultural cooperatives. More specifically, this study examines how member participation is related to some aspects of heterogeneity. Previous research has not empirically compared differences in member participation between homogenous and heterogeneous cooperatives. The research question that leads chapter 2 is the following: What is the relation between level of heterogeneity and level of member participation in the governance of agricultural cooperatives?

Since there are two types of member participation in cooperative governance that are of interest of this chapter (at the general assembly, and at the board of directors), two propositions have been developed. These propositions are the following: 
Proposition 1: When the cooperative is more homogeneous, the level of member participation at the general assembly is low. When the level of heterogeneity increases, the level of member participation at the general assembly increases. When the cooperative reaches certain level of heterogeneity (without a dominant group) the level of member participation at the general assembly decreases.

Proposition 2: The more the level of heterogeneity (e.g., in terms of volume) increases, the more medium and large farmers participate in the board of directors.

To generate results for the study, twelve Brazilian agricultural cooperatives have been examined. The results have been analyzed in two steps. First, by means of theory building research (EISENHARDT, 1989), a measurement scale has been developed for heterogeneity. The scale ranks cooperatives from homogeneous to more heterogeneous taking into account both cooperatives and members characteristics. Second, the relation between level of heterogeneity and member participation has been investigated by means of scatter plots, and logistic regression. The results of chapter two give insight into the relationship between different levels of heterogeneity and member participation, and a comprehensive overview of how the various aspects of heterogeneity affect member participation.

Chapter three - "The costs of democratic control" examines the relation between the level of member participation and democratic costs in agricultural cooperatives. Level of member participation is the main (direct) driver of these costs. The examination of the costs of democratic control incurred by agricultural cooperatives is an issue that has been insufficiently explored. This study aims to bridge this gap in the literature, by discussing and examining these costs in detail. The research question that leads chapter 3 is the following: What is the relation between level of member participation and democratic costs in agricultural cooperatives?

Since there are two types of member participation in cooperative governance that are of interest of this chapter (at the general assembly, and at the board of directors), and two types of democratic costs (direct and opportunity - with regard to under and overrepresentation), five propositions have been formulated in this chapter. These propositions are the following: 
Proposition 1: The higher is the level of member participation at the general assembly, the higher are the direct democratic costs.

Proposition 2: When the level of member participation at the general assembly is low, the more likely the cooperative is to incur opportunity costs of underrepresentation. When the level of member participation at the general assembly increases until all (groups of) members are (proportionally) represented, opportunity democratic costs are likely to decrease. When the level of member participation at the general assembly is high, the more likely the cooperative is to incur opportunity costs of overrepresentation.

Proposition 3: The larger is the board of directors, the higher are the direct democratic costs at the board of directors.

Proposition 4: Smaller boards are more likely than larger boards to incur opportunity costs of underrepresentation.

Proposition 5: Larger boards are more likely than smaller boards to incur opportunity costs of overrepresentation.

The results of chapter three give insight into the relation between differences in level of member participation in collective cooperative governance bodies (i.e., general assembly and board of directors) and direct and opportunity democratic costs across cooperatives. In other words, it gives insights about costs that result from horizontal and from diagonal conflicts of interests across cooperatives.

Chapter four - "The costs of cooperative governance: democratic and agency costs" uses the results from previous chapters to examine how cooperatives can control both democratic and agency costs considering different levels of member participation. It is a key issue for cooperatives because, at the same time: (1), member-democratic control makes decision making process slower and more costly in cooperatives in contrast with investor-owned firms, and (2), cooperatives lack some of the mechanisms which investor-owned firms use to control agency costs. Insufficient research has examined both democratic and agency costs in agricultural cooperatives. The research question that leads chapter 4 is the following: How is 
the ability of cooperatives to control both democratic and agency costs related to the level of member participation?

We have developed 6 propositions for these relations. Three of them are related to the balance between democratic costs at the general assembly and usage of mechanisms to reduce exposure to agency problems, and three propositions are related to the balance between democratic costs at the board of directors and usage of mechanisms to reduce exposure to agency problems. These propositions are the following:

Proposition 1: The lower the level of member participation at the general assembly, the lower the direct democratic costs at the general assembly and the higher the usage of mechanisms to reduce exposure to agency problems.

Proposition 2: The lower the level of member participation at the general assembly, the higher the opportunity democratic costs at the general assembly with regard to underrepresentation and the higher the usage of mechanisms to reduce exposure to agency problems.

Proposition 3: The higher the level of member participation at the general assembly, the higher the opportunity democratic costs at the general assembly with regard to overrepresentation and the lower the usage of mechanisms to reduce exposure to agency problems.

Proposition 4: The lower the level of member participation at the board of directors (i.e., the smaller the board size), the lower the direct democratic costs at the board of directors and the higher the usage of mechanisms to reduce exposure to agency problems.

Proposition 5: The lower the level of member participation at the board of directors, the higher the opportunity democratic costs at the board of directors with regard to underrepresentation and the higher the usage of mechanisms to reduce exposure to agency problems.

Proposition 6: The higher the level of member participation at the board of directors, the higher the opportunity democratic costs at the board of directors with regard to 
overrepresentation at the board of directors and the lower the usage of mechanisms to reduce exposure to agency problems.

The results of this chapter give insight into how cooperatives can control both democratic and agency costs considering different levels of member participation. Furthermore, it gives insight into the relative importance of both democratic and agency costs in each of their forms (direct and opportunity).

The final chapter, conclusion, gives an overview of the contributions of the thesis as a whole. Specifically, the chapter: (1), discusses the answers to the research questions; (2), outlines the study's theoretical, methodological and managerial implications; (3), describes the limitations of the study and gives direction for further research. 
DOES HETEROGENEITY MATTER?

\subsection{Introduction}

Decision making in cooperatives is likely to be a more costly process than in investor-owned firms (STAATZ, 1987a, 1987d; ZYLBERSZTAJN, 1994). Then, a challenge cooperatives face is to minimize decision making costs. This study examines the relation between the level of heterogeneity and the level of member participation in cooperative governance. According to the literature on cooperatives, the level of heterogeneity affects the level of member participation in cooperative governance, while the level of member participation in turn affects decision making costs (democratic and agency costs). These two variables play a very relevant role in this thesis.

We have chosen agricultural cooperatives to look for evidences for this study. Agricultural cooperatives may encounter significant heterogeneity both within the organization (e.g., number of products or product qualities received) and amongst its members (e.g., farm size). A heterogeneity measurement model that ranks cooperatives from homogeneous to heterogeneous, while taking into account both cooperatives and members characteristics, is developed in the first part of the study.

In the second part, we examine whether heterogeneity matters for member participation in cooperative governance. This is because, according to a group of cooperative scholars, the more heterogeneous members a cooperative has and the more heterogeneous a cooperative is, the more the interests of the various constituents (group of members) are likely to conflict, resulting in various groups actively attempting to control the decision making process in the cooperative (HANSMANN, 1996; HENDRIKSE; BIJMAN, 2002; KALOGERAS et al, 2009). On the other hand, another group (e.g., ÖSTERBERG; NILSSON, 2009, amongst others) note that when the cooperative is more heterogeneous, members may feel that cooperative business has become so complex (e.g., large cooperatives have often multipurpose activities, whereby many members are interested in only a specific branch of business) that they may not understand them, have little knowledge of them, and are alienated 
from them. As a result, they do not participate. Therefore, it seems valuable to gain insight into whether heterogeneity matters for member participation in cooperative governance. Particularly, since level of member participation is a source of decision making costs (democratic and agency costs).

The research question that leads the present study is the following: What is the relation between level of heterogeneity and level of member participation in the governance of agricultural cooperatives?

\subsection{Theoretical framework}

\section{Heterogeneity}

Cooperatives may encounter significant heterogeneity both amongst its members and within the firm. Explaining each type of heterogeneity is the focus of this section.

\section{Member's heterogeneity}

Members may differ in terms of: (1) their individual characteristics; and (2) their farm's characteristics.

With regard to individual characteristics, members may differ mainly in terms of:

a) Demographic characteristics, such as: age (ZUSMAN, 1982; ILIOPOULOS; COOK, 1999; ÖSTERBERG; NILSSON, 2009); educational level (ILIOPOULOS; COOK, 1999), amongst others;

b) Economic characteristics, such as: percentage of non-farm income (ILIOPOULOS; COOK, 1999); business objectives (ILIOPOULOS; COOK, 1999); risk preference (CONDON, 1987), amongst others; and

c) Beliefs, such as: cooperative principles, collective action, individual member identity as associated with cooperative membership, life satisfaction with farming, equitable treatment among members (GRAY; KRAENZLE, 1998), amongst others. 
With regard to farms' characteristics, members may differ mainly in terms of farm size (ZUSMAN, 1982; CONDON, 1987; HART; MOORE, 1996; ILIOPOULOS; COOK, 1999; KARANTININIS; ZAGO, 2001; ÖSTERBERG; NILSSON, 2009); farm technology efficiency (ZUSMAN, 1982; KARANTININIS; ZAGO, 2001); geographic distance from the farm to the headquarters (ILIOPOULOS; COOK, 1999; ÖSTERBERG; NILSSON, 2009); number of different commodities produced (STAATZ, 1987b; HART; MOORE, 1996; ILIOPOULOS; COOK, 1999; ÖSTERBERG; NILSSON, 2009); number of different inputs purchased (STAATZ, 1987b; HART; MOORE, 1996; ILIOPOULOS; COOK, 1999; ÖSTERBERG; NILSSON, 2009), amongst others.

\section{Cooperative's heterogeneity}

Within the firm, characteristics which cooperatives may differ are mainly related to: the number of products or product qualities received, percentage that each product or product qualities represent in the annual revenues of the cooperative, percentage of members who deliver each product or product qualities, amongst others.

\section{Member participation in cooperative governance}

Members may participate in cooperative governance mainly in three ways: (1) attending general assemblies; (2) holding a position in the board of directors; and (3) holding a position in the executive board.

Although members may also participate in committees ${ }^{10}$ and in the internal audit board ${ }^{11}$, these participations are not of interest of the present study, because members do not make decisions at those levels.

\footnotetext{
${ }^{10}$ Cooperatives use to establish various kinds of committees which members voluntarily participate (e.g., education and training committee).

${ }^{11}$ Members who participate at the supervisory committee (i.e., audit board) are those who were voted to do it. The principal task of the supervisory committee, for example, is to control the activities of the board of directors, of the management, and those of any commission (HENRŸ, 2005). According to Forcadell (2005), normally three accounts auditors form the audit committee, which has the basic role of auditing the accounts and financial documents presented to the general assembly. This is also the rule applied in Brazil.
} 


\section{Cooperative governance bodies}

Then, the governance bodies a cooperative firm has are: the general assembly, the board of directors, and the executive board. Explaining the main characteristics of each one is the focus of this section.

\section{$\underline{\text { General assembly }}$}

According to the guidelines for cooperative legislation (e.g., HENR $\ddot{Y}, 2005$ ) of the International Labour Organization with the agreement of the International Cooperative Alliance, the ordinary and the extraordinary general assembly, composed exclusively of the members of the cooperative, is the supreme decision making body of the cooperative. The Brazilian Law of Cooperatives, number 5764, in force since 1971, at its $38^{\text {th }}$ Article, confirms that and adds that cooperatives decisions are binding to all cooperative members, even if absent or dissenting.

The $44^{\text {th }}$ Article of the Law 5764 sets that the agenda of a general assembly shall include: (I) accountability of the cooperative situation, approved by the internal audit board, including: a) report of the cooperatives activities; b) balance sheet; c) surplus distribution or contribution to cover losses arising from the insufficiency of contributions to cover the expenses of the company; (II) destination of the surplus or apportionment of the losses; (III) election of members for the board of directors, internal audit board, and other bodies, if any (e.g., their representatives in that of a higher level structure [for example, a central cooperative] of which the cooperative is a member); (IV) establishment of the income of their representatives (members of the board of directors, executive board, and internal audit board); (V) any other business unless it is an issue for the agenda of an extraordinary general assembly (BRASIL, 1971).

\section{Extraordinary general assembly}

The $46^{\text {th }}$ Article of the Law 5764 sets that the agenda of an extraordinary general assembly shall include: (I) modification of the bylaws/statutes within the limits of the law and the universally recognized cooperative values and principles; (II) merger, consolidation or 
dissolution; (III) change of the objective of the association; (IV) voluntary dissolution of the company and appointment of liquidators; (V) accounts of the liquidator (BRASIL, 1971).

\section{Board of directors and Executive board}

The $47^{\text {th }}$ Article of the Law 5764 sets that the cooperative shall be managed by an executive board or board of directors formed exclusively by members of the cooperative, who are elected by the general assembly. It sets also $\left(48^{\text {th }}\right.$ Article) that both the board of directors and the executive board may contract external executives to perform managerial roles. Costa (2010) shows that Brazilian agricultural cooperatives use three models of governance. In the first model, the general assembly elects a number of members to hold a position in the board of directors. After elected, board members either may elect members amongst themselves to hold a position in the executive board or may contract an external executive to perform the role of CEO. In the second model, the general assembly elects members to hold a position in the board of directors and, separately, some others to hold a position in the executive board. In this second model, the executive board may contract an external executive to perform the role of CEO. In the third model, the general assembly either may elect members to hold a position in the board of directors and, separately, some others to hold a position in the executive board, or they may give to the board of directors the power to elect (and to dismiss) the executive board, who can also be contracted. The third model is a kind of mixed model.

According to the Brazilian law 5764, board members are elected to hold a position for no longer than four years. Each four years at least $1 / 3$ of the group shall be renewed (BRASIL, 1971). Zylbersztajn (1994) argues that insofar as decision making process in traditional cooperatives is slower and more costly process than do in investor-owned firms because decisions are made not only in the executive level, but also in the general assembly and in the board of directors, electing a CEO for a period longer than 4 years would help to economize on decision making costs. According to him, cooperatives spend more transaction costs any time they need to renew their elected executives.

This law does not set anything else on the topic of the board of directors. Henrÿ (2005) observes that, by default, all matters which do not explicitly come under the authority of the general assembly are under the power and responsibility of the board of directors. Some of the powers/responsibilities of the board of directors, according to Henrÿ (2005) are: 
- verify that the audit is conducted regularly and within the prescribed time limits before discussing the conclusion with the supervisory committee, if any, and/or the general assembly;

- $\quad$ convene the ordinary and extraordinary general assemblies and prepare their agenda according to the bylaws/statutes;

- $\quad$ prepare the management report (including an activity plan for the following year) and the annual budget;

- facilitate the exercise of the rights of the members and make certain that they assume their obligations;

- $\quad$ facilitate the work of the auditors;

- nominate, if necessary, a manager or director, member or not of the cooperative, and ensure that the manager or director carries out the assigned duties correctly. In practice, this employee must assume the management functions which are not explicitly reserved to be performed by the board;

- $\quad$ make certain that its functioning be transparent by adopting internal regulations, unless drawn up by the general assembly;

- $\quad$ take on any other right or obligation, assigned by the general assembly or contained in the bylaws/statutes.

Perraut (1983) and Cook (1994) observe that the managerial roles that a chairman of a cooperative performs are not only significantly different but often more difficult than in investor-owned firms. More than this, Cook (1994) argues that members expect that cooperative leadership will lie in the coordinated performance of the cooperative and farm entity instead of in personality and behavior. That means that members select as leaders people who create the expectation that they will be able to maintain goal direction, facilitate task achievement, and ensure group cohesiveness (COOK, 1994).

According to Cook (1994), a member holding a position in the executive board of a cooperative has to perform a set of managerial roles such as:

- $\quad$ interpersonal role, such as: figurehead, liaison and leadership role, ${ }^{12}$

- $\quad$ informational role, such: as monitor, disseminator, spokesperson; and

\footnotetext{
${ }^{12}$ See also Perraut (1983).
} 
- decisional role, such as: entrepreneur, conflict resolution handler, negotiator, resource allocator.

\section{Cooperative governance characteristics}

\section{$\underline{\text { Voting }}$}

The voting rule for primary cooperatives is one member/one vote regardless of the amount of capital invested by the member in the cooperative and the member scale of transaction carried with the cooperative (i.e., patronage). In secondary and higher-level cooperative organizations, a system of plural voting rights may be applied. (HENRŸ, 2005; BRASIL, 1971).

Gripsrud, Lenvik and Olsen (2000) argue that in a number of countries, cooperatives are now adapting to a changing environment. However, many scholars argue that in some cases (e.g., disregarding democracy and applying voting proportional to patronage) the cooperative may end up as an ordinary investor-owned-firm. Nonetheless, it is important to observe many innovation processes that some cooperatives (e.g., Danish Crown) are proposing to reduce potential conflicts of interests as they become larger, more international, and more marketoriented. For example, despite the $9^{\text {th }}$ Article of Danish Crown's Article of Association in its $1^{\text {rst }}$ paragraph sets that each member shall have one vote, it also sets that the vote may be divided into two so that the voting right may be exercised or used differently for each of the two halves. The $7^{\text {th }}$ paragraph explains about the exercise of the two halves when a member is, at the same time, producer of two or three of the three products that the cooperative receives. If a member is a pig supplier or a sow supplier and a cattle supplier at the same time, such member will be entitled to exercise the voting right at both categories such that only a half vote is used in each category. Otherwise, the $2^{\text {nd }}$ paragraph sets that the member may transfer half of the vote to a person connected with the farm, for example, through marriage or permanent cohabitation with the member, as direct or indirect (co-) owner of the farm or as an employee at the farm. (DANISH CROWN, 2006). 


\section{$\underline{\text { Majorities }}$}

At ordinary general assemblies, decisions may be taken by a simple majority if the required quorum of members is present or represented. (BRASIL, 1971; HENRŸ, 2005). Simple majority means that, during the election, the candidate or proposal in question obtains a number of votes corresponding to at least half of the votes counting in the election, disregarding all blank or invalid votes.

At extraordinary general assemblies, in the case where resolutions concerning the association contract (be it a modification of the bylaws/statutes or a decision on merging/amalgamating, dividing, dissolving, converting or on affiliating the cooperative with an apex organization)

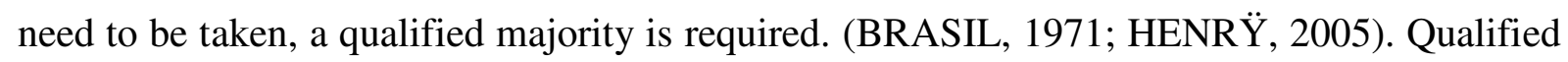
majority means at least a two-thirds majority.

\section{Quorum}

Henrÿ (2005) suggests that by fixing a quorum, the decision making process respects the principles of democracy and economic efficiency. Fixing a quorum means to fix "the minimum number of members who must be present or represented for the general assembly to validly sit, deliberate and vote." (HENR $\ddot{Y}, 2005$, p. 39-40). However, according to him, where the general assembly repeatedly fails to gather the required quorum, a second meeting, with the same agenda, may decide regardless of the number of members present or represented.

The $4^{\text {th }}$ Article of the Brazilian Cooperative Law number 5764, in its $6^{\text {th }}$ paragraph, sets that the quorum of the general assembly shall be based on the number of members, rather than the amount of represented capital. This law, in its $40^{\text {th }}$ article, fixes that the quorum of the general assembly shall be $2 / 3$ of the number of members. When it fails, a second meeting shall held half of the number of the membership plus one member. Otherwise, a third meeting shall held the presence of a minimum of ten members. Regarding general assemblies of secondary and higher-level cooperative organizations, a minimum of members is not required by law (BRASIL, 1971). 
With regard to voting by proxy, even though cooperatives from other countries (e.g., Danish Crown from Denmark) allow voting by proxy, Brazilian law does not. Voting by proxy means that, when a member who is entitled to vote is prevented from attending the (local district) meeting, the member might appoint, in writing, another member to vote on his/her behalf. Danish Crown, for example, allows either member's spouse, or another member, or even a person employed at member's farm to vote on behalf of the member prevented to attend. A member or proxy may vote as proxy for only one member. (DANISH CROWN, 2006).

Another way to involve the greatest possible number of members in the decision making process, according to Henrÿ (2005), would be to run a virtual general assembly. Neither an administrative centre nor the physical presence of the members is required to hold a general assembly. Otherwise, they should be free to discuss and vote via, for example, the Internet. What matters is the democratic control by the members, not their physical presence at meetings, although this may still help to generate and regenerate the necessary reciprocal confidence. "Voting by mail or via the Internet might be a way to involve the greatest possible number of members in the decision making process, whenever the physical presence of the members is not necessary." (HENRŸ, 2005, p. 41).

\section{Nucleus meetings (pre general assemblies)}

Gorroñogoitia (s. d) argues that when the number of members is relatively small and the businesses of the cooperative are not so complex, the general assembly may be a means of active member participation. Nonetheless, when the number of members increases, the active member participation in general assemblies becomes more difficult. Doing so would lead to long-term sessions that would exceed the natural capacity for participation. As a result, cooperatives have tended to specialize the general assembly session to the information, presentation of alternatives developed for the projects submitted for approval and voting decision, and have created pre-general assemblies or nucleus meetings. The objective of pregeneral assemblies is to give didactically the necessary information about the projects submitted for approval and voting decision, to smaller groups of members, due the diversity of levels of perception of the members about the themes that are discussed at the general assembly (GORROÑOGOITIA, s. d). 
Henrÿ (2005) suggests that cooperatives should form regional assemblies and/or assemblies by sections in a number of cases: when the size of a cooperative in terms of territorial coverage or the number of members is such that the necessary quorum is difficult to attain or the proceedings of the general assembly become too cumbersome; or wherein a multi-purpose cooperative diverse interests so require. These decentralized assemblies (i.e., nucleus meetings or pre general assemblies) elect their representatives to a delegates' assembly which replaces the general assembly. The $42^{\text {th }}$ Article of the Brazilian Cooperative Law number 5764 confirms that and sets that members from cooperatives that have a membership larger than three thousand may be represented by delegates since they are not holding any other sit at the cooperative and since it is settled by the statute of the cooperative. It is also possible, according to the same article, $4^{\text {th }}$ paragraph, that delegates represent members who live more than $50 \mathrm{~km}$ far away from the cooperative headquarters, even when the cooperative has a membership smaller than three thousand.

\section{Levels of member participation in cooperative governance}

\section{$\underline{\text { General assembly }}$}

Gorroñogoitia (s. d) argues that, amongst others, participating in a general assembly means: to renew member commitment of participating in the cooperative experience; voting in decisions that affect everyone; and ultimately, to act in the social activity, to be an active part in building the cooperative, whose development depends on components that affect your personal life, family and society.

Although member participation in general assemblies has these above described meanings, and is a statutory obligation, the level of member participation is highly variable among members, i.e., some members participate and others may never attend even an annual assembly. For instance, Gray and Kraenzle (1998) show that around $42 \%$ of cooperative members do not participate in general meetings in a large cooperative in the United States. Laursen, Karantininis and Bhuyan (2008) show that around half of cooperative members never or rarely participate in general meetings in three large cooperatives in Denmark.

There is a strong debate in the cooperative literature about whether or not members have strong incentives to participate. On the one hand, a group of authors (e.g., COOK, 1994; 
HANSMANN, 1999; GORTON; SCHMID, 1999) argues that cooperative members would have strong incentives to control the cooperative. Gorton and Schmid (1999), for instance, observe that considering that cooperatives are businesses that are owned by the same individuals who transact with it, then, originally, the cooperative members would have strong incentives to control or, at least, monitor the performance of the cooperative. Cook (1994, p. 50) argues that "because the decisions made at the cooperative level have an effect on the value of the member's fixed assets and working capital, the member will have a tendency to inspect resource allocation decisions on an individual basis." According to Hansmann (1999, p. 397):

[...] transactions between a typical member and the cooperative represent a substantial fraction of the member's income. This means that it is quite worthwhile for the member to invest heavily in becoming informed about the cooperative's affairs, which in turn permits the member to participate thoughtfully in elections to the board and other matters of cooperative governance.

Hendrikse (1998, p. 202) suggests that "there are several observations suggesting that decision making in cooperatives differs from decision making in investor-owned firms." One particular is because members are both suppliers of raw materials and capital, while shareholders of an investor-owned firm are only providers of capital.

This gives members the incentive to structure the internal organization of a cooperative in such a way that they have confidence that their substantial (financial) stakes are protected and their interests are advanced. This manifests itself in more extensive decision-making power being allocated to the general humbly of cooperatives than to the annual shareholders meeting of investor-owned firms. (HENDRIKSE, 1998, p. 203-204).

According to Österberg and Nilsson (2009, p. 182):

It is likely that many members have a desire to control the cooperative. They may consider the cooperative important to them because their farming operations often depend on the cooperatives, and they have invested money in it. Hence, it is only natural that members have a wish that the cooperatives are successful businesses, and that they are run in the interests of the members.

However, according to another group of authors (e.g., GRAY; DUFFEY, 1996; HOGELAND, 2006; FULTON, 1999) members would have weak incentives to be involved in the governance of the cooperative. This is because a couple of reasons. First, according to a group of authors (e. g., RHODES, 1978, ÖSTERBERG; NILSSON, 2009), it is due the freerider problem: 
Seldom does any cooperative member have an economic self-interest for trying to discipline management. His potential costs exceed his potential benefits. While all members together may have an economic incentive, the rational choice is for each individual to hope the others make the effort while he reaps the benefits. (RHODES, 1978, p. 223 apud STAATZ, 1987a, p. 129).

Second, (especially large) cooperatives have widely dispersed ownership, which provides individual members with few incentives to monitor the performance of their cooperative (FULTON, 1999). Based on this account, according to Hogeland (2006) one may expect member control to be weak in many cooperatives, and that management takes control.

\section{Board of directors and executive board}

Member participation in the board of directors (and in the executive board) is an obligation since they are elected to do so. I.e., board members are elected and receive an income to participate in all the board meetings, meetings between board and management, meetings between board and (internal and external) audit boards, and meetings between board and membership. The participation of members who hold a position in the governance in all the cooperative meetings is mandatory. This means that while the level of member participation in general assemblies may be diverse, the level of member participation at the board meetings is given by the number of seats the board of each cooperative has.

\section{Impact of heterogeneity on member participation in cooperative governance}

The literature on member participation in cooperative governance has been enriched by explanations from a variety of perspectives, including game-theory (e.g., STAATZ, 1987a), mutual incentives theory (e.g., BIRCHALL; SIMMONS, 2004a; 2004b; 2004c), theory of planned behavior (e.g., BHUYAN, 2007), and, most importantly, from the literature on collective action and (internal) transaction costs (e.g., STAATZ, 1987c), which has already been presented in section 1.5 .

However, former studies do not take into account whether member participation differs between more homogenous and more heterogeneous cooperatives. According to Reynolds (1997) even though agricultural producers have an incentive to form and support a cooperative when it provides benefits which would not be provided by individual actions, members of a cooperative typically have diverse economic interests (e.g., which may encompass size, type and location of farm enterprises). In this sense, Kalogeras et al (2009) 
argue: "members with different characteristics and conflicting preferences are inclined to compete for rents." For instance, Iliopoulos (s. d., p. 8) observes:

Consider a policy (e.g., the allocation of overhead costs) which creates a rent ' $R$ ' for the distribution of which members may compete. When members deliver substantially different product quantities, a policy that allocates overhead costs equally among members, for example, may result in a transfer of wealth from high to low volume producers. In order to compete for this rent, each member tries to influence decision making by expending resources to increase the probability of capturing the rent.

Gray and Kraenzle (1998) argue that member participation in the governance gives cooperatives their distinctive character. However, conflicts of interests are likely to arise because of the combination of heterogeneity and democracy. Traditional cooperatives give the same benefits to members with different characteristics. Then, "given that members have conflicting interests, member meetings will be an arena for promoting views, forging alliances and engaging in politics in general", as observed by Gripsrud, Lenvik and Olesen (2000).

\subsection{Research design}

\section{Methodological approach}

The general scheme of the present study is shown in Figure 6.

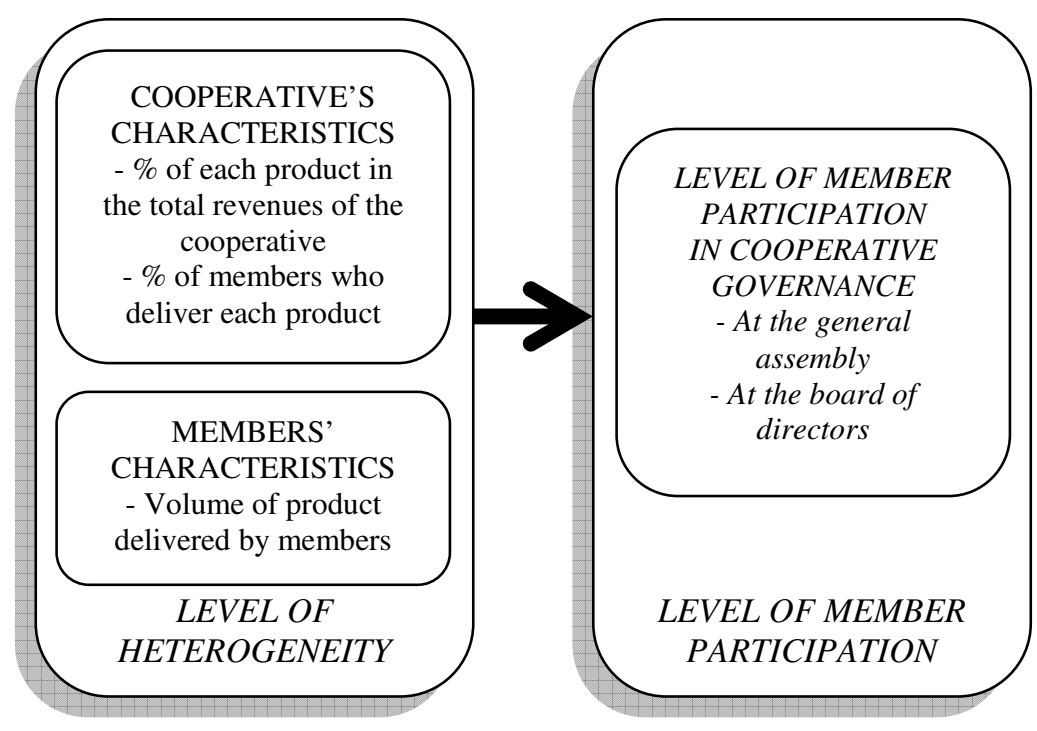

Figure 6 - Scheme of the study 
Following this scheme, the objective of the present study is threefold:

(1), to develop a heterogeneity measurement model that ranks cooperatives from homogeneous to heterogeneous, while taking into account both cooperatives and members characteristics;

(2), to examine whether there are differences in level (i.e., percentage) of member participation attending general assemblies across more homogenous and more heterogeneous cooperatives;

(3), to examine whether there are differences in characteristics of members holding a position in the board of directors across more homogenous and more heterogeneous cooperatives (e.g., whether large farmers participate more).

To achieve the first objective, a qualitative approach by means of theory building research (see Part 1 further) has been taken in order to develop a heterogeneity measurement model. To achieve the second research objective, results from the qualitative research have been examined by means of scatter plots (see Part 2 further). To achieve the third research objective, results from the qualitative research have been examined by means of logistic regression (see Part 2 further).

\section{Part 1 - Qualitative approach: heterogeneity measurement}

In order to develop our heterogeneity measurement, and, then, to shape our propositions, we have used theory building research (EISENHARDT, 1989) approach. It is a process of inducting theory using case studies from specifying the research questions to reaching closure. It uses the main steps such as follows: (1) specifying research questions and the main concepts to shape the initial design of the theory; (2) selecting the cases; (3) developing research instruments; (4) generating data; (5) analyzing data; (6) developing propositions. Each one of the steps is described in the next sections. 


\section{Specifying research questions and concepts}

The main research question at the beginning of the present study has been "What is the relation between level of heterogeneity and level of member participation in the governance of agricultural cooperatives?" Based on the literature, we can distinguish between two different types of heterogeneity's characteristics: (a), cooperative's characteristics; and (b), members' characteristics. The present study uses the following heterogeneity's characteristics as proxies to explain differences in member participation in cooperative governance: (1), percentage of each product in the total (agribusiness) revenues of the cooperative; and (2), percentage of members who deliver each product, as proxies for cooperative's characteristics; and (3), volume of product delivered by active members, as proxy for members' characteristics. These three variables are appropriate in assessing heterogeneity since they are more likely than others to capture differences between members which can lead to conflicts of interests.

As is explained earlier, there are two types of members' characteristics: members' individual characteristics, and farms' members' characteristics. Then, farms' members' characteristics are chosen instead of members' individual characteristics. Heckathorn (1993) argues that more than analyzing heterogeneity based on variations in demographic factors like race, ethnicity, or age; analyzing factors like interest in the public good, resources available to contribute to public goods production, and the cost of those contributions enhance our understanding of the demographic factors. Previous studies on member participation in cooperative governance (e.g., GRAY; KRAENZLE, 1998; GRIPSRUD; LENVIK; OLSEN, 2000) did not find relationship between member's age and member participation.

1) Percentage of each product in the total revenue of the cooperative. A cooperative that has more products representing high percentages in the total revenues is likely to have more conflicts of interests. Particularly, it holds true when farmers are specialized in each product. Gripsrud, Lenvik and Olsen (2000, p. 11) argue that "most agricultural cooperatives have restricted their areas of business to a particular type of product handle to reduce heterogeneity - or rather to reduce the potential conflicts of interests."

2) Percentage of members who deliver each product. Although this variable has not been used as proxy for heterogeneity in previous studies, is important to note that there may be 
differences in the relation between percentage each product represent in the annual sales of the cooperative and percentage of members who deliver each product. These differences are likely to bring conflicts of interests to the decision making process, as when a small percentage of the members delivering high quality product (or some different product) generates more revenues than a large percentage of other members delivering standard (or another) product (see Figure 7, for an example).

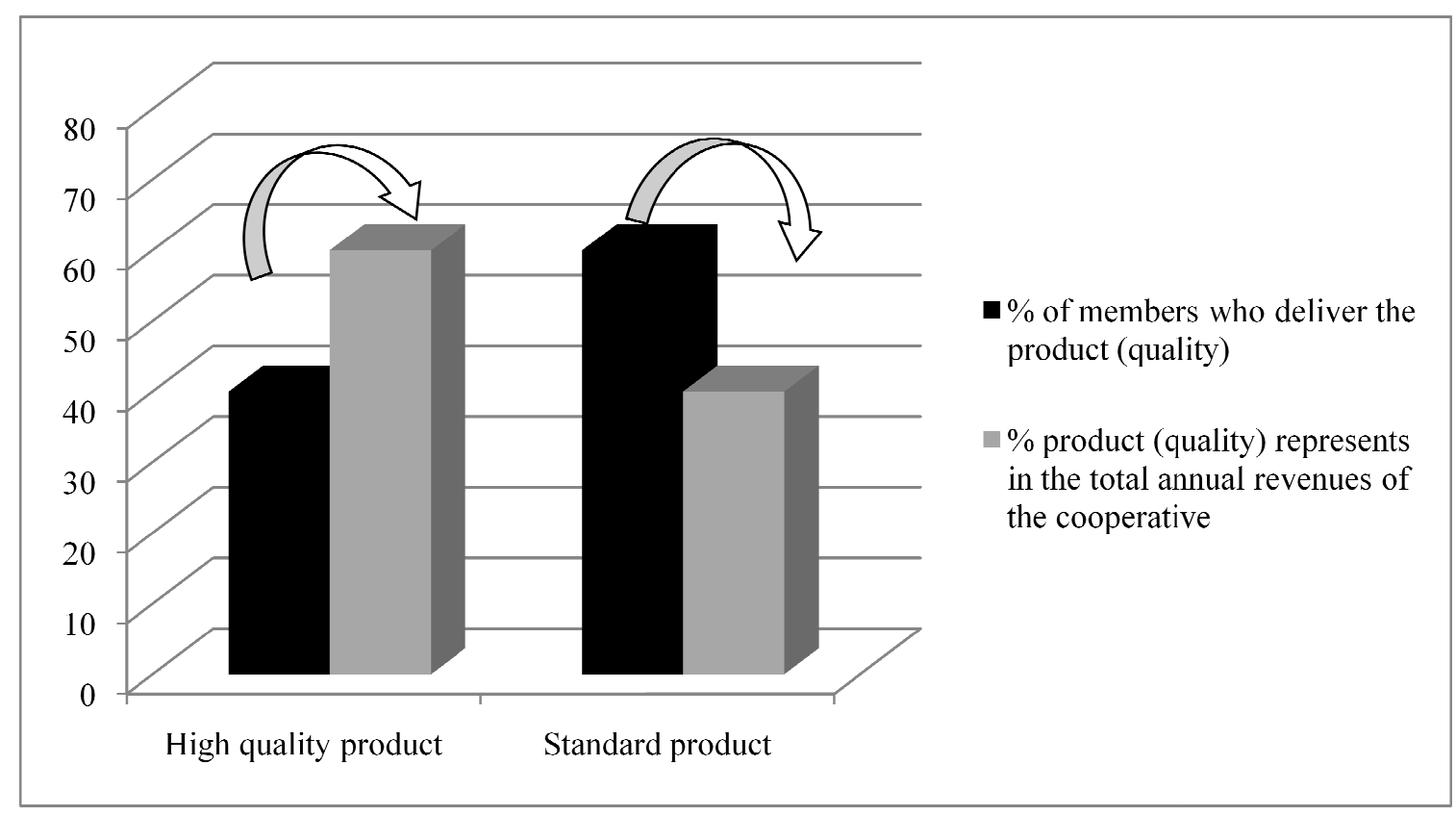

Figure 7 - Percentage of members who deliver each (quality of) product Vs. percentage that each (quality of) product represents in the annual revenues

3) Volume of product delivered by active members. Gray and Kraenzle (1998), for example, have shown that this variable is positively related to member participation attending general assemblies.

Subsequently, the following complementary questions have been defined:

RQ1: What is the relation between cooperative characteristics and level of member participation in the governance of agricultural cooperatives?

RQ1a: What is the relation between the percentage of each product in the total revenues of the cooperative and level of member participation in the governance of agricultural cooperatives?

RQ1b: What is the relation between the percentage of members who deliver each product and level of member participation in the governance of agricultural cooperatives? 
RQ2: What is the relation between farm's members' characteristics and level of member participation in the governance of agricultural cooperatives?

RQ2a: What is the relation between the volume of product delivered by active members and level of member participation in the governance of agricultural cooperatives?

\section{Selection of cases}

For this study, twelve cases (each case forms a cooperative) from Rio Grande do Sul (the most southern state of Brazil) have been selected. Rio Grande do Sul (RS) has been the selected location for this study because of two main reasons. First, RS has been the selected location because has a large variety of homogenous and heterogeneous cooperatives which is necessary for our study. In RS there are cooperatives that receive and process either only one product, or a great variety of products (e.g., grains, dairy, meat, fruit) altogether. Therefore, differences in cooperatives characteristics can be found in the state's cooperatives. In addition, this state is the largest producer of several agricultural products for both the domestic and international market (see Annex 1). As a result, a combination of both small and large producers can be found. Therefore, also differences in member characteristics can be found in the state's cooperatives. Second, RS has been the selected location because it is an area where the author has a considerable number of connections (e.g., OCERGS, FECOAGRO, FEARROZ, etc).

A general characterization of the cases is given in Table 5. It shows that cooperatives with different number of products and with different size (e.g., considering number of active members) were interviewed. 
Table 5 - General characterization of the cases

\begin{tabular}{|c|c|c|c|}
\hline Cooperative & $\begin{array}{c}\text { Cooperative age in } \\
2010 \text { (years) }\end{array}$ & $\begin{array}{l}\text { Size (Number of } \\
\text { active members) }\end{array}$ & $\begin{array}{c}\text { Number of products received } \\
\text { by the cooperative }\end{array}$ \\
\hline COOP-A & 53 & 10,730 & 10 \\
\hline$C O O P-B$ & 53 & 8,236 & 5 \\
\hline $\mathrm{COOP}-\mathrm{C}$ & 53 & 4,946 & 7 \\
\hline COOP-D & 47 & 4,776 & 9 \\
\hline COOP-E & 53 & 4,612 & 9 \\
\hline$C O O P-F$ & 42 & 3,760 & 6 \\
\hline$C O O P-G$ & 55 & 3,743 & 4 \\
\hline COOP-H & 42 & 3,728 & 6 \\
\hline COOP-I & 53 & 3,254 & 6 \\
\hline COOP-J & 59 & 1,125 & 4 \\
\hline$C O O P-K$ & 79 & 1,013 & 2 \\
\hline$C O O P-L$ & 53 & 500 & 4 \\
\hline Mean & 54 & 4,202 & 6 \\
\hline Minimum & 42 & 500 & 2 \\
\hline Махітит & 79 & 10,730 & 10 \\
\hline
\end{tabular}

\section{Developing research instruments}

In developing the research instrument, the objective was to generate a set of data that would allow us to make comparisons amongst cooperatives ranging from more homogeneous to more heterogeneous, given a number of cooperatives' and members' characteristics. Table 6 shows the main concepts of the research with regard to heterogeneity and how they have been measured.

Table 6 - Main concepts of the research: heterogeneity

\begin{tabular}{c|c|c|c|c}
\hline Bloc & Type & Variable & Concept & Measurement \\
\hline \multirow{2}{*}{$\begin{array}{c}\text { Cooperative's } \\
\text { characteristics }\end{array}$} & PERCPROD & $\begin{array}{c}\text { Share of each product in } \\
\text { the total revenues of the } \\
\text { cooperative }\end{array}$ & Percentage of each product \\
\cline { 3 - 5 } & PERCMEMB & $\begin{array}{c}\text { Distribution of members } \\
\text { who deliver each } \\
\text { product }^{13}\end{array}$ & Percentage of each group \\
\cline { 3 - 5 } & $\begin{array}{c}\text { Member's } \\
\text { characteristics }\end{array}$ & PERCVOL & $\begin{array}{c}\text { Volume of product } \\
\text { delivered by active } \\
\text { members }\end{array}$ & $\begin{array}{c}\text { \% of members who deliver small } \\
\text { volume of products; } \\
\text { \% of members who deliver } \\
\text { medium volume of products; and } \\
\text { of members who deliver large } \\
\text { volume of products }\end{array}$ \\
\hline
\end{tabular}

\footnotetext{
${ }^{13}$ This percentage may reach more than $100 \%$ because some members may deliver more than one product to the cooperative.

${ }^{14}$ This is in accordance to the measurement of each cooperative. We have chosen this method because each cooperative has its internal conflicting groups with regard to farm size.
} 


\section{Data generating}

Data has been generated thought multiple methods, including personal interviews with the elected manager and hired director of each cooperative; document analysis (in the cooperative records, reports, minutes, and balance sheets); and observations (on cooperatives' websites).

The sequence of the steps is the following. First, after developing the research instrument, data from websites of the cooperatives has been generated in order to make triangulation possible at the interviews. Then, in each cooperative, the elected manager and hired director have been interviewed, while cooperative formal records have been analyzed. The period in which data was generated was from $9^{\text {th }}$ July till $3^{\text {th }}$ August, 2010. The case studies instrument is attached in Appendix 1.

\section{Data analysis}

In this section we present the analysis of data generated on 'heterogeneity'. Most importantly, the rational of the development of the heterogeneity measurement is explained in two sections. Section 1 explains the development of a heterogeneity measurement by means of the coefficient of variation. Section 2 explains the development of a heterogeneity measurement by means of grouping method.

\section{Section 1: Coefficient of variation measurement model}

The first rational we have examined to develop a heterogeneity measurement has been the coefficient of variation (CV). It is a usual measurement of diversity applied by (biological) scholars (e.g., ROTH, 1976). CV is a measure which captures the variability of each selected characteristic. The coefficient of variation is defined according to Equation 1 as follows:

$$
\begin{array}{cl}
\mathrm{CV}_{\mathrm{i}}=\frac{100 \sigma_{\mathrm{i}}}{\mu_{\mathrm{i}}} & \text { Equation1 }
\end{array}
$$

Two steps have been taken to analyze each of the heterogeneity selected variable. First, the standard deviation $(\sigma)$ and the mean $(\mu)$ of each variable $\left(_{i}\right)$ of heterogeneity (PERCPROD, 
PERCMEMB, PERCVOL) for each cooperative have been calculated. With the $\sigma$ and the $\mu$, the $\mathrm{CV}$ of each variable of heterogeneity for each cooperative has been calculated.

Second, in order to rank cooperatives from more homogeneous to more heterogeneous, two rules were applied for each variable. The first rule classifies cooperatives according to their $\mathrm{CV}$ values, from highest to lowest. The second rule uses the coefficient of variation to determine the levels of heterogeneity in the following manner: heterogeneity in terms of percentage that each product represents in the annual sales of the cooperative (PERCPROD) increases as $\mathrm{CV}$ values for PERCPROD decreases; the exception is the zero value (i.e., $\mathrm{CV}$ null indicates homogeneity). The same rule applies to the other variables (i.e., PERCMEMB, and PERCVOL).

\section{Data Results using coefficient of variation heterogeneity measurement model}

The results of each one of the three selected variables of heterogeneity (CV_PERCPROD, CV_PERCMEMB, CV_PERCVOL) and the average of all the characteristics, analyzed by means of the coefficient of variation measurement, are presented in Figures 8 to 11 respectively. Calculations for each variable are presented in Appendix 2.

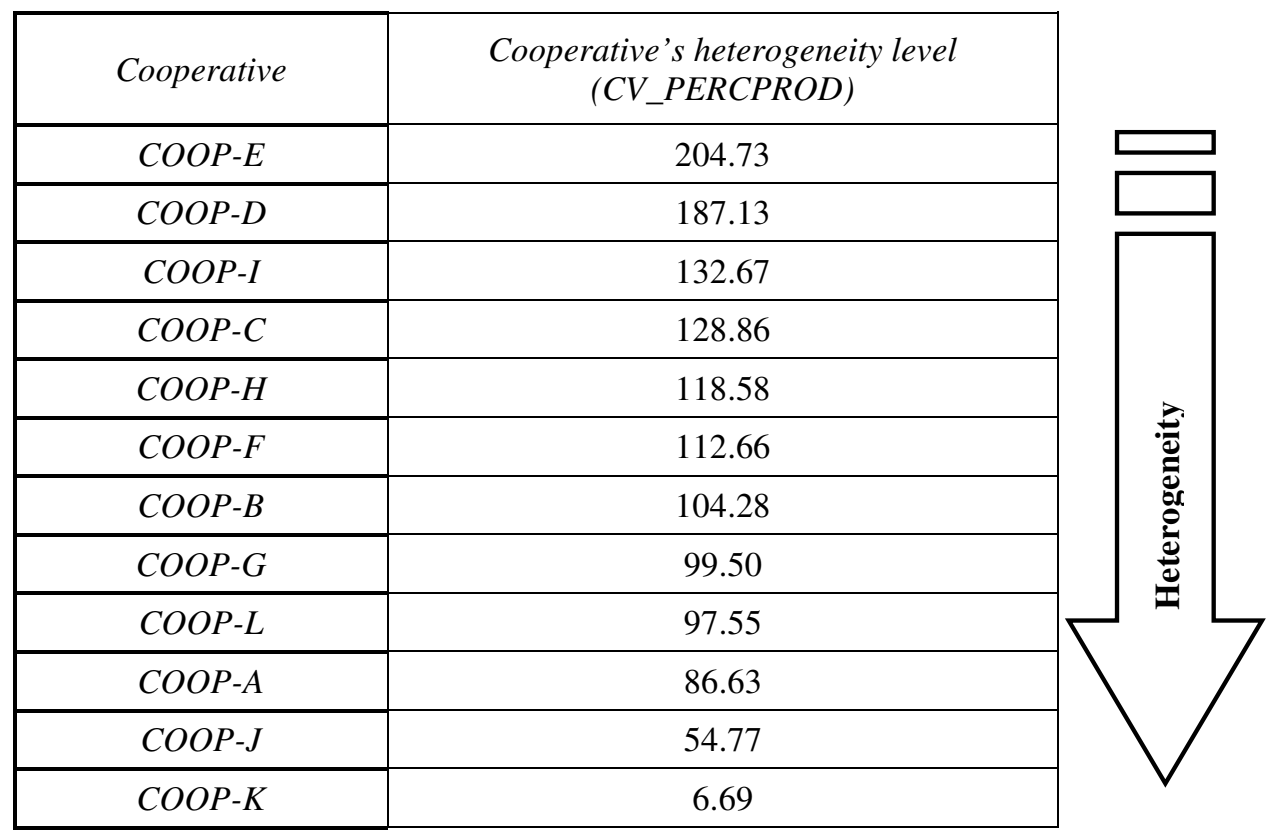

Figure 8 - Homogeneity-heterogeneity for cooperative's characteristics (CV_PERCPROD)

Considering the level of heterogeneity with regard to the variability of the percentages of all products a cooperative receives in the total revenues of the cooperative, the variable CV_PERCPROD (see Figure 8) says that some of the researched cooperatives (e.g., COOP-E, 
COOP-D， COOP-I， COOP-C， COOP-H， COOP-F， COOP-B， COOP-G， COOP-L, respectively) are more homogeneous in terms of products (i.e., a unique product or product quality has a higher percentage in the total revenues of the cooperative than the other products or product qualities) than others (e.g., COOP-A, COOP-J, COOP-K). It is important to say that although COOP-K receives only one product, we consider, in this case, the number of product qualities it receives (i.e., standard and high quality products). This is because the cooperative has not only one group of producers, but two instead. The CV heterogeneity measurement clearly demonstrates the diversity of interests that is likely to exist between these two groups.

\begin{tabular}{|c|c|}
\hline Cooperative & $\begin{array}{c}\text { Cooperative's heterogeneity level } \\
\text { (CV_PERCMEMB) }\end{array}$ \\
\hline COOP-E & 181.50 \\
\hline COOP- $F$ & 127.78 \\
\hline COOP-A & 119.43 \\
\hline COOP-C & 113.89 \\
\hline COOP-D & 113.25 \\
\hline COOP-I & 93.12 \\
\hline COOP- $B$ & 85.90 \\
\hline COOP- $H$ & 83.96 \\
\hline COOP- $G$ & 80.82 \\
\hline COOP- $L$ & 75.21 \\
\hline COOP-J & 55.44 \\
\hline COOP- $K$ & 23.52 \\
\hline
\end{tabular}

Figure 9 - Homogeneity-heterogeneity for cooperative's characteristics (CV_PERCMEMB)

Considering the level of heterogeneity with regard to the variability of the percentages of members who deliver each product, the variable CV_PERCMEMB (see Figure 9) says that some of the researched cooperatives (e.g., COOP-E, COOP-F, COOP-A, COOP-C, COOP-D, COOP-I, COOP-B, COOP-H, COOP-G, COOP-L, respectively) are more homogeneous in terms of the percentages of members who deliver each product than others (e.g., COOP-J, COOP-K). 


\begin{tabular}{|c|c|}
\hline Cooperative & $\begin{array}{c}\text { Farm's members heterogeneity level } \\
(\text { CV_PERCVOL })\end{array}$ \\
\hline COOP $-E$ & 130.91 \\
\hline COOP $-B$ & 130.87 \\
\hline COOP $-G$ & 121.71 \\
\hline$C O O P-F$ & 111.13 \\
\hline$C O O P-H$ & 90.28 \\
\hline$C O O P-A$ & 78.74 \\
\hline$C O O P-L$ & 78.74 \\
\hline$C O O P-D$ & 73.82 \\
\hline$C O O P-I$ & 68.51 \\
\hline$C O O P-K$ & 62.66 \\
\hline$C O O P-C$ & 56.57 \\
\hline$C O O P-J$ & 14.14 \\
\hline
\end{tabular}

Figure 10 - Homogeneity-heterogeneity for farm's members' characteristics (CV_PERCVOL)

Considering the level of heterogeneity with regard to the variability of the percentages of groups who deliver different volumes (i.e., large, medium, small) of products, the variable CV_PERCVOL (see Figure 10) says that some of the researched cooperatives (e.g., COOP-E, COOP-B, COOP-G, COOP-F, COOP-H, respectively) are more homogeneous in terms of the percentages of members who deliver each product than others (e.g., COOP-A, COOP-L, COOP-D, COOP-I, COOP-K, COOP-C, COOP-J, respectively).

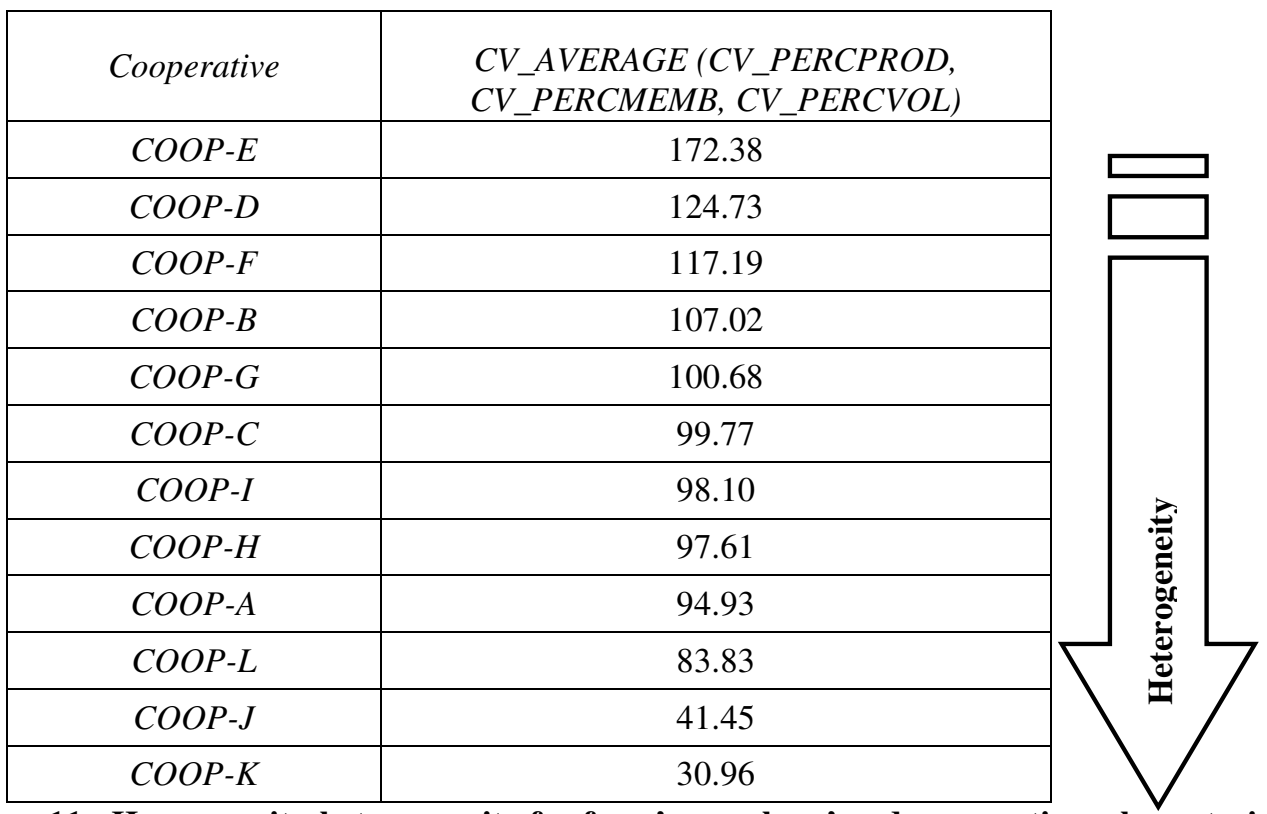

Figure 11 - Homogeneity-heterogeneity for farm's members' and cooperatives characteristics (CV_ AVERAGE)

Finally, Figure 11 ranks cooperatives from homogeneous to more heterogeneous considering the average of all the variables which have been examined. The variable CV_AVERAGE says 
that, considering CV_PERCPROD, CV_PERCMEMB, CV_PERCVOL together, some of the researched cooperatives (e.g., COOP-E, COOP-D, COOP-F, COOP-B, COOP-G, respectively) are more homogeneous (in general terms) than others (e.g., COOP-C, COOP-I, COOP-H, COOP-A, COOP-L, COOP-J, COOP-K, respectively).

\section{Conclusion of the analysis of the $\mathrm{CV}$ as a heterogeneity measurement model}

The former analysis provides a measurement of the variability and does not provide a satisfactory measurement of heterogeneity in a democratic environment. For example, in terms of variability of the percentages of all products (PERCPROD) the variable CV_PERCPROD classified COOP-H as less heterogeneous and COOP-L as more heterogeneous (see Figure 8). However, COOP-H has two products which have high shares in its revenues (52\% and 35\%, see Table 48 in Appendix 2), i.e., the cooperative has two heterogeneous groups. In the COOP-L case, the cooperative was classified as more heterogeneous (see Figure 8). However, it has only one product that represents a high percentage in its revenues (65\%, see Table 48 in Appendix 2). With regard to the variable PERCMEMB some misclassifications can also be noted. It is, for example, the case of COOP-A which was classified by CV_PERCMEMB as more homogeneous (see Figure 9) while it has at least two groups of conflicting members (44\% and $38 \%$, see Table 49 in Appendix 2).

As a result, another rational needs to be applied. We propose a measurement of heterogeneity based on grouping. This may help to show the presence (absence) of a dominant group and the size of the minority group(s).

\section{Section 2: Grouping measurement model}

Cooperatives are collective and democratic firms. It means that they share the same benefits amongst different member-patrons. As a consequence, it is likely that there will be groups of members with different characteristics conflicting with each other in the decision making process. As a result, it is important that the presence (absence) of a dominant group and the size of the minority group(s) - regarding each of the members' and cooperatives' characteristics - be observed more than the variability of these data. Then, we propose a measurement of heterogeneity based on grouping. The steps taken to determine rankings from 
homogeneous to more heterogeneous for each one of the heterogeneity selected variables, using grouping, are explained below.

The heterogeneity variable 'share that each product represents in the annual sales of the cooperative' has been defined by taking the following steps. First, the share of each product received by a cooperative in the total annual revenues obtained by the cooperative has been calculated. ${ }^{15}$ Second, for each cooperative, all products $(\mathrm{P})$ have been ranked from the highest to the lowest weight. Then, two rules have been used to analyze these rankings. The first rule is based in the highest weight $\left(\mathrm{P}_{1}\right)$. A cooperative in which one product was responsible for more than $50 \%$ of the revenues was considered to be more homogenous than a cooperative in which no single product was responsible for more than $50 \%$ of the revenues. The second rule has focused on the second highest weight $\left(\mathrm{P}_{2}\right)$. The rule has been used to determine the size of 'minority groups' within cooperatives dominated by one product (i.e., those cooperatives in which one type of product has a weighting of more than $50 \%$ in the cooperative revenues). A cooperative with a large minority group has been considered to be more heterogeneous than a cooperative with a small minority group. Figure 12 shows the classification scheme proposed.

\begin{tabular}{|c|c|c|}
\hline Level & Specification & Category \\
\hline 1 & $\mathrm{P}_{1}>50 \% ; \mathrm{P}_{2} \leq 10 \%$ & One dominant party \\
\hline 2 & $\mathrm{P}_{1}>50 \% ; 11 \% \leq \mathrm{P}_{2} \leq 20 \%$ & One majority party and one small minority \\
\hline 3 & $\mathrm{P}_{1}>50 \% ; 21 \% \leq \mathrm{P}_{2} \leq 30 \%$ & One majority party and one significant minority \\
\hline 4 & $\mathrm{P}_{1}>50 \% ; 31 \% \leq \mathrm{P}_{2} \leq 40 \%$ & One majority party and one large minority \\
\hline 5 & $\mathrm{P}_{1}<50 \% ; \mathrm{P}_{2}<50 \%$ & No majority groups \\
\hline
\end{tabular}

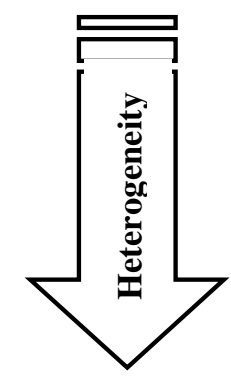

$\mathrm{P}_{1}=$ weight of main product received by cooperative in total revenues of the cooperatives $\mathrm{P}_{2}=$ weight of second largest product

Figure 12 - PERCPROD using grouping heterogeneity measurement

The variable 'percentage of members who deliver each product' has been defined by taking the following steps. First, the percentage of members who deliver each product to the cooperative has been calculated. ${ }^{16}$ Second, for each cooperative, all the percentages have been ranked from the highest to the lowest weight. Then, two rules have been used to analyze these rankings. The first rule has looked at the weight of the largest group of producers $\left(\mathrm{PG}_{1}\right)$ of the

\footnotetext{
${ }^{15}$ Only the agricultural businesses of cooperatives have been considered in calculating the total revenues of each cooperative. This is because most of RS's cooperatives have also other businesses such as supermarkets, gas stations, etc.

${ }^{16}$ This percentage may reach more than $100 \%$ because some members may deliver more than one product to the cooperative.
} 
cooperative. A cooperative in which one producer group was responsible for more than $50 \%$ of the percentage of members was considered to be more homogenous than a cooperative in which no producer group was responsible for more than $50 \%$ of the percentage of members. The second rule has focused on the weighting of the second largest group of producers of the cooperative $\left(\mathrm{PG}_{2}\right)$. The rule has been used to determine the size of 'minority producer groups' within cooperatives dominated by one producer group (i.e., those cooperatives in which one producer group has a weighting of more than $50 \%$ of the percentage of members). A cooperative with a large minority group was considered to be more heterogeneous than a cooperative with a small minority group. Figure 13 shows the classification scheme proposed.

\begin{tabular}{|c|c|c|}
\hline Level & Specification & Category \\
\hline 1 & $\mathrm{PG}_{1}>50 \% ; \mathrm{PG}_{2} \leq 20 \%$ & One dominant party \\
\hline 2 & $\mathrm{PG}_{1}>50 \% ; 21 \% \leq \mathrm{PG}_{2} \leq 30 \%$ & One majority party and one small minority \\
\hline 3 & $\mathrm{PG}_{1}>50 \% ; 31 \% \leq \mathrm{PG}_{2} \leq 40 \%$ & One majority party and one significant minority \\
\hline 4 & $\mathrm{PG}_{1}>50 \% ; 41 \% \leq \mathrm{PG}_{2}<50 \%$ & One majority party and one large minority \\
\hline 5 & $\mathrm{PG}_{1}<50 \% ; \mathrm{PG}_{2}<50 \%$ or & No majority groups \\
\hline \multicolumn{2}{|c|}{$\mathrm{PG}_{1}>50 \% ; \mathrm{PG}_{2}>50 \%$} \\
\hline
\end{tabular}

Figure 13 - PERCMEMB using grouping heterogeneity measurement

The variable 'volume of product delivered by the members' has been defined by taking the following steps. First, the percentage of members who deliver each volume of products (large, medium, small) to the cooperative has been calculated. Second, for each cooperative, the percentages of farmers who deliver large, medium, and small volume of products of each cooperative have been ranked in this sequence. Then, two rules have been used to analyze these rankings. The first rule has looked at the weight of the large farmers (LF) of the cooperative. What has been observed here is the fact that even though large farmers may be the minority group of the cooperative, they still hold a certain bargaining power against the medium and smallholders because they represent the majority of the cooperative's product's volume. ${ }^{17} 18$ Then, the extent to which large farmers have more or less bargaining power

\footnotetext{
${ }^{17}$ Bogetoft and Olesen (2004) discuss this situation in terms of high quality producers and standard producers.

${ }^{18}$ Zuzman (1982) argues that the diffusion of power due to the democratic control of cooperatives raises the possibility that a majority of members, who may contribute only a small part of the patronage or capital of the organization, may impose policies that exploit the minority of large patrons. Staatz (1987a) and Bogetoft and Olesen (2004) argue that such exploitation is limited by the possibility that large farmers may withdraw their patronage and take their business elsewhere, unless potential market competition is not intense and that cooperative holds a secure monopoly.
} 
would depend on the size of the medium producers' group (who are the second bargaining group). In that case, the rule of our categorization measurement model has looked at the weight of both large (LF) and medium farmers (MF). A cooperative in which large farmers were more than $50 \%$ of the members was considered to be more homogenous. However, as the percentage of medium farmers increases, the bargaining power of large farmers starts to decrease. Figure 14 illustrates the classification scheme proposed.

\begin{tabular}{|c|c|c|}
\hline Level & Specification & Category \\
\hline 1 & $\begin{array}{c}\mathrm{LF}>50 \% \text { or } \\
\mathrm{LF}<50 \% ; \mathrm{MF}>50,1 \%\end{array}$ & One dominant group \\
\hline 2 & $\mathrm{LF}<50 \% ; 0 \% \leq \mathrm{MF} \leq 12.4 \%$ & One bargaining group and one small minority \\
\hline 3 & $\mathrm{LF}<50 \% ; 12.5 \% \leq \mathrm{MF} \leq 25 \%$ & One bargaining group and one significant minority \\
\hline 4 & $\mathrm{LF}<50 \% ; 25.1 \% \leq \mathrm{MF} \leq 37.5 \%$ & One bargaining group and one large minority \\
\hline 5 & $\mathrm{LF}<50 \% ; 37.6 \% \leq \mathrm{MF} \leq 50.1 \%$ & No majority groups \\
\hline
\end{tabular}

Figure 14 - PERCVOL using grouping heterogeneity measurement

\section{Data Results using grouping heterogeneity measurement model}

The results of each of the selected variables of heterogeneity (PERCPROD, PERCMEMB, PERCVOL) that have been analyzed by means of the grouping heterogeneity measurement model (as well as the average score of each cooperative, based on these three variables) are presented in Table 7. Calculations for each variable are presented in the Appendix 3.

Table 7 - Levels of heterogeneity using Grouping measurement of heterogeneity

\begin{tabular}{c|c|c|c|c}
\hline Cooperative & PERCPROD & PERCMEMB & PERCVOL & AVERAGE \\
\hline COOP $-C$ & 2 & 2 & 1 & 1.67 \\
\hline COOP $-E$ & 3 & 2 & 2 & 2.33 \\
\hline$C O O P-B$ & 2 & 3 & 2 & 2.33 \\
\hline$C O O P-F$ & 3 & 2 & 3 & 2.67 \\
\hline$C O O P-G$ & 3 & 3 & 2 & 2.67 \\
\hline$C O O P-I$ & 3 & 4 & 1 & 2.67 \\
\hline$C O O P-L$ & 3 & 4 & 1 & 2.67 \\
\hline$C O O P-D$ & 2 & 5 & 1 & 2.67 \\
\hline$C O O P-J$ & 5 & 3 & 4 & 4.00 \\
\hline$C O O P-H$ & 4 & 5 & 3 & 4.00 \\
\hline$C O O P-K$ & 4 & 5 & 4 & 4.33 \\
\hline$C O O P-A$ & 5 & 5 & 3 & 4.33 \\
\hline
\end{tabular}


Considering the level of heterogeneity with regard to the percentages of all products a cooperative receives in the total revenues of the cooperative, the variable PERCPROD (see Column 2) says the following. There are not cooperatives with one dominant party only (i.e., level 1). Instead, some cooperatives COOP-C, COOP-B, and COOP-D) have one majority party and one small minority (i.e., level 2), being those the most homogeneous of the sample. Some of them (COOP-E, COOP-F, COOP-G, COOP-I, COOP-L) have one majority party and one significant minority (i.e., level 3), some of them (COOP-H and COOP-K) have one majority party and one large minority (i.e., level 4). Finally, the variable says that two cooperatives (COOP-J and COOP-A) have no majority groups, being the most heterogeneous ones with regard to the percentages of all products a cooperative receives in the total revenues of the cooperative.

Research results regarding the level of heterogeneity using grouping measurement model (Table 7) show that, in average, there are cooperatives more homogeneous (e. g. COOP-C, COOP-E, COOP-B), cooperatives not so homogeneous and not so heterogeneous (COOP-F, COOP-G, COOP-I, COOP-L, COOP-D), and cooperatives more heterogeneous (COOP-J, COOP-H, COOP-K, COOP-A).

\section{$2.4 \quad$ Propositions}

Following the literature and the general scheme of the study (shown earlier in Figure 6), the general proposition can be now formulated.

General proposition: The level of member participation in cooperative governance is related to the level of heterogeneity.

Since there are two types of member participation in cooperative governance that are of interest of the present study, the general proposition can be divided into two sub-propositions: (1), relation between level of heterogeneity and member participation at the general assembly; and (2), relation between level of heterogeneity and member participation holding a position in the board of directors. Developing each one is the aim of this section. 
With regard to the relation between level of heterogeneity $(x)$ and level of member participation at the general assembly $(y)$, two different stream of literature on cooperatives can be distinguished. According to a group of authors, there is a linear relation between level of heterogeneity and level of member participation in cooperative governance. The more heterogeneous the members of a cooperative are, and the more heterogeneous a cooperative is, the more the interests of the various constituents (group of members) are likely to conflict, resulting in various groups actively attempting to take control of the decision making process in the cooperative (HANSMANN, 1996; HENDRIKSE; BIJMAN, 2002; KALOGERAS et $a l, 2009$ ). According to another group of authors (e.g., ÖSTERBERG; NILSSON, 2009), when the cooperative is more heterogeneous, members may feel that cooperative business has become so complex (e.g., large cooperatives have often multipurpose activities, whereby many members are interested in only a specific branch of business) that they may not understand the cooperative's business activities, have little knowledge about them, and are alienated from them. As a result, they do not participate.

The present thesis postulates that both streams of literature are partially right. Based on the results from the grouping measurement of heterogeneity, we develop a model that suggests a non-linear relation between member participation and heterogeneity. The model predicts that members have a stronger incentive to participate when heterogeneity increases, as long as there is a dominant group. When there is a dominant group and the cooperative is homogenous (category 1 cooperative, i.e., $x_{l}$ ), there is less incentive for members to participate because the interests of the members are aligned $\left(y_{1}\right)$. When there is a dominant group and the cooperative is heterogeneous (category 4 cooperative, i.e., $x_{4}$ ), members have the strongest incentive to participate to protect their interest $\left(y_{4}\right)$ : members from the dominant group to protect their interests, and the large minority groups to prevent the dominant group from taking control of the cooperative. Without a dominant group (category 5 cooperative, i.e., $\left.x_{5}\right)$ there is less incentive to participate because there is less threat of exploitation by the majority group, and member participation starts to fall again $\left(y_{5}=y_{1}\right)$. Figure 15 visualizes this relation. 


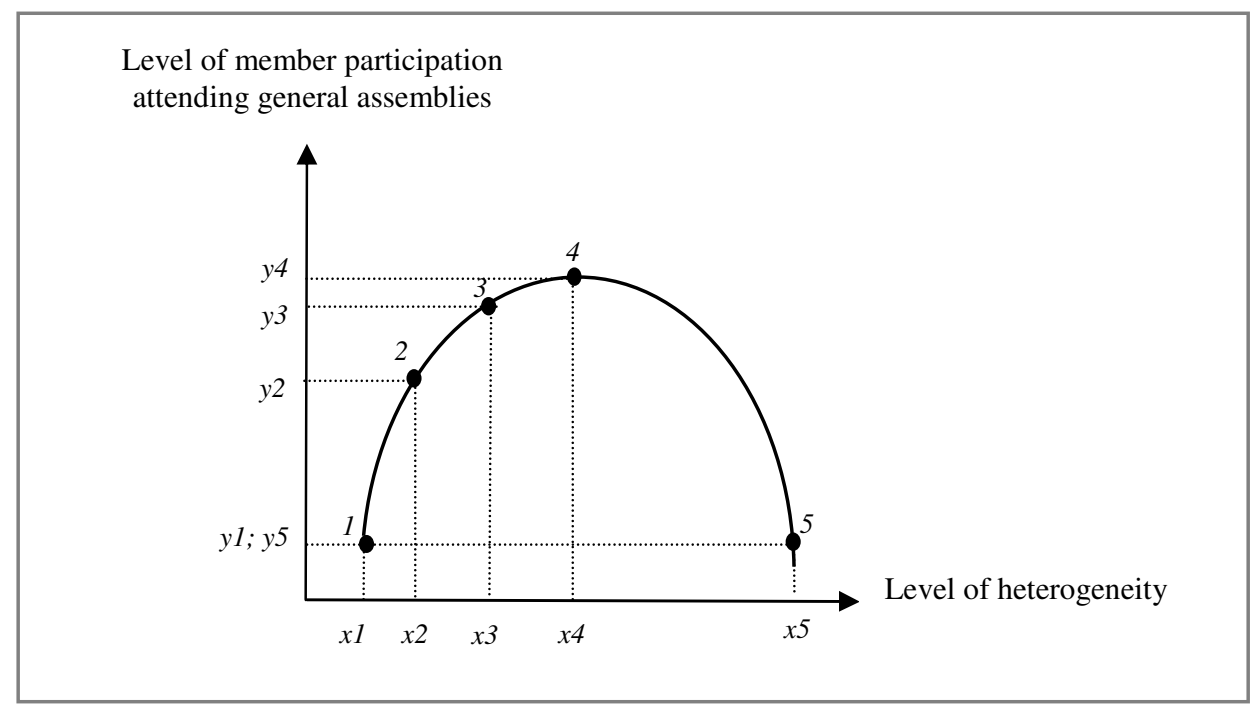

Figure 15 - Relation between level of heterogeneity and level of member participation at the general assembly

Then, the following proposition arises:

Proposition 1 (relation between level of heterogeneity and member participation attending general assemblies):

When the cooperative is more homogeneous $\left(x_{1}\right)$, the level of member participation at the general assembly is low $\left(y_{1}\right)$. When the level of heterogeneity increases $\left(x_{2}, x_{3}, x_{4}\right)$, the level of member participation at the general assembly increases $\left(y_{2}, y_{3}, y_{4}\right)$. When the cooperative reaches certain level of heterogeneity (without a dominant group) ( $\left.x_{5}\right)$ the level of member participation at the general assembly decreases $\left(y_{5}\right)$.

When cooperatives encounter significant heterogeneity both within the firm and amongst its members, it is expected that increased differences result in higher conflicts of interests in the decision making process. STAATZ (1987a) observes that as a result of the diversity of member interests, some kinds of cooperative members (e.g., large farmers) may demand to be involved in the control of the cooperative. For example, serving as an elected officer in order to protect their interests (i.e., balancing the demands of small producers who control the majority of the votes in the cooperative) (CHITHELEN, 1985; BANERJEE et al, 2001). Farm size is the most explicative variable for member participation in cooperative governance. (GRAY; KRAENZLE, 1998; ILIOPOULOS; COOK, 1999, p. 28). This is because "the diffusion of political power as a result of the one-person/one-vote principle raises the possibility that a majority of members who may contribute only a small part of the patronage 
and capital may approve policies that exploit the minority of larger patrons who own the nonrevenue-bearing capital" as observes Cook (1994, p. 49). Then, the following propositions arise:

Proposition 2 (relation between level of heterogeneity and member participation holding a position in the board of directors):

The more the level of heterogeneity (e.g., in terms of volume) increases, the more medium and large farmers participate in the board of directors.

\section{Part 2 - Quantitative approach}

In this part of the research, the heterogeneity measurement, earlier developed in part 1 , serves as a basis for the examination of the relation between level of heterogeneity and level of member participation in cooperative governance.

\section{Developing research instruments}

The research instrument used to generate data for this part of the research is complementary to the one already explained in part 1 (see Appendix 1). Table 8 shows how the variables used to examine the relation between level of heterogeneity and level of member participation (at the general assembly and at the board of directors) have been measured.

Table 8 - Measurement: level of heterogeneity and level of member participation

\begin{tabular}{|c|c|c|c|c|}
\hline Bloc & Type & Variable & Concept & Measurement \\
\hline \multirow{3}{*}{ 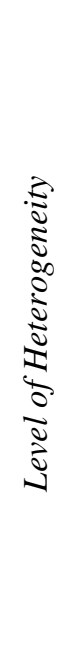 } & 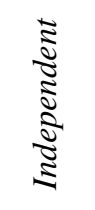 & CV_PERCPROD & $\begin{array}{l}\text { Variability of the shares } \\
\text { of all products the } \\
\text { cooperative receives in } \\
\text { the total revenues of the } \\
\text { cooperative }\end{array}$ & $\mathrm{CV}_{\text {PERCPROD }}=\frac{\underline{\sigma}_{\text {PERCPROD }}}{\mu_{\text {PERCPROD }}}$ \\
\hline & 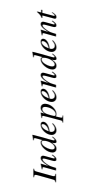 & CV_PERCMEMB & $\begin{array}{l}\text { Variability of the weights } \\
\text { of all groups of members } \\
\text { who deliver each product }\end{array}$ & $\mathrm{CV}_{\text {PERCMEMB }}=\frac{\underline{\sigma}_{\text {PERCMEMB }}}{\mu_{\text {PERCMEMB }}}$ \\
\hline & 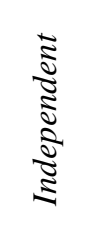 & CV_PERCVOL & $\begin{array}{l}\text { Variability of the } \\
\text { percentages of groups of } \\
\text { members who deliver } \\
\text { large, medium and small } \\
\text { volume of products to the } \\
\text { cooperative }\end{array}$ & $\mathrm{CV}_{\text {PERCVOL }}=\frac{\underline{\sigma}_{\text {PERCVOL }}}{\mu_{\text {PERCVOL }}}$ \\
\hline
\end{tabular}




\begin{tabular}{|c|c|c|c|c|}
\hline & 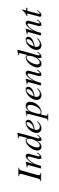 & CV_AVERAGE & $\begin{array}{l}\text { Average level of } \\
\text { heterogeneity considering } \\
\mathrm{CV} \text { as a measurement } \\
\text { model }\end{array}$ & $\begin{array}{l}{\left[\left(C V \_P E R C P R O D\right)+\right.} \\
\left(C V \_P E R C M E M B\right)+ \\
\left.\left(C V \_P E R C V O L\right)\right] / 3\end{array}$ \\
\hline & 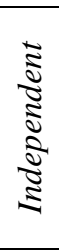 & PERCPROD & $\begin{array}{l}\text { Levels of cooperative } \\
\text { heterogeneity with } \\
\text { regard to the size of the } \\
\text { main product }\left(\mathrm{P}_{1}\right) \text { in } \\
\text { relation with the size of } \\
\text { the minorities }\left(\mathrm{P}_{2}\right)\end{array}$ & $\begin{array}{l}1=\mathrm{P} 1>50 \% ; \mathrm{P} 2 \leq 10 \% \\
2=\mathrm{P} 1>50 \% ; 11 \leq \mathrm{P} 2 \leq 20 \% \\
3=\mathrm{P} 1>50 \% ; 21 \leq \mathrm{P} 2 \leq 30 \% \\
4=\mathrm{P} 1>50 \% ; 31 \leq \mathrm{P} 2 \leq 40 \% \\
5=\mathrm{P} 1<50 \% ; \mathrm{P} 2<50\end{array}$ \\
\hline & 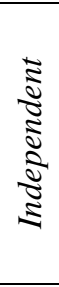 & PERCMEMB & $\begin{array}{l}\text { Levels of cooperative } \\
\text { heterogeneity with } \\
\text { regard to the size of the } \\
\text { largest group of } \\
\text { producers }\left(\mathrm{PG}_{1}\right) \text { in } \\
\text { relation to the size of } \\
\text { the minorities }\left(\mathrm{PG}_{2}\right)\end{array}$ & $\begin{aligned} 1= & \text { PG } 1>50 \% ; \text { PG } 2 \leq 20 \% \\
2= & \text { PG } 1>50 \% ; 21 \leq \mathrm{PG} 2 \leq 30 \% \\
3= & \text { PG1 }>50 \% ; 31 \leq \mathrm{PG} 2 \leq 40 \% \\
4= & \text { PG } 1>50 \% ; 41 \leq \mathrm{PG} 2<50 \% \\
5= & \text { PG } 1<50 \% ; \text { PG }<50 \text { or } \\
& \text { PG1 }>50 \% ; \text { PG } 2>50\end{aligned}$ \\
\hline & 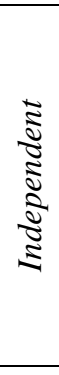 & PERCVOL & $\begin{array}{l}\text { Levels of members' } \\
\text { heterogeneity with } \\
\text { regard to the size of the } \\
\text { bargaining groups } \\
\text { (large=LF, } \\
\text { medium=MF) in } \\
\text { relation with the size of } \\
\text { the majority } \\
\text { (smallholders) }\end{array}$ & $\begin{aligned} 1=\mathrm{LF}>50 \% \text { or } \\
\quad \mathrm{LF}<50 \% ; \mathrm{MF}>50,1 \% \\
2=\mathrm{LF}<50 \% ; 0 \% \leq \mathrm{MF} \leq 12.4 \% \\
3=\mathrm{LF}<50 \% ; 12.5 \% \leq \mathrm{MF} \leq 25 \% \\
4=\mathrm{LF}<50 \% ; 25.1 \% \leq \mathrm{MF} \leq 37.5 \% \\
5=\mathrm{LF}<50 \% ; 37.6 \% \leq \mathrm{MF} \leq 50.1 \%\end{aligned}$ \\
\hline & 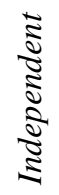 & AVERAGE & $\begin{array}{l}\text { Average level of } \\
\text { heterogeneity considering } \\
\text { grouping as a } \\
\text { measurement model }\end{array}$ & $\begin{array}{l}{[\text { (PERCPROD })+(\text { PERCMEMB })+} \\
(\text { PERCVOL })] / 3\end{array}$ \\
\hline \multirow{2}{*}{\multicolumn{2}{|c|}{ อิ }} & MAINPROD & $\begin{array}{l}\text { Whether the board } \\
\text { member delivers the main } \\
\text { product (in terms of } \\
\text { revenues) the cooperative } \\
\text { receives }\end{array}$ & $\begin{array}{l}1=\text { Yes } \\
0=\text { No }\end{array}$ \\
\hline & & NUMBPROD & $\begin{array}{l}\text { Number of products } \\
\text { which the board member } \\
\text { delivers to the } \\
\text { cooperative }\end{array}$ & $\begin{array}{l}1=1 \text { product } \\
2=2 \text { products } \\
3=3 \text { products } \\
4=4 \text { products }\end{array}$ \\
\hline 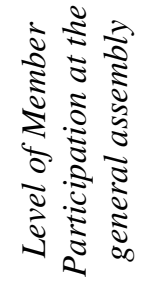 & 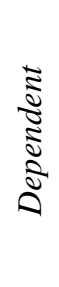 & MPATGA & $\begin{array}{l}\text { Level of member } \\
\text { participation at the } \\
\text { general assembly }\end{array}$ & $\begin{array}{l}\text { Number of members who } \\
\text { participate in 2010's GA x } 100 \\
\text { /Number of cooperative members }\end{array}$ \\
\hline
\end{tabular}




\begin{tabular}{|c|c|c|c|c|}
\hline 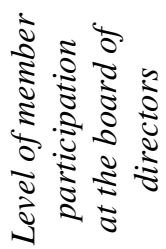 & 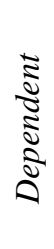 & BoardLM & $\begin{array}{l}\text { Whether the board } \\
\text { member delivers a } \\
\text { large/medium volume of } \\
\text { products (considering the } \\
\text { measurement of each } \\
\text { cooperative) }\end{array}$ & $\begin{array}{l}1=\text { Yes } \\
0=\text { No }\end{array}$ \\
\hline
\end{tabular}

Table 8 introduces two new (control) variables to the study. These variables have been used to examine the relation between level of heterogeneity and level of member participation at the board of directors.

a) Main type of production (MAINPROD). Gray and Kraenzle (1998) have shown that the percentage of gross farm sales from the sale of milk is positively related to member participation of dairy-farmer members attending general assemblies in an American cooperative. Gripsrud, Lenvik and Olsen (2000) have shown that farmers specialized in sheep production tend to conclude that it is difficult to make themselves heard at members meetings in a Norwegian meat cooperative that handles mainly cattle combined with milk.

b) Number of different commodities produced by the members (NUMBPROD). With regard to the number of commodities delivered to the cooperative, studies have shown that the more interests the farmer members have in the cooperative (e.g., higher number of commodities delivered to the cooperative) the more incentives they would have to participate. Iliopoulos and Cook (1999) find the number of different commodities produced by the members as one of the most important dimensions of member heterogeneity.

\section{Methods of analysis}

Two methods of analysis (scatter plot, and logistic regression) have been used to examine the propositions ( 1 and 2 , respectively) of this study.

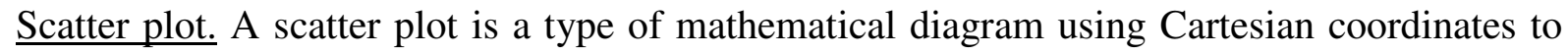
display values for two variables for a set of data. It is a useful tool when researchers want to examine the relation between two sets of data. One of the most interesting aspects of a scatter plot is its ability to show nonlinear relationships between variables. Relations may be positive (rising), negative (falling), or null (uncorrelated). A line of best fit (i.e., a trend line) can be drawn in order to study the correlation between the variables. The more the two data sets are 
correlated, the more the scatters tend to concentrate in the vicinity of the trend line; if the two data sets are numerically identical, the scatters fall on the trend line exactly.

Logistic regression. According to Hair et al, (2006), amongst the available dependence techniques (e.g., multiple regression analysis, discriminant analysis, logistic regression, analysis of variance, multivariate analysis of variance, conjoint analysis), logistic regression is the appropriate technique to use when the dependent variable has only two groups (i.e., binary). The two groups can represent, for example, characteristics. If the characteristic is, for instance, farm size, logistic regression represents the two groups of interest as a binary variable with values of 0 and 1, where either one group can be assigned the value of 1 (e.g., larger farmers) and the other group the value of 0 (e.g., smaller farmers).

Logistic regression differs from multiple regression, for instance, in being specifically designed to predict the probability of an event occurring (i.e., the probability of an observation being in the group coded 1). To define a relationship bounded by 0 and 1 , logistic regression uses the logistic curve (which is S-shaped to stay within the range of 0 and 1) to represent the relationship between the independent $(\mathrm{x})$ and dependent $(\mathrm{y})$ variables. The membership groups are predicted from the logistic curve as follows: for each observation, the logistic regression technique predicts a probability value between 0 and 1 . Plotting the predicted values for all values of the independent variable generates the S-shaped logistic curve. This predicted probability is based on the value(s) of the independent variable(s) and the estimated coefficients. If the predicted probability is greater than .50 , then the prediction is that the outcome is 1 (the event happened); otherwise, the outcome is predicted to be 0 (the event did not happened) (HAIR et al, 2006).

While in multiple regression a linear relationship is estimated between the dependent and independent variables in logistic regression the prediction of the dependent variable is estimated by a variate composed of the logistic coefficient(s) and the corresponding independent variable(s) (i.e., a nonlinear logistic transformation), since the predicted values can never be outside the range of 0 and 1 . This is because, in their original form, probabilities are not constrained to values between 0 and 1 . Restating a probability in a way that the new variable always falls between 0 and 1 is done by expressing a probability as odds (i.e., the ratio of the probability of the two outcomes or events) as follows: Prob $_{\mathrm{i}} \div\left(1-\right.$ Prob $\left._{\mathrm{i}}\right)$. In this form, any probability value can be stated in a metric variable that can be directly estimated. 
Another particularity of the logistic model that is absent in the multiple regression, for example, is the transformation of the dependent variable in a metric variable (i.e., logit value) that can have both positive and negative values, but that can always be transformed back to a probability value that is between 0 and 1 . It is done by taking the logarithm of the odds. Odds ratios less than 1.0 will have a negative logit value, odds ratios greater than 1.0 will have positive logit values, and the odds ratio of 1.0 has a logit value of 0 (and probability of 0.50 ) (HAIR et al, 2006).

The process of estimating the logistic coefficients (see Equation 2) is similar to that used in regression, although in this case only two actual values are used for the dependent variable $(0$ and 1). This process can accommodate one or more independent variables, and they can be either metric or non-metric (binary) (HAIR et al, 2006).

$$
\operatorname{Logit}_{\mathrm{i}}=\ln \left(\frac{\text { prob }_{\text {event }}}{1-\text { prob }_{\text {event }}}\right)=\mathrm{b}_{0}+\mathrm{b}_{1} \mathrm{x}_{1}+\ldots+\mathrm{b}_{\mathrm{n}}
$$

Equation 2

According to Hair et al (2006), instead of using ordinary least squares (i.e., minimizing the squared deviations) as is done in multiple regression, logistic regression uses the maximum likelihood method (i.e., the likelihood that an event will occur) to estimate the model. The 'likelihood value' is the basic measure of how well the maximum likelihood estimation procedure fits. Logistic regression measures model estimation fit with the value of (-2) times the $\log$ of likelihood value (i.e., $-2 L L$ or $-2 \log$ likelihood). The maximum value for $-2 L L$ is 0 . It corresponds to a perfect fit (likelihood $=1$ and $-2 L L$ is then 0 ). As a result, the lower the $2 L L$ value, the better the model fits. With the likelihood value, between models comparisons (i.e., a three steps approach that first, estimates a null model; second, estimates the proposed model; and third, assess $-2 L L$ difference) can be made in order to assess the difference in predictive fit from one equation to another, with statistical tests for the significance of these differences. Another possible assessment of the goodness of fit of the estimated model is the pseudo $\mathrm{R}^{2}$ measure. A perfect fit has a $-2 L L$ value of 0.00 and $\mathrm{R}_{\text {LOGIT }}^{2}$ of 1.0. 


\subsection{Empirical results}

Table 9 presents research results regarding level of member participation attending general assemblies.

Table 9 - Level of member participation at general assemblies in researched cooperatives

\begin{tabular}{c|c} 
Cooperative & $\begin{array}{c}\text { Level (\%) of member participation } \\
\text { at general assemblies }\end{array}$ \\
\hline COOP-G & 2 \\
\hline COOP-F & 3 \\
\hline COOP-C & 3 \\
\hline COOP-E & 4 \\
\hline COOP-L & 4 \\
\hline COOP-A & 5 \\
\hline COOP-D & 7 \\
\hline COOP-H & 8 \\
\hline COOP-I & 12 \\
\hline COOP- $B$ & 17 \\
\hline COOP- $K$ & 40 \\
\hline COOP-J & 41 \\
\hline Mean & 12 \\
\hline Minimum & 2 \\
\hline Maximum & 41 \\
\hline
\end{tabular}

Table 9 shows that the level of member participation in most cooperatives is low; in only two of the 12 cooperatives do around $40 \%$ of the members attend general assemblies. For the majority of the cooperatives, only between $2-17 \%$ of the members attend general assemblies. The average of member participation attending general assemblies in researched cooperatives is $12 \%$.

Tables 10 and 11 present the characteristics of the 149 members who hold a position in the board of directors of the 12 researched cooperatives with regard to volume of the product delivered to the cooperative and type(s) of product(s) delivered to the cooperative, respectively. In addition, Table 12 presents the percentage ${ }^{19}$ that each product represents in the total annual revenues of each cooperative.

\footnotetext{
${ }^{19}$ Percentages smaller than 1 were rounded to 1.
} 
Table 10 - Volume of products delivered by board members of researched cooperatives

\begin{tabular}{|c|c|c|c|c|c|c|c|c|c|c|c|c|c|c|c|c|c|c|c|c|}
\hline Cooperative & $\begin{array}{c}\text { Memb. } \\
1\end{array}$ & $\begin{array}{c}\text { Memb. } \\
2 \\
\end{array}$ & $\begin{array}{c}\text { Memb. } \\
3 \\
\end{array}$ & $\begin{array}{c}\text { Memb. } \\
4\end{array}$ & $\begin{array}{c}\text { Memb. } \\
5\end{array}$ & $\begin{array}{c}\text { Memb. } \\
6 \\
\end{array}$ & $\begin{array}{c}\text { Memb. } \\
7\end{array}$ & $\begin{array}{c}\text { Memb. } \\
8 \\
\end{array}$ & $\begin{array}{c}\text { Memb. } \\
9\end{array}$ & $\begin{array}{c}\text { Memb. } \\
10\end{array}$ & $\begin{array}{c}\text { Memb. } \\
11\end{array}$ & $\begin{array}{c}\text { Memb. } \\
12 \\
\end{array}$ & $\begin{array}{c}\text { Memb. } \\
13\end{array}$ & $\begin{array}{c}\text { Memb. } \\
14\end{array}$ & $\begin{array}{c}\text { Memb. } \\
15\end{array}$ & $\begin{array}{c}\text { Memb. } \\
16\end{array}$ & $\begin{array}{c}\text { Memb. } \\
17 \\
\end{array}$ & $\begin{array}{c}\text { Memb. } \\
18 \\
\end{array}$ & $\begin{array}{c}\text { Memb. } \\
19\end{array}$ & $\begin{array}{c}\text { Memb. } \\
20\end{array}$ \\
\hline COOP-A & $S$ & $\mathrm{M}$ & $S$ & $S$ & $S$ & $\mathrm{~S}$ & $\mathrm{~S}$ & $\mathrm{~S}$ & $\mathrm{~S}$ & $\mathrm{~S}$ & $\mathrm{~S}$ & $\mathrm{M}$ & $\mathrm{S}$ & $\mathrm{S}$ & $\mathrm{S}$ & $\mathrm{S}$ & $S$ & $S$ & $\mathrm{~S}$ & $\mathrm{~S}$ \\
\hline$C O O P-B$ & $\mathrm{~L}$ & $\mathrm{~L}$ & $\mathrm{~S}$ & $\mathrm{~L}$ & $\mathrm{~S}$ & $\mathrm{M}$ & $\mathrm{M}$ & $S$ & $S$ & $\mathrm{M}$ & $\mathrm{S}$ & $\mathrm{S}$ & $\mathrm{L}$ & $\mathrm{S}$ & $\mathrm{M}$ & $\mathrm{S}$ & $\mathrm{S}$ & $\mathrm{S}$ & $\mathrm{L}$ & \\
\hline COOP-C & $\mathrm{S}$ & M & $\mathrm{L}$ & $\mathrm{S}$ & M & $\mathrm{S}$ & M & $\mathrm{L}$ & $\mathrm{S}$ & $\mathrm{S}$ & $\mathrm{S}$ & $\mathrm{S}$ & M & $\mathrm{S}$ & $\mathrm{S}$ & & & & & \\
\hline COOP-D & M & $\mathrm{S}$ & M & $\mathrm{M}$ & $\mathrm{M}$ & $\mathrm{M}$ & $\mathrm{M}$ & $\mathrm{S}$ & $\mathrm{S}$ & M & $\mathrm{M}$ & $\mathrm{S}$ & & & & & & & & \\
\hline COOP-E & $\mathrm{M}$ & $\mathrm{M}$ & $\mathrm{S}$ & $\mathrm{S}$ & $\mathrm{M}$ & $\mathrm{S}$ & $\mathrm{S}$ & $S$ & $S$ & & & & & & & & & & & \\
\hline COOP-F & $\mathrm{S}$ & $\mathrm{S}$ & $\mathrm{M}$ & $\mathrm{M}$ & $\mathrm{M}$ & $\mathrm{S}$ & $\mathrm{S}$ & $\mathrm{M}$ & & & & & & & & & & & & \\
\hline$C O O P-G$ & $S$ & $\mathrm{~S}$ & $\mathrm{~S}$ & $\mathrm{M}$ & $\mathrm{M}$ & $\mathrm{S}$ & $\mathrm{S}$ & $\mathrm{S}$ & $\mathrm{M}$ & $\mathrm{S}$ & & & & & & & & & & \\
\hline COOP-H & $\mathrm{S}$ & $\mathrm{M}$ & $\mathrm{S}$ & $\mathrm{M}$ & $\mathrm{S}$ & $\mathrm{M}$ & $\mathrm{S}$ & $\mathrm{M}$ & $\mathrm{M}$ & $\mathrm{M}$ & $\mathrm{S}$ & $\mathrm{S}$ & & & & & & & & \\
\hline COOP-I & $\mathrm{M}$ & $\mathrm{M}$ & $\mathrm{S}$ & $\mathrm{L}$ & $\mathrm{M}$ & $\mathrm{M}$ & $\mathrm{S}$ & $\mathrm{L}$ & $\mathrm{M}$ & & & & & & & & & & & \\
\hline COOP-J & $\mathrm{M}$ & $\mathrm{M}$ & $\mathrm{M}$ & $\mathrm{M}$ & $\mathrm{M}$ & $\mathrm{M}$ & $\mathrm{M}$ & $\mathrm{M}$ & $\mathrm{M}$ & & & & & & & & & & & \\
\hline COOP-K & $\mathrm{L}$ & $\mathrm{S}$ & $\mathrm{L}$ & $\mathrm{L}$ & $\mathrm{M}$ & $\mathrm{M}$ & $\mathrm{M}$ & $\mathrm{S}$ & $\mathrm{S}$ & $\mathrm{M}$ & $\mathrm{S}$ & $\mathrm{S}$ & $\mathrm{S}$ & $\mathrm{M}$ & $\mathrm{L}$ & $\mathrm{M}$ & $\mathrm{L}$ & $\mathrm{M}$ & $S$ & $\mathrm{~S}$ \\
\hline COOP-L & $\mathrm{M}$ & $\mathrm{L}$ & $\mathrm{M}$ & $\mathrm{L}$ & $\mathrm{L}$ & $\mathrm{M}$ & & & & & & & & & & & & & & \\
\hline
\end{tabular}

$\mathrm{S}=$ Member who delivers small volume of product to the cooperative; $\mathrm{M}=$ Member who delivers medium volume; $\mathrm{L}=$ Member who delivers large volume 
Table 11 - Products delivered by board members of researched cooperatives

\begin{tabular}{|c|c|c|c|c|c|c|c|c|c|c|c|c|c|c|c|c|c|c|c|c|}
\hline Cooperative & $\begin{array}{c}\text { Memb. } \\
1\end{array}$ & $\begin{array}{c}\text { Memb. } \\
2\end{array}$ & $\begin{array}{c}\text { Memb. } \\
3\end{array}$ & $\begin{array}{c}\text { Memb. } \\
4\end{array}$ & $\begin{array}{c}\text { Memb. } \\
5\end{array}$ & $\begin{array}{c}\text { Memb. } \\
6 \\
\end{array}$ & $\begin{array}{c}\text { Memb. } \\
7 \\
\end{array}$ & $\begin{array}{c}\text { Memb. } \\
8 \\
\end{array}$ & $\begin{array}{c}\text { Memb. } \\
9\end{array}$ & $\begin{array}{c}\text { Memb. } \\
10\end{array}$ & $\begin{array}{c}\text { Memb. } \\
11\end{array}$ & $\begin{array}{c}\text { Memb. } \\
12\end{array}$ & $\begin{array}{c}\text { Memb. } \\
13\end{array}$ & $\begin{array}{c}\text { Memb. } \\
14 . \\
\end{array}$ & $\begin{array}{c}\text { Memb. } \\
15 \\
\end{array}$ & $\begin{array}{c}\text { Memb. } \\
16\end{array}$ & $\begin{array}{c}\text { Memb. } \\
17\end{array}$ & $\begin{array}{c}\text { Memb. } \\
18\end{array}$ & $\begin{array}{c}\text { Memb. } \\
19 \\
\end{array}$ & $\begin{array}{c}\text { Memb. } \\
20\end{array}$ \\
\hline COOP-A & SU/L & $\mathrm{S} / \mathrm{M} / \mathrm{T}$ & $\mathrm{D} / \mathrm{L} / \mathrm{M} / \mathrm{S}$ & $\mathrm{S} / \mathrm{L}$ & $\mathrm{L} / \mathrm{M}$ & $\mathrm{M} / \mathrm{L}$ & $\mathrm{D} / \mathrm{L}$ & $\mathrm{M} / \mathrm{S}$ & $\mathrm{M} / \mathrm{S}$ & SU/M/S & $\mathrm{L} / \mathrm{M}$ & SU/M/S & $\mathrm{S} / \mathrm{M} / \mathrm{L}$ & $\mathrm{D} / \mathrm{L} / \mathrm{M}$ & $\mathrm{S} / \mathrm{L}$ & $\mathrm{S} / \mathrm{M} / \mathrm{T}$ & $\mathrm{D} / \mathrm{M} / \mathrm{S} / \mathrm{F}$ & $\mathrm{SU} / \mathrm{M} / \mathrm{F}$ & $\mathrm{S} / \mathrm{M} / \mathrm{L}$ & $\mathrm{S} / \mathrm{M} / \mathrm{SU}$ \\
\hline COOP-B & $\mathrm{S} / \mathrm{M} / \mathrm{T}$ & $\mathrm{S} / \mathrm{M} / \mathrm{T}$ & $\mathrm{S} / \mathrm{M} / \mathrm{T} / \mathrm{L}$ & $\mathrm{S} / \mathrm{M} / \mathrm{T} / \mathrm{L}$ & $\mathrm{S}$ & $\mathrm{S} / \mathrm{M} / \mathrm{T} / \mathrm{L}$ & $\mathrm{S} / \mathrm{M} / \mathrm{T} / \mathrm{L}$ & $\mathrm{S} / \mathrm{M} / \mathrm{L}$ & $\mathrm{S} / \mathrm{M}$ & $\mathrm{S} / \mathrm{M} / \mathrm{T}$ & $\mathrm{S} / \mathrm{M} / \mathrm{L}$ & $\mathrm{S} / \mathrm{P}$ & $\mathrm{S} / \mathrm{M} / \mathrm{T}$ & $\mathrm{S} / \mathrm{M} / \mathrm{T}$ & $\mathrm{S} / \mathrm{P}$ & $\mathrm{S} / \mathrm{M} / \mathrm{T}$ & $\mathrm{S} / \mathrm{M}$ & $\mathrm{S} / \mathrm{M}$ & $\mathrm{S} / \mathrm{M}$ & \\
\hline $\mathrm{COOP}-\mathrm{C}$ & $\mathrm{S} / \mathrm{M} / \mathrm{T}$ & $\mathrm{S} / \mathrm{M} / \mathrm{T} / \mathrm{B}$ & $\mathrm{S} / \mathrm{M} / \mathrm{T}$ & $\mathrm{S} / \mathrm{M}$ & $\mathrm{S} / \mathrm{M} / \mathrm{T}$ & S & $\mathrm{S}$ & $\mathrm{S} / \mathrm{M} / \mathrm{T} / \mathrm{B}$ & $\mathrm{S} / \mathrm{T}$ & $\mathrm{S} / \mathrm{M} / \mathrm{T}$ & $\mathrm{S} / \mathrm{M} / \mathrm{T}$ & $\mathrm{S} / \mathrm{T}$ & $\mathrm{S} / \mathrm{M} / \mathrm{T}$ & $\mathrm{S} / \mathrm{M} / \mathrm{T}$ & $\mathrm{S} / \mathrm{T}$ & & & & & \\
\hline COOP-D & $\mathrm{S} / \mathrm{F} / \mathrm{M}$ & $\mathrm{M} / \mathrm{L}$ & $\mathrm{S} / \mathrm{F} / \mathrm{T} / \mathrm{M}$ & $\mathrm{A} / \mathrm{S}$ & $\mathrm{S} / \mathrm{M} / \mathrm{T}$ & $\mathrm{S} / \mathrm{M} / \mathrm{T} / \mathrm{L}$ & $\mathrm{S} / \mathrm{M} / \mathrm{T} / \mathrm{L}$ & $\mathrm{M} / \mathrm{F}$ & A & A & $\mathrm{S} / \mathrm{T}$ & $\mathrm{S} / \mathrm{F} / \mathrm{L}$ & & & & & & & & \\
\hline COOP-E & $\mathrm{A}$ & $\mathrm{A}$ & $\mathrm{A} / \mathrm{S}$ & $\mathrm{A} / \mathrm{s}$ & $\mathrm{A}$ & $\mathrm{A}$ & $\mathrm{S}$ & $\mathrm{A}$ & $\mathrm{S}$ & & & & & & & & & & & \\
\hline COOP-F & $\mathrm{S} / \mathrm{M} / \mathrm{T} / \mathrm{L}$ & S/M/T/L & $\mathrm{S} / \mathrm{M} / \mathrm{T} / \mathrm{L}$ & $\mathrm{S} / \mathrm{M} / \mathrm{T} / \mathrm{L}$ & $\mathrm{S} / \mathrm{M} / \mathrm{T} / \mathrm{L}$ & $\mathrm{S} / \mathrm{M} / \mathrm{T} / \mathrm{L}$ & $\mathrm{S} / \mathrm{M} / \mathrm{T} / \mathrm{L}$ & $\mathrm{S} / \mathrm{M} / \mathrm{T} / \mathrm{L}$ & & & & & & & & & & & & \\
\hline COOP-G & $\mathrm{S} / \mathrm{T} / \mathrm{L}$ & $\mathrm{S} / \mathrm{T}$ & $\mathrm{S} / \mathrm{T} / \mathrm{L}$ & $\mathrm{L} / \mathrm{S} / \mathrm{T}$ & $\mathrm{S} / \mathrm{T}$ & $\mathrm{S} / \mathrm{T} / \mathrm{L}$ & $\mathrm{S} / \mathrm{T} / \mathrm{L}$ & $\mathrm{S} / \mathrm{L}$ & $\mathrm{S} / \mathrm{T}$ & $\mathrm{S} / \mathrm{T} / \mathrm{L}$ & & & & & & & & & & \\
\hline COOP-H & $\mathrm{M} / \mathrm{S} / \mathrm{T}$ & $\mathrm{M} / \mathrm{S} / \mathrm{T}$ & $\mathrm{M} / \mathrm{S}$ & $\mathrm{M} / \mathrm{S} / \mathrm{T}$ & $\mathrm{M} / \mathrm{S}$ & $\mathrm{M} / \mathrm{S} / \mathrm{T} / \mathrm{L}$ & $\mathrm{M} / \mathrm{S}$ & $\mathrm{M} / \mathrm{L}$ & $\mathrm{M} / \mathrm{S} / \mathrm{T} / \mathrm{L}$ & $\mathrm{S} / \mathrm{T}$ & $\mathrm{M} / \mathrm{S} / \mathrm{L}$ & $\mathrm{S} / \mathrm{T}$ & & & & & & & & \\
\hline COOP-I & $\mathrm{S} / \mathrm{T} / \mathrm{M}$ & $\mathrm{S} / \mathrm{T} / \mathrm{M}$ & $\mathrm{S} / \mathrm{T} / \mathrm{M}$ & $\mathrm{S} / \mathrm{T} / \mathrm{M}$ & $\mathrm{S} / \mathrm{T} / \mathrm{M} / \mathrm{A}$ & $\mathrm{S} / \mathrm{T} / \mathrm{M}$ & $\mathrm{S} / \mathrm{T} / \mathrm{M}$ & $\mathrm{S} / \mathrm{T} / \mathrm{M}$ & $\mathrm{S} / \mathrm{T} / \mathrm{M}$ & & & & & & & & & & & \\
\hline COOP-J & $\mathrm{S} / \mathrm{T} / \mathrm{M}$ & $\mathrm{S} / \mathrm{T}$ & $\mathrm{S} / \mathrm{T} / \mathrm{M}$ & $\mathrm{S} / \mathrm{T} / \mathrm{M}$ & $\mathrm{S} / \mathrm{T} / \mathrm{L}$ & $\mathrm{S} / \mathrm{T} / \mathrm{L}$ & $\mathrm{S} / \mathrm{T}$ & $\mathrm{S} / \mathrm{T} / \mathrm{L}$ & $\mathrm{S} / \mathrm{T}$ & & & & & & & & & & & \\
\hline COOP-K & $\mathrm{C} / \mathrm{V}$ & $\mathrm{C} / \mathrm{V}$ & $\mathrm{C} / \mathrm{V}$ & $\mathrm{C}$ & $\mathrm{C} / \mathrm{V}$ & $\mathrm{C} / \mathrm{V}$ & $\mathrm{C}$ & $\mathrm{C} / \mathrm{V}$ & C & $\mathrm{C} / \mathrm{V}$ & $\mathrm{C} / \mathrm{V}$ & $\mathrm{C} / \mathrm{V}$ & $\mathrm{C} / \mathrm{V}$ & $\mathrm{C} / \mathrm{V}$ & $\mathrm{C} / \mathrm{V}$ & $\mathrm{C} / \mathrm{V}$ & $\mathrm{C} / \mathrm{V}$ & $\mathrm{C} / \mathrm{V}$ & $\mathrm{C} / \mathrm{V}$ & $\mathrm{C}$ \\
\hline COOP-L & $\mathrm{S} / \mathrm{T}$ & $\mathrm{S} / \mathrm{M} / \mathrm{T}$ & $\mathrm{A} / \mathrm{S}$ & $\mathrm{S} / \mathrm{T}$ & $\mathrm{A} / \mathrm{S} / \mathrm{T}$ & $\mathrm{A}$ & & & & & & & & & & & & & & \\
\hline \multicolumn{21}{|c|}{$\begin{array}{c}\text { Memb.=Member; A=Rice; } \mathrm{S}=\text { Soybeans; } \mathrm{F}=\mathrm{Beans} ; \mathrm{M}=\text { Maize; } \mathrm{T}=\text { Wheat } \mathrm{L}=\mathrm{Milk} ; \mathrm{C}=\mathrm{Standard} \text { grapes; } \mathrm{V}=\text { Wine grapes; } \mathrm{SU}=\mathrm{Pork} ; \mathrm{B}=\mathrm{Barley} ; \mathrm{D}=\mathrm{Chicken} \\
\text { Table } 12 \text { - Percentage of each products received by researched cooperative }\end{array}$} \\
\hline Cooperative & $\frac{\pi}{8}$ & 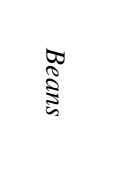 & 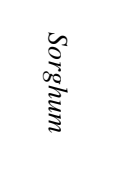 & 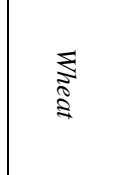 & 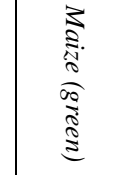 & $\begin{array}{l}3 \\
\S \\
\S\end{array}$ & 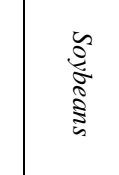 & $\begin{array}{l}\frac{n}{3} \\
\frac{1}{2} \\
\frac{5}{2} \\
\frac{5}{2}\end{array}$ & ई & ڤ & 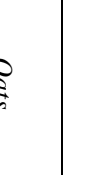 & 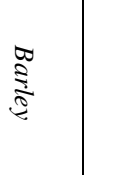 & 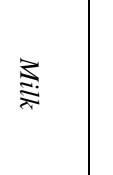 & 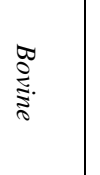 & 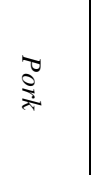 & §. & $\underset{8}{\$}$ & $\underset{0}{\stackrel{3}{a}}$ & 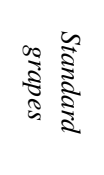 & 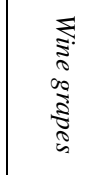 \\
\hline СООР-А & & $1 \%$ & & $9 \%$ & $19 \%$ & & $21 \%$ & & $1 \%$ & $1 \%$ & $\%$ & $2 \%$ & $18 \%$ & & $19 \%$ & $9 \%$ & & & & \\
\hline COOP-B & & & & $17 \%$ & $14 \%$ & & $60 \%$ & & & & & & $6 \%$ & & $3 \%$ & & & & & \\
\hline $\mathrm{COOP}-\mathrm{C}$ & & & & $13 \%$ & $16 \%$ & & $57 \%$ & & & $1 \%$ & $\%$ & $4 \%$ & $5 \%$ & & $3 \%$ & & & & & \\
\hline COOP-D & $13 \%$ & $6 \%$ & & $3 \%$ & $2 \%$ & & $67 \%$ & & & & $\%$ & & $5 \%$ & $1 \%$ & $1 \%$ & & & & & \\
\hline COOP-E & $67 \%$ & $1 \%$ & $1 \%$ & $3 \%$ & $1 \%$ & & $24 \%$ & & & & $\%$ & & $1 \%$ & & & & $1 \%$ & & & \\
\hline COOP-F & & $1 \%$ & & $13 \%$ & $21 \%$ & & $55 \%$ & & & & & & $8 \%$ & & & & & $2 \%$ & & \\
\hline$C O O P-G$ & & & & $14 \%$ & $2 \%$ & & $55 \%$ & & & & & & $29 \%$ & & & & & & & \\
\hline COOP-H & & & & $7 \%$ & $52 \%$ & $1 \%$ & $35 \%$ & $1 \%$ & & & & & $5 \%$ & & & & & & & \\
\hline COOP-I & $6 \%$ & & & $21 \%$ & $5 \%$ & & $64 \%$ & $2 \%$ & & & & & $3 \%$ & & & & & & & \\
\hline COOP-J & & & & $30 \%$ & $10 \%$ & & $45 \%$ & & & & & & $15 \%$ & & & & & & & \\
\hline СООР-K & & & & & & & & & & & & & & & & & & & $53 \%$ & $47 \%$ \\
\hline COOP-L & $24 \%$ & & & $10 \%$ & $1 \%$ & & $65 \%$ & & & & & & & & & & & & & \\
\hline
\end{tabular}


Relation between level of heterogeneity and level of member participation at the general assembly

The scatter plot has been used to examine the relation suggested by proposition 1: When the cooperative is more homogeneous, the level of member participation at the general assembly is low. When the level of heterogeneity increases, the level of member participation at the general assembly increases. When the cooperative reaches certain level of heterogeneity (without a dominant group) the level of member participation at the general assembly decreases.

The relation has been analyzed by using the data results (with regard to heterogeneity) from the coefficient of variation $^{20}$ (as previously developed in section 1; see Figures 8-11), from the grouping measurement (as previously developed in section 2; see Table 7), and from the level of member participation at the general assembly (see Table 9).

The relations between each heterogeneity variable (CV_PERCPROD, CV_PERCMEMB, CV_PERCVOL) as well as the average (CV_AVERAGE) using CV measurement of heterogeneity and member participation attending general assemblies (MPATGA) are presented in Figures 16 to 19 respectively. ${ }^{21}$

\footnotetext{
${ }^{20}$ Even though the grouping measurement maybe the more robust tool to examine heterogeneity, also the results from the coefficient of variation measurement have been used in order to examine the proposed relation between heterogeneity and member participation.

21 Note that in order to examine the positive relation between level of heterogeneity and level of member participation at the general assembly in a scatter plot using the $\mathrm{CV}$ as a measurement of heterogeneity, we had to transform the results from low (more heterogeneous) to high. Otherwise, we would have to analyze relation between level of homogeneity and level of member participation, what is not the aim of the study. The transformation is shown in Appendix 4.
} 


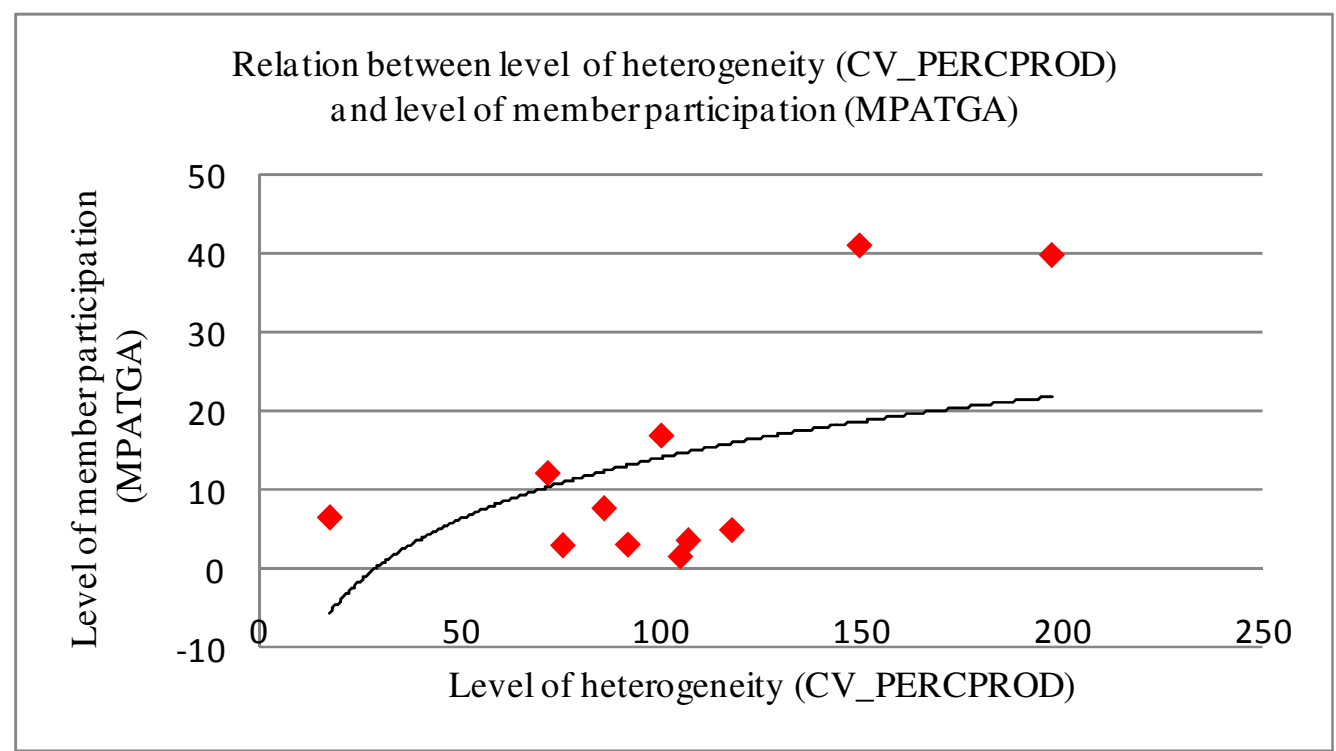

Figure 16 - Research results for the relation between level of heterogeneity (CV_PERCPROD) and level of member participation (MPATGA)

Figure 16 shows that level of member participation at the general assembly is positively related with the heterogeneity variable 'CV_PERCPROD' (i.e., variability of the shares of all product the cooperative receives in the total revenue of the cooperative), as is expected. It shows that when the level of heterogeneity is low (e.g., 17.6), level of member participation is low (around $7 \%)$, as is the case of COOP-D (17.6, 7\%). It also shows that when the level of heterogeneity increases (e.g., 72.06-100.45), the level of member participation increases (around 12-17\%), as is the case of COOP-I $(72.06,12 \%)$ and COOP-B $(100.45,17 \%)$. It shows that when the level of heterogeneity reaches a certain level (e.g., 105.23-118.1), the level of member participation decreases as is the case of COOP-G (105.23, 2\%), COOP-L (107.18, 4\%), and COOP-A (118.1, $5 \%)$. Considering the whole sample, the degree of correlation between the two variables is good $(\approx 0.70)$. 


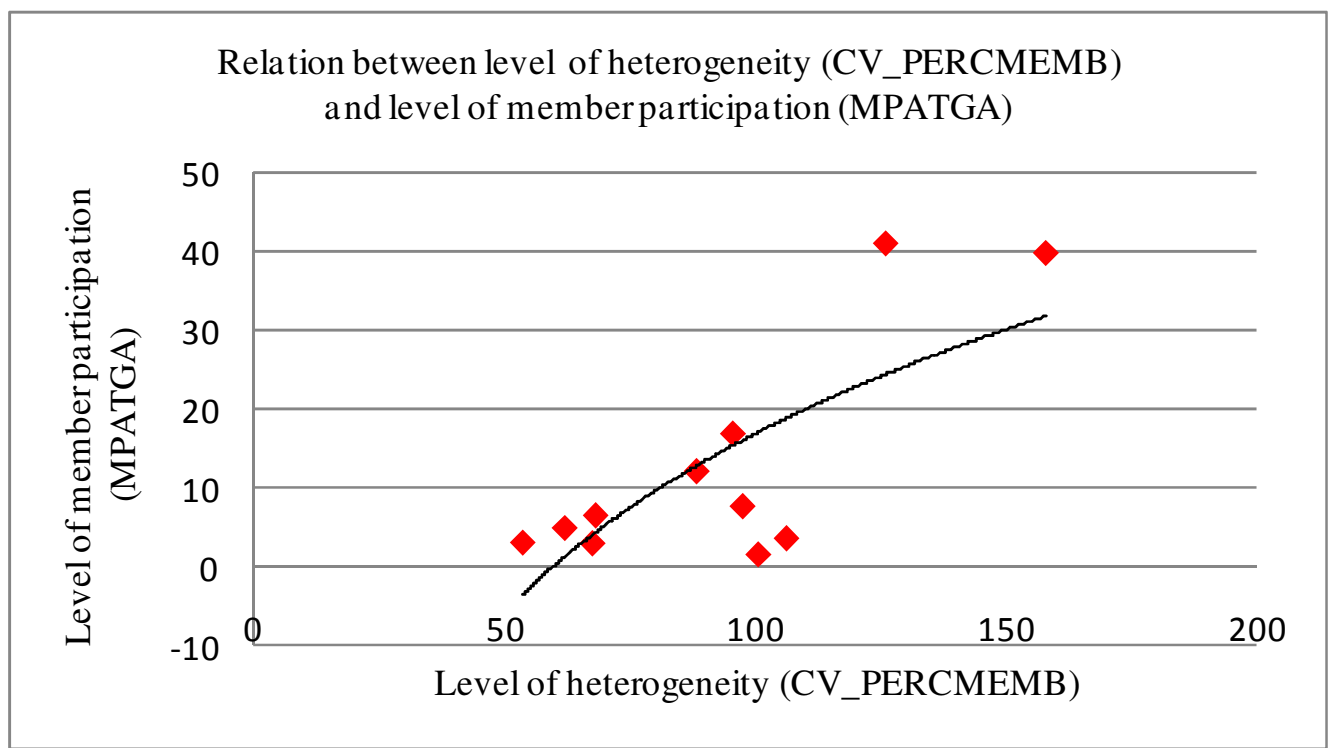

Figure 17 - Research results for the relation between level of heterogeneity (CV_PERCMEMB) and level of member participation (MPATGA)

Figure 17 shows that level of member participation at the general assembly is positively related with the heterogeneity variable 'CV_PERCMEMB' (i.e., variability of the weights of all groups of members who deliver each product), as is expected. It does show that when the level of heterogeneity is low (e.g., 53.72-68.25), level of member participation is low (around 3-7\%), as is the case of COOP-F (53.72, 3\%), COOP-A (62.07, 5\%), COOP-C (67.61, 3\%), and COOP-D $(68.25,7 \%)$. It shows also that when the level of heterogeneity increases (e.g., 88.38-95.60), the level of member participation increases (around 12-17\%), as is the case of COOP-I $(88.38,12 \%)$ and COOP-B $(95.60,17 \%)$. It shows that when the level of heterogeneity reaches a certain level (e.g., 97.54-106.29), the level of member participation decreases as is the case of COOP-H (97.54, 8\%), COOP-G (100.68, 2\%), and COOP-L (106.29, 4\%). Considering the whole sample, the degree of correlation between the two variables is good $(\approx 0.70)$. 


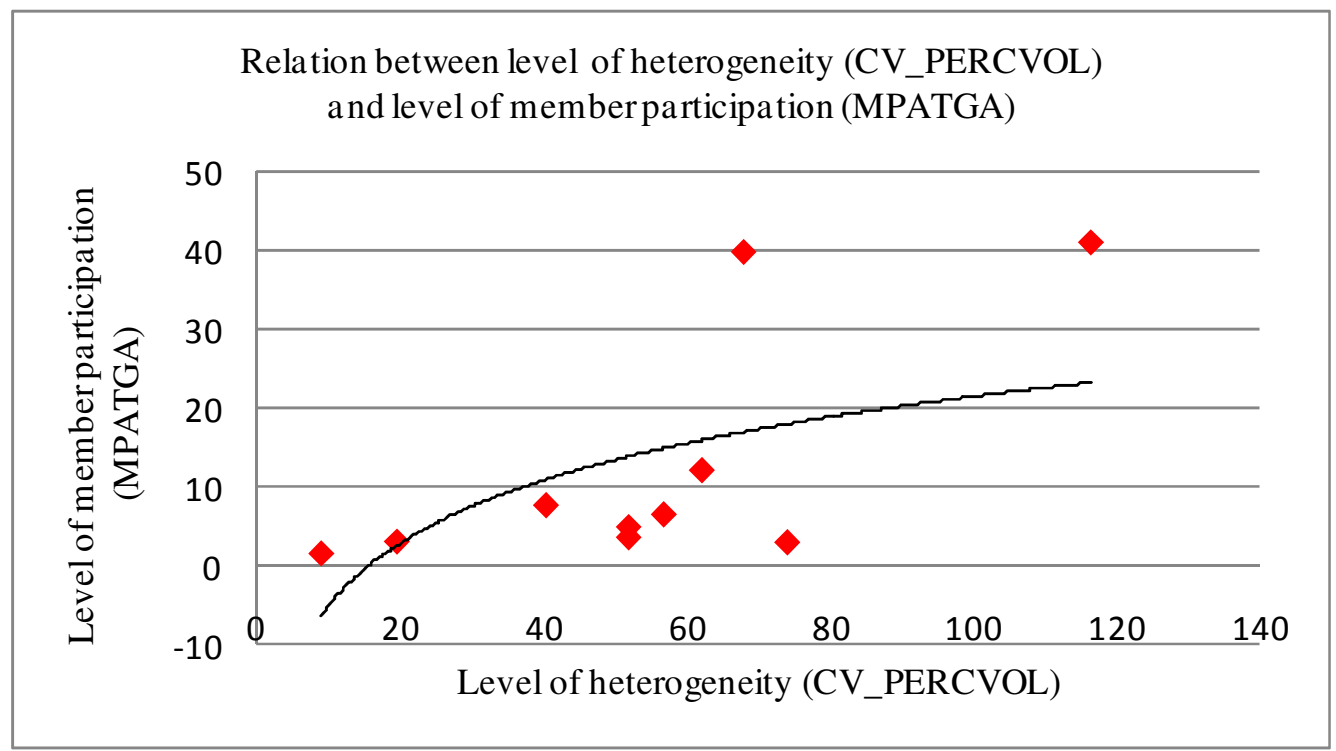

Figure 18 - Research results for the relation between level of heterogeneity (CV_PERCVOL) and level of member participation (MPATGA)

Figure 18 shows that level of member participation at the general assembly is positively related with the heterogeneity variable 'CV_PERCVOL' (i.e., variability of the percentages of groups of members who deliver large, medium and small volume of products to the cooperative), as is expected. The figure shows that when the level of heterogeneity is low (e.g., 9.2-57.9), level of member participation is low (around 2-8\%), as is the case of COOP-G (9.2, 2\%), COOP-F (19.78, 3\%), COOP-H (40.63, 8\%), COOP-A (52.17, 5\%), COOP-L (52.17, 4\%), and COOP-D $(57.09,7 \%)$. The figure furthermore shows that when the level of heterogeneity increases (e.g., 62.40-68.25), the level of member participation increases (around 12-40\%), as is the case of COOP-I $(62.40,12 \%)$ and COOP-K $(68.25,40 \%)$. It shows that when the level of heterogeneity reaches a certain level (e.g., 74.34), the level of member participation decreases (3\%) as is the case of COOP-C $(74.34,3 \%)$. Considering the whole sample, the degree of correlation between the two variables is moderated $(\approx 0.60)$. 


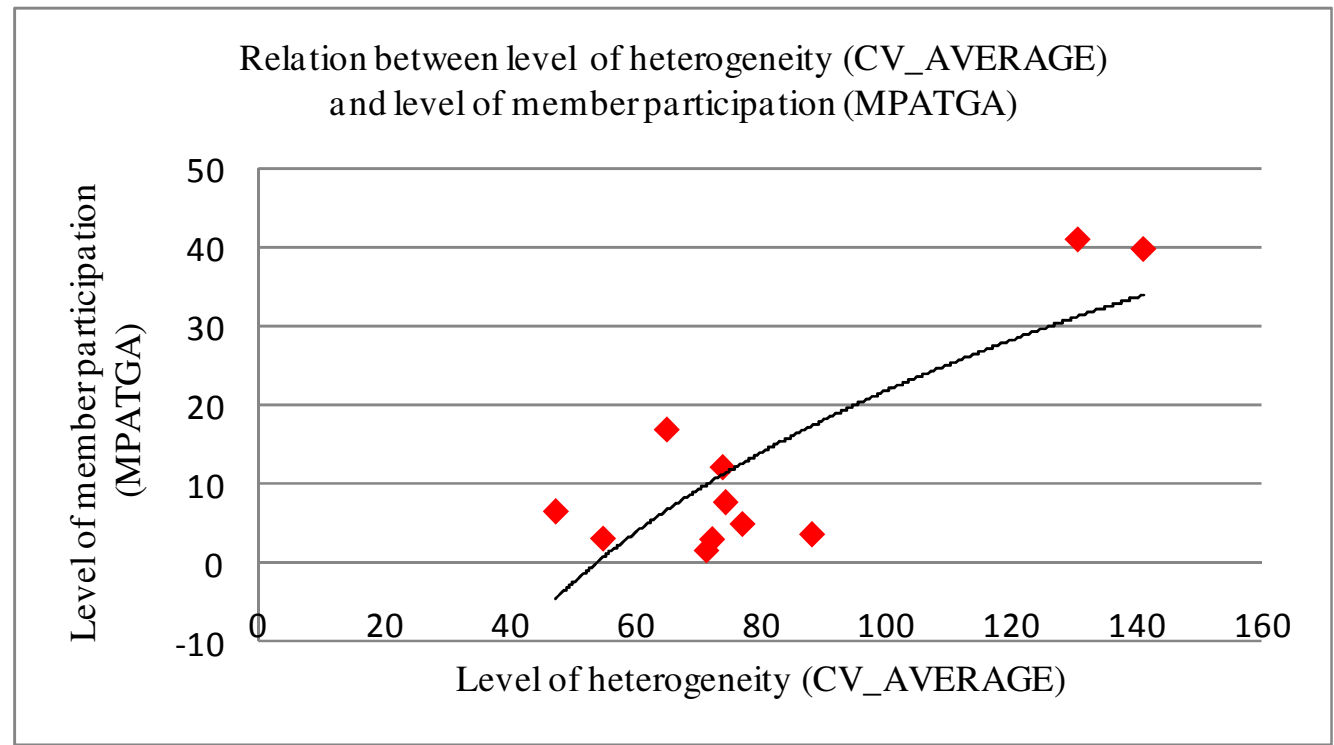

Figure 19 - Research results for the relation between level of heterogeneity (CV_AVERAGE) and level of member participation (MPATGA)

Figure 19 shows that level of member participation at the general assembly is positively related with the heterogeneity variable 'CV_AVERAGE' (i.e., average level of heterogeneity considering $\mathrm{CV}$ as a measurement model), as is expected. It shows that when the level of heterogeneity is low (e.g., 47.65-72.61), level of member participation is low (around 3-7\%), as is the case of COOP-D (47.65, 7\%), COOP-F (55.19, 3\%), COOP-G (71.7, 2\%), and COOP-C (72.61, 3\%). It also shows that when the level of heterogeneity increases (e.g., 74.28), the level of member participation increases (around 12\%), as is the case of COOP-I (74.28, 12\%). It shows that when the level of heterogeneity reaches a certain level (e.g., 74.77-88.55), the level of member participation decreases (4-8\%) as is the case of COOP-H (74.77, 8\%), COOP-A (77.45, $5 \%)$, COOP-L $(88.55,4 \%)$. Considering the whole sample, the degree of correlation between the two variables is very good $(\approx 0.80)$.

\section{Discussion}

The results show, as expected, that positive relation exists between heterogeneity and the level of member participation at the general assembly. The degree of correlation found between the heterogeneity variables and the dependent variable was either moderate (CV_PERCVOL), or good (CV_PERCPROD, CV_PERCMEMB), or very good (CV_AVERAGE). 
The relations between each heterogeneity variable (PERCPROD, PERCMEMB, PERCVOL) as well as and the average using grouping measurement of heterogeneity and member participation attending general assemblies (MPATGA) are presented in Figures 20 to 23 respectively.

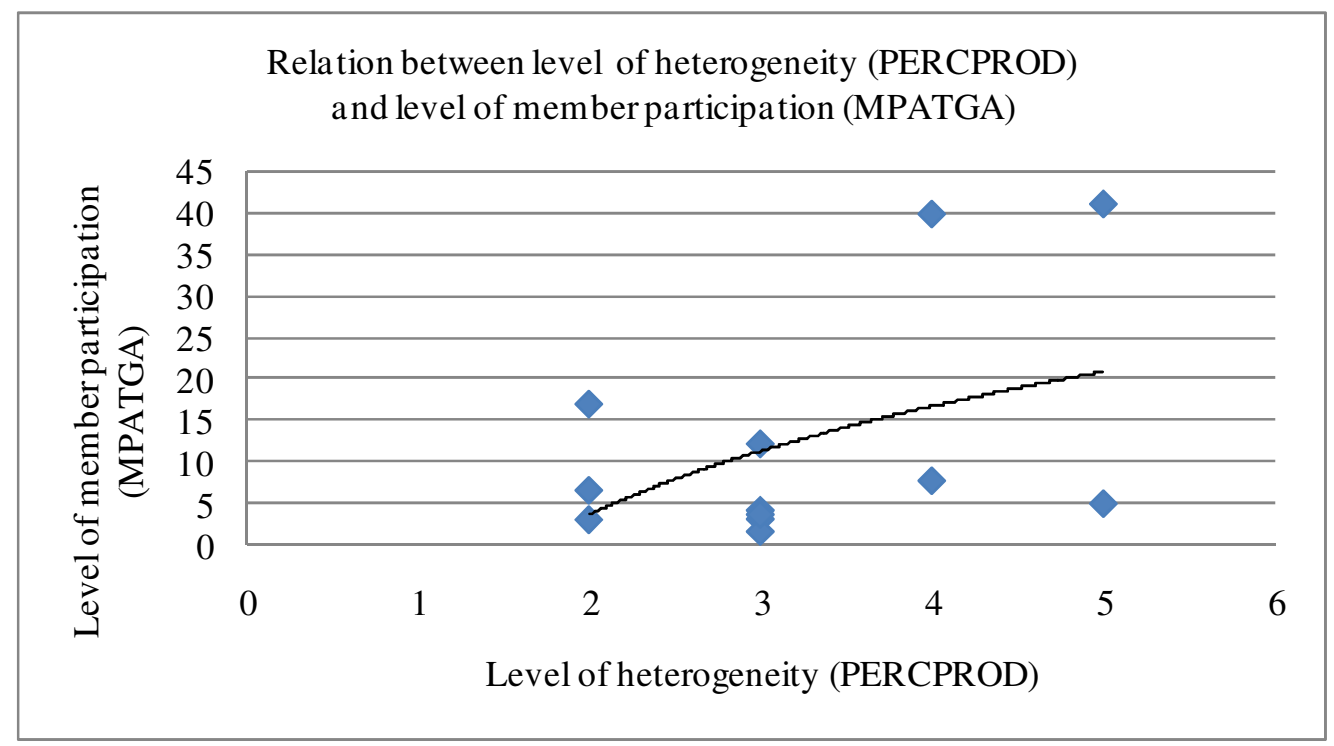

Figure 20 - Research results for the relation between level of heterogeneity (PERCPROD) and level of member participation (MPATGA)

Figure 20 shows that level of member participation at the general assembly is positively related with the heterogeneity variable 'PERCPROD' (i.e., levels of cooperative heterogeneity with regard to the size of the main product in relation with the size of the minorities), as is expected. It shows that when the level of heterogeneity is low (e.g., level 2), level of member participation is low (around 3-7\%), as is the case of COOP-C (2, 3\%), and COOP-D (2, 7\%). It shows also that when the level of heterogeneity increases (e.g., level 3), the level of member participation increases (around 12\%), as is the case of COOP-I $(3,12 \%)$. It shows that when the level of heterogeneity reaches a certain level (e.g., 5), the level of member participation decreases, as is the case of COOP-A $(5,5 \%)$. Considering the whole sample, the degree of correlation between the two variables is moderated $(\approx 0.50)$. 


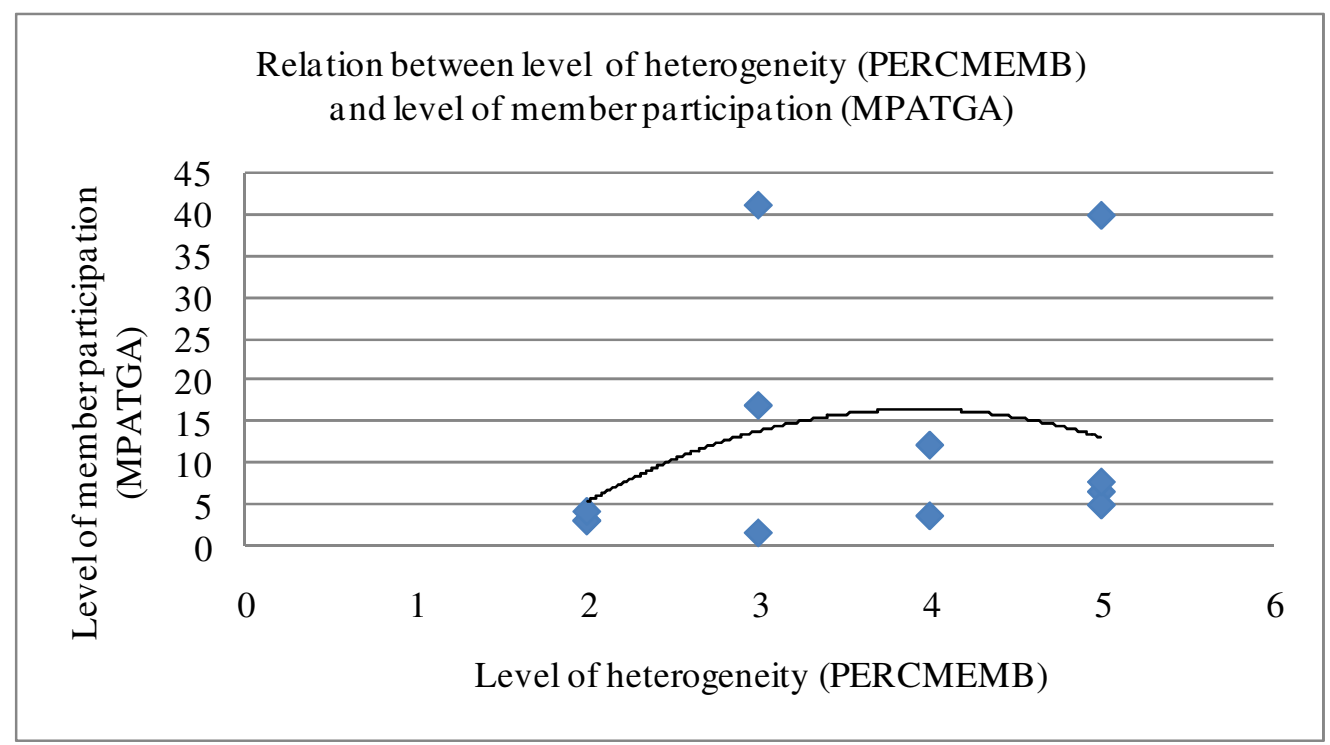

Figure 21 - Research results for the relation between level of heterogeneity (PERCMEMB) and level of member participation (MPATGA)

Figure 21 shows that level of member participation at the general assembly is positively related with the heterogeneity variable 'PERCMEMB' (i.e., levels of cooperative heterogeneity with regard to the size of the largest group of producers in relation to the size of the minorities), as is expected. It shows that when the level of heterogeneity is low (e.g., level 2), level of member participation is low (around 3-4\%), as is the case of COOP-F (2, 3\%), COOP-C (2, 3\%) and COOP-E (2, 4\%). It shows also that when the level of heterogeneity increases (e.g., level 3), the level of member participation increases (around 17\%), as is the case of COOP-B (3, 17\%). It shows that when the level of heterogeneity reaches a certain level (e.g., 5), the level of member participation decreases (5-8\%) as is the case of COOP-A (5, 5\%), COOP-D (5, 7\%), and COOP-H $(5,8 \%)$. Considering the whole sample, the degree of correlation between the two variables is weak $(\approx 0.20)$. 


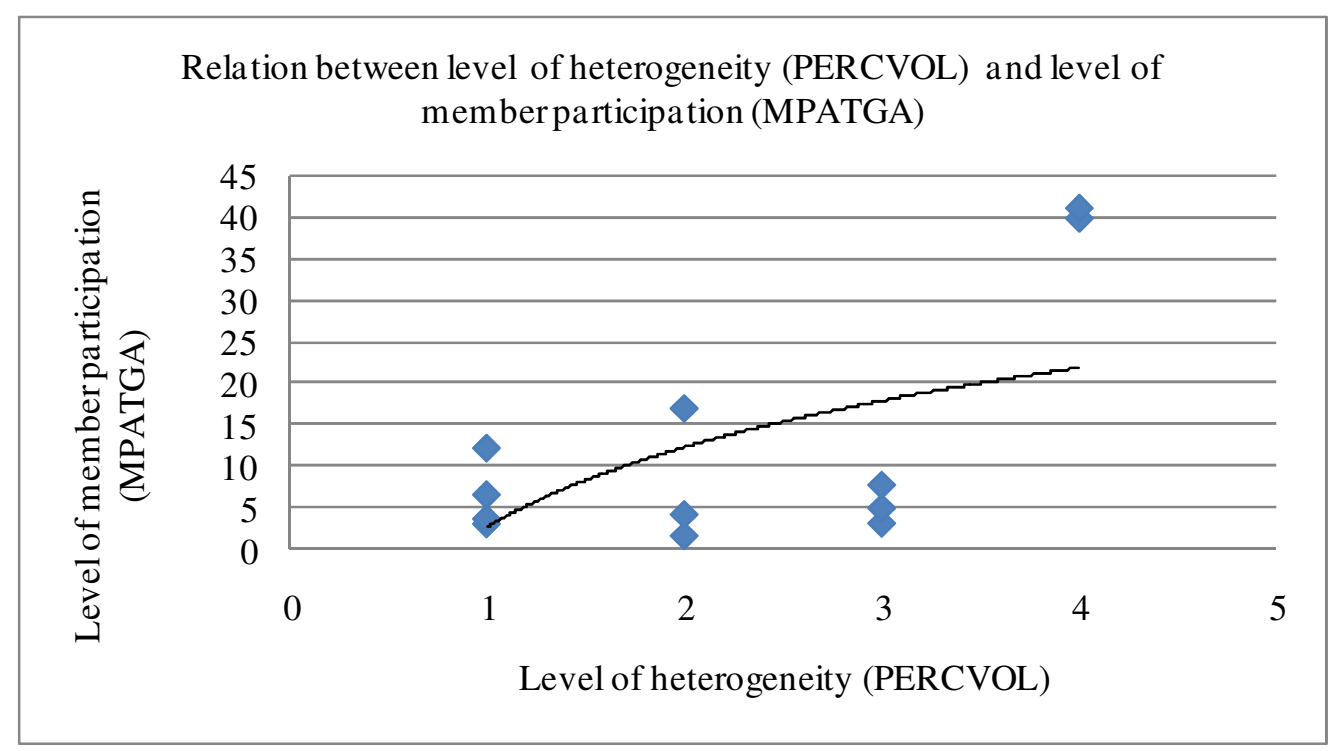

Figure 22 - Research results for the relation between level of heterogeneity (PERCVOL) and level of member participation (MPATGA)

Figure 22 shows that level of member participation at the general assembly is positively related with the heterogeneity variable 'PERCVOL' (i.e., levels of member heterogeneity with regard to the size of the bargaining groups in relation to the size of the majority), as is expected. It shows that when the level of heterogeneity is low (e.g., level 1), level of member participation is low (around 3-7\%), as is the case of COOP-C (1,3\%), COOP-L (1, 4\%), and COOP-D (1, 7\%). Furthermore, it shows that when the level of heterogeneity increases (e.g., level 2), the level of member participation increases (around 17\%), as is the case of COOP-B (2, 17\%). However, it does not show that when the level of heterogeneity reaches a certain level (e.g., 5), the level of member participation decreases. Considering the whole sample, the degree of correlation between the two variables is good $(\approx 0.70)$. 


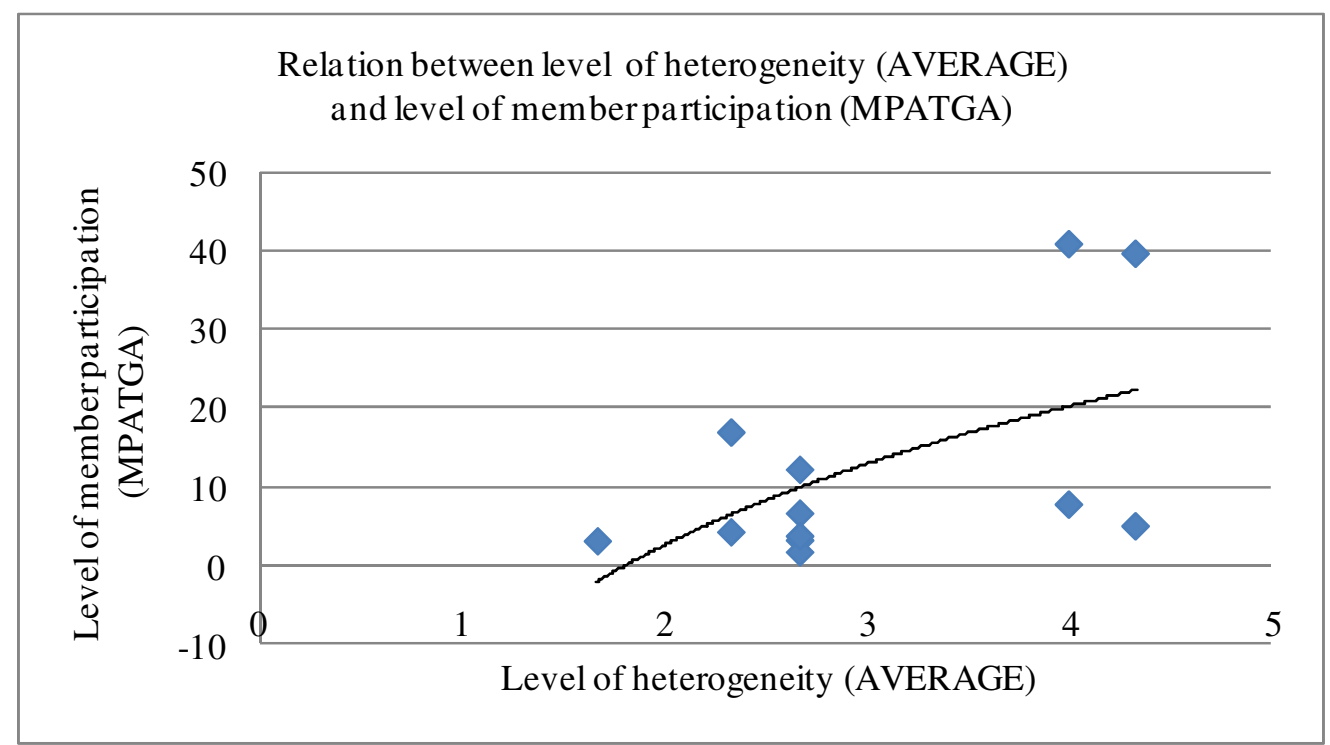

Figure 23 - Research results for the relation between level of heterogeneity (AVERAGE) and level of member participation (MPATGA)

Figure 23 shows that level of member participation at the general assembly is positively related with the heterogeneity variable 'AVERAGE' (i.e., average level of heterogeneity considering grouping as a heterogeneity measurement model), as is expected. It shows that when the level of heterogeneity is low (e.g., level 1.67), level of member participation is low (around 3\%), as is the case of COOP-C $(1.67,3 \%)$. It also shows that when the level of heterogeneity increases (e.g., level 2.33), the level of member participation increases (around 4\%), as is the case of COOP-E $(2.33,4 \%)$. Additional, the results show that when the level of heterogeneity increases (e.g., level 2.67), the level of member participation increases (around 7-12\%), as is the case of COOP-D $(2.67,7 \%)$, and COOP-I $(2.67,12 \%)$. It shows that when the level of heterogeneity reaches a certain level (e.g., 4.33), the level of member participation decreases as is the case of COOP-A $(4.33,5 \%)$. Considering the whole sample, the degree of correlation between the two variables is moderated $(\approx 0.60)$. 


\section{Discussion}

Apart from PERCVOL, the other heterogeneity variables (PERCPROD, PERCMEMB, AVERAGE) supported the relation suggested by proposition 1 . The degree of correlation found between the heterogeneity variables and the dependent variable was either weak (PERCMEMB), or moderated (PERCPROD, AVERAGE).

Relation between level of heterogeneity and level of member participation at the board of directors

Logistic regression has been used to examine proposition 2: The more the level of heterogeneity (e.g., in terms of volume) increases, the more medium and large farmers participate in the board of directors. The analysis has been done in two different ways (see Equations 3a and 3b). First, we have used data results of the coefficient of variation heterogeneity measurement model (see Figures 8-11) which has been previously developed in Section 1. Second, we have used data results of the grouping heterogeneity measurement model (see Table 7) which has been developed in Section 2.

ProbBoardLM $=\alpha_{0}+\alpha_{1}$ (heterogeneity variable using CV measurement model)

$+\alpha_{2}$ MAINPROD $+\alpha_{3}$ NUMBPROD

ProbBoardLM $=\beta_{0}+\beta_{1}$ (heterogeneity variable using grouping measurement model)

$+\beta_{2}$ MAINPROD $+\beta_{3}$ NUMBPROD

Equation $3 b$

Step 1: Logistic regression results considering CV measurement of heterogeneity

Table 13 presents the descriptive statistics of the independent variables of the model based on the CV measurement of heterogeneity (CV_PERCPROD, CV_PERCMEMB, CV_PERCVOL, CV_AVERAGE). It also shows the statistics of the control variables (MAINPROD, NUMBPROD) and of the dependent variable itself (BoardLM). As one can see in column 3, characteristics of 149 board members were observed. 
Table 13 - Descriptive statistics for variables of the research

\begin{tabular}{c|c|c|c|c|c|c}
\hline \multirow{2}{*}{ Variable } & Type & Observations & Mean & $\begin{array}{c}\text { Standard } \\
\text { Deviation }\end{array}$ & Minimum & Maximum \\
\hline BoardLM & Dependent & 149 & 0.50 & 0.50 & 0 & 1 \\
\hline CV_PERCPROD & Independent & 149 & 111.17 & 50.35 & 6.69 & 204.73 \\
\hline CV_PERCMEMB & Independent & 149 & 96.15 & 37.97 & 23.52 & 181.5 \\
\hline CV_PERCVOL & Independent & 149 & 84.84 & 33.01 & 14.14 & 130.91 \\
\hline CV_AVERAGE & Independent & 149 & 97.39 & 34.89 & 30.96 & 172.38 \\
\hline MAINPROD & Control & 149 & 0.89 & 0.31 & 0 & 1 \\
\hline NUMBPROD & Control & 149 & 2.54 & 0.88 & 1 & 4 \\
\hline
\end{tabular}

Tables 14-17 present the results obtained from estimating 4 logistic regressions to explain the heterogeneity determinants of the probability that board members are either medium or large farmers. Each of these logistic regressions considers one alternative independent variable (CV_PERCPROD, CV_PERCMEMB， CV_PERCVOL，CV_AVERAGE). All potential predictors were first included in the regression model. However, due to the existence of multicollinearity, we have modeled them separately as the tables below show.

Table 14 - Logistic regression using data from CV heterogeneity measurement (CV_PERCPROD) Dependent variable: Probability board member is either medium or large volume deliver $(\mathbf{y})$ Number of observations: 149

\begin{tabular}{l|c|c|c|c}
\hline Variable & Coef. & Std. Err. & P>|z| & Odds Ratio \\
\hline CV_PERCPROD & -0.0015 & 0.0033 & 0.656 & 0.999 \\
\hline MAINPROD & 1.4100 & 0.6900 & 0.041 & 4.096 \\
\hline NUMBPROD & 0.2354 & 0.2024 & 0.245 & 1.265 \\
\hline Constant & -1.7127 & 0.8253 & 0.038 & \\
\hline Log Likelihood & -98.733884 & & \\
\hline Overall Model fit & 9.08 & \\
\hline LR chi ${ }^{2}$ & 0.0282 & \\
\hline Prob $>$ chi ${ }^{2}$ & 0.0440 & \\
\hline Pseudo R ${ }^{2}$ & $84.00 \%$ & \\
\hline Sensitivity & $37.84 \%$ & & \\
\hline Specificity & $61.07 \%$ \\
\hline Correctly classified & 0.6306 & \\
\hline Area under ROC curve &
\end{tabular}

Results of this logistic regression (Table 14) suggest that the probability that board members are either medium or large farmers is not related to cooperative heterogeneity, in terms of percentage of each product in the cooperatives' revenues. 
Table 15- Logistic regression using data from CV heterogeneity measurement (CV_PERCMEMB) Dependent variable: Probability board member is either medium or large volume deliver (y) Number of observations: 149

\begin{tabular}{l|c|c|c|c}
\hline Variable & Coef. & Std. Err. & P>|z| & Odds Ratio \\
\hline CV_PERCMEMB & -0.0126 & 0.0051 & 0.013 & 0.987 \\
\hline MAINPROD & 1.0506 & 0.7076 & 0.138 & 2.859 \\
\hline NUMBPROD & 0.3380 & 0.2160 & 0.118 & 1.402 \\
\hline Constant & -0.6452 & 0.8885 & 0.468 & \\
\hline Log Likelihood & -95.417548 & \\
\hline Overall Model fit & 15.72 & \\
\hline LR chi ${ }^{2}$ & 0.0013 & \\
\hline Prob $>$ chi ${ }^{2}$ & 0.0761 & \\
\hline Pseudo R ${ }^{2}$ & $76.00 \%$ & & \\
\hline Sensitivity & $55.41 \%$ & & \\
\hline Specificity & $65.77 \%$ & & \\
\hline Correctly classified & 0.6914 & \\
\hline Area under ROC curve &
\end{tabular}

Results of this logistic regression (Table 15) suggest that the probability that board members are either medium or large farmers is inversely related to CV_PERCMEMB, and statistically significant at 5\% (P value $=0.013)$. In consonance with proposition 2 , this result suggests that the more the value of this variable decreases (note that in section 1 we have explained that heterogeneity increases as $\mathrm{CV}$ decreases), the higher the probability that medium and large farmers participate in the board of directors. The magnitude of the change in probability due to CV_PERCMEMB is the following: when the variable CV_PERCMEMB increases by one point, the odds that the probability that the board member is either medium or large decrease by $1.3 \%$.

Table 16- Logistic regression using data from CV heterogeneity measurement (CV_PERCVOL) Dependent variable: Probability board member is either medium or large volume deliver (y) Number of observations: 149

\begin{tabular}{|c|c|c|c|c|}
\hline Variable & Coef. & Std. Err. & $P>|z|$ & Odds Ratio \\
\hline$C V \_P E R C V O L$ & -0.0152 & 0.0057 & 0.007 & 0.985 \\
\hline MAINPROD & 1.4586 & 0.6853 & 0.033 & 4.300 \\
\hline NUMBPROD & 0.2612 & 0.2054 & 0.203 & 1.299 \\
\hline Constant & -0.6801 & 0.8660 & 0.432 & \\
\hline Log Likelihood & \multicolumn{4}{|l|}{-94.955526} \\
\hline \multicolumn{5}{|l|}{ Overall Model fit } \\
\hline$L R$ chi $^{2}$ & \multicolumn{4}{|l|}{16.64} \\
\hline Prob $>c h i^{2}$ & \multicolumn{4}{|l|}{0.0008} \\
\hline Pseudo $R^{2}$ & \multicolumn{4}{|l|}{0.0806} \\
\hline Sensitivity & \multicolumn{4}{|l|}{$74.67 \%$} \\
\hline Specificity & \multicolumn{4}{|l|}{$50.00 \%$} \\
\hline Correctly classified & \multicolumn{4}{|l|}{$62.42 \%$} \\
\hline Area under ROC curve & \multicolumn{4}{|l|}{0.6775} \\
\hline
\end{tabular}


Results of this logistic regression (Table 16) suggest that the probability that board members are either medium or large farmers is inversely related to heterogeneity in terms of CV_PERCVOL, with strong statistical significance $(P$ value $=0.007)$. This result suggests, as expected, that the more the value of this variable decreases (note that in section 1 we have explained that heterogeneity increases as $\mathrm{CV}$ decreases), the higher the probability that medium and large farmers participate in the board of directors. The magnitude of the change in probability due to CV_PERCVOL is the following: when the variable CV_PERCVOL increases by one point, the odds that the probability that the board member is either medium or large decrease by $1.5 \%$. Results of this regression suggest also that the probability that board members are either medium or large farmers is positively related to the variable MAINPROD, with statistical significance at $5 \%(P$ value $=0.033)$.

Table 17- Logistic regression using data from CV heterogeneity measurement (CV_AVERAGE) Dependent variable: Probability board member is either medium or large volume deliver (y) Number of observations: 149

\begin{tabular}{l|c|c|c|c}
\hline Variable & Coef. & Std. Err. & P>|z| & Odds Ratio \\
\hline CV_AVERAGE & -0.0197 & 0.0077 & 0.010 & 0.980 \\
\hline MAINPROD & 1.0867 & 0.7010 & 0.121 & 2.964 \\
\hline NUMBPROD & 0.3920 & 0.2189 & 0.073 & 1.480 \\
\hline Constant & -0.2372 & 0.9811 & 0.809 & \\
\hline Log Likelihood & -95.219038 & & \\
\hline Overall Model fit & 16.11 & \\
\hline LR chi ${ }^{2}$ & 0.0011 & \\
\hline Prob $>$ chi $^{2}$ & 0.0780 & \\
\hline Pseudo $R^{2}$ & $78.67 \%$ & \\
\hline Sensitivity & $50.00 \%$ & & \\
\hline Specificity & $64.43 \%$ & & \\
\hline Correctly classified & 0.7070 & \\
\hline Area under ROC curve &
\end{tabular}

Analogous to the significance level found for CV_PERCVOL (1\%), the probability that board members are either medium or large farmers is inversely related to CV_AVERAGE (i.e., heterogeneity in general terms). The magnitude of the change in probability due to CV_AVERAGE is the following: when the variable CV_AVERAGE increases by one point, the odds that the probability that the board member is either medium or large decreases by $2 \%$. Results of this regression suggest also that the probability that board members are either medium or large farmers is positively related to the variable NUMBPROD, with statistical significance at $10 \%(P$ value $=0.073)$. 


\section{Discussion}

We have estimated 4 logistic regressions (Tables 14-17) to examine the heterogeneity determinants of the probability that board members are either medium or large farmers. Each of these logistic regressions compared the relationship between the probability that board members are either medium or large farmers with one alternative heterogeneity variable (CV_PERCPROD, CV_PERCMEMB, CV_PERCVOL, CV_AVERAGE) and the control variables (MAINPROD, NUMBPROD). In the first model, the variable CV_PERCPROD was not found related. In the second model, the variable CV_PERCMEMB was found significant at 5\%. In the third model, the variable CV_PERCVOL was found significant at $1 \%$. And, in the fourth model, the variable CV_AVERAGE was also found significant at $1 \%$. So, according to the assessment of the significance of the coefficients, the models three (Table 16) and four (Table 17) were the ones in which the predictors better explained the dependent variable. It should be noticed, however, that variable CV_AVERAGE might be strongly significant because it is the average of the other two variables (CV_PERCPROD, CV_PERCMEMB) along with CV_PERCVOL. In order to check whether there is strong correlation between the variables, we have calculated the correlation matrix shown in Table 18.

Table 18 - Correlation matrix of the independent variables

\begin{tabular}{l|c|c|c|c}
\hline & $C V \_P E R C P R O D$ & $C V \_P E R C M E M B$ & $C V \_P E R C V O L$ & $C V \_A V E R A G E$ \\
\hline$C V \_P E R C P R O D$ & 1.00 & & & \\
\hline$C V \_P E R C M E M B$ & $(0.97)$ & 1.00 & & \\
\hline$C V \_P E R C V O L$ & $(0.95)$ & $(0.93)$ & 1.00 & \\
\hline$C V \_A V E R A G E$ & $(0.96)$ & $(0.97)$ & $(0.89)$ & 1.00 \\
\hline
\end{tabular}

Correlations greater than .50 are shown between brackets

As is shown by Table 18, there is a strong correlation (0.89) between CV_PERCVOL and CV_AVERAGE. As a result, CV_PERCVOL may influence the good fit of CV_AVERAGE.

In addition, looking to the overall fit of the two models, one can see that the Prob $>\operatorname{chi}^{2}$ of the third model is almost zero, that suggests that the third model is better than the fourth. The Pseudo $\mathrm{R}^{2}$ of the third model (higher than the one of the fourth model) also suggests that it is the best model. 
Step 2: Logistic regression results considering grouping heterogeneity measurement model

Table 19 presents the descriptive statistics (mean, standard deviation, minimum, maximum) for the (grouping measurement of heterogeneity) alternative independent variables (PERCPROD, PERCMEMB, PERCVOL) hypothesized to explain probability that board members are either medium or large farmers at a sample of 12 Brazilian agricultural cooperatives, as well as for the control (MAINPROD, NUMBPROD) and for the dependent variable itself (BoardLM).

Table 19- Descriptive statistics for variables of the research

\begin{tabular}{c|c|c|c|c|c|c}
\hline Variable & Type & Observations & Mean & $\begin{array}{c}\text { Standard } \\
\text { Deviation }\end{array}$ & Minimum & Maximum \\
\hline BoardLM & Dependent & 149 & 0.50 & 0.50 & 0 & 1 \\
\hline PERCPROD & Independent & 149 & 3.30 & 1.10 & 2 & 5 \\
\hline PERCMEMB & Independent & 149 & 3.74 & 1.22 & 2 & 5 \\
\hline PERCVOL & Independent & 149 & 2.38 & 1.09 & 1 & 4 \\
\hline MAINPROD & Control & 149 & 0.89 & 0.31 & 0 & 1 \\
\hline NUMBPROD & Control & 149 & 2.54 & 0.88 & 1 & 4 \\
\hline
\end{tabular}

Tables 20-22 present the results obtained from estimating 3 logistic regressions to explain the (grouping) heterogeneity determinants of the probability that board members are either medium or large farmers. Each of these regressions compares the relationship of one alternative heterogeneity variable (PERCPROD, PERCMEMB, PERCVOL) and the control variables (MAINPROD, NUMBPROD) with the probability that board members are either medium or large farmers. Note that as these variables are categories (level 1, 2, 3, 4 and 5), we created dummy variables for them, as one can see in the logistic regressions. Note that Table 20 shows only the variables PERCPROD-3, PERCPROD-4, and PERCPROD-5 because of two reasons: (1), there were no cooperatives classified at level 1 with regard to PERCPROD (see Table 7); and (2), the (STATA) program dropped the variable PERCPROD-2 at the estimation. 
Table 20- Logistic regression using data from grouping heterogeneity measurement (PERCPROD) Dependent variable: Probability board member is either medium or large volume deliver (y) Number of observations: 149

\begin{tabular}{|c|c|c|c|c|}
\hline Variable & Coef. & Std. Err. & $P>|z|$ & Odds Ratio \\
\hline PERCPROD-3 & 0.1977 & 0.4406 & 0.654 & 1.219 \\
\hline PERCPROD-4 & 0.4009 & 0.4896 & 0.413 & 1.493 \\
\hline PERCPROD-5 & -0.3331 & 0.5036 & 0.508 & 0.717 \\
\hline MAINPROD & 1.2641 & 0.6983 & 0.070 & 3.540 \\
\hline NUMBPROD & 0.2918 & 0.2112 & 0.167 & 1.339 \\
\hline Constant & -1.9538 & 0.8141 & 0.016 & \\
\hline Log Likelihood & \multicolumn{4}{|l|}{-97.866599} \\
\hline \multicolumn{5}{|l|}{ Overall Model fit } \\
\hline$L R$ chi $^{2}$ & \multicolumn{4}{|l|}{10.82} \\
\hline Prob $>c h i^{2}$ & \multicolumn{4}{|l|}{0.0551} \\
\hline Pseudo $R^{2}$ & \multicolumn{4}{|l|}{0.0524} \\
\hline Sensitivity & \multicolumn{4}{|l|}{$70.67 \%$} \\
\hline Specificity & \multicolumn{4}{|l|}{$45.95 \%$} \\
\hline Correctly classified & \multicolumn{4}{|l|}{$58.39 \%$} \\
\hline Area under ROC curve & \multicolumn{4}{|l|}{0.6311} \\
\hline
\end{tabular}

The results of this logistic regression ( Table 20) show that cooperative heterogeneity in terms of percentage of each product in the cooperatives' revenues using grouping measurement (PERCPROD) does not appear to significantly influence the probability that board members are either medium or large farmers. In other words, probability that board members are either medium or large farmers is not related to whether a cooperative has not a unique product representing a high percentage in the total revenues or whether it has.

Table 21- Logistic regression using data from grouping heterogeneity measurement (PERCMEMB) Dependent variable: Probability board member is either medium or large volume deliver (y) Number of observations: 149

\begin{tabular}{l|c|c|c|c}
\hline Variable & Coef. & Std. Err. & P>|z| & Odds Ratio \\
\hline PERCMEMB-3 & 0.5049 & 0.4916 & 0.304 & 1.657 \\
\hline PERCMEMB-4 & 2.3483 & 0.8699 & 0.007 & 10.468 \\
\hline PERCMEMB-5 & 0.3596 & 0.4580 & 0.432 & 1.433 \\
\hline MAINPROD & 1.5091 & 0.7200 & 0.036 & 4.522 \\
\hline NUMBPROD & 0.1903 & 0.2038 & 0.350 & 1.210 \\
\hline Constant & -2.3175 & 0.8787 & 0.008 & \\
\hline Log Likelihood & -93.722646 & & \\
\hline Overall Model fit & 19.11 & & \\
\hline LR chi ${ }^{2}$ & 0.0018 & & \\
\hline Prob $>$ chi ${ }^{2}$ & 0.0925 & & \\
\hline Pseudo R ${ }^{2}$ & $60.00 \%$ & & \\
\hline Sensitivity & $62.16 \%$ & & \\
\hline Specificity & $61.07 \%$ \\
\hline Correctly classified & 0.6854 & & \\
\hline Area under ROC curve & & & \\
\hline
\end{tabular}


Results of this logistic regression (Table 21) suggest that the probability that board members are either medium or large farmers is positively, and strongly $(1 \%)$ statistical significant ( $P$ value $=0.007)$ related to PERCMEMB-4. This result suggests, as expected, that probability that board members are either medium or large farmers is related to whether the cooperative has a level of heterogeneity category 4 (i.e., when the cooperative has one majority party and one large minority of percentage of members who deliver each product). The magnitude of the change in probability due to PERCMEMB-4 is the following: when the variable PERCMEMB-4 increases by one point, the odds that the probability that the board member is either medium or large increases by $947 \%$.

Table 22- Logistic regression using data from grouping heterogeneity measurement (PERCVOL)

\begin{tabular}{|c|c|c|c|c|}
\hline \multicolumn{5}{|c|}{ Dependent variable: Probability board member is either medium or large volume deliver (y) } \\
\hline \multicolumn{5}{|c|}{ Number of observations: 149} \\
\hline Variable & Coef. & Std. Err. & $P>|z|$ & Odds Ratio \\
\hline PERCVOL-2 & -0.9954 & 0.4897 & 0.042 & 0.370 \\
\hline PERCVOL-3 & -1.6446 & 0.5133 & 0.001 & 0.193 \\
\hline PERCVOL-4 & 0.5925 & 0.5727 & 0.301 & 1.808 \\
\hline MAINPROD & 0.7795 & 0.7580 & 0.304 & 2.180 \\
\hline NUMBPROD & 0.5642 & 0.2439 & 0.021 & 1.758 \\
\hline Constant & -1.5505 & 0.7986 & 0.052 & \\
\hline Log Likelihood & \multicolumn{4}{|l|}{-89.048316} \\
\hline \multicolumn{5}{|l|}{ Overall Model fit } \\
\hline$L R$ chi $^{2}$ & \multicolumn{4}{|l|}{28.45} \\
\hline Prob $>c h i^{2}$ & \multicolumn{4}{|l|}{0.0000} \\
\hline Pseudo $R^{2}$ & \multicolumn{4}{|l|}{0.1378} \\
\hline Sensitivity & \multicolumn{4}{|l|}{$64.00 \%$} \\
\hline Specificity & \multicolumn{4}{|l|}{$72.97 \%$} \\
\hline Correctly classified & \multicolumn{4}{|l|}{$68.46 \%$} \\
\hline Area under ROC curve & \multicolumn{4}{|l|}{0.7398} \\
\hline
\end{tabular}

Results of this logistic regression (Table 22) suggest that the probability that board members are either medium or large farmers is negatively related to heterogeneity in terms of PERCVOL-2 and PERCVOL-3, with statistical significance at 5\% $(P$ value $=0.042)$ and at $1 \%(P$ value $=$ 0.001 ), respectively. Contrary to what the proposition suggest, this result indicates that the more the value of this variable decreases (when there is one bargaining group, $\mathrm{LF}<50 \%$, and either a small or a significant minority, $0<\mathrm{MF}<25 \%$ ), the higher the probability that medium and large farmers participate in the board of directors. 


\section{Discussion}

We have estimated 3 logistic regressions (Tables 20-22) to examine the (grouping) heterogeneity determinants of the probability that board members are either medium or large farmers. Each of these logistic regressions compared the probability that board members are either medium or large farmers with one heterogeneity variable (PERCPROD, PERCMEMB, PERCVOL) and the control variables (MAINPROD, NUMBPROD). In the first model (Table 20), all the dummies used for PERCPROD did not show significance. In the second model (Table 21), one dummy used for PERCMEMB (PERCMEMB-4) was found significant at 1\%. In the third model (Table 22), two dummies used for PERCVOL (PERCVOL-2 and PERCVOL-3) were found significant at $5 \%$ and $1 \%$, respectively, but inversely related. Therefore, the second model was the one which the predictors better explained the dependent variable. So, PERCMEMB-4 is good predictor to explain the probability that board members are either medium or large volume deliver.

\subsection{Conclusion}

A challenge cooperatives face is to minimize decision making costs. This study has examined the relationship between two aspects of cooperatives that affect the ability with which they can minimize democratic and agency costs: the level of heterogeneity and the level of member participation in cooperative governance. These two variables play a very relevant role in this thesis. A heterogeneity measurement model that ranks cooperatives from homogeneous to heterogeneous taking into account both cooperatives and members characteristics has been developed in the first part of the study by means of theory building research (EISENHARDT, 1989).

Following scholars from biological science (e.g., ROTH, 1976) who use the coefficient of variation as a measurement of diversity we have examined the $\mathrm{CV}$ as a heterogeneity measurement model. This model was found to be of only limited use because it does not provide a satisfactory measurement of heterogeneity in a democratic environment. For instance, it has 
classified some cooperatives as less heterogeneous and others as more heterogeneous when, in fact, should be the other way around. Therefore, another rational was applied.

A proposed measurement of heterogeneity based on grouping, with the aim of showing the presence (absence) of a dominant group and the size of the minority group(s), was developed in the study. Cooperatives are collective and democratic firms. It means that they share the same benefits amongst different member-patrons. As a consequence, it is likely that there will be groups of members with different characteristics conflicting with each other in the decision making process. As a result, it is important that the presence (absence) of a dominant group and the size of the minority group(s) - regarding each of the members' and cooperatives' characteristics - be observed more than the variability of these data.

In the second part of the chapter, we examined whether heterogeneity matters for member participation in cooperative governance. In other words, we examined whether members from more heterogeneous cooperatives participate more in the governance than members from more homogenous ones. The research question that led the present study has been the following: What is the relation between level of heterogeneity and level of member participation in the governance of agricultural cooperatives? In order to answer this question, we have developed two propositions, based on previous studies (e.g., STAATZ, 1987a) and on the results from the grouping measurement of heterogeneity.

The first proposition aimed to examine the relation between level of heterogeneity and member participation attending general assemblies. It suggested that: When the cooperative is more homogeneous, the level of member participation at the general assembly is low. When the level of heterogeneity increases, the level of member participation at the general assembly increases. When the cooperative reaches certain level of heterogeneity (without a dominant group) the level of member participation at the general assembly decreases. In examining this relation by means of the CV heterogeneity measurement, a positive relation, as expected, was found. The degree of correlation found between the heterogeneity variables and the dependent variable was either moderate (CV_PERCVOL), or good (CV_PERCPROD, CV_PERCMEMB), or very good (CV_AVERAGE). 
With regard to the grouping measurement of heterogeneity, most of the heterogeneity variables (PERCPROD, PERCMEMB, AVERAGE) supported the relation suggested by proposition 1 . The degree of correlation found between the heterogeneity variables and the dependent variable was either weak (PERCMEMB), or moderate (PERCPROD, AVERAGE).

The second proposition aimed to examine the relation between level of heterogeneity and member participation at the board of directors. It suggested that: The more the level of heterogeneity (e.g., in terms of volume) increases, the more medium and large farmers participate in the board of directors. We have estimated 4 logistic regressions to examine the $(C V)$ heterogeneity determinants of the probability that board members are either medium or large farmers. Each of these logistic regressions examined whether the probability that board members are either medium or large farmers is related to one alternative heterogeneity variable (CV_PERCPROD, CV_PERCMEMB，CV_PERCVOL，CV_AVERAGE) and the control variables (MAINPROD, NUMBPROD). In the first model, the predictor variable (CV_PERCPROD) was not found related. In the second model, the predictor variable (CV_PERCMEMB) was found significant at 5\%. The predictor variables of the third (CV_PERCVOL) and fourth models (CV_AVERAGE) were both found significant at $1 \%$. However, we have found strong correlation between them. Since CV_AVERAGE is the mean of the other two variables (CV_PERCPROD, CV_PERCMEMB) and also CV_PERCVOL, we can conclude that CV_PERCVOL is influencing the good fit of CV_AVERAGE.

We have estimated 3 logistic regressions to examine the (grouping) heterogeneity determinants of the probability that board members are either medium or large farmers. Each of these logistic regressions examined whether the probability that board members are either medium or large farmers is related to one alternative heterogeneity variable (PERCPROD, PERCMEMB, PERCVOL) and the control variables (MAINPROD, NUMBPROD). In the first model, all the dummies for PERCPROD were not found significant. In the second model, one dummy for PERCMEMB (PERCMEMB-4) was found significant at 1\%. In the third model, two dummies for PERCVOL (PERCVOL-2 and PERCVOL-3) were found inversely related. Therefore, the second model was the one which the predictors better explained the dependent variable. 
As a result, the second proposition has been also accepted, i.e., higher levels of heterogeneity do play a role in the probability of medium and large farmers participating more in cooperative governance than smallholders. Looking to all of the 7 logistic regressions, two variables (one related to cooperatives' characteristics and another related to members' characteristics) were found strongly significant to predict the probability that medium and large farmers participate as a board members: (1), levels of cooperative heterogeneity with regard to the size of the largest group of producers $\left(\mathrm{PG}_{1}\right)$ in relation to the size of the minorities $\left(\mathrm{PG}_{2}\right)$ (i.e., the variable PERCMEMB) and also the variable CV_PERCMEMB (i.e., variability of the weights of all groups of members who deliver each product); and (2), variability of the percentages of groups of members who deliver large, medium and small volume of products to the cooperative (i.e., the variable CV_PERCVOL).

\section{Theoretical and methodological contributions}

First, the present study has developed a method, called grouping, for measuring the level of heterogeneity in cooperatives. It is important to measure heterogeneity, because it is a significant source of conflict of interests between members. No previous studies have been identified which have operationalized the concept of heterogeneity.

Second, the present study has contributed to insights about how cooperative heterogeneity and level of member of member participation at the general assembly are related. Even though studies examine member participation in cooperative governance, they do not compare differences in member participation between homogeneous and heterogeneous cooperatives. Gaining an accurate picture of this relation is important, because both heterogeneity and member participation are sources of decision making costs. There is not a common view in the literature about the relation between heterogeneity and member participation in cooperative governance. Some studies assume that there is a positive linear relation between member participation and heterogeneity (HANSMANN, 1996; HENDRIKSE; BIJMAN, 2002; KALOGERAS et al, 2009): when heterogeneity increases, members have more incentive to actively participate in the governance of the cooperative. However, other studies (ÖSTERBERG; NILSSON, 2009) state that member participation may decrease as heterogeneity increases, because the cooperative 
becomes to complex to manage. The present thesis postulates that both streams of literature are partially right. Based on the results from the grouping measurement of heterogeneity, a model (see Figure 15) was developed which predicts a non-linear relation between member participation and heterogeneity.

\section{Managerial implications}

The grouping measurement of heterogeneity developed in the present study gives to cooperatives a tool to examine how heterogeneous they are with regard to members' characteristics; how the relative distribution of (economic) power is settle amongst the producer groups; and what potential conflicts of interests exist amongst the groups as a result. Cooperatives should take heterogeneity with regard to members' characteristics into account when designing board composition. Potential conflicts of interest at member level could be mitigated at board of directors' level. 


\subsection{Introduction}

There is a long-running debate in the cooperative literature around the question of whether the democratic control of cooperatives has more advantages than disadvantages. For instance, Österberg and Nilsson (2009) argue that the democratic principle has been a core element of cooperative business since the inception of the cooperative business form. However, according to the authors, member control is becoming increasingly problematic, especially in large cooperatives with diversified business activities and which have large and heterogeneous memberships. Staatz (1987d) and Hendrikse and Veerman (2001) argue that democratic control of cooperatives by its members also has benefits, as it can lead to more informed decisions.

Following this debate, a more specific issue that cooperative scholars (e.g., BIRCHALL; SIMMONS, 2004b) discuss is whether democratic control is compatible with market efficiency or whether it is a cost that would act as a disadvantage in the long-run. According to Zylbersztajn (1994) and Staatz (1987a), decision making in cooperatives is likely to be a more costly process than do in investor-owned firms. In the view of Staatz (1987a), this is because different types of members of a cooperative (e.g., soya and rice producers) will have conflicting preferences for how the cooperative should set prices and allocate costs. From this perspective, decision making in cooperatives is a more costly process than in investor-owned firms because the cooperative is democratically controlled by members-patrons with heterogeneous interests. Although there is some theoretical discussion about this issue, no empirical research has been done on the costs of the democratic control.

In the present study we aim to discuss and examine the costs of democratic control, an important factor affecting competitiveness of traditional agricultural cooperatives. Following the literature, the main source of democratic costs in agricultural cooperatives is the level of member participation in cooperative governance. There is a view in the literature (e.g. BHUYAN, 2007) that high member participation is essential for cooperative success. This is because members 
participating (actively) in its governance will be more loyal to the cooperative, which is essential for its success (BHUYAN, 2007). Likewise, the negative apathy of members toward their organizations and organizational activities, as reflected by a lower level of member participation, is deemed to impact negatively on the performance of the cooperative (BHUYAN, 2007). Either members that feel ignored by their management (GOODMAN, 1994; WACHENHEIM et al, 2001), or members that lack understanding of some practices of their cooperatives (CROPP et al, 1998), are likely to have a negative attitude towards their cooperatives. However, it is important to note that high member participation does not only bring benefits (and likewise, that lower participation does not always have disadvantages). Increased member participation also carries costs, amongst others because members bring different, potentially conflicting interests to the decision-making process (BIRCHALL; SIMMONS, 2004b).

\section{Research justification}

Since the mid-1980s, the literature on the governance of organizations in general (and also the cooperative literature, e.g., ILIOPOULOS; COOK, 1999; GRIPSRUD; LENVIK; OLSEN, 2000; ILIOPOULOS; HENDRIKSE, 2008) has been enriched by research that focuses on intra-firm transaction costs. Most of these studies, however, have focused only on influence costs, a range of costs that includes certain types of democratic costs (though not all types, see section 3.3 below). We argue that previous research has not taken into account: (1) the importance of democratic costs in cooperative decision making costs; (2) the effect of differences in level of member participation on democratic costs; (3) differences in terms of democratic and influence costs; and (4) differences in terms of democratic and agency costs.

\section{Research question}

The present study aims to bridge this gap in the literature, by discussing and examining democratic costs in agricultural cooperatives, as well as the main (direct) driver of these costs: the level of member participation. More specifically, the study examines the following research question: What is the relation between level of member participation and democratic costs in agricultural cooperatives? 


\subsection{Theoretical framework}

\section{Cooperative's democratic decision making and heterogeneity}

According to Nourse $(1922 ; 1945)$, since the beginning of the cooperative business form there is a perception that democracy is very compatible with the cooperative philosophy of bringing together farmers with a common need (RHODES, 1987). A 'common need', when the first cooperatives in America were set-up at the end of the $19^{\text {th }}$ century, for example, was not to supersede investor-owned processing companies, but rather to improve profits for farmers (NOURSE, 1945). In fact, the main objective of forming cooperatives was to demonstrate to investor-owned firms that farmers could and would process and market their own products jointly, if they did not receive sufficient prices for their products sold to the investor-owned processing firms. Once the prices offered by investor-owned firms improved, cooperatives were subsequent content to maintain 'stand-by' capacity (i.e., to use the treat of vertical integration to keep investor owned firms 'honest'), and focus on their core activity of farming, rather than to obtain a dominating position within the processing industries.

Nowadays, cooperatives are not content with merely keeping 'stand-by capacity'; they frequently grow larger than investor-owned firms through effective market penetration, expansion into new markets, take-over of other businesses, and merge with other cooperatives to obtain dominant positions in processing industries ${ }^{22}$ (BUTLER, 1988; GRAY; BUTLER, 1994; BIRCHAAL; SIMMONS, 2004a). As cooperatives became $\operatorname{larger}^{23}$ and more diverse in their operations, membership becomes increasingly heterogeneous (STAATZ, 1987d). Membership heterogeneity may increase conflicts of interests between members, as traditional cooperatives generate the same benefits (e.g., one vote, price for the commodities delivered) to members with different characteristics (e.g., farm size, farm distance).

\footnotetext{
${ }^{22}$ For example, Danish Crown in the pork industry or Fonterra in the dairy industry.

${ }^{23}$ For instance, according to Kraenzle et al, (2004), size of American cooperatives has increased dramatically during the past 40 years.
} 
Members, thus, have three complementary mechanisms to express dissatisfaction with the decision making process (HIRSHMAN, 1970): exit, voice and disloyalty (the extent to which members do not market their product to the cooperative). According to the analysis of Svendsen (2007), when exit becomes more costly (e.g., because there are few alternative trading partners for farmers), cooperative members will (to a larger degree) have to rely on voice (as disloyalty is often prohibited in the membership contract). As a result, farmers become locked-in to the joint action, what can give rise to non-Pareto optimal outcomes for individual farmer members. 'NonPareto optimal ${ }^{24}$ in that case means that the outcome of a collective decision leaves some farmer members worse off. The challenge for cooperatives, thus, is to build an organization with sufficient cohesion to withstand the disintegrating forces arising out of the conflicting interests of individual (groups of) members (SVENDSEN, 2007).

Rather than cohesion, there is a group of cooperative scholars (e.g., KAARLEHTO, 1955; 1956; OHM, 1956; TRIFON, 1961) who argue that agricultural cooperatives are a coalition of participants (e.g., different groups of farmers, management, board members, input suppliers, lenders, and nonmember customers). Each coalition has his own preferences and consequently pursues different objectives (CONDON, 1987) and participates only as long as benefits outweigh costs of taking part in the collective action (STAATZ, 1987a). Then, "the outcome of a bargaining process is determined by the relative power of different participants in the organization. So the assumption is that the coalition member that can impose his strategy on the coalition will determine the goals and strategies of the cooperative (...)." (SVENDSEN, 2007, p. 117). Authors, who view the cooperative as a coalition, have focused on two important situations in which conflicts could arise: among farmer-members of the cooperative; and between farmermembers and other actors in the cooperative, such as managers (STAATZ, 1987b). The former type of conflict leads to democratic costs, and is the focus of the present chapter. The latter type of conflict leads to agency costs, and is the focus of the next chapter.

\footnotetext{
${ }^{24}$ Pareto-efficiency criteria means attempting to reach solutions where as many as possible are being left in a better position without making anyone else worse off at the lowest costs (MUELLER, 1989). The Pareto-optimal equilibrium is achieved in the market where "individual atoms negotiate with each other until they reach a state of the economy in which one can improve his position without hurting someone else..." (FUROBOTN; RICHTER, 1998).
} 


\section{Cooperative's democratic decision making and level of member participation}

It is argued by cooperative scholars (e.g., GRAY; BUTLER, 1994; BIRCHALL; SIMMONS, 2004a; GORROÑOGOITIA, s. d.; amongst others) that maximum involvement by members in the cooperative decision making process is possible when cooperatives are small in scale and simple in structure. With a small number of members and with cooperative businesses still familiar to them, the general assembly is a collectively means to express the will of the members, by means of the vote (GORROÑOGOITIA, s. d.). In a small cooperative, where it is possible to accommodate the total membership in town-meeting type decision making, member control does not present compromising problems (GRAY; BUTLER, 1994).

However, when a cooperative grows larger in terms of membership and businesses, it becomes difficult to keep active member participation. The individual incentive not to contribute increases in large groups and, the larger the group, the lower the value of a unit of the collective good to each individual is likely to be (OLSON, 1965). Mobilizing individuals may be easier for small groups than large ones (GAVIOUS; MISHARI, 1999). As cooperatives grow into thousands of members, new requirements are placed in order to keep decision making still democratic. All members can hardly ever be assembled at one place and at one time. If they could be assembled, getting member input organized, articulated, and discussed would become extremely awkward and difficult (BUTLER, 1988; GRAY, 1988). When a cooperative has larger membership and its businesses become more complex, general assemblies would take more time than it would be possible to participate (GORROÑOGOITIA, s. d.). Gorroñogoitia (s. d.) argues that, as a result, the general assembly must tend to specialize on the information, presentation of alternatives developed for the projects submitted for approval and voting decision. In addition, pre-general assemblies are created, assembling then smaller groups of members, with the objective of giving didactically more information to members about the projects submitted to voting.

Olson (1965) argues that the larger the number of people who must be coordinated the higher the cost. When the cooperative's managers do try to develop an active membership strategy, this adds costs to the running of the business that investor-owned firms do not incur. This is because members do not have enough incentive to participate once "their ownership stake has little 
monetary value and their individual 'voice' is insignificant" in a large cooperative (BIRCHALL; SIMMONS, 2004c, p. 5).

\section{Differences between decision making processes in cooperatives and investor-owned firm}

Zylbersztajn (1994) argues that decision making in traditional cooperatives is slower and more costly process than do in investor-owned firms because decisions are made not only in the executive level, but also in the general assembly and in the board of directors.

Staatz (1987b) argues that decision making process in agricultural cooperatives is different from decision making process in investor-owned firm's competitors, due to various structural characteristics. First, cooperatives are user-controlled firms. This means that voting power is not proportional to the percentage of equity investment made by investors/members in the cooperative. Rather, voting takes place according to the one-member/one-vote rule. ${ }^{25}$ Second, cooperatives are user-owned firms. That means that members of a cooperative are not only the suppliers of its equity capital, but are also the major users of the firm's services. Third, cooperatives are user-benefited firms, meaning that the net returns from the cooperatives activities are distributed to their members mainly based on their patronage ${ }^{26}$. Cooperatives pay only a strictly limited dividend on equity capital invested in the organization. Furthermore, capital gains are not a major benefit of stock ownership in cooperatives, in contrast to investorowned firms. This is because there is a very limited or nonexistent secondary market for the stock of cooperative firms.

As a result of these characteristics, cooperative members face different incentives to make decisions than do stockholders of investor-owned firm competitors (STAATZ, 1987b). For instance, while price setting decision in an investor-owned firm (i.e., a firm that is not vertically integrated into farming) is a common decision, in a cooperative it is not. Because members of a cooperative who produce or purchase different products will have different preferences for how

\footnotetext{
${ }^{25}$ Or, voting may be proportional to patronage or even stock ownership, but subject to some limit such as restricting any one member from having more than 5 percent of the total votes (STAATZ, 1987b).

${ }^{26}$ Patronage means the volume of product that is transacted between the member and the cooperative.
} 
the cooperative should set prices and allocate costs, price setting and cost allocation become more complicated in a cooperative than in an investor-owned firm (ZUSMAN, 1982; STAATZ, 1987b). The same applies to many other cooperative decisions which affect the distribution of wealth or other benefits among members or constituent groups of the organization. The main decisions are related to: premium for different levels of product quality (e.g., SHAPIRO, 1983), services/inputs to offer to members (e.g., STAATZ, 1987b, HANSMANN, 1996, ILIOPOULOS; COOK, 1999), location of facilities (e.g., STAATZ, 1987b), distribution of surplus (e.g., KALOGERAS et al, 2007), investment in long-term projects (e.g., PORTER; SCULLY, 1987; ILIOPOULOS; COOK, 1999), investment portfolio (e.g., COOK, 1994; ILIOPOULOS; COOK, 1999), incentive payments for managers (e.g., HVIID, 2001), amongst others.

\subsection{Democratic costs}

The concept of democratic costs has been largely ignored by the cooperative literature until now. ${ }^{27}$ Democratic costs are a particular type of decision making costs that agricultural cooperatives incur since they are firms democratically controlled by members-patrons. More specifically, democratic costs are:

(1), the costs resultant from the need of providing incentives for members to participate in the collective decision making process;

(2), the costs resultant from either horizontal or diagonal conflicts of interests amongst members who have to make decisions about how the benefits of (using) the cooperative are distributed amongst them. Horizontal conflicts of interests (i.e., among members) arise when members attempt to collectively make decisions about the distribution of benefits and costs at the general assembly. Diagonal conflicts of interests (i.e., among members and members of the board of

\footnotetext{
27 A possible reason for that can be because democracy is a particular characteristic of cooperatives, and, as the cooperative literature comes mainly from the literature on investor-owned firms, the concept of this cost has been ignored. The little literature that has been developed until now on democratic costs has been made by political scientists who study democratic costs of nations.
} 
directors) arise either when board members do not represent all members groups or when board is overrepresented; and

(3), the costs resultant from the cooperative's attempts to manage these conflicts or to prevent them.

\section{Differences between democratic and other decision making costs incurred by agricultural cooperatives}

It is important to note that democratic costs have a different meaning from both agency and influence costs.

Differences between democratic and agency costs

As is explained earlier in this section, democratic costs are the costs of collective decision making that result from horizontal and diagonal conflicts of interests. In their turn, agency costs are the costs which members (i.e., owners) incur when they delegate control to a manager. Agency costs result from vertical conflicts of interests (i.e., between members and management), i.e., the costs of monitoring the performance and behavior of the management and the costs when management makes decisions which are not in the best interest of members. The difference between diagonal and vertical conflicts of interests needs perhaps some clarification. In the former, the board benefits some member groups at the expense of other groups, and a conflict of interest exists between these groups and the board. In the latter, management benefits itself at the expense of the cooperative (i.e., all member groups), and a conflict of interests exists between all members and management.

\section{Differences between democratic and influence costs}

Influence costs include a range of decision making costs, mainly those related to member (group) informal attempts (e.g., outside meetings) to influence management decision making for their (group) benefit (see MILGROM; ROBERTS, 1990; ILIOPOULOS; COOK, 1999). The concept 
disregards, for example, the costs of collective decision making at the level of the general assembly.

\section{Types of democratic costs}

Both in the horizontal (at the general assembly) and in the diagonal level (at the board of directors), democratic costs may arise in the form of direct and opportunity costs.

\section{Direct democratic costs}

Direct democratic costs are the costs associated with members' time, board and executives' time and salary spent with collective decision making process.

Direct democratic costs at the general assembly are incurred when members communicate and negotiate about what decision to take; e.g., , the costs of cooperative members' time, the costs of executives' salaries and time spent on general (and pre-general) assemblies.

Direct democratic costs at the board of directors are incurred when board members communicate and negotiate about what decision to take, e.g., the salary of board members.

\section{Opportunity democratic costs}

Opportunity democratic costs are the costs associated with delayed decisions (which can result in lost opportunities), or failure to achieve decisions which maximize the benefit of all members.

At the general assembly, they arise in situations such as: (1), when each (group) member attempts to influence the collective decision making process to his (their) own benefit; (2), when uninformed members make wrong or no decisions; and (3), when decision making takes too much time (which can result in lost opportunities).

At the board of directors, they are incurred either when membership is underrepresented, or overrepresented at the board of directors. When membership is underrepresented at the board of 
directors, board members may make uninformed or no decisions or decisions that privilege producer groups who are represented at the board. When membership is overrepresented, board members may take too much time (which can result in lost opportunities) to make decisions.

\section{What affects democratic costs?}

As is explained in the first section, the main source of democratic costs is the level of member participation in cooperative governance. The relation between level of member participation (at the general assembly and at the board of directors) and (direct and opportunity) democratic costs is discussed in this section.

\section{Relation between level of member participation and democratic costs}

\section{$\underline{\text { Relation between level of member participation and direct democratic costs }}$}

\section{Direct democratic costs at the general assembly}

At the general assembly, direct democratic costs are likely to arise when a cooperative increases time spent on general meetings (e.g., pre-general assemblies at different cities, districts, regions). This means an increasing amount of executives' time (and salary), as well as member' time spent on meetings. Also, with an increasing number of (pre)general assemblies, more money is spent on organizing and hosting these meetings.

\section{Direct democratic costs at the board of directors}

At the board of directors, direct democratic costs are likely to arise when a cooperative increases its board size. A larger board means, for example, that salary costs increase. 


\section{Summary}

In other words, a positive relation is likely to exist between level of member participation and democratic costs. Higher levels of member participation $(x)$ increase direct costs of democratic control $(y)$. Figure 24 shows two hypothetical trends in this relation.

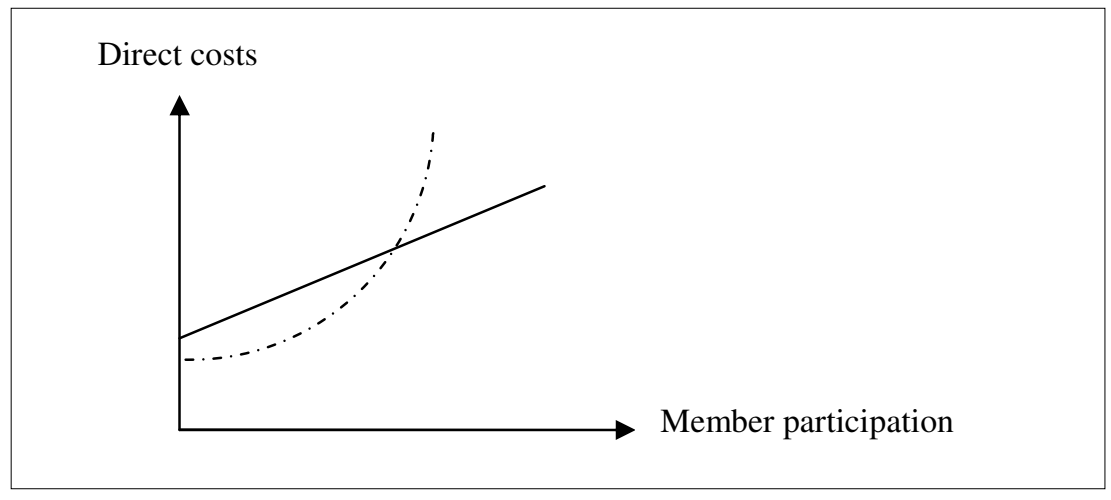

Figure 24 - Hypothetical relations between member participation and direct costs of democratic control

\section{Relation between level of member participation and opportunity democratic costs}

\section{Opportunity democratic costs at the general assembly}

Opportunity democratic costs at the general assembly are likely to arise in situations such as: (1), when each member (or coalition member) attempts to influence the decision making process to his own benefit; (2), when uninformed members make wrong decisions; ${ }^{28}$ and (3), when decision making takes-up too much time (which can result in lost opportunities), i.e., time which members could have spent on their farms, and cooperative executives on planning and managing the cooperative effectively. ${ }^{29}$

\footnotetext{
${ }^{28}$ Birchall (2000) calls the attention to whether member-ownership by producers/customers is an effective means of corporate governance. Condon (1987) observes that member-patrons primary experience is related to farm management and typically have little prior experience in controlling the affairs of a large and complex business enterprise.

${ }^{29}$ Staatz (1987) argues that because much of the time of cooperative manager may be spent on member relations (since members are patrons and users at the same time) these organizations are put at a competitive disadvantage as their managers have less time than investor-owned firm's managers for strategic planning and administration.
} 
Opportunity democratic costs at the board of directors

Opportunity democratic costs at the board of directors are expected to arise when a cooperative has either a too small or too large board.

A board is too small when not all groups of members (e.g., rice producers, dairy producers) are represented (i.e., underrepresented). When not all different member-groups are represented, the board might make uninformed decisions, or decisions which benefit their constituents rather than the cooperative as a whole.

A board is too large when some member-groups are overrepresented. Because membership is overrepresented, decision making is likely to take too much time (which can result in lost opportunities). In general, opportunity costs are likely to increase when board size becomes excessively large, even if interests of the various groups are aligned, because decision making becomes difficult. Mayer (1994) argues that extremely large boards can be cumbersome, slow, and expensive.

\section{Summary}

The relation between member participation and opportunity costs of democratic control is more complex. Figure 25 shows a hypothetical trend in the relation between member participation and opportunity costs of democratic control. With low member participation, i.e., when some member groups are underrepresented $\left(x_{1}\right)$, opportunity costs are likely to be high $\left(y_{2}\right)$, because either uninformed decisions, or decisions which benefit those few members who are participating in the decision making process will be taken. Therefore, increased member participation until all groups are (proportionally) represented $\left(x_{2}\right)$ is likely to reduce opportunity costs $\left(y_{1}\right)$. When member participation increases until (some) groups are overrepresented $\left(x_{3}\right)$, the marginal benefits of increased member participation is likely to fall $\left(y_{3}\right)$ because decision making becomes difficult. 


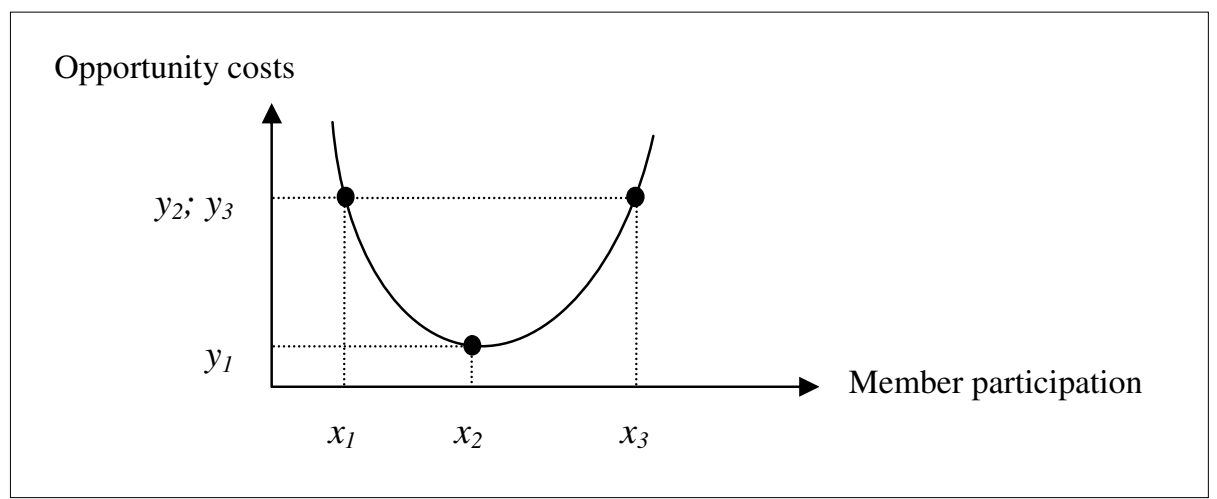

Figure 25 - Hypothetical relation between member participation and opportunity costs of democratic control

\section{$\underline{\text { Relation between level of member participation and total democratic cost }}$}

Rather than controlling either direct or opportunity costs of democratic control, cooperatives should attempt to control them both; i.e., they should attempt to reduce total democratic costs. Total cost results from the combination of direct and opportunity costs which cooperatives incur in dealing with democratic control. The relation between member participation and total cost of democratic control (i.e., direct and opportunity costs) therefore depends on the relative weight of direct and opportunity costs in total costs. When direct costs are relatively more important, increased member participation is unlikely to bring much benefit, as total costs of democratic control will rise as a result. When opportunity costs are relatively more important, cooperatives will have more scope to increase member participation, at least when member participation is low, in order to reduce total cost of democratic control.

Regardless of the relative importance of the two types of costs, when member participation is low, increased member participation is likely to reduce total costs, at least initially, if the increase in direct costs is off-set by a reduction in opportunity costs. When member participation is already high, increased member participation is likely to increase total costs, as the increase in direct costs cannot be off-set anymore by a decrease in opportunity costs. ${ }^{30}$ Figure 26 shows two hypothetical trends in the relation between member participation and total costs of democratic control.

\footnotetext{
${ }^{30}$ As is explained in the previously, when member participation reaches a certain level, the marginal benefit of increased member participation in reducing opportunity costs is likely to fall.
} 


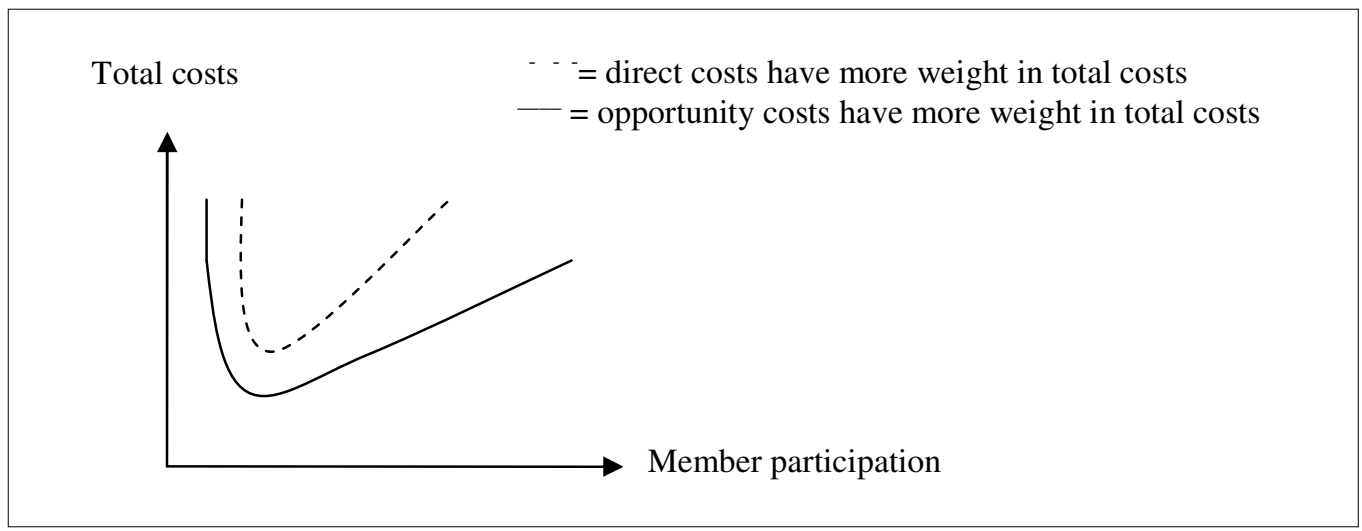

Figure 26 - Hypothetical relations between member participation and total costs of democratic control

\section{How much participation is needed at the general assembly?}

In order to economize on democratic costs at general assemblies, large-scale cooperatives do not need 'mass' participation. Rather, as Birchall and Simmons (2004c) argue, they do need to identify which groups are underrepresented and mobilize them to participate. According to Birchall and Simmons (2004c), cooperatives need to target three types of members. First, they need to target a group of 'true believers' who can be persuaded to be trained as potential board members. Second, they need to target a group of members who can be formed into a kind of 'supporters club' who believe in the aims of the organization and will participate through voting or attending annual meetings or social events. Third, they need to target a group of those who believe vaguely in the ethos of the organization, will not participate, but want to be kept informed and to have their views canvassed occasionally.

\section{How much participation is needed at the board of directors?}

In order to economize on democratic costs at the board of directors, cooperatives need to set a board of directors' size that represents interests of particular segments of the membership. Gray and Butler (1994) suggest that the greater the diversity in membership (large numbers of dissimilar characteristics), so does the need for representation. They argue that there are many possibilities to divide membership: by geographic districts; by type of farming operation; by size of farming operation. According to Gray and Butler (1994), all of these divisions account for member diversity. 


\subsection{Propositions}

Since there are two types of member participation in cooperative governance that are of interest of the present study, two categories of propositions have been developed: (1), with regard to member participation at the general assembly (see propositions 1 and 2); and (2), with regard to member participation at the board of directors (see propositions 3, 4 and 5).

Proposition 1 (relation between level of member participation at the general assembly and direct democratic costs):

The higher is the level of member participation at the general assembly, the higher are the direct democratic costs.

Proposition 2 (relation between level of member participation at the general assembly and opportunity democratic costs) (see Figure 25):

When the level of member participation at the general assembly is low $\left(x_{1}\right)$, the more likely the cooperative is to incur opportunity costs of underrepresentation $\left(y_{2}\right)$. When the level of member participation at the general assembly increases until all (groups of) members are (proportionally) represented $\left(x_{2}\right)$, opportunity democratic costs are likely to decrease $\left(y_{1}\right)$. When the level of member participation at the general assembly is high $\left(x_{3}\right)$, the more likely the cooperative is to incur opportunity costs of overrepresentation $\left(y_{3}\right)$.

Proposition 3 (relation between level of member participation in the board of directors and direct democratic costs):

The larger is the board of directors, the higher are the direct democratic costs at the board of directors. 
Proposition 4 (relation between level of member participation in the board of directors and opportunity democratic costs with regard to underrepresentation):

Smaller boards are more likely than larger boards to incur opportunity costs of underrepresentation.

Proposition 5 (relation between level of member participation in the board of directors and opportunity democratic costs with regard to overrepresentation):

Larger boards are more likely than smaller boards to incur opportunity costs of overrepresentation.

\subsection{Research design}

The unit of analysis of the study is the cooperative. The study examines twelve agricultural cooperatives. The objective of the analysis is to identify differences in level of member participation and democratic costs across cooperatives.

\section{Selection of cases}

For this study, twelve cases from the Brazilian state of Rio Grande do Sul have been selected. Rio Grande do Sul (RS) has been the selected location for this study because it has a rich variety of small and large memberships and small and large boards of directors. Furthermore, in RS one can find large differences in cooperatives with regard to the number of products they receive, and number of regions (cities) in which they hold nucleus meeting. Differences in these attributes are likely to lead to differences in democratic costs across the cooperatives. 


\section{Data gathering method}

For the study, semi-structured interviews have been held both with elected and hired executive managers at all 12 cooperatives. Therefore, a total of 24 interviews have been held between July and August-2010 and on December-2010. The interviews have been conducted by means of personal visits. Besides semi-structured interviews with management, also open interviews with experts have been conducted in order to obtain background information about the cooperatives. In total 6 experts have been interviewed on July-2010. The protocol used for the semi-structured interviews is given in Appendix 1.

\section{Research concepts and variables}

Based on the literature review we can distinguish between two types of member participation in cooperative governance: (1), member participation at the general assembly; and (2), member participation at the board of directors. Furthermore, we can distinguish between two types of democratic costs: (1), direct democratic costs; and (2), opportunity democratic costs (with regard to under and overrepresentation). The proxies we have used to measure these concepts (i.e., the operationalisation of these concepts) are outlined in this section.

Member participation at general assembly: This variable is measured by examining 'percentage of member participation at pre-general assemblies'.

Direct costs at the general assembly: Direct democratic costs at the general assembly arise when a cooperative increases the time, money or other resources spent on general assemblies. For example, a cooperative increases time with general assemblies by creating nucleuses of members (at different cities where the cooperatives members come from) and, as a consequence, nucleuses assemblies in order to help member participation in the decision making process. The study uses 'number of members per nucleus' as proxy for direct costs at the general assembly. A low score on this ratio, relative to other cooperatives, is an indicator that the cooperative has high democratic costs, because it spends a lot of resources (per member) organizing meetings (i.e., it will have fewer members per nucleus than other cooperatives). 
Opportunity costs at general assembly: Opportunity democratic costs at the general assembly arise when membership is either under or overrepresented at the general assembly (and also pregeneral assembly). When membership is underrepresented (i.e., not members from all cities or members who produce all products the cooperative receives are present), for example, members who are present may make either wrong (e.g., uniformed) or decisions that benefit themselves in spite of the membership as a whole. On the other hand, when membership is overrepresented at the general assembly, decision making process may take too much time and, as a consequence, decisions may be frequently delayed (which can result in lost opportunities). As proxy for under and overrepresentation, the study uses the ratio 'number of nucleuses per cities from where cooperative members come from'. The ratio signifies the number of nucleuses locations per city. A ratio lower than one is an indicator for underrepresentation, i.e., when a city has no location for a meeting, it suggests that the city is underrepresented in the decision making process. A ratio higher than one is an indicator for overrepresentation.

Member participation at the board of directors: 'Board size' is used as proxy for member participation at the board of directors. Larger boards signify higher member participation at the board of directors.

Direct costs at the board of directors: 'Total board salary per year' is used as proxy for direct democratic costs at the board of directors. The salary of all board members (excluding the executive board) is summed up to determine salary costs. Larger boards do not necessary include higher total salary costs; cooperatives could reduce average salary per board member as they increase board size.

Opportunity costs at the board of directors - underrepresentation: When membership is underrepresented at the board of directors, board members may make uninformed decisions with regard to issues that belong to member groups who are not represented. By doing so, the cooperative incurs opportunity democratic costs at the board of directors with regard to underrepresentation. Although there is a number of variables that can be used (e.g., by geographic districts, by size of farming operations, by product, etc.), this study uses the 'number of different products a cooperative receives' to characterize cooperative membership. As was explained in the previous chapter, the number of different products a cooperative receives is an 
important source for conflicts of interests. To reduce these conflicts and improve cooperative decision making, all products the cooperative receives should be represented at the board of directors by (at least) one board member (i.e., one of the board members should produce this product). When this is not the case, membership is underrepresented at the board. This is the 'absolute rule for board representation', that is used in this study as proxy for opportunity democratic costs at the board of directors, with regard to underrepresentation.

Opportunity costs at the board of directors - overrepresentation: When membership is overrepresented at the board of directors, decision making process at the board may take more time than a smaller board would do (which can result in lost opportunities). This is because the more members than it is necessary the board has, the more conflicts of interests are likely to arise in the decision making process. By doing so, the cooperative incurs in opportunity democratic costs at the board of directors with regard to overrepresentation. As with opportunity costs associated with underrepresentation, the number of different products a cooperative receives is used here to characterize cooperative membership. However, unlike the absolute rule outlined above, proportional board representation is used to analyze opportunity costs associated with overrepresentation. According to the 'proportional rule', products should be represented at the board in the same proportion that they are represented in the annual sales of the cooperative. Overrepresentation occurs when a product has higher proportional representation at the board, than its share of the annual revenues justifies (e.g., , rice producers are responsible for generating $30 \%$ of the cooperative revenues, but deliver 8 out of 10 board members). A supplement to this rule is necessary to use it in practice. Board members frequently produce two or more products. Which product does such a board member represent? According to the proportional rule, a board member who produces two types of products has half a representation for each product (and a member who produces three has one third, and so on).

Table 23 gives an overview of the operationalisation of the study's key concepts. 
Table 23 - Operationalisation of the main concepts of the research

\begin{tabular}{|c|c|c|c|}
\hline Category & Variable & Proxy & Meaning \\
\hline \multirow[t]{2}{*}{ Member participation } & $\begin{array}{l}\text { Member participation at the } \\
\text { general assembly }\end{array}$ & $\begin{array}{l}\text { Percentage of member } \\
\text { participation at pre-general } \\
\text { assemblies }\end{array}$ & $\begin{array}{l}\text { High participation at pre- } \\
\text { general assemblies is an } \\
\text { indicator for high member } \\
\text { participation }\end{array}$ \\
\hline & $\begin{array}{l}\text { Member participation at the } \\
\text { board of directors }\end{array}$ & Board size & $\begin{array}{l}\text { Large board is an indicator } \\
\text { for high board participation }\end{array}$ \\
\hline \multirow{2}{*}{$\begin{array}{l}\text { Democratic costs at } \\
\text { the general assembly }\end{array}$} & $\begin{array}{l}\text { Direct democratic costs at the } \\
\text { general assembly }\end{array}$ & $\begin{array}{l}\text { Number of members per } \\
\text { nucleus }\end{array}$ & $\begin{array}{l}\text { A low score on this ratio is } \\
\text { an indicator that the } \\
\text { cooperative has high direct } \\
\text { costs of democratic control }\end{array}$ \\
\hline & $\begin{array}{l}\text { Opportunity democratic costs } \\
\text { at the general assembly }\end{array}$ & $\begin{array}{l}\text { Number of nucleuses } \\
\text { locations per city }\end{array}$ & $\begin{array}{l}\text { A ratio lower than one is an } \\
\text { indicator for } \\
\text { underrepresentation }\end{array}$ \\
\hline \multirow{3}{*}{$\begin{array}{l}\text { Democratic costs at } \\
\text { the board of directors }\end{array}$} & $\begin{array}{l}\text { Direct democratic costs at the } \\
\text { board of directors }\end{array}$ & $\begin{array}{l}\text { Total board salary costs per } \\
\text { cooperative per year }\end{array}$ & $\begin{array}{l}\text { Higher salary costs is an } \\
\text { indicator for higher direct } \\
\text { costs of democratic control }\end{array}$ \\
\hline & $\begin{array}{l}\text { Opportunity democratic costs } \\
\text { at the board of directors } \\
\text { related to underrepresentation }\end{array}$ & $\begin{array}{l}\text { Absolute rule: all products } \\
\text { the cooperative receives } \\
\text { should be represented at } \\
\text { the board by at least one } \\
\text { board member }\end{array}$ & $\begin{array}{l}\text { If not all products are } \\
\text { represented at the board, } \\
\text { this is an indicator for } \\
\text { opportunity costs related to } \\
\text { underrepresentation }\end{array}$ \\
\hline & $\begin{array}{l}\text { Opportunity democratic costs } \\
\text { at the board of directors } \\
\text { related to overrepresentation }\end{array}$ & $\begin{array}{l}\text { Proportional rule: products } \\
\text { should be represented at } \\
\text { the board in the same } \\
\text { proportion they are } \\
\text { represented in the annual } \\
\text { sales of the cooperative }\end{array}$ & $\begin{array}{l}\text { If a product has higher } \\
\text { proportional representation } \\
\text { in the board than its share } \\
\text { of the revenues justifies, } \\
\text { this is an indicator for } \\
\text { opportunity costs related to } \\
\text { overrepresentation }\end{array}$ \\
\hline
\end{tabular}

\section{Rules for validation of propositions}

Table 24 shows under which conditions the propositions will be validated. 
Table 24 - Rules for validation of propositions

\begin{tabular}{|c|c|c|}
\hline \multirow{2}{*}{ Propositions } & \multicolumn{2}{|c|}{ When are the propositions validated? } \\
\hline & Independent variables (proxies) & Dependent variables (proxies) \\
\hline $\begin{array}{l}\text { 1: The higher is the level of member } \\
\text { participation at the general } \\
\text { assembly, the higher are the direct } \\
\text { democratic costs. }\end{array}$ & $\begin{array}{l}\text { The cooperative has high (low) } \\
\text { proportional member participation at } \\
\text { pre-general assemblies relative to } \\
\text { other cooperatives }\end{array}$ & $\begin{array}{l}\text { The cooperative has low (high) } \\
\text { number of members per nucleus } \\
\text { relative to other cooperatives }\end{array}$ \\
\hline $\begin{array}{l}\text { 2: When the level of member } \\
\text { participation at the general } \\
\text { assembly is low, the more likely the } \\
\text { cooperative is to incur opportunity } \\
\text { costs of underrepresentation. }\end{array}$ & $\begin{array}{l}\text { The cooperative has low } \\
\text { participation at the pre-general } \\
\text { assembly relative to other } \\
\text { cooperatives }\end{array}$ & $\begin{array}{l}\text { The cooperative has less than one } \\
\text { nucleus location per city }\end{array}$ \\
\hline $\begin{array}{l}\text { When the level of member } \\
\text { participation at the general } \\
\text { assembly increases until all (groups } \\
\text { of) members are (proportionally) } \\
\text { represented, opportunity democratic } \\
\text { costs are likely to decrease. }\end{array}$ & & \\
\hline $\begin{array}{l}\text { When the level of member } \\
\text { participation at the general } \\
\text { assembly is high, the more likely the } \\
\text { cooperative is to incur opportunity } \\
\text { costs of overrepresentation. }\end{array}$ & $\begin{array}{l}\text { The cooperative has high } \\
\text { participation at the pre-general } \\
\text { assembly relative to other } \\
\text { cooperatives }\end{array}$ & $\begin{array}{l}\text { The cooperative has more than one } \\
\text { nucleus location per city }\end{array}$ \\
\hline $\begin{array}{l}\text { 3: The larger is the board of } \\
\text { directors, the higher are the direct } \\
\text { democratic costs at the board of } \\
\text { directors. }\end{array}$ & $\begin{array}{l}\text { The cooperative has a large board } \\
\text { relative to other cooperatives }\end{array}$ & $\begin{array}{l}\text { The cooperative has higher total } \\
\text { salary costs }\end{array}$ \\
\hline $\begin{array}{l}\text { 4: Smaller boards are more likely } \\
\text { than larger boards to incur } \\
\text { opportunity costs of } \\
\text { underrepresentation. }\end{array}$ & $\begin{array}{l}\text { The cooperative has a small board } \\
\text { relative to other cooperatives }\end{array}$ & $\begin{array}{l}\text { Not all products received by the } \\
\text { cooperative are represented at the } \\
\text { board of directors }\end{array}$ \\
\hline $\begin{array}{l}\text { 5: Larger boards are more likely } \\
\text { than smaller boards to incur } \\
\text { opportunity costs of } \\
\text { overrepresentation. }\end{array}$ & $\begin{array}{l}\text { The cooperative has a large board } \\
\text { relative to other cooperatives }\end{array}$ & $\begin{array}{l}\text { One or more products the } \\
\text { cooperative receives have a higher } \\
\text { proportional representation in the } \\
\text { board than its/their share of the } \\
\text { revenues justifies }\end{array}$ \\
\hline
\end{tabular}




\subsection{Research results and analysis}

\section{Direct democratic costs at the general assembly}

Table 25 shows the numbers of the researched cooperatives for membership size, number of nucleuses, percentage of member participation at pre-general assemblies, and number of members per nucleus.

Table 25 - Level of member participation and number of members per nucleus in researched cooperatives

\begin{tabular}{c|c|c|c|c}
\hline Cooperative & Membership Size & $\begin{array}{c}\text { Number of } \\
\text { nucleuses }\end{array}$ & $\begin{array}{c}\text { Percentage (i.e., level) } \\
\text { of Member } \\
\text { participation at pre- } \\
\text { general assemblies }\end{array}$ & $\begin{array}{c}\text { Number of members } \\
\text { per nucleus }\end{array}$ \\
\hline COOP-J & 1,125 & 0 & - & - \\
\hline COOP-B & 8,236 & 172 & 6 & 48 \\
\hline COOP-F & 3,760 & 63 & 17 & 201 \\
\hline COOP-E & 4,612 & 23 & 18 & 53 \\
\hline COOP-A & 10,730 & 201 & 18 & 199 \\
\hline COOP-D & 4,776 & 24 & 22 & 167 \\
\hline COOP-H & 3,728 & 14 & 35 & 101 \\
\hline COOP- $L$ & 500 & 3 & 44 & 374 \\
\hline COOP-C & 4,946 & 49 & 47 & 51 \\
\hline COOP- $G$ & 3,743 & 10 & 54 & 121 \\
\hline COOP- $K$ & 1,013 & 20 & 55 & 159 \\
\hline COOP-I & 3,254 & 27 & 32 & 48 \\
\hline Mean & 4,202 & 51 & 1 & 374 \\
\hline Minimum & 500 & 0 & 55 & 61 \\
\hline Maximum & 10,730 & 201 & 6 & \\
\hline
\end{tabular}

The results show that the level of member participation at pre-general assemblies is generally low. For only four cooperatives, COOP-C, COOP-G, COOP-K and COOP-I, does member participation at pre-general assemblies exceeds $40 \%$.

The relation between level (\%) of member participation at pre-general assemblies and number of members per nucleus is presented in Figure 27. 


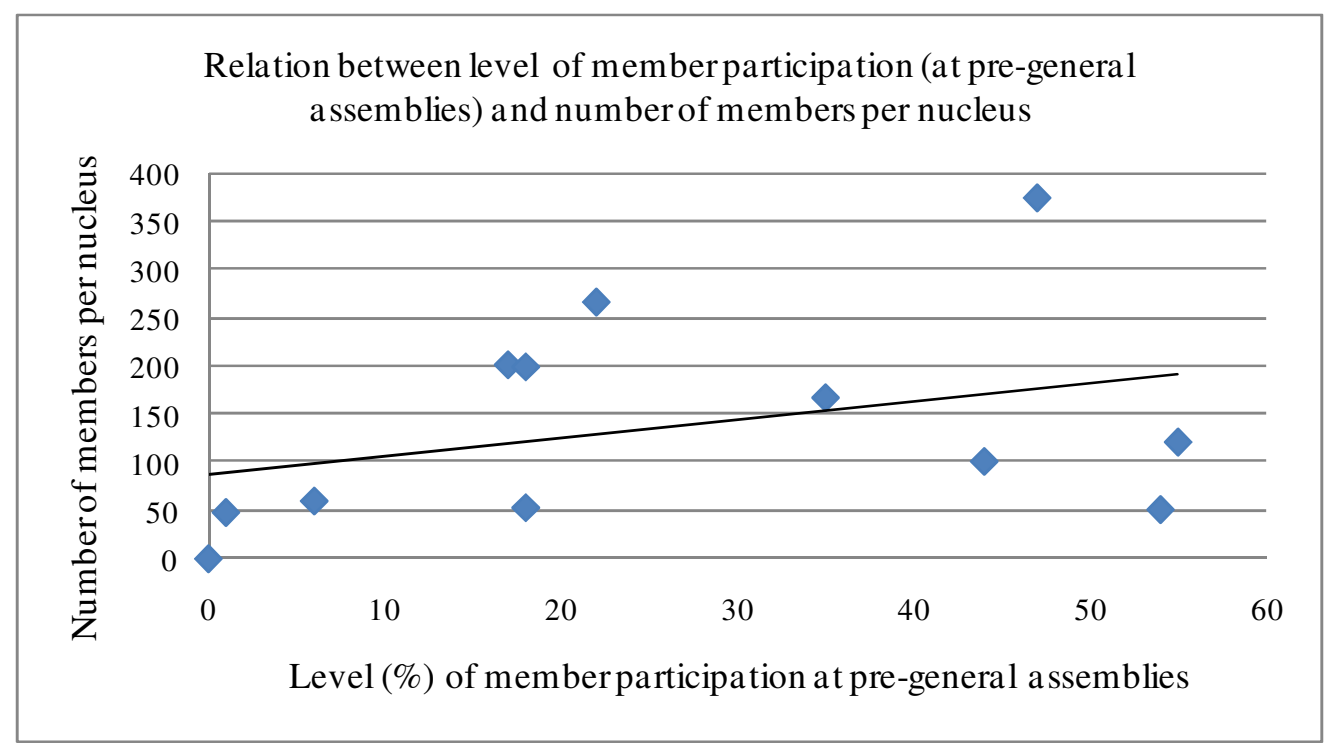

Figure 27 - Relation between percentage of member participation at pre-general assemblies and number of members per nucleus in research cooperatives

The results do not (completely) support the proposition. On the one hand, COOP-K and COOP-I have a high level of member participation and a low number of members per nucleus. Their results support the proposition, because these cooperatives decreased the number of members per nucleus and reached a higher level of member participation.

On the other hand, there are some cooperatives which have a low number of members per nucleus, and a low level of member participation; and also other cooperatives which have a high number of members per nucleus, and a high level of member participation at the general assembly. This means that the former group has created a very high number of nucleuses to help member participation, but have not achieved a high level of member participation at the general assembly. Furthermore, the second group has not created too much nucleuses, but has achieved high level of member participation. This indicates that creating more nucleuses than is necessary (i.e. more than one nucleus meeting per city) makes cooperatives incur higher democratic costs and does not much increasing the level of member participation. 


\section{Opportunity democratic costs at the general assembly}

Table 26 shows the numbers of the researched cooperatives for number of cities, number of nucleuses, percentage of member participation at pre-general assemblies, and number of nucleuses per city.

Table 26 - Level of member participation and number of nucleuses per city in researched cooperatives

\begin{tabular}{|c|c|c|c|c|}
\hline Cooperative & $\begin{array}{l}\text { Number of } \\
\quad \text { cities }\end{array}$ & $\begin{array}{l}\text { Number of } \\
\text { nucleuses }\end{array}$ & $\begin{array}{l}\text { Percentage (i.e., level) } \\
\text { of member participation } \\
\text { at pre-general } \\
\text { assemblies }\end{array}$ & $\begin{array}{c}\text { Number of nucleuses } \\
\text { per city }\end{array}$ \\
\hline COOP-J & 7 & 0 & - & 0 \\
\hline$C O O P-B$ & 23 & 172 & 1 & 7 \\
\hline COOP-F & 6 & 63 & 6 & 11 \\
\hline COOP-E & 5 & 23 & 17 & 5 \\
\hline$C O O P-D$ & 5 & 24 & 18 & 5 \\
\hline COOP-A & 20 & 201 & 18 & 10 \\
\hline СOOP-H & 14 & 14 & 22 & 1 \\
\hline$C O O P-L$ & 4 & 3 & 35 & 0.75 \\
\hline $\mathrm{COOP}-\mathrm{C}$ & 15 & 49 & 44 & 3 \\
\hline$C O O P-G$ & 10 & 10 & 47 & 1 \\
\hline СООР-K & 7 & 20 & 54 & 3 \\
\hline COOP-I & 9 & 27 & 55 & 3 \\
\hline Mean & 10 & 51 & 29 & 4 \\
\hline Minimum & 4 & 0 & 1 & 0 \\
\hline Maximum & 23 & 201 & 55 & 11 \\
\hline
\end{tabular}

Table 26 shows that most cooperatives (COOP-B, COOP-F, COOP-E, COOP-D, COOP-A, COOP-C, COOP-K, COOP-I) do incur opportunity democratic costs at the general assembly related to overrepresentation. This is because they have created a high number of nucleuses per city from where their members come from, in order to help member participation, when one nucleus per city would be already sufficient. On the other hand, COOP-J and COOP-L do incur in opportunity democratic costs at the general assembly related to underrepresentation. COOP-J has members in 7 cities and has not any nucleus. As COOP-J has no nucleuses, the cooperative does not make pre-general assemblies, i.e., all its members are assembled in only one general assembly. This suggest there is some underrepresentation in this cooperative, as it may difficult for some members to attend the (centralized) meeting at the headquarters rather than to attend 
(decentralized) meeting at the local office (i.e. the nucleus). COOP-L has no nucleus in the city where the headquarter of the cooperative is placed. However, the cooperative assembles members from other cities in nucleus meetings. Members from this city have only the opportunity to participate directly in the general assembly. It suggests underrepresentation. Exceptions are COOP-H, and COOP-G which have the optimal number of nucleuses per city. It means that COOP-H and COOP-G do not incur either in opportunity costs related to under nor related to overrepresentation at the general assembly.

Figure 28 shows the relation between level of member participation and number of nucleus per city. A nonlinear relationship between the two variables is shown by means of a scatter plot with a trend line.

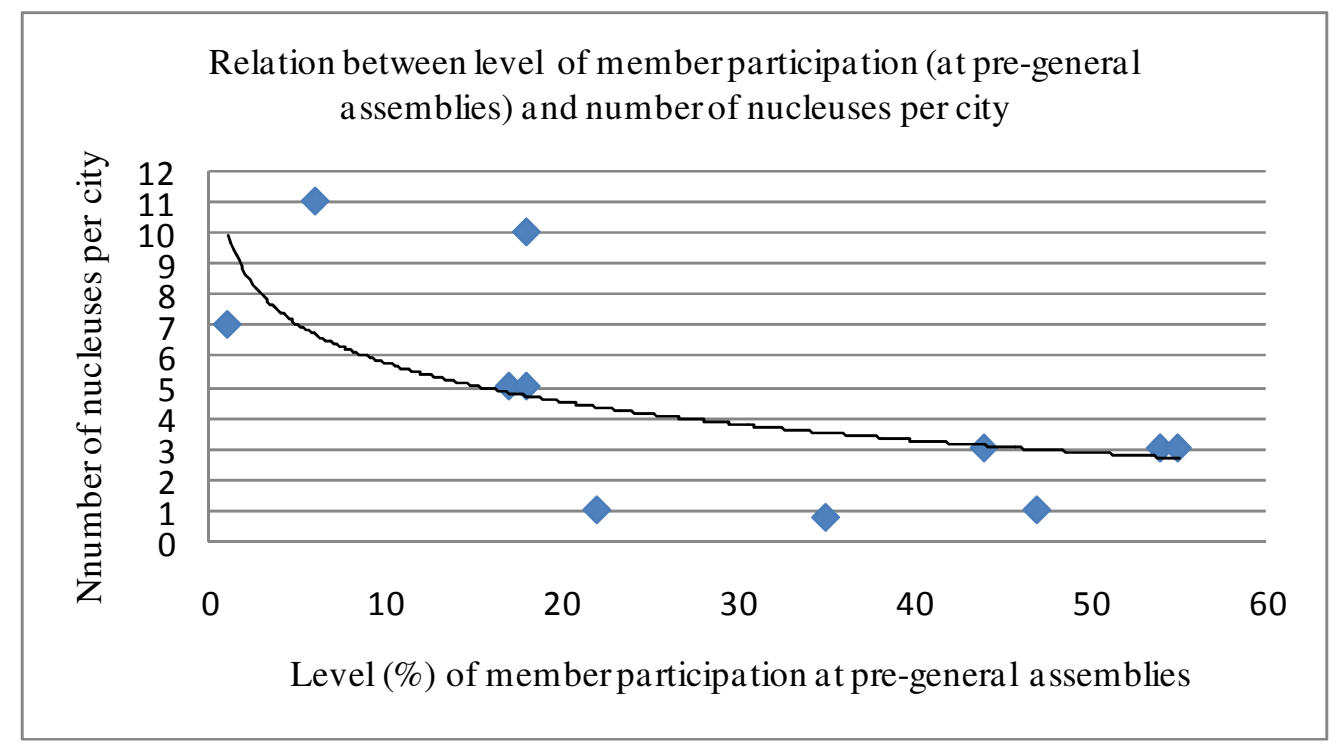

Figure 28 - Relation between percentage of member participation at pre-general assemblies and number of nucleuses per city

A strict interpretation of proposition 2, relating to both under and overrepresentation would suggest that the proposition is not validated. Costs related to underrepresentation meanwhile, do not seem to be related to the level of member participation in the way described in the proposition. This holds particularly true for the downward sloping part of the curve: those cooperatives with the lowest level of member participation have the highest number of nucleuses per city. However, it could be that these particular cooperatives have increased the number of 
nucleuses per city in an attempt to increase member participation. If so, the strategy has clearly not worked.

On the other hand, the results of the cooperatives on the upward sloping part of the curve do seem to support the proposition 2 related to overrepresentation. Those cooperatives with the highest level of member participation also seem to incur costs as they have multiple nucleus locations per city.

\section{Direct democratic costs at the board of directors}

Table 27 presents the numbers of the researched cooperatives with regard to board size, board total salary per year, and salary of one board member per year.

Table 27 - Board size and salary of board members/year in researched cooperatives

\begin{tabular}{|c|c|c|c|}
\hline Cooperative & Board Size & $\begin{array}{c}\text { Board Total Salary/ } \\
\operatorname{Year}(R \$)\end{array}$ & $\begin{array}{c}\text { Salary of one Board } \\
\text { member/Year }(R \$)\end{array}$ \\
\hline COOP-L & 6 & 15,000 & 2,500 \\
\hline$C O O P-F$ & 8 & 29,376 & 3,672 \\
\hline COOP-E & 9 & 65,988 & 7,332 \\
\hline COOP-I & 9 & 65,124 & 7,236 \\
\hline COOP-J & 9 & 72,000 & 8,000 \\
\hline COOP-G & 10 & 61,380 & 6,138 \\
\hline$C O O P-D$ & 12 & 66,000 & 5,500 \\
\hline COOP-H & 12 & 56,880 & 4,740 \\
\hline $\mathrm{COOP}-\mathrm{C}$ & 15 & 65,126 & 4,341 \\
\hline$C O O P-B$ & 19 & 109,200 & 5,747 \\
\hline СООР-A & 20 & 91,780 & 4,589 \\
\hline COOP-K & 20 & 106,827 & 5,341 \\
\hline Mean & 12 & 67,057 & 5,428 \\
\hline Minimum & 6 & 15,000 & 2,500 \\
\hline Maximum & 20 & 109,200 & 8,000 \\
\hline
\end{tabular}

The relation between board size and board total salary per year is shown in Figure 29. 


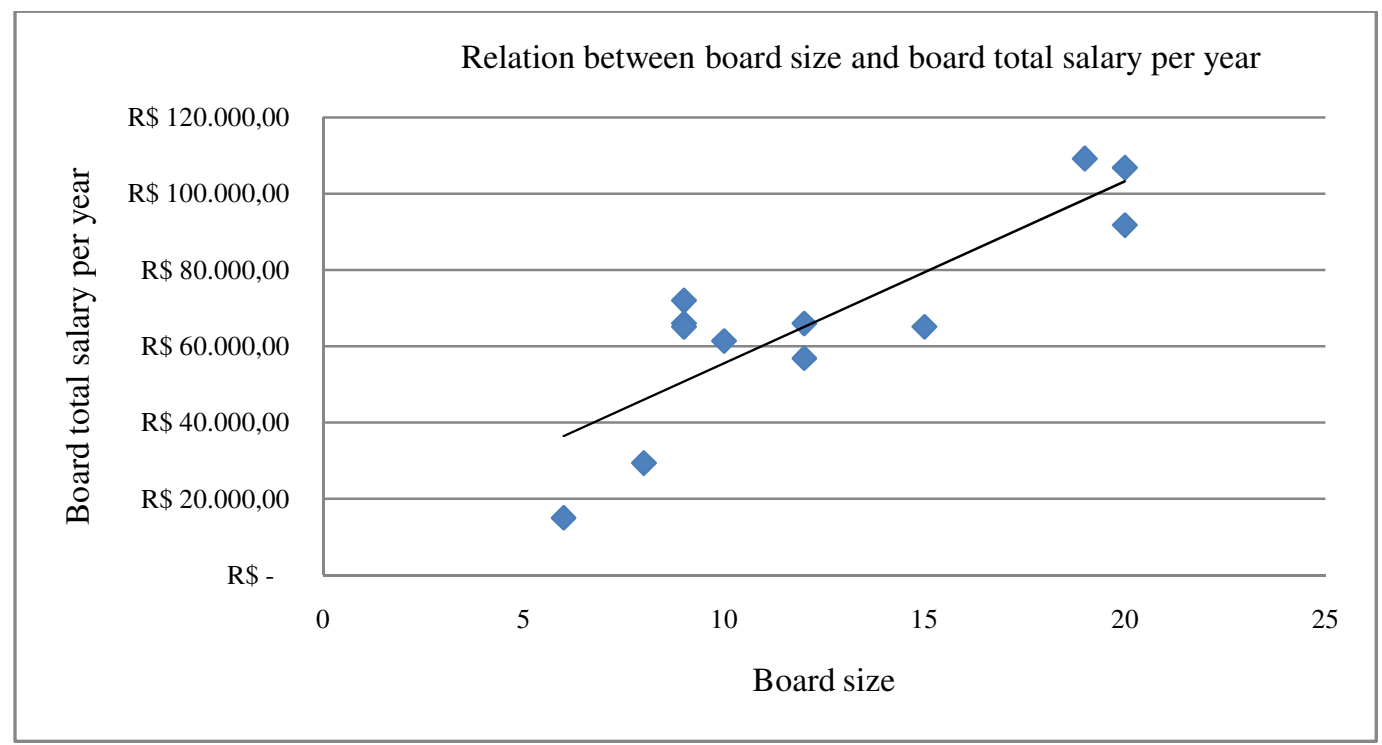

Figure 29 - Relation between board size and board total salary per year

As is shown in Figure 29, board total salary costs increase when board size increases. This is because cooperatives which increase board size do not reduce average salary cost per board member. In fact, the two cooperatives with the smallest board total salary costs, also have the lowest average salary cost per board member. The results clearly support proposition 3, that states that direct democratic costs at the board of directors increase as member participation at the board increases (as measured by board size).

\section{Opportunity democratic costs at the board of directors - underrepresentation}

Table 28 presents the numbers of the researched cooperatives for the products delivered by their board members. Table 29 shows the percentage ${ }^{31}$ that each product represents in the annual revenues of each cooperative.

\footnotetext{
${ }^{31}$ Percentages smaller than 1 were rounded to 1.
} 
Table 28 - Products delivered by board members of researched cooperatives

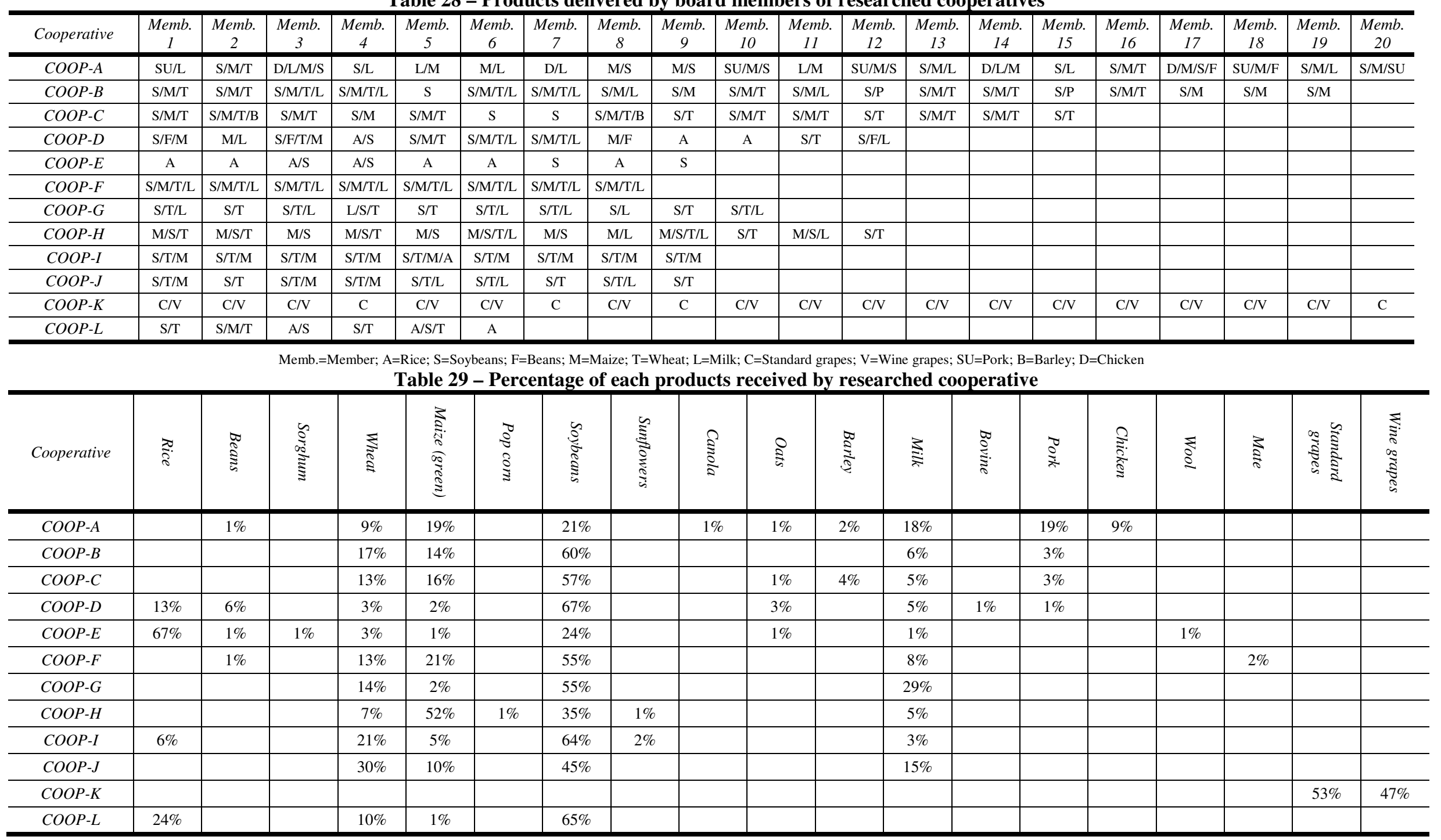


Table 28 shows that most board members deliver multiple products. It can be an advantage for cooperatives because board members delivering multiple products should be more informed about the various market conditions affecting the cooperative than board members delivering a single product. Table 29 shows that most cooperatives have a couple of main products (2-3 products); i.e., products which generate most of their revenues. Furthermore, the figure shows that most cooperatives also receive, besides their main product(s), a lot of 'side-products' (4-6 products) which contribute to their revenues only marginally (1-5\%).

Table 30 presents the board size, number and name of the products received by researched cooperatives, the (absolute) number of board members producing each product, and the analysis of the absolute representation rule for each product of the researched cooperatives.

Table 30 - Opportunity democratic costs at the board of directors (underrepresentation)

\begin{tabular}{|c|c|c|c|}
\hline $\begin{array}{l}\text { Cooperativel } \\
\text { Board size }\end{array}$ & $\begin{array}{c}\text { Number/Name of } \\
\text { products received } \\
\text { by cooperatives }\end{array}$ & $\begin{array}{c}\text { Number of Board Members } \\
\text { producing each product }\end{array}$ & $\begin{array}{c}\text { Absolute rule: each product } \\
\text { the cooperative receives } \\
\text { should be represented by } \\
\text { (at least) one board } \\
\text { member }\end{array}$ \\
\hline \multirow{11}{*}{$\begin{array}{l}\text { COOP-A } \\
(20 \text { Board } \\
\text { members })\end{array}$} & 10 & \multicolumn{2}{|c|}{3 out of 10 products are underrepresented } \\
\hline & Beans & 2 & \\
\hline & Wheat & 2 & \\
\hline & Maize & 16 & \\
\hline & Soybeans & 13 & \\
\hline & Canola & 0 & Underrepresented \\
\hline & Oats & 0 & Underrepresented \\
\hline & Barley & 0 & Underrepresented \\
\hline & Milk & 11 & \\
\hline & Pork & 5 & \\
\hline & Chicken & 4 & \\
\hline \multirow{6}{*}{$\begin{array}{l}\text { COOP-B } \\
\text { (19 Board } \\
\text { members })\end{array}$} & 5 & \multicolumn{2}{|c|}{ No products are underrepresented } \\
\hline & Wheat & 10 & \\
\hline & Maize & 16 & \\
\hline & Soybeans & 19 & \\
\hline & Milk & 6 & \\
\hline & Pork & 2 & \\
\hline
\end{tabular}




\begin{tabular}{|c|c|c|c|}
\hline \multirow{8}{*}{$\begin{array}{l}\text { COOP-C } \\
(15 \text { Board } \\
\text { members })\end{array}$} & 7 & \multicolumn{2}{|c|}{3 out of 7 products are underrepresented } \\
\hline & Wheat & 12 & \\
\hline & Maize & 10 & \\
\hline & Soybeans & 15 & \\
\hline & Oats & 0 & Underrepresented \\
\hline & Barley & 2 & \\
\hline & Milk & 0 & Underrepresented \\
\hline & Pork & 0 & Underrepresented \\
\hline \multirow{10}{*}{$\begin{array}{l}\text { COOP-D } \\
\text { (12 Board } \\
\text { members })\end{array}$} & 9 & \multicolumn{2}{|c|}{3 out of 9 products are underrepresented } \\
\hline & Rice & 3 & \\
\hline & Beans & 4 & \\
\hline & Wheat & 5 & \\
\hline & Maize & 7 & \\
\hline & Soybeans & 8 & \\
\hline & Oats & 0 & Underrepresented \\
\hline & Milk & 4 & \\
\hline & Bovine & 0 & Underrepresented \\
\hline & Pork & 0 & Underrepresented \\
\hline \multirow{10}{*}{$\begin{array}{l}\text { COOP-E } \\
\text { (9 Board } \\
\text { members) }\end{array}$} & 9 & \multicolumn{2}{|c|}{7 out of 9 products are underrepresented } \\
\hline & Rice & 7 & \\
\hline & Beans & 0 & Underrepresented \\
\hline & Sorghum & 0 & Underrepresented \\
\hline & Wheat & 0 & Underrepresented \\
\hline & Maize & 0 & Underrepresented \\
\hline & Soybeans & 4 & \\
\hline & Oats & 0 & Underrepresented \\
\hline & Milk & 0 & Underrepresented \\
\hline & Wool & 0 & Underrepresented \\
\hline \multirow{7}{*}{$\begin{array}{l}\text { COOP-F } \\
\text { (8 Board } \\
\text { members) }\end{array}$} & 6 & \multicolumn{2}{|c|}{2 out of 6 products are underrepresented } \\
\hline & Beans & 0 & Underrepresented \\
\hline & Wheat & 8 & \\
\hline & Maize & 8 & \\
\hline & Soybeans & 8 & \\
\hline & Milk & 8 & \\
\hline & Maté & 0 & Underrepresented \\
\hline
\end{tabular}




\begin{tabular}{|c|c|c|c|}
\hline \multirow{5}{*}{$\begin{array}{l}\text { COOP-G } \\
\text { (10 Board } \\
\text { members) }\end{array}$} & 4 & \multicolumn{2}{|c|}{1 out of 4 products are underrepresented } \\
\hline & Wheat & 9 & \\
\hline & Maize & 0 & Underrepresented \\
\hline & Soybeans & 10 & \\
\hline & Milk & 7 & \\
\hline \multirow{7}{*}{$\begin{array}{l}\text { COOP-H } \\
\text { (12 Board } \\
\text { members })\end{array}$} & 6 & \multicolumn{2}{|c|}{2 out of 6 products are underrepresented } \\
\hline & Wheat & 7 & \\
\hline & Maize & 10 & \\
\hline & Popcorn & 0 & Underrepresented \\
\hline & Soybeans & 10 & \\
\hline & Sunflowers & 0 & Underrepresented \\
\hline & Milk & 4 & \\
\hline \multirow{7}{*}{$\begin{array}{l}\text { COOP-I } \\
\text { (9 Board } \\
\text { members) }\end{array}$} & 6 & \multicolumn{2}{|c|}{2 out of 6 products are underrepresented } \\
\hline & Rice & 1 & \\
\hline & Wheat & 9 & \\
\hline & Maize & 9 & \\
\hline & Soybeans & 9 & \\
\hline & Sunflowers & 0 & Underrepresented \\
\hline & Milk & 0 & Underrepresented \\
\hline \multirow{5}{*}{$\begin{array}{l}\text { COOP-J } \\
\text { (9 Board } \\
\text { members) }\end{array}$} & 4 & \multicolumn{2}{|c|}{ No products are underrepresented } \\
\hline & Wheat & 9 & \\
\hline & Maize & 3 & \\
\hline & Soybeans & 9 & \\
\hline & Milk & 3 & \\
\hline \multirow{3}{*}{$\begin{array}{l}\text { COOP-K } \\
\text { (20 Board } \\
\text { members) }\end{array}$} & 2 & \multicolumn{2}{|c|}{ No products are underrepresented } \\
\hline & Common Grapes & 20 & \\
\hline & Wine Grapes & 16 & \\
\hline \multirow{5}{*}{$\begin{array}{l}\text { COOP-L } \\
\text { (6 Board } \\
\text { members) }\end{array}$} & 4 & \multicolumn{2}{|c|}{ No products are underrepresented } \\
\hline & Rice & 3 & \\
\hline & Wheat & 5 & \\
\hline & Maize & 4 & \\
\hline & Soybeans & 1 & \\
\hline
\end{tabular}

Table 30 shows that, according to the absolute rule of board representation, 8 out of 12 cooperatives have underrepresented boards (i.e., not all products the cooperatives receive are represented at the board). From the 8 cooperatives which the board is underrepresented, 4 of them have small board (considering smaller boards the ones which have less than 12 members) and 4 
of them have large board (considering larger boards the ones which have 12 members or more). As a consequence, the results do not validate proposition 4 .

However, almost all products which are 'underrepresented' at the board of directors are products which contribute only marginally to the cooperatives' revenues. For example, COOP-E has 7 products (out of a total of 9) which are not represented at the board. However, none of the products individually contributes more than $3 \%$ to the revenues, and as a group they contribute only $9 \%$. Unsurprisingly, COOP-E's board is dominated, and in fact completely made-up, of rice and soya producers who together are responsible for $91 \%$ of the cooperative's revenues. COOPE's situation is typical of the other cooperatives that have underrepresentation at the board. This suggests a couple of things.

First, cooperatives should think about whether they want to continue to receive products which contribute little to their revenues. If so, should not these products be better represented at board level, for example by one board member who represents all minority producers? If the minority producers are better represented at the board of directors, perhaps their contribution to cooperative revenues would increase.

Second, the absolute rule is perhaps too harsh in determining underrepresentation (since each product the cooperative receives should be represented by, at least, one board member). Should products which do not contribute significantly to the cooperatives revenues be represented at the board of directors? However, as is outlined earlier, cooperatives can attempt to increase product representation by trying to obtain board members who produce a marginal product besides one of the main products.

\section{Opportunity democratic costs at the board of directors - overrepresentation}

Table 31 gives us both an overview of the products received by the cooperatives (which have percentages in the total revenues of the cooperative higher than 10\%), the percentages that each product represent in the total annual revenues of the cooperative, the proportion of board members who deliver each product, and shows the results for the proportional rule with the conclusion from the rule. 
Table 31 - Opportunity democratic costs at the board of directors (overrepresentation)

\begin{tabular}{|c|c|c|c|c|c|}
\hline $\begin{array}{c}\text { Cooperative } \\
\text { (and number of } \\
\text { board members) }\end{array}$ & $\begin{array}{l}\text { Products received } \\
\text { by the cooperative }\end{array}$ & $\begin{array}{c}\text { Percentage of the } \\
\text { products in the total } \\
\text { annual revenues }\end{array}$ & $\begin{array}{c}\text { Required } \\
\text { representation }\end{array}$ & $\begin{array}{l}\text { Actual } \\
\text { representation }^{3}\end{array}$ & Conclusion \\
\hline \multirow{5}{*}{$\begin{array}{l}\text { COOP-A } \\
(20 \text { Board } \\
\text { members })\end{array}$} & \multicolumn{5}{|c|}{3 out of 4 products are overrepresented } \\
\hline & Maize & $19 \%$ & 4 & 6 & Over \\
\hline & Soybeans & $21 \%$ & 4 & 5 & Over \\
\hline & Milk & $18 \%$ & 4 & 5 & Over \\
\hline & Pork & $19 \%$ & 4 & 2 & \\
\hline \multirow{4}{*}{$\begin{array}{l}\text { COOP-B } \\
\text { (19 Board } \\
\text { members })\end{array}$} & \multicolumn{5}{|c|}{1 out of 3 products are overrepresented } \\
\hline & Wheat & $17 \%$ & 3 & 3 & \\
\hline & Maize & $14 \%$ & 3 & 6 & Over \\
\hline & Soybeans & $60 \%$ & 11 & 7 & \\
\hline \multirow{4}{*}{$\begin{array}{l}\text { COOP-C } \\
\text { (15 Board } \\
\text { members })\end{array}$} & \multicolumn{5}{|c|}{2 out of 3 products are overrepresented } \\
\hline & Wheat & $13 \%$ & 2 & 4 & Over \\
\hline & Maize & $16 \%$ & 2 & 3 & Over \\
\hline & Soybeans & $57 \%$ & 9 & 7 & \\
\hline \multirow{3}{*}{$\begin{array}{l}\text { COOP-D } \\
(12 \text { Board } \\
\text { members })\end{array}$} & \multicolumn{5}{|c|}{1 out of 2 products are overrepresented } \\
\hline & Rice & $13 \%$ & 2 & 3 & Over \\
\hline & Soybeans & $67 \%$ & 8 & 3 & \\
\hline \multirow{3}{*}{$\begin{array}{l}\text { COOP-E } \\
(9 \text { Board } \\
\text { members })\end{array}$} & \multicolumn{5}{|c|}{1 out of 2 products are overrepresented } \\
\hline & Rice & $67 \%$ & 6 & 6 & \\
\hline & Soybeans & $24 \%$ & 2 & 3 & Over \\
\hline \multirow{4}{*}{$\begin{array}{l}\text { COOP-F } \\
(8 \text { Board } \\
\text { members })\end{array}$} & \multicolumn{5}{|c|}{1 out of 3 products are overrepresented } \\
\hline & Wheat & $13 \%$ & 1 & 2 & Over \\
\hline & Maize & $21 \%$ & 2 & 2 & \\
\hline & Soybeans & $55 \%$ & 4 & 2 & \\
\hline \multirow{4}{*}{$\begin{array}{l}\text { COOP-G } \\
\text { (10 Board } \\
\text { members })\end{array}$} & \multicolumn{5}{|c|}{1 out of 3 products are overrepresented } \\
\hline & Wheat & $14 \%$ & 1 & 4 & Over \\
\hline & Soybeans & $55 \%$ & 6 & 4 & \\
\hline & Milk & $29 \%$ & 3 & 3 & \\
\hline \multirow{3}{*}{$\begin{array}{l}\text { COOP-H } \\
\text { (12 Board } \\
\text { members })\end{array}$} & \multicolumn{5}{|c|}{ No products are overrepresented } \\
\hline & Maize & $52 \%$ & 6 & 4 & \\
\hline & Soybeans & $35 \%$ & 4 & 4 & \\
\hline \multirow{3}{*}{$\begin{array}{l}\text { COOP-I } \\
(9 \text { Board } \\
\text { members })\end{array}$} & \multicolumn{5}{|c|}{ 1out of 2 products are overrepresented } \\
\hline & Wheat & $21 \%$ & 2 & 3 & Over \\
\hline & Soybeans & $64 \%$ & 6 & 3 & \\
\hline
\end{tabular}




\begin{tabular}{|c|c|c|c|c|c|}
\hline \multirow{5}{*}{$\begin{array}{l}\text { COOP-J } \\
\text { (9 Board } \\
\text { members) }\end{array}$} & \multicolumn{5}{|c|}{1 out of 4 products are overrepresented } \\
\hline & Wheat & $30 \%$ & 3 & 4 & Over \\
\hline & Maize & $10 \%$ & 1 & 1 & \\
\hline & Soybeans & $45 \%$ & 4 & 4 & \\
\hline & Milk & $15 \%$ & 1 & 1 & \\
\hline \multirow{3}{*}{$\begin{array}{l}\text { COOP-K } \\
(20 \text { Board } \\
\text { members })\end{array}$} & \multicolumn{5}{|c|}{1 out of 2 products are overrepresented } \\
\hline & Common Grapes & $53 \%$ & 11 & 12 & Over \\
\hline & Wine Grapes & $47 \%$ & 9 & 8 & \\
\hline \multirow{4}{*}{$\begin{array}{l}\text { COOP-L } \\
\text { (6 Board } \\
\text { members) }\end{array}$} & \multicolumn{5}{|c|}{2 out of 3 products are overrepresented } \\
\hline & Rice & $24 \%$ & 1 & 2 & Over \\
\hline & Wheat & $10 \%$ & 1 & 2 & Over \\
\hline & Soybeans & $65 \%$ & 4 & 0 & \\
\hline
\end{tabular}

Troducts which revenues are higher than $10 \%$ of the cooperative total annual revenues.

${ }^{2}$ According to the proportion rule, i.e., products should be represented at the board in the same proportion they are represented in the annual sales of the cooperative.

${ }^{3}$ A board member who produces two types of products has half a representation for each product (and a member who produces three has one third, and so on).

The results from Table 31 show that only in one cooperative (COOP-H), membership is not overrepresented, meaning that only one cooperative does not incur in opportunity democratic costs at the board of directors with regard to overrepresentation. On the other hand, at 8 cooperatives, membership is overrepresented at the board of directors with regard to one product; at 2 cooperatives, membership is overrepresented at the board of directors with regard to two products; and at 1 cooperative, membership is overrepresented at the board of directors with regard to three products. From the 11 cooperatives which the board is overrepresented, 4 of them have small board (considering smaller boards the ones which have less than 12 members) and 4 of them have large board (considering larger boards the ones which have 12 members or more). As a consequence, the results do not validate proposition 5, as both small and large boards are overrepresented, considering the proportional rule.

Although in most of the cases the overrepresentation is not high, in three cooperatives a third producers group (in terms of revenues) has more board members than the second group. For example, at COOP-C, wheat producers (the third producer group in terms of revenues), who represent $13 \%$ of the cooperatives annual revenues, are represented in the board of directors by four members, when they should be represented by two. At the same time, maize producers (the second largest revenue of the cooperative, with 16\%) are represented by three board members, 
i.e., less than the number of board members representing the third group. The same happens with COOP-B and COOP-G.

\section{Discussion}

The present study has discussed the costs of democratic control in member-controlled firms, such as agricultural cooperatives. More specifically, we have examined the relation between level of member participation (at the general assembly and at the board of directors) and democratic costs. Level of member participation is the main driver of democratic costs in agricultural cooperatives. Five propositions have helped us to obtain a picture of the direct and opportunity democratic costs that agricultural cooperatives face. Our conclusions about the costs of democratic control of the researched cooperatives are the following.

First, almost all of the studied cooperatives incur direct democratic costs at the general assembly. This is because they create nucleuses of members and make nucleuses assemblies to help active member participation. This works to some extent, as the creation of nucleuses helps to increase the level of member participation somewhat. Despite these efforts, member participation remains low for almost all cooperatives. Furthermore, some cooperatives (COOP-F and COOP-B) have created a very high number of nucleuses but have not reached an increase in their level of member participation at the general assembly. This suggests that creating more nucleuses than is necessary does not help too much increasing the level of member participation.

Second, most cooperatives (COOP-B, COOP-F, COOP-E, COOP-D, COOP-A, COOP-C, COOP-K, COOP-I) incur opportunity democratic costs at the general assembly related to overrepresentation. This is because they have created a lot of nucleuses per city, in order to increase member participation, while one nucleus per city would be sufficient.

Third, some cooperatives (COOP-E, COOP-I, COOP-J, COOP-G, and COOP-B) do incur in direct democratic costs at the board of directors because they have smaller board size but pay higher salaries per member. 
Fourth, most cooperatives (COOP-E, COOP-D, COOP-C, COOP-I, COOP-H, COOP-G, COOP$\mathrm{F}$ and COOP-A) incur opportunity democratic costs at the board of directors related to underrepresentation of some member groups. It should be noted that in some instances, the products that are underrepresented contribute little to the annual revenues of the cooperative.

Fifth, most cooperatives do incur opportunity democratic costs at the board of directors related to overrepresentation. In some cooperatives (COOP-E, COOP-D, COOP-K, COOP-I, COOP-L, COOP-J and COOP-F), the level of overrepresentation is not very high, e.g., instead of two a cooperative has three board members representing a product. In other cooperatives (COOP-C, COOP-B, COOP-G and COOP-A), the level of overrepresentation is slightly higher.

Table 32 presents a categorization of the costs of democratic control which the studied cooperatives face.

Table 32 -The costs of democratic control in researched cooperatives

\begin{tabular}{|c|c|c|c|c|c|c|}
\hline \multirow{3}{*}{ Cooperative } & \multicolumn{3}{|c|}{ General Assembly } & \multicolumn{3}{|c|}{ Board of Directors } \\
\hline & \multirow[b]{2}{*}{ Direct } & \multicolumn{2}{|c|}{ Opportunity } & \multirow[b]{2}{*}{ Direct } & \multicolumn{2}{|c|}{ Opportunity } \\
\hline & & $\begin{array}{c}\text { Under- } \\
\text { representation }\end{array}$ & $\begin{array}{c}\text { Over- } \\
\text { representation }\end{array}$ & & $\begin{array}{c}\text { Under- } \\
\text { representation }\end{array}$ & $\begin{array}{c}\text { Over- } \\
\text { representation }\end{array}$ \\
\hline$C O O P-A$ & + & + & 0 & 0 & + & + \\
\hline$C O O P-B$ & + & + & 0 & + & 0 & + \\
\hline $\mathrm{COOP}-\mathrm{C}$ & + & + & 0 & 0 & + & + \\
\hline$C O O P-D$ & + & + & 0 & 0 & + & + \\
\hline COOP-E & + & + & 0 & + & + & + \\
\hline$C O O P-F$ & + & + & 0 & 0 & + & + \\
\hline COOP-G & + & 0 & 0 & + & + & + \\
\hline $\mathrm{COOP}-\mathrm{H}$ & + & 0 & 0 & 0 & + & 0 \\
\hline COOP-I & + & + & 0 & + & + & + \\
\hline COOP-J & 0 & 0 & + & + & 0 & + \\
\hline COOP-K & + & + & 0 & 0 & 0 & + \\
\hline$C O O P-L$ & + & 0 & + & 0 & 0 & + \\
\hline
\end{tabular}




\section{Conclusion}

The present study has aimed to contribute to the debate on democratic costs. The reason for that is because we have not found empirical studies in the cooperative literature on the costs of democratic control, even though it is well known in the cooperative literature that decision making in cooperatives is likely to be a more costly process than in investor-owned firms.

In order to do that, we have identified the main driver of these costs, which is the level of member participation. We have examined the relation between democratic costs and member participation by means of five propositions. The study has examined the following relations: (1), between member participation at the general assembly and direct democratic costs (Proposition 1); (2), between member participation at the general assembly and opportunity democratic costs (Proposition 2); (3), between member participation at the board of directors and direct democratic costs (Proposition 3); (4), between member participation at the board of directors and opportunity democratic costs with regard to underrepresentation (Proposition 4); (5), between member participation at the board of directors and opportunity democratic costs with regard to overrepresentation (Proposition 5).

As democratic costs are difficult to measure, particularly opportunity costs, we have used proxies for examining the relations between our main variables. For example, 'percentage of member participation at pre-general assemblies' has been used as proxy for the variable 'member participation at general assembly', and 'number of members per nucleus' has been used as proxy to 'direct costs at the general assembly'. In order to test the propositions, we have used data from twelve agricultural cooperatives from the Brazilian state of Rio Grande do Sul (RS).

Proposition 1 recommended that the higher is the level of member participation at the general assembly, the higher are the direct democratic costs. The results do not (completely) support the proposition. On the one hand, there are some cooperatives in which the level of member participation is high and the number of members per nucleus is low (what do support the proposition). On the other hand, there are some cooperatives which have a low number of members per nucleus, and a low level of member participation; and also other cooperatives which 
have a high number of members per nucleus, and a high level of member participation at the general assembly (what do not support the proposition).

Proposition 2 suggested that when the level of member participation at the general assembly is low, the more likely the cooperative is to incur opportunity costs of underrepresentation. When the level of member participation at the general assembly increases until all (groups of) members are (proportionally) represented, opportunity democratic costs are likely to decrease. When the level of member participation at the general assembly is high, the more likely the cooperative is to incur opportunity costs of overrepresentation. The results do not (completely) support the proposition. On the one hand, those cooperatives with the highest number of nucleuses per city have the lowest level of member participation (what do not support the proposition). On the other hand, those cooperatives with the lowest number of nucleuses per city have the highest level of member participation (what do support the proposition). However, it could be that the former group of cooperatives has increased the number of nucleuses per city in an attempt to increase member participation. If so, the strategy has clearly not worked.

Proposition 3 recommended that the larger is the board of directors, the higher are the direct democratic costs at the board of directors. The results clearly support proposition 3 , because cooperatives which increase board size do not reduce average salary cost per board member.

Proposition 4 suggested that smaller boards are more likely than larger boards to incur opportunity costs of underrepresentation. The results do not validate proposition 4 , since from the 8 cooperatives which the board is underrepresented, 4 of them have small board (considering smaller boards the ones which have less than 10 members) and four of them have large board (considering larger boards the ones which have more than 10 members).

Proposition 5 suggested that larger boards are more likely than smaller boards to incur opportunity costs of overrepresentation. The results do not validate proposition 5, as both small and large boards are overrepresented, considering the proportional rule. 
The present study provided some theoretical, methodological and managerial contributions. Sections below outline these contributions. Limitations of the research and directions for further research are given further in chapter 5 .

\section{Theoretical contributions}

In the present study, we have contributed to the literature, by: (1), developing the concept of democratic costs; (2), distinguishing the concept more clearly from agency costs and influence costs; (3), establishing two different types of democratic costs: direct and opportunity costs; and (4) examining the relation between level of member participation (at the general assembly and at the board of directors) and democratic costs.

By distinguishing between direct and opportunity democratic costs, the study has drawn attention to the fact that the mechanisms to increase member participation are not without costs. Frequently, studies focus mainly on the benefits of increased member participation, disregarding some of the costs associated with it. These costs include both direct costs, as when more resources are spent on holding meetings, and opportunity costs, as the decision making process becomes slower because more people are involved in cooperative governance.

With regard to opportunity costs, a further distinction has been made between costs associated to under-and overrepresentation. In addition, in the present study, new methods and measures have been developed to assess these (opportunity) democratic costs. For example, one measure for opportunity costs at the board of directors is to look at whether all products the cooperative receives are represented at the board of directors by at least one board member. When it is not the case, membership is underrepresented at the board of directors.

Furthermore, the present study has shown that the relation between member participation at the board of directors and democratic costs is more complex than often assumed in the literature. Compared to previous studies, this study focused not only on board size, but also on board composition; i.e., which member groups the board represents. Board composition, with regard to internal stakeholder groups, is an important topic to study because a board which misrepresents the cooperative is a likely source for opportunity democratic costs, as the board will make 
uniformed decisions or decisions which benefit some member groups, rather than the cooperative as a whole. The study has developed theoretical models (e.g., Figure 26, which shows that members should take the relative costs of both direct and opportunity costs in total democratic costs into account when determining the optimal size and composition of their board).

\section{Managerial implications}

The present study has shown that member participation at the general assembly is low for most cooperatives, even though some of them spend a lot of resources attempting to improve member participation. Clearly, this strategy has not worked. Cooperatives should consider that increased heterogeneity and complexity of cooperatives might form an unsurpassable barrier to increasing member participation.

In addition, the present study has shown that most of the studied cooperatives have underrepresented boards. Related to the previous point, cooperatives also have to be aware of overrepresented boards. The results showed that most of the examined cooperatives have producer groups which dominate the board to a larger extent than their contribution to the revenues of the cooperative justifies. This 'crowd-outs' board representatives of some of the other producer groups. Cooperatives should attempt to increase product representation at the board in order to align the economic interests groups have in the cooperative better with their control rights. Amongst others, this can be achieved by allocating some of the board seats of the overrepresented groups to that of the underrepresented seats. An alternative strategy is to obtain board members who produce multiple products; e.g., a board member who produces marginal products of the cooperative (i.e., products which contribute little to cooperative revenues) besides one of the main products. Another approach is that cooperatives could allocate a board seat to a 'minority-representative'; i.e., a board member which represents various minority products. The point is that board representativeness can be increased without increasing board size.

Our advice to cooperatives is that they should pay more attention at their best possible membership representation levels at the general assembly and at the board of directors to keep 
their firms competitive in terms of decision making costs in relation to other cooperatives and particularly to their investor-owned firm competitors.

- At the general assembly, creating too much nucleus (more than one nucleus per city) increases direct democratic costs and does not seem to increase member participation.

- At the board of directors, for the cooperatives that have marginal products underrepresented, of course, an increase in board size would mean that marginal producer groups would be better represented. But it would also mean an increase in direct costs, as higher salary costs need to be paid. However, in this case, there is no one-to-one trade-off between direct and opportunity costs. As is explained above, cooperatives can increase the representativeness of the board without increasing board size; i.e., by electing board members who produce both majority and minority products. 


\section{THE COSTS OF COOPERATIVE GOVERNANCE: DEMOCRATIC AND}

\section{AGENCY COSTS}

\subsection{Introduction}

A key issue for cooperatives is to minimize both democratic and agency costs in the context of different levels of member participation. It may be difficult for cooperatives to reduce them both, because a trade-off between the two types of costs may exist: reducing democratic (agency) cost can increase agency (democratic) costs. For example, delegating more control to the management team may reduce democratic costs, since decision making processes require less input or participation of the members. However, with lower level of member participation, agency costs are likely to increase, as fewer members will monitor management. In deciding about how much control to delegate to management, cooperatives have to take into account that any reduction in democratic costs achieved through less member participation, may be offset by an increase in agency costs. This study examines how the ability of cooperatives to reduce democratic costs without incurring excessive agency costs is related to the level of member participation in cooperative governance (at the general assembly and at the board of directors).

\section{Problem statement}

The literature on cooperatives has been recently enriched by some debates with regard to two issues. The first issue relates to the cost of democracy. For instance, Birchall and Simmons (2004b) raise two questions: (1), to what extend cooperatives renewing their focus on membership is bringing benefits or costs?; and (2), is there a 'cooperative advantage' that makes democratic control compatible with market efficiency or democracy is a cost which would act as a disadvantage in the long-run. Birchall (2000b) calls the attention to whether member-ownership by producers/customers is an effective means of corporate governance. According to Birchall and Simmons (2004b, p. 468) "member participation does carry costs either because of the need to provide incentives to members to become interested or because they bring different, potentially conflicting interests to the decision-making process." Birchall and Simmons raise two questions 
more: (1), how much participation is needed? (BIRCHALL; SIMMONS, 2004c); and (2), can cooperatives continue to be genuine member-owned and controlled businesses once they become very large? (BIRCHALL; SIMMONS, 2004a). For instance, Österberg and Nilsson (2009) suggest that if on the one hand the principle of democracy has been a core element of cooperative business even since the inception of the cooperative business form, on the other hand, member control is becoming increasingly problematic, especially in large cooperatives with diversified business activities and with large and heterogeneous memberships.

The second issue relates to the cost of separation of ownership and control. Birchall and Simmons (2004a) argue: If cooperative cannot continue to be genuine member-owned and controlled businesses once they become very large, is it possible for representatives they have chosen effectively to govern on their behalf?

The present study aims to contribute to this debate by examining how the ability of cooperatives to reduce democratic costs without incurring excessive agency costs is related to the level of member participation in cooperative governance.

Participation in cooperative decision making is highly variable amongst members, i.e., some participate a lot, others not at all. Furthermore, participation is highly variable amongst cooperatives, i.e., it is much higher in some cooperatives than in others. A higher level of member participation may increase democratic costs in a cooperative, as more members participate in the collective decision making process. At the same time, a higher level of member participation may reduce agency costs, as more members monitor management. The net effect of member participation on these two types of costs may depend not only on the level of participation, but also the type of participation. Some of these types of participation may have a beneficial (adverse) effect, either on one of the two types of costs, or on both.

The research question that leads the present study is the following: How is the ability of cooperatives to control both democratic and agency costs related to the level of member participation? 


\subsection{The costs of cooperative governance}

As is explained in chapter 1 , decision making costs incurred by agricultural cooperatives encompass the three decision making bodies of a cooperative: horizontal (amongst members at the general assembly), diagonal (between members and board members), and vertical level (between members and managers). Costs related to horizontal and diagonal conflicts of interest are associated with democratic costs, while costs related to vertical conflicts of interests are associated to agency costs. Because chapters 1 and 3 have already discussed democratic costs and differences between democratic and agency costs in more detail, this present chapter presents shortly again the concept of democratic costs (see section 4.2.1) and discuss agency costs in more detail (see section 4.2.2).

\subsubsection{Democratic costs}

Democratic costs are:

(1), the costs resultant from the need of providing incentives for members to participate in the collective decision making process;

(2), the costs resultant from either horizontal or diagonal conflicts of interests amongst members who have to make decisions about how the benefits of (using) the cooperative are distributed amongst them. Horizontal conflicts of interests (i.e., among members) arise when members attempt to collectively make decisions about the distribution of benefits and costs at the general assembly. Diagonal conflicts of interests (i.e., among members and members of the board of directors) arise either when board members do not represent all members groups or when board is overrepresented; and

(3), the costs resultant from the cooperative's attempts to manage these conflicts or to prevent them. 


\subsubsection{Agency costs}

Agency costs incurred by agricultural cooperatives are the costs which members incur when they delegate control to a manager. More specifically, agency costs are:

(1), the costs of monitoring the performance and behavior of the management; and

(2), the costs when management makes decisions which benefit themselves rather than the cooperative (i.e., the members as a whole).

Agency costs result from vertical conflicts of interests (i.e., between members and management) with regard to the governance of the cooperative.

Agency costs can be a particular problem in cooperatives, because they lack some of the mechanisms which investor-owned firms use in reducing these costs. For example, public-listed investor-owned firms use external corporate governance principles (e.g., equitable treatment, transparency, accountability, and responsibility) and governance mechanisms (e.g., capital markets, takeover risk, market analysts, competitive agencies, among others) in order to control (the performance of) management. In another example, unlisted investor-owned firms, ownership is generally concentrated, which means that each owner has a strong incentive to monitor the performance of the agent. In cooperatives, there is not: (1), information generated by a secondary market (because cooperatives shares do not appreciate and there is not a secondary market for them) ${ }^{32}$ (CONDON, 1987), nor (2), external/knowledgeable board members, for use in the evaluation and control of management behavior. Furthermore, there are not enough incentives for members to control the performance of the management because the benefits that members receive from the cooperative comes from the premium prices they get for products they deliver to the cooperative and the lower prices they pay for the inputs they purchase from the cooperative, rather than a (large) distribution of surplus (ZYLBERSZTAJN, 1994).

\footnotetext{
32 According to Ang, Cole, and Lin (2000), the only information that is available, perhaps, are the differences in interest rate offered by banks to cooperatives demanding debt capital.
} 
If the concept of democratic costs has been largely ignored by the (cooperative) literature until now, the concept of agency costs, according to Machado Filho (2009), has emerged in the literature since around the 1970's. For instance, Jensen and Meckling (1976) observe that agency costs arise as a consequence of emergence of complex organizations, switching the management of the firm, before assigned to principals (owners), to knowledgeable and skilled agents (managers) by means of contracts. These contracts should specify: (1), the nature of residual claims; and (2), the allocation of steps in the decision making process among agents (FAMA; JENSEN, 1983, p. 302).

The owner has the residual rights of control. In other words, a firm's owners are those persons who share two formal rights: the right to control the firm and the right to appropriate the firm's residual earnings (net returns to the firm, including net current earnings and the net increase in capital value of any assets or other rights that the firm itself owns). Residual claims are the rights to the net income generated by the firm, i.e., the amount left over after all promised payments to fixed claim holders (e.g., employees, debtors). Owners are the residual risk bearers of the firm because net cash flows are uncertain and may be negative. Residual rights of control are defined as the rights to make any decision regarding the use of an asset that is not explicitly attenuated by law or assigned to other parties by contract. This is because transaction costs prevent the writing of comprehensive contracts, and so actual contracts are highly incomplete (HART; MOORE, 1996, p. 55).

Because the owner (i. e. principal, residual claimant) contracted an agent to manage his firm, he (i. e. the owner) bears now the formal authority, while the real authority is assigned to the agent. Real authority means the effective control over decisions within organizations. Formal authority means the right to elect the firm's board of directors and to vote directly on a small set of fundamental issues (HANSMANN, 1988; 1996; AGHION; TIROLE, 1997).

Jensen and Meckling (1976, p. 308) define an agency relationship as "a contract under one or more persons (the principal) engage another person (the agent) to perform some service on their behalf which involves delegating some decision making authority to the agent." 
The authors observe that there are two main behavioral assumptions from which agency problems are likely to arise.

First, the agent and the principal are limitedly (bounded) rational, meaning that they cannot foresee all future contingencies and thus cannot perfectly calculate their optimal behavior (related to their relationship). Because of bounded rationality, it is not costless to either write or enforce contracts, as limitations on the human abilities of the actors prevent them from doing so. As a result, the principal and the agent will enter together into an incomplete (and imperfect) contract.

Second, both the principal and agent (but particularly the agent) may exhibit opportunistic behavior, meaning that they will act in their self-interest not bound by (incomplete) previous arrangements. Jensen and Meckling (1976) aware that "if both parties to the relationship are utility maximizers there is good reason to believe that the agent will not always act in the best interests of the principal."

According to Condon (1987) economists have proposed a number of objectives a firm's manager might follow if allowed the latitude to do so. Such objectives include the maximization of some form of firm revenue (BAUMOL, 1959), firm growth rate (MARRIS, 1963), or managerial amenities (WILLIAMSON, 1966). Jensen and Meckling (1979a, 1979b) and Fama and Jensen (1983a, 1983b) offered a more general theory in which all agent groups within a firm (owners, directors, employees, management, etc.) will pursue the objective of constrained personal utility maximization. Managers will act so as to maximize the value of their pecuniary and non pecuniary reward. Pecuniary awards are based on salary and contractual performance incentives specified by the firm. Non pecuniary rewards are based on the utility gained from actions that managers perceive will increase their present and future stock of human capital and by such personal amenities as good working conditions, large and cooperative staffs, prestige, etc.

According to Jensen and Meckling (1976), the principal can limit divergences from his interest by establishing appropriate incentives for the agent and by incurring monitoring costs designed to limit the aberrant activities of the agent. Moreover, they observe: 
"It is generally impossible for the principal or the agent at zero cost to ensure that the agent will make optimal decisions from the principal's viewpoint. In most agency relationships the principal and the agent will incur positive monitoring and bonding costs (non-pecuniary as well as pecuniary), and in addition there will be some divergence between the agent's decisions and those decisions which would maximize the welfare of the principal. (JENSEN; MECKLING, 1976, p. 308).

The theory of cooperatives has moved from cooperative decision making emanated solely from members to managers acting as agents of principals (CONDON, 1987; COOK, 1994). According to Cook (1994), while in the beginning of the cooperative theory authors from management science, organizational behavior and economics (e.g., AIZSILNIEKS, 1952; ARESVIK, 1955; CLARK, 1952; EMELIANOFF, 1948; PHILLIPS, 1953; ROBOTKA, 1957) consider that there was little or no role of/for management in cooperatives (i.e., the cooperative decision making emanated solely from members), later, another group of authors from the theory of the firm (e.g., ALCHIAN; DEMSETZ, 1972; FAMA, 1980; JENSEN; MECKLING, 1976; FAMA; JENSEN, 1983; ARROW, 1951; WILLIAMSON, 1964; STAATZ, 1987a; 1987b; COTTERILL, 1987) suggest that managers act as agents of principals and attempt to optimize the value of their pecuniary and non pecuniary rewards. In the meantime, a group of authors (e.g., HELMBERGER; HOOS, 1962; SAVAGE, 1954; TRIFON, 1961) counter the first wave of authors and consider that cooperative management behavior does affect the economic performance of their organization and the performance of their patron-members' firms.

The general problem of motivating one person or organization to act on behalf of another is known among economists as the principal-agent problem (i.e., agency problem).

The principal-agent problem in cooperatives is seen as the control problem (VITALIANO, 1983; COOK, 1995). It is detailed below from the standpoint of Fulton (2004):

Because cooperative shares are not traded on the open market, cooperative share values cannot be used as a convenient performance measurement. The result is that operational inefficiencies can go unobserved. As well, owned dispersed ownership, especially in large cooperatives, provides individual members with few incentives to monitor the performance of their cooperative (FULTON, 2000, p. 4).

According to agency theory (e.g., JENSEN; MECKLING, 1976) and to the literature on cooperatives (e.g., CONDON, 1987), managerial behavior can be partially constrained by expending resources on monitoring and contractual incentives, but this process can be costly and imperfect. 


\subsubsection{Types of democratic and agency costs}

Democratic and agency costs in cooperatives may arise in the form of direct and opportunity costs. Table 33 shows the definitions of all of these types of costs.

Table 33 - Definitions of democratic and agency costs in agricultural cooperatives and their direct and opportunity forms

\begin{tabular}{|c|c|}
\hline Type of Cost & Definition \\
\hline Democratic & $\begin{array}{l}\text { Result from horizontal and diagonal conflicts of interest among members with regard to the } \\
\text { governance of the cooperative. Result from the exploitation of the minority by the majority. }\end{array}$ \\
\hline Direct & $\begin{array}{l}\text { They are the costs associated with the members' time, board and executives' time and salary } \\
\text { spent with collective decision making process. } \\
\text { Direct democratic costs at the general assembly are incurred when members communicate and } \\
\text { negotiate about what decision to take; e.g., the costs of cooperative members' time, the costs of } \\
\text { executives' salaries and time spent on general (and pre-general) assemblies. } \\
\text { Direct democratic costs at the board of directors are incurred when board members } \\
\text { communicate and negotiate about what decision to take, e.g., the salary of board members. }\end{array}$ \\
\hline Opportunity & $\begin{array}{l}\text { They are the costs associated with delayed decisions (which can result in lost opportunities), or } \\
\text { failure to achieve decisions which maximize the benefit of all members. } \\
\text { At the general assembly, they arise in situations such as: (1), when each member attempts to } \\
\text { influence the collective decision making process to his own benefit; (2), when uninformed } \\
\text { members make wrong or no decisions; and (3), when decision making takes too much time } \\
\text { (which can result in lost opportunities). } \\
\text { At the board of directors, they are incurred either when membership is either underrepresented, } \\
\text { or overrepresented at the board of directors. When membership is underrepresented at the } \\
\text { board of directors, board members may make uninformed or no decisions or decisions that } \\
\text { privilege producer groups who are represented at the board. When membership is } \\
\text { overrepresented, board members may take too much time (which can result in lost } \\
\text { opportunities) to make decisions. }\end{array}$ \\
\hline Agency & $\begin{array}{l}\text { Result from a vertical conflict of interests between members and management with regard to } \\
\text { the governance of the cooperative. Result from the exploitation of the equity holders by the } \\
\text { manager. }\end{array}$ \\
\hline Direct & $\begin{array}{l}\text { They are incurred when board members (or members) monitor the performance of the agent } \\
\text { (e.g., the costs of auditing, etc). }\end{array}$ \\
\hline Opportunity & $\begin{array}{l}\text { They are the costs associated with delayed decisions (which can result in lost opportunities), or } \\
\text { failure to achieve decisions which maximize the benefit of the members. E.g., these costs may } \\
\text { result from too little monitoring by (board) members, as the management team may make } \\
\text { opportunistic decisions which benefit themselves, rather than the members who have elected } \\
\text { them. Furthermore, these costs may result from too much monitoring, as resources used in the } \\
\text { monitoring process could have been used for other objectives. }\end{array}$ \\
\hline
\end{tabular}




\subsubsection{What affects democratic and agency costs}

As is explained in chapters 1 and 3, one of the main drivers of democratic and agency costs is the level of member participation in cooperative governance. Increasing this level helps to affect agency costs positively, but may affect democratic costs either positively or negatively. This is the main discussion of the present chapter. In this section, we examine the relations between level of member participation and democratic and agency costs separately (see Table 34).

Table 34 - Relations between level of member participation and democratic and agency costs (and their direct and opportunity forms)

\begin{tabular}{l|l}
\hline Type of Cost & \multicolumn{1}{c}{ Relation with the level of member participation } \\
\hline Democratic & $\begin{array}{l}\text { A higher level of member participation at the general assembly and at the board of directors may } \\
\text { increase direct democratic costs in a cooperative, as more members participate in the collective } \\
\text { decision making process. }\end{array}$ \\
$\begin{array}{l}\text { Democratic costs are likely to arise also, and in the form of } \text { opportunity costs, when level of member } \\
\text { participation at the board is either too small (i.e., lower than it is necessary), i.e., when not all groups } \\
\text { of members (e. g. rice producers, dairy producers) are represented (i.e., underrepresented) or when } \\
\text { the board is too large (i.e., large than it is necessary), i.e., when some groups of members are } \\
\text { overrepresented. }\end{array}$
\end{tabular}

At the general assembly, direct democratic costs are likely to arise when a cooperative increases time spent on general meetings (e. g. pre-general assemblies at different cities, districts, regions). This means an increasing amount of executives' time (and salary), as well as member' time spent on Direct meetings. Also, with an increasing number of (pre)general assemblies, more money is spent on organizing and hosting these meetings.

At the board of directors, direct democratic costs are likely to arise when a cooperative increases its board size. A larger board means, for example, that salary costs increase.

At the general assembly, opportunity democratic costs are likely to arise in situations such as: (1), when each member (or coalition member) attempts to influence the decision making process to his own benefit; (2), when uninformed members make wrong decisions; and (3), when decision making takes-up too much time (which can result in lost opportunities), i.e., time which members could have spent on their farms, and cooperative executives on planning and managing the cooperative effectively.

At the board of directors, opportunity democratic costs are expected to arise when a cooperative has either a too small or too large board. A board is too small when not all groups of members (e.g., rice producers, dairy producers) are represented (i.e., underrepresented). When not all different membergroups are represented, the board might make uninformed decisions, or decisions which benefit their constituents rather than the cooperative as a whole. A board is too large when some member-groups are overrepresented. Because membership is overrepresented, decision making is likely to take too much time (which can result in lost opportunities). In general, opportunity costs are likely to increase when board size becomes excessively large, even if interests of the various groups are aligned, because decision making becomes difficult. 


\begin{tabular}{l|l}
\hline Agency & $\begin{array}{l}\text { A higher level of member participation at the general assembly and at the board of directors may } \\
\text { reduce agency costs, as more members monitor management. }\end{array}$ \\
\hline Direct & $\begin{array}{l}\text { Direct agency costs should increase with lower levels of member participation at the general } \\
\text { assembly and at the board of directors because the cooperative needs to use more resources in } \\
\text { monitoring management. }\end{array}$ \\
\hline Opportunity & $\begin{array}{l}\text { With low member participation at the general assembly and at the board of directors, exposure to } \\
\text { opportunity costs is higher because management is more likely to make decisions which benefit } \\
\text { themselves rather than the cooperative (i.e., the members as a whole). }\end{array}$ \\
\hline
\end{tabular}

\subsubsection{Balancing democratic costs and usage of agency mechanisms in the context of high (low) member participation}

According to Staatz (1987b), when the cost of collective decision making is likely to increase with the diversity of the group and level of member participation, cooperatives that delegate greater decision making (i.e., real authority) to management thus may be better able to compete with investor-owned firms, albeit at the cost of less direct member involvement in decision making.

In delegating decision making (i.e., real authority) to management (and the board), cooperatives have to take into account that any reduction in (total) democratic costs resulting from a reduced need for member participation, may lead to increased agency cost, both direct ${ }^{33}$ and opportunity ${ }^{34}$ agency costs. The focus in this study is on how cooperatives can balance democratic costs and opportunity agency costs.

Direct agency costs are the costs incurred in employing mechanisms to reduce agency problems. Agency problems, like when management makes decisions which benefit themselves rather than the cooperative, are the source of opportunity agency costs. It is likely that reducing direct agency costs is a smaller concern for cooperatives compared to the risk of exposure to high opportunity agency costs. For example, the cost of an additional internal audit (a direct cost) is

\footnotetext{
${ }^{33}$ Direct agency costs are, for example, the design of incentive payments for managers, frequency by which management is audited by the internal board and by external auditors, etc.

${ }^{34}$ Opportunity agency costs are the risks that: (1), management may act contrary to the members' wishes, and (2), management captures (non-)pecuniary benefits.
} 
small when compared to the cost of fraudulent actions of management (an opportunity costs). Therefore, cooperatives are expected to focus more on reducing opportunity agency costs, rather than on minimizing direct agency costs.

According to agency theory, it is usually possible by expending resources (i.e., employing 'mechanisms') to alter the risk of high opportunity agency costs. These 'mechanisms' include (internal and external) auditing, formal control systems, budget restrictions, and the establishment of incentive compensation systems (JENSEN; MECKLING, 1976, p. 323), the design of institutions to gather information, protect investments, allocate decisions and ownership rights (MILGROM; ROBERTS, 1992).

According to the literature on cooperatives (e.g., ZYLBERSZTAJN, 2002; HENR ILIOPOULOS, s. d.), there are several mechanisms (e.g., frequency by which management is audited by the (audit) board, frequency by which management is audited by external auditors, use of variable compensation for management, frequency by which management and board meet) which cooperatives can use to reduce opportunity costs.

For instance, cooperatives may increase the frequency by which management is audited by the (audit) board. According to Henrÿ (2005), cooperatives which have such organ which acts on behalf of the members seem to function better than those without it. This is because members often lack the necessary qualifications to exercise an effective and continuous control over the board of directors and the management.

In addition, cooperatives may increase the frequency by which management is audited by external auditors. Henrÿ (2005) observes that the dual system of internal control mechanisms (i.e., board of directors and internal auditors) does not replace the obligatory external audit of the cooperative.

Furthermore, cooperatives may use a variable compensation for management. By adding a variable compensation and tying it with the cooperative operational and financial efficiency, the cooperative may be able to align the interests of the management with the cooperative ones. However, variable compensation is also known to increase the risk managers take in controlling 
the organization, particularly if it is asymmetrically structured (i.e., when bonuses but not penalties are included in the contract, which is almost always the case). This is because possible gains of risk taking flow to both manager and owners, while losses only flow to the owners. This particularly holds true for public listed investor-owned firms, where variable compensation may be a very high portion of the total salary of the management. Therefore, the effect of using variable compensation on reducing opportunity agency costs is not clear.

The usage of these mechanisms to reduce agency problems is particularly important with lower level of member participation, as management will be less intensively monitored by the members.

\subsection{Propositions}

Delegating more control to the management team (i.e., lower level of member participation) may reduce democratic costs. However, with lower level of member participation, agency costs are likely to increase, as fewer members will monitor management. This study examines how the ability of cooperatives to reduce democratic costs without incurring excessive agency costs is related to the level of member participation in cooperative governance (at the general assembly and at the board of directors). We expect that cooperatives will use more mechanisms (e.g., increase frequency of internal and external audits) to reduce exposure to agency problems, when member participation is low.

We have suggested 6 propositions for these relations. Three of them are related to the balance between democratic costs at the general assembly and usage of mechanisms to reduce exposure to agency problems, and three are related to the balance between democratic costs at the board of directors and usage of mechanisms to reduce exposure to agency problems. 
Proposition 1 (relation between direct democratic costs at the general assembly and usage of agency mechanisms):

The lower the level of member participation at the general assembly, the lower the direct democratic costs at the general assembly and the higher the usage of mechanisms to reduce exposure to agency problems.

Proposition 2 (relation between opportunity democratic costs of underrepresentation at the general assembly and usage of agency mechanisms):

The lower the level of member participation at the general assembly, the higher the opportunity democratic costs at the general assembly with regard to underrepresentation and the higher the usage of mechanisms to reduce exposure to agency problems.

Proposition 3 (relation between opportunity democratic costs of overrepresentation at the general assembly and usage of agency mechanisms):

The higher the level of member participation at the general assembly, the higher the opportunity democratic costs at the general assembly with regard to overrepresentation and the lower the usage of mechanisms to reduce exposure to agency problems.

Proposition 4 (relation between direct democratic costs at the board of directors and usage of agency mechanisms):

The lower the level of member participation at the board of directors (i.e., the smaller the board size), the lower the direct democratic costs at the board of directors and the higher the usage of mechanisms to reduce exposure to agency problems.

Proposition 5 (relation between opportunity democratic costs of underrepresentation at the board of directors and usage of agency mechanisms):

The lower the level of member participation at the board of directors, the higher the opportunity democratic costs at the board of directors with regard to underrepresentation and the higher the usage of mechanisms to reduce exposure to agency problems. 
Proposition 6 (relation between opportunity democratic costs of overrepresentation at the board of directors and usage of agency mechanisms):

The higher the level of member participation at the board of directors, the higher the opportunity democratic costs at the board of directors with regard to overrepresentation at the board of directors and the lower the usage of mechanisms to reduce exposure to agency problems.

\subsection{Research design}

\section{Selection of cases}

Evidences from 12 Brazilian cooperatives, from the state of Rio Grande do Sul, have been used to examine the relations proposed above. Rio Grande do Sul (RS) has been the selected location for this study because it has a rich variety of small and large memberships and small and large boards of directors. Also, in RS one can find large differences in cooperatives with regard to number of nucleuses, number of members per nucleus, board representation, etc. Differences in these attributes are likely to lead to differences in democratic costs across the cooperatives. In addition, in the states' cooperatives one can find large differences in frequency of internal and external audits, what is necessary for our study. Last but not least, RS has been the selected location because it is an area where the author has a considerable number of connections (e.g., OCERGS, FECOAGRO, FEARROZ, etc.). A general characterization of the researched cooperatives is given by Table 35 . 
Table 35 - General characterization of the researched cooperatives

\begin{tabular}{|c|c|c|c|c|c|c|c|c|c|c|}
\hline $\begin{array}{l}\frac{0}{\vdots} \\
\frac{0}{2} \\
\vdots \\
0 \\
0\end{array}$ & 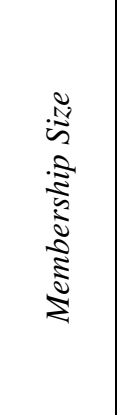 & 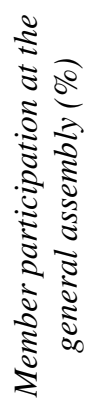 & 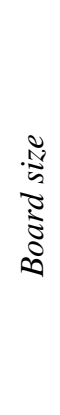 & 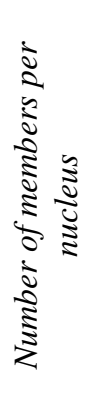 & 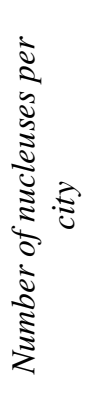 & 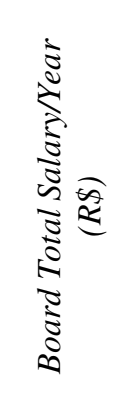 & 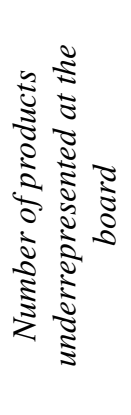 & 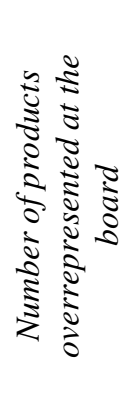 & 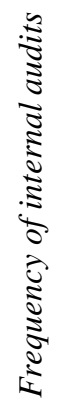 & 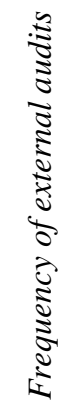 \\
\hline COOP-A & 10,730 & 5 & 20 & 53 & 10 & 91,780 & 3 & 3 & 7 & 60 \\
\hline$C O O P-B$ & 8,236 & 17 & 19 & 48 & 7 & 109,200 & 0 & 1 & 30 & 30 \\
\hline $\mathrm{COOP}-\mathrm{C}$ & 4,946 & 3 & 15 & 101 & 3 & 65,126 & 3 & 2 & 15 & - \\
\hline$C O O P-D$ & 4,776 & 7 & 12 & 199 & 5 & 66,000 & 3 & 1 & 30 & 60 \\
\hline COOP-E & 4,612 & 4 & 9 & 201 & 5 & 65,988 & 7 & 1 & 10 & 60 \\
\hline$C O O P-F$ & 3,760 & 3 & 8 & 60 & 11 & 29,376 & 2 & 1 & 30 & - \\
\hline COOP-G & 3,743 & 2 & 10 & 374 & 1 & 61,380 & 1 & 1 & 10 & 90 \\
\hline COOP-H & 3,728 & 8 & 12 & 266 & 1 & 56,880 & 2 & 0 & 3 & 120 \\
\hline COOP-I & 3,254 & 12 & 9 & 121 & 3 & 65,124 & 2 & 1 & 30 & 90 \\
\hline COOP-J & 1,125 & 41 & 9 & - & - & 72,000 & 0 & 1 & 30 & 360 \\
\hline$C O O P-K$ & 1,013 & 40 & 20 & 51 & 3 & 106,827 & 0 & 1 & 30 & 360 \\
\hline COOP-L & 500 & 4 & 6 & 167 & 0,75 & 15,000 & 0 & 2 & 30 & 30 \\
\hline Mean & 4,202 & 12 & 12 & 149 & 4 & 67,057 & 2 & 1 & 21 & 126 \\
\hline Minimum & 500 & 2 & 6 & 0 & 0 & 15,000 & 0 & 0 & 3 & 30 \\
\hline Maximum & 10,730 & 41 & 20 & 374 & 11 & 109,200 & 7 & 3 & 30 & 360 \\
\hline
\end{tabular}

\section{Data generating}

Data has been generated thought multiple methods. They include: (1), personal interviews with elected executive managers and hired executives of each cooperative; (2), document analysis (in cooperative records, e.g., general and pre-general assembly minutes, balance sheets, etc); and (3) observations (on cooperatives' websites). The data has been generated from July, 2010 till February, 2011. A protocol of the generated data is attached in Appendix 1.

\section{Operationalization of the concepts}

Table 36 gives an overview of the operationalization of the study's key concepts. The concepts and proxies related to democratic costs have already been presented in chapter 3 . 
Table 36 - Operationalisation of the main concepts of the research

\begin{tabular}{|c|c|c|c|}
\hline Category & Variable & Proxy & Meaning \\
\hline \multirow{2}{*}{ Member participation } & $\begin{array}{l}\text { Member participation } \\
\text { at the general assembly }\end{array}$ & $\begin{array}{l}\text { Percentage of member } \\
\text { participation at the } \\
\text { general assembly }\end{array}$ & $\begin{array}{l}\text { Low (high) participation at } \\
\text { general assembly is an indicator } \\
\text { for low (high) level of member } \\
\text { participation at the general } \\
\text { assembly }\end{array}$ \\
\hline & $\begin{array}{l}\text { Member participation } \\
\text { at the board of directors }\end{array}$ & Board size & $\begin{array}{l}\text { Smaller (larger) board is an } \\
\text { indicator of lower (higher) level of } \\
\text { member participation at the board } \\
\text { of directors }\end{array}$ \\
\hline \multirow{2}{*}{$\begin{array}{l}\text { Democratic costs at } \\
\text { the general assembly }\end{array}$} & $\begin{array}{l}\text { Direct democratic costs } \\
\text { at the general assembly }\end{array}$ & $\begin{array}{l}\text { Number of members } \\
\text { per nucleus }\end{array}$ & $\begin{array}{l}\text { Low (high) score on this ratio is } \\
\text { an indicator that the cooperative } \\
\text { has high (low) direct democratic } \\
\text { costs at the general assembly }\end{array}$ \\
\hline & $\begin{array}{l}\text { Opportunity } \\
\text { democratic costs at the } \\
\text { general assembly }\end{array}$ & $\begin{array}{l}\text { Number of nucleuses } \\
\text { locations per city }\end{array}$ & $\begin{array}{l}\text { A ratio lower (higher) than one is } \\
\text { an indicator of } \\
\text { underrepresentation } \\
\text { (overrepresentation) }\end{array}$ \\
\hline \multirow{3}{*}{$\begin{array}{l}\text { Democratic costs at } \\
\text { the board of directors }\end{array}$} & $\begin{array}{l}\text { Direct democratic costs } \\
\text { at the board of directors }\end{array}$ & $\begin{array}{l}\text { Total board salary per } \\
\text { year }\end{array}$ & $\begin{array}{l}\text { Low (high) total board salary/year } \\
\text { is an indicator of low (high) direct } \\
\text { democratic costs at the board of } \\
\text { directors }\end{array}$ \\
\hline & $\begin{array}{l}\text { Opportunity } \\
\text { democratic costs at the } \\
\text { board of directors with } \\
\text { regard to } \\
\text { underrepresentation }\end{array}$ & $\begin{array}{l}\text { Absolute rule: all } \\
\text { products the } \\
\text { cooperative receives } \\
\text { should be represented at } \\
\text { the board by at least one } \\
\text { board member }\end{array}$ & $\begin{array}{l}\text { If not all products are represented } \\
\text { at the board, this is an indicator } \\
\text { for opportunity costs related to } \\
\text { underrepresentation }\end{array}$ \\
\hline & $\begin{array}{l}\text { Opportunity } \\
\text { democratic costs at the } \\
\text { board of directors with } \\
\text { regard to } \\
\text { overrepresentation }\end{array}$ & $\begin{array}{l}\text { Proportional rule: } \\
\text { products should be } \\
\text { represented at the board } \\
\text { in the same proportion } \\
\text { they are represented in } \\
\text { the annual sales of the } \\
\text { cooperative }\end{array}$ & $\begin{array}{l}\text { If a product has higher } \\
\text { proportional representation in the } \\
\text { board than its share of the } \\
\text { revenues justifies, this is an } \\
\text { indicator for opportunity costs } \\
\text { related to overrepresentation }\end{array}$ \\
\hline \multirow{2}{*}{$\begin{array}{l}\text { Usage of mechanisms } \\
\text { to reduce exposure to } \\
\text { agency problems }\end{array}$} & \multicolumn{2}{|c|}{ Frequency of internal audits } & $\begin{array}{l}\text { Lower (higher) frequency is an } \\
\text { indicator of high (low) usage of } \\
\text { mechanisms }\end{array}$ \\
\hline & \multicolumn{2}{|c|}{ Frequency of external audits } & $\begin{array}{l}\text { Lower (higher) frequency is an } \\
\text { indicator of high (low) usage of } \\
\text { mechanisms }\end{array}$ \\
\hline
\end{tabular}


With regard to usage of mechanisms to reduce exposure to agency problems, two types of variables are examined: (1), frequency of internal audits; (2), frequency of external audits. A high usage of these mechanisms indicates a strong orientation of the cooperative towards reducing agency problems. The study did not examine cooperatives' usage of variable compensation, which is another mechanism to reduce these problems. As is explained previously, the effect of variable compensation on reducing exposure to agency problems is uncertain.

\section{Rules for validation of the propositions}

Chapter 3 already examined the relation between level of member participation and democratic costs. That chapter has shown that the relation between member participation and democratic costs by and large follows the logic of the propositions. The focus of the empirical part of the present study is therefore mainly on examining how the usage of mechanisms to reduce agency problems (i.e., agency mechanisms) differs across cooperatives. To validate the propositions, usage of agency mechanisms will be compared across various groups of cooperatives. Cooperatives will be placed into groups based on two dimensions: (1), level of member participation; (2), level of (direct or opportunity) democratic cost. An example of this, related to proposition 1, is given below in Figure 30 (for more information about the inputs for these groups, see Appendix 5).

\begin{tabular}{|c|c|c|c|}
\hline \multirow{4}{*}{$\begin{array}{l}\text { Direct Democratic costs } \\
\text { at the general assembly }\end{array}$} & & \multicolumn{2}{|c|}{ Level of Member participation at the general assembly } \\
\hline & & High & Low \\
\hline & High & $\begin{array}{c}(1) \\
\text { COOP-K } \\
\text { COOP-I } \\
\text { COOP-B } \\
\text { COOP-J }\end{array}$ & $(2)$ \\
\hline & Low & (3) & $\begin{array}{c}(4) \\
\text { COOP-D } \\
\text { COOP-H } \\
\text { COOP-L } \\
\text { COOP-E }\end{array}$ \\
\hline
\end{tabular}

Figure 30 - Two groups of cooperatives are examined: cooperatives with high member participation and high direct democratic costs Vs. cooperatives with low member participation and low direct democratic costs

To validate proposition 1, the usage of agency mechanisms across two groups needs to be compared between: (1), a group of those cooperatives with high member participation and high direct democratic costs; and (2), a group of those cooperatives with low member participation and 
low democratic costs. Based on the proposition, it can be deduced that the cooperatives from the second group will use more agency mechanisms than cooperatives from the first group. Whether that is the case it will be presented in the results section, also for the other propositions. Note that for the other propositions, comparison between other types of groups may be made. Furthermore, note that not all cooperatives are included for the validation of each proposition. For example, the cooperatives which are placed in boxes 2 and 3 of Figure 30 are not included in the validation process of proposition 1 . The underlying logic of the proposition only applies to cooperatives from boxes 1 and 4.

Table 37 presents the rules for validation for all propositions. Propositions 2 and 3 could not be validated because no comparisons between groups could be made. With regard to proposition 2, underrepresentation at the general assembly is not (or hardly) an issue for almost all cooperatives. With regard to proposition 3, almost all cooperatives with high member participation incur opportunity costs of overrepresentation at the level of the general assembly. 
Table 37 - Rules for validation of the propositions

\begin{tabular}{|c|c|c|}
\hline Propositions & Which groups are compared? & When are the propositions validated? \\
\hline $\begin{array}{l}\text { 1: The lower the level of member } \\
\text { participation at the general } \\
\text { assembly, the lower the direct } \\
\text { democratic costs at the general } \\
\text { assembly and the higher the usage of } \\
\text { mechanisms to reduce exposure to } \\
\text { agency problems. }\end{array}$ & $\begin{array}{l}\text { Group 1: Cooperatives with high } \\
\text { member participation and high direct } \\
\text { democratic costs } \\
\text { Group 2: Cooperatives with low } \\
\text { member participation and low direct } \\
\text { democratic costs }\end{array}$ & $\begin{array}{l}\text { If Group } 2 \text { uses more agency } \\
\text { mechanisms than Group } 1 .\end{array}$ \\
\hline $\begin{array}{l}\text { 2: The lower the level of member } \\
\text { participation at the general } \\
\text { assembly, the higher the opportunity } \\
\text { democratic costs at the general } \\
\text { assembly with regard to } \\
\text { underrepresentation and the higher } \\
\text { the usage of mechanisms to reduce } \\
\text { exposure to agency problems. }\end{array}$ & $\begin{array}{l}\text { Group 1: Cooperatives with high } \\
\text { member participation and low } \\
\text { opportunity democratic cost of } \\
\text { underrepresentation } \\
\text { Group 2: Cooperatives with low } \\
\text { member participation and high } \\
\text { opportunity democratic cost of } \\
\text { underrepresentation }\end{array}$ & $\begin{array}{l}\text { If Group } 2 \text { uses more agency } \\
\text { mechanisms than Group } 1 .\end{array}$ \\
\hline $\begin{array}{l}\text { 3: The higher the level of member } \\
\text { participation at the general } \\
\text { assembly, the higher the opportunity } \\
\text { democratic costs at the general } \\
\text { assembly with regard to } \\
\text { overrepresentation and the lower the } \\
\text { usage of mechanisms to reduce } \\
\text { exposure to agency problems. }\end{array}$ & $\begin{array}{l}\text { Group 1: Cooperatives with high } \\
\text { member participation and high } \\
\text { opportunity democratic cost of } \\
\text { overrepresentation } \\
\text { Group 2: Cooperatives with low } \\
\text { member participation and low } \\
\text { opportunity democratic cost of } \\
\text { overrepresentation }\end{array}$ & $\begin{array}{l}\text { If Group } 2 \text { uses more agency } \\
\text { mechanisms than Group } 1 .\end{array}$ \\
\hline $\begin{array}{l}\text { 4: The lower the level of member } \\
\text { participation at the board of } \\
\text { directors (i.e., the smaller the board } \\
\text { size), the lower the direct democratic } \\
\text { costs at the board of directors and } \\
\text { the higher the usage of mechanisms } \\
\text { to reduce exposure to agency } \\
\text { problems. }\end{array}$ & $\begin{array}{l}\text { Group 1: Cooperatives with high } \\
\text { member participation and high direct } \\
\text { democratic costs } \\
\text { Group 2: Cooperatives with low } \\
\text { member participation and low direct } \\
\text { democratic costs }\end{array}$ & $\begin{array}{l}\text { If Group } 2 \text { uses more agency } \\
\text { mechanisms than Group } 1 .\end{array}$ \\
\hline $\begin{array}{l}\text { 5: The lower the level of member } \\
\text { participation at the board of } \\
\text { directors, the higher the opportunity } \\
\text { democratic costs at the board of } \\
\text { directors with regard to } \\
\text { underrepresentation and the higher } \\
\text { the usage of mechanisms to reduce } \\
\text { exposure to agency problems. }\end{array}$ & $\begin{array}{l}\text { Group 1: Cooperatives with high } \\
\text { member participation and low } \\
\text { opportunity democratic cost of } \\
\text { underrepresentation } \\
\text { Group 2: Cooperatives with low } \\
\text { member participation and high } \\
\text { opportunity democratic cost of } \\
\text { underrepresentation }\end{array}$ & $\begin{array}{l}\text { If Group } 2 \text { uses more agency } \\
\text { mechanisms than Group } 1 .\end{array}$ \\
\hline $\begin{array}{l}\text { 6: The higher the level of member } \\
\text { participation at the board of } \\
\text { directors, the higher the opportunity } \\
\text { democratic costs at the board of } \\
\text { directors with regard to } \\
\text { overrepresentation at the board of } \\
\text { directors and the lower the usage of } \\
\text { mechanisms to reduce exposure to } \\
\text { agency problems. }\end{array}$ & $\begin{array}{l}\text { Group 1: Cooperatives with high } \\
\text { member participation and high } \\
\text { opportunity democratic cost of } \\
\text { overrepresentation } \\
\text { Group 2: Cooperatives with low } \\
\text { member participation and low } \\
\text { opportunity democratic cost of } \\
\text { overrepresentation }\end{array}$ & $\begin{array}{l}\text { If Group } 2 \text { uses more agency } \\
\text { mechanisms than Group } 1 .\end{array}$ \\
\hline
\end{tabular}




\subsection{Research results and analysis}

\section{Results for member participation at the general assembly}

Three propositions have been developed which relate member participation at the general assembly to democratic costs and usage of agency mechanisms. As is explained in the previous section, only one of these propositions could be validated.

Results for proposition 1: Cooperatives with high member participation and high direct democratic costs VS. Cooperatives with low member participation and low direct democratic $\underline{\text { costs }}$

Figure 31 shows the two groups of cooperatives which are compared. Cooperatives are regarded as having low member participation when less than $12 \%$ of their members participate at the general assembly. Number of members per nucleus is taken as proxy for direct democratic costs at the general assembly. The lower the number of members per nucleus the higher the direct democratic costs at the general assembly, since more resources are spent per member on organizing meetings. High direct democratic costs at the general assembly, means less than 149 members per nucleus. 149 is the median number of members per nucleus of the researched cooperatives.

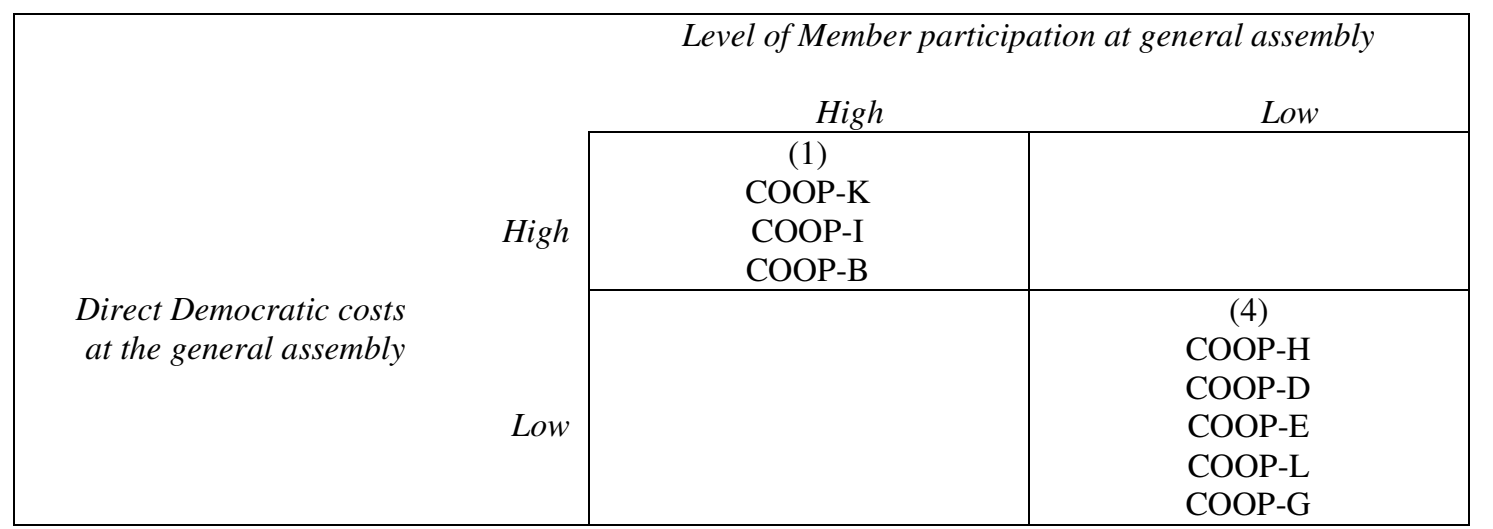

Figure 31 - Two groups of cooperatives: high member participation and high direct democratic costs Vs. low member participation and low direct democratic costs

Tables 38 and 39 below compare the usage of agency mechanisms (frequency of internal audits, Table 38; and frequency of external audits, Table 39) across the two groups of cooperatives 
Table 38 - Direct democratic costs at the general assembly and usage of mechanisms (frequency of internal audits) to reduce exposure to agency problems of cooperatives with high/low levels of member participation at

\begin{tabular}{|c|c|c|c|}
\hline Cooperative & $\begin{array}{l}\text { Level }(\%) \text { of member } \\
\text { participation at the } \\
\text { general assembly }\end{array}$ & $\begin{array}{c}\text { Direct democratic costs at the } \\
\text { general assembly (number of } \\
\text { members per nucleus) }\end{array}$ & $\begin{array}{c}\text { Usage of mechanisms to } \\
\text { reduce exposure to agency } \\
\text { problems } \\
\text { (frequency of internal audits) }\end{array}$ \\
\hline COOP-K & \multirow{3}{*}{ High } & 51 & 30 \\
\hline COOP-I & & 121 & 30 \\
\hline$C O O P-B$ & & 48 & 30 \\
\hline $\mathrm{COOP}-\mathrm{H}$ & \multirow{5}{*}{ Low } & 266 & 3 \\
\hline$C O O P-D$ & & 199 & 30 \\
\hline COOP-E & & 210 & 10 \\
\hline COOP-L & & 167 & 30 \\
\hline COOP-G & & 374 & 10 \\
\hline
\end{tabular}

Table 39 - Direct democratic costs at the general assembly and usage of mechanisms (frequency of external audits) to reduce exposure to agency problems of cooperatives with high/low levels of member participation at

\begin{tabular}{c|c|c|c}
\hline \multicolumn{3}{|c|}{ the general assembly } \\
Cooperative & $\begin{array}{c}\text { Level (\%) of member } \\
\text { participation at the } \\
\text { general assembly }\end{array}$ & $\begin{array}{c}\text { Direct democratic costs at the } \\
\text { general assembly (number of } \\
\text { members per nucleus) }\end{array}$ & $\begin{array}{c}\text { Usage of mechanisms to } \\
\text { reduce exposure to agency } \\
\text { problems }\end{array}$ \\
(frequency of external audits)
\end{tabular}

These relations are also depicted below in Figures 32 (considering frequency of internal audits as the mechanism) and 33 (considering frequency of external audits as the mechanism). 


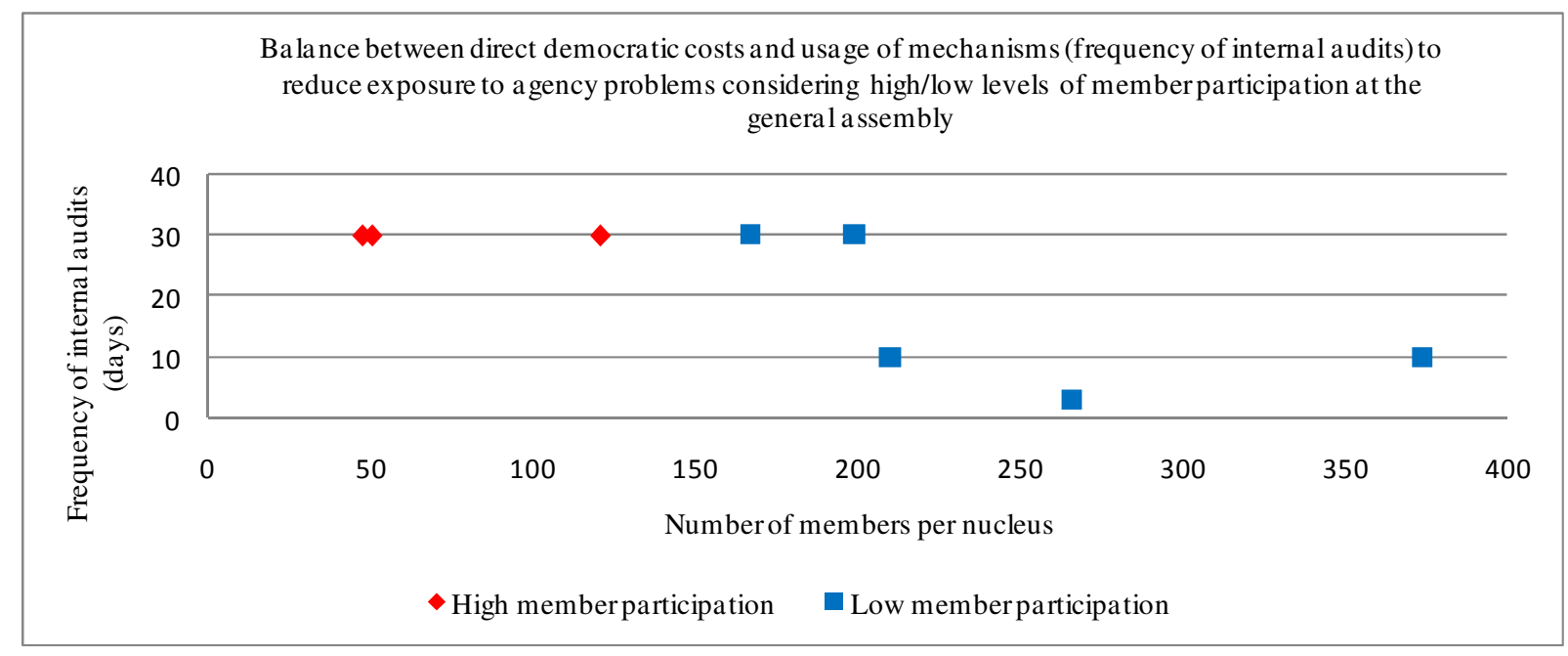

Figure 32 - Balance between direct democratic costs and usage of mechanisms (frequency of internal audits) to reduce exposure to agency problems considering high/low levels of member participation at the general assembly

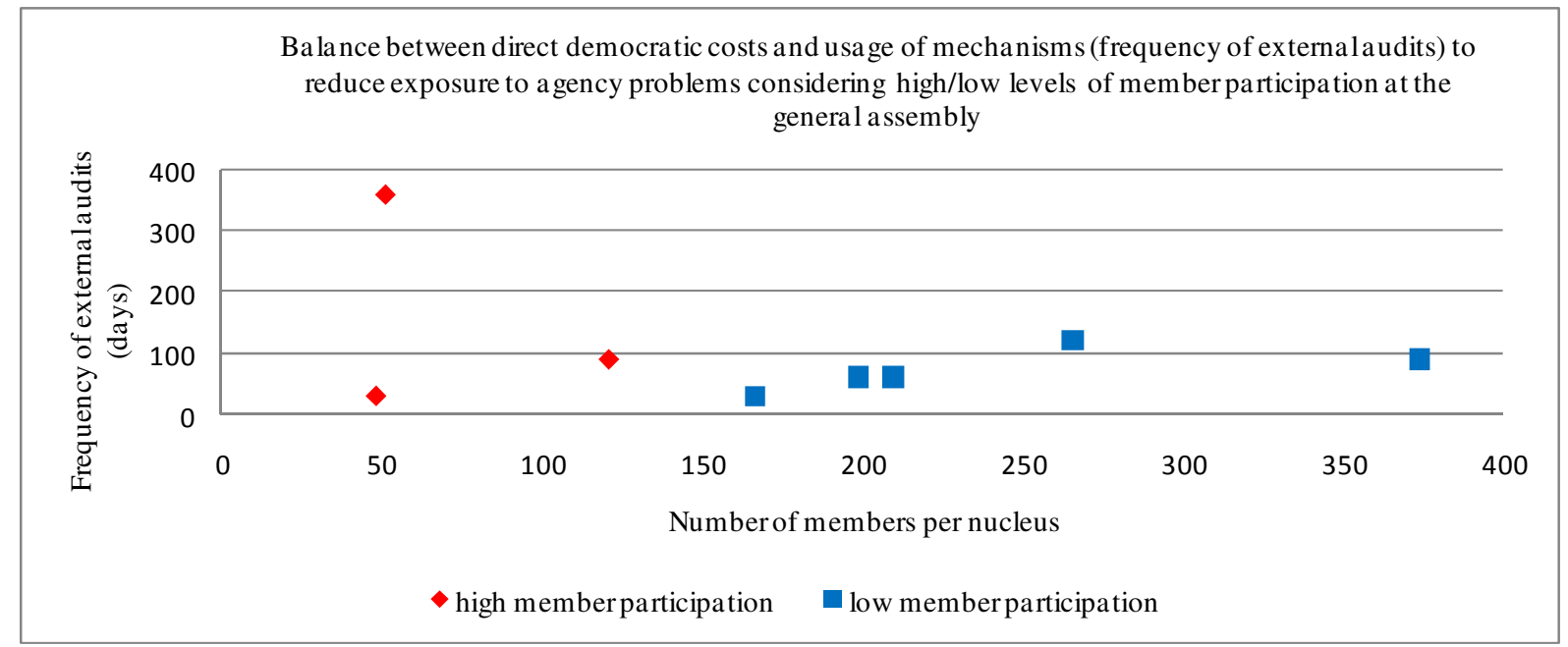

Figure 33 - Balance between direct democratic costs and usage of mechanisms (frequency of external audits) to reduce exposure to agency problems considering high/low levels of member participation at the general assembly

In support of Proposition 1, cooperatives with low member participation and low direct democratic costs generally do have more audits, both internal and external, than cooperatives with high member participation and high direct democratic costs. Cooperatives from the former group seem to compensate the lack of member participation with more frequent auditing. For instance, COOP-H has a lower level of member participation at the general assembly (8\%), and a high number of members per nucleus (266). By offering members less opportunity to participate in nucleus meetings (when compared to other cooperatives; see the number of members per nucleus ratio), the cooperative may save on some democratic costs. However, reduced member 
participation also means that less members are monitoring the management, which may increase agency problems. To prevent that, the cooperative has a high frequency of internal audits (once every 3 days). Therefore, part of the cost savings related to democratic costs may be negotiated by an increase in direct agency costs

\section{Results for member participation at the board}

Three propositions have been developed which relate member participation at the board to democratic costs and usage of agency mechanisms. The validation of these propositions is outlined below.

Results for proposition 4: Cooperatives with high member participation and high direct democratic costs VS. Cooperatives with low member participation and low direct democratic $\underline{\text { costs }}$

Figure 34 shows the two groups of cooperatives which are compared. Cooperatives are regarded as having low member participation at the board, when their board size has less than 12 members (note that those which have 12 or more are considered with higher member participation). Cooperatives are regarded as having high direct democratic costs at the board, when the total annual salary costs are higher than 67,057 . This amount is the average board total salary per year. 


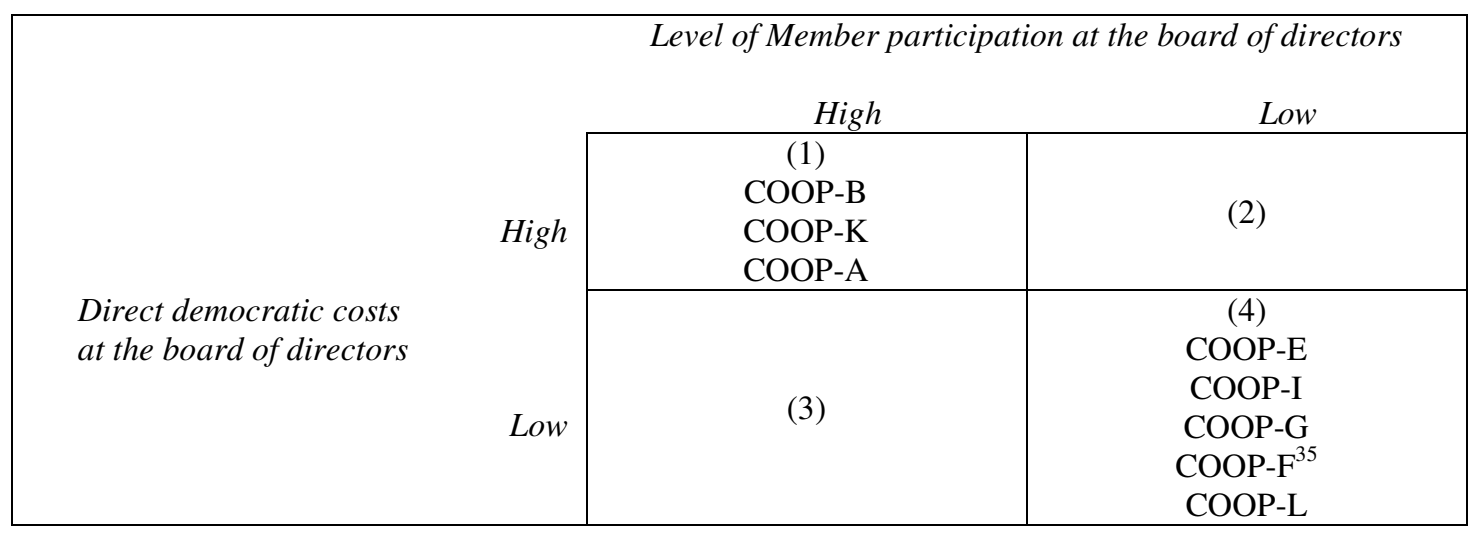

Figure 34 - Two groups of cooperatives: high member participation and high direct democratic costs Vs. low member participation and low direct democratic costs

Tables 40 and 41 below compare the usage of agency mechanisms (frequency of internal audits, Table 40; and frequency of external audits, Table 41) across the two groups of cooperatives.

Table 40 - Direct democratic costs at the board of directors and usage of mechanisms (frequency of internal audits) to reduce exposure to agency problems of cooperatives with high/low levels of member participation at the board of directors

\begin{tabular}{c|c|c|c}
\hline Cooperative & $\begin{array}{c}\text { Level of member } \\
\text { participation at the } \\
\text { board of directors } \\
\text { (board size) }\end{array}$ & $\begin{array}{c}\text { Direct Democratic cost at the } \\
\text { board of directors (Board total } \\
\text { salary/year in R\$) }\end{array}$ & $\begin{array}{c}\text { Usage of mechanisms to reduce } \\
\text { exposure to agency problems } \\
\text { (frequency of internal audits) }\end{array}$ \\
\hline COOP-B & High & 109,200 & 30 \\
COOP-K & & 106,827 & 30 \\
COOP-A & Low & 91,780 & 7 \\
COOP-E & & 65,988 & 10 \\
COOP-I & 65,124 & 30 \\
COOP-G & 61,380 & 30 \\
COOP-F & & 29,376 & 30 \\
COOP-L & & 15,000 & 30 \\
\hline
\end{tabular}

Table 41 - Direct democratic costs at the board of directors and usage of mechanisms (frequency of external audits) to reduce exposure to agency problems of cooperatives with high/low levels of member participation at the board of directors

\begin{tabular}{c|c|c|c}
\hline Cooperative & $\begin{array}{c}\text { Level of member } \\
\text { participation at the } \\
\text { board of directors }\end{array}$ & $\begin{array}{c}\text { Direct democratic costs at the } \\
\text { board of directors (board total } \\
\text { salary/year in } R \$ \text { ) }\end{array}$ & $\begin{array}{c}\text { Usage of mechanisms to reduce } \\
\text { exposure to agency problems } \\
\text { (frequency of external audits) }\end{array}$ \\
\hline COOP-B & High & 109,200 & 30 \\
COOP- $K$ & Low & 106,827 & 360 \\
COOP-A & & 91,780 & 60 \\
\hline COOP-E & & 65,988 & 60 \\
COOP-I & & 65,124 & 90 \\
COOP- $G$ & & 61,380 & 90 \\
COOP- $L$ & & 15,000 & 30 \\
\hline
\end{tabular}

\footnotetext{
${ }^{35}$ This cooperative has not external audits. Because of this, it is not analyzed in Table 45 and Figure 37.
} 
These relations are also depicted below in Figures 35 (considering frequency of internal audits) and 36 (considering frequency of external audits).

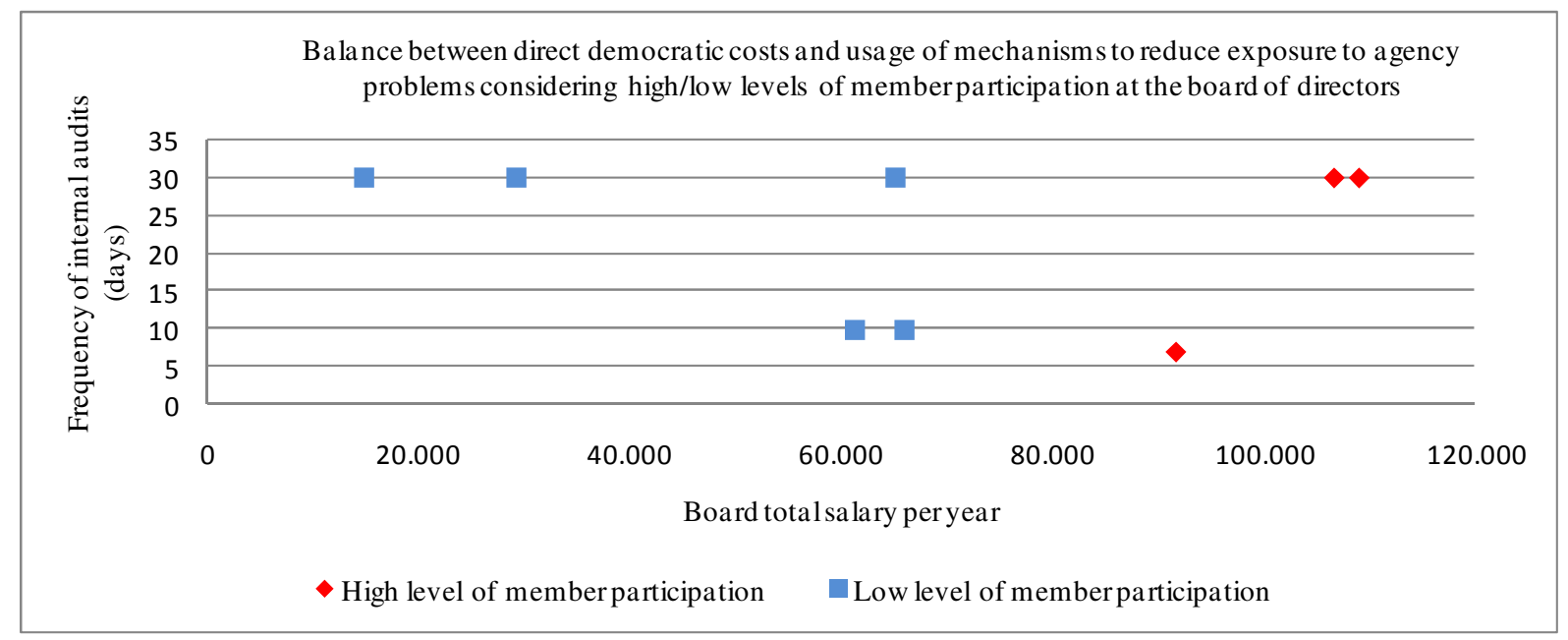

Figure 35 - Balance between direct democratic costs and usage of mechanisms (frequency of internal audits) to reduce exposure to agency problems considering high/low levels of member participation at the board of directors

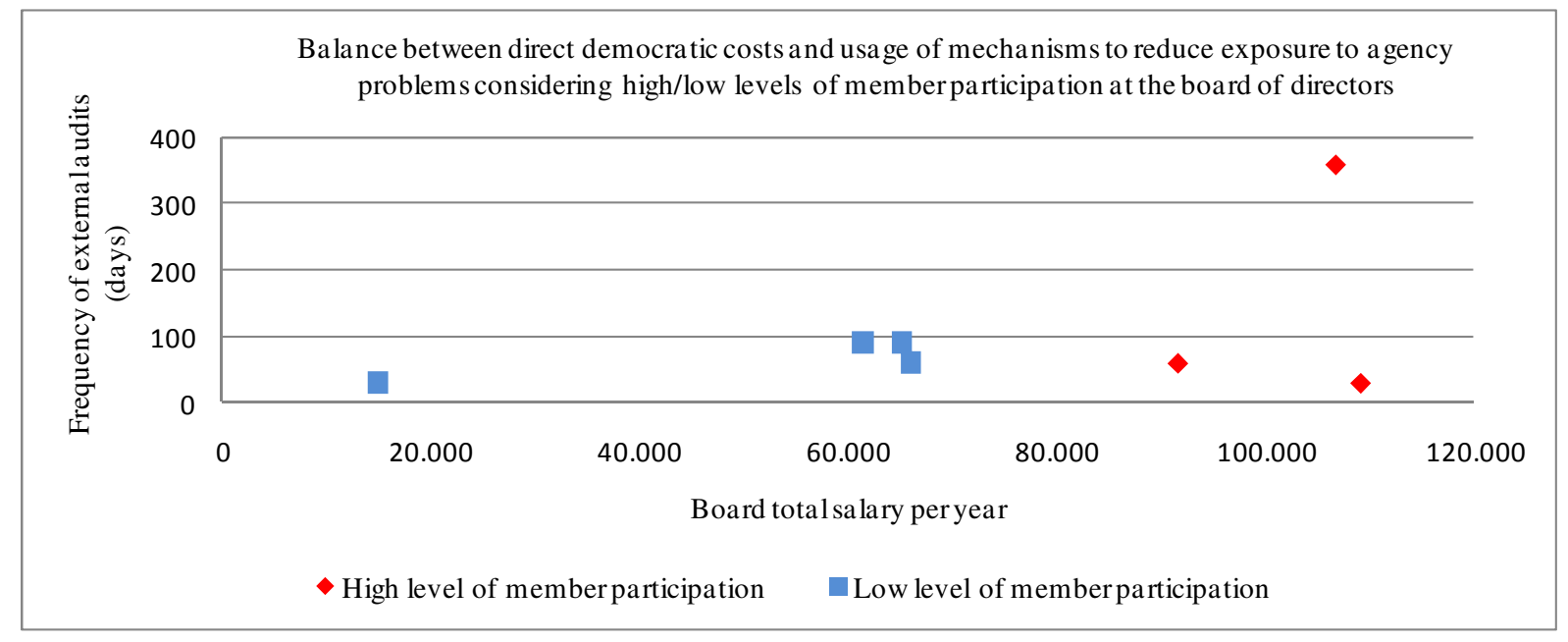

Figure 36 - Balance between direct democratic costs and usage of mechanisms (frequency of external audits) to reduce exposure to agency problems considering high/low levels of member participation at the board of directors

The results partially support the proposition. Cooperatives that have a small board do not have more internal audits than those cooperatives with a large board. Note, this does not necessarily mean that the underlying logic of the proposition is not supported (i.e., that cooperatives with low member participation should use more agency mechanisms), it can also mean that some of the cooperatives incur high costs in their decision making process. 
According to the proposition, cooperatives which have lower level of member participation should increase the frequency by which they are audited, since member participation is low, which can increase the risk of agency problems. Cooperatives with small board size and low frequency of audits may therefore incur high opportunity agency costs. With regard to internal audits, this applies to COOP-I, COOP-F and COOP-L, which all have low member participation and a low frequency of internal audits. Particular COOP-I seems to incur high costs related to its internal decision making. Besides an increased risk to agency problems, and thus potentially high opportunity agency costs, COOP-I also has relatively high annual salary costs for a small board, and also significant direct democratic costs.

With regard to external audits, most cooperatives have more or less the same frequency of auditing. Exception is COOP-K, which is audited much less frequently (once per year) than the other cooperatives. COOP-K'S use of external audits follows the logic of the proposition: its high member participation at the board, while increases direct democratic costs in the form of high salary costs, reduces the need for (additional) mechanisms to monitor management.

Results for proposition 5: Cooperatives with high member participation and low opportunity democratic costs VS. Cooperatives with low member participation and high opportunity democratic costs

Figure 37 shows the two groups of cooperatives which are compared. Cooperatives are regarded as having low member participation at the board, when their board size has less than 12 members (note that those which have 12 or more are considered with higher member participation). Cooperatives are regarded as having high opportunity democratic costs at the board, when they have products underrepresented at the board. 


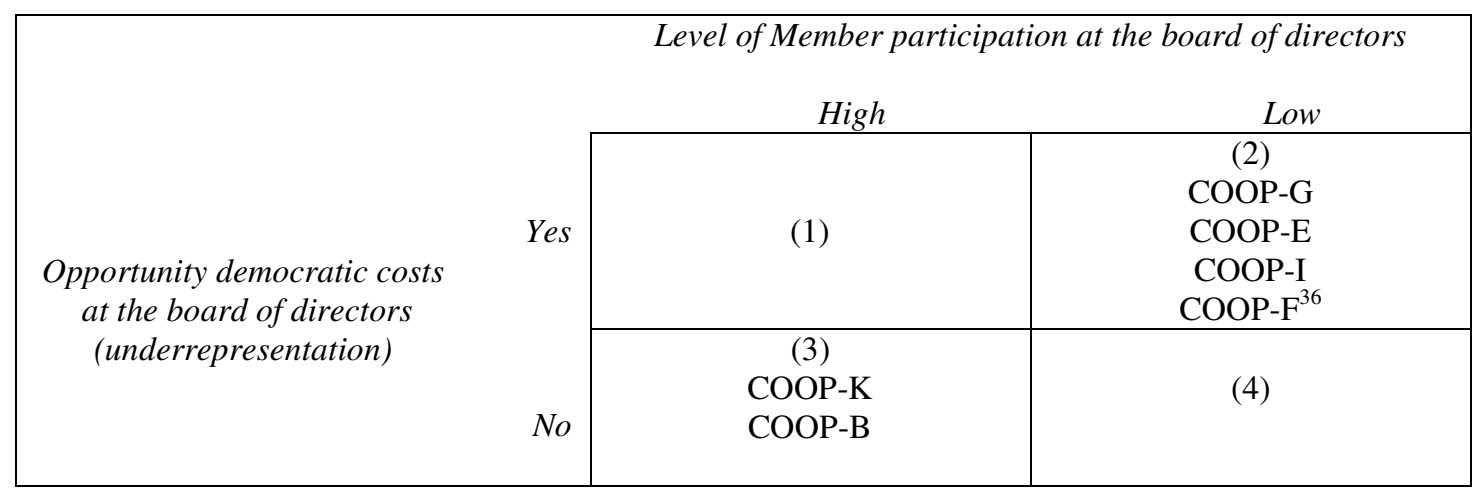

Figure 37 - Two groups of cooperatives: low member participation and opportunity democratic costs Vs. high member participation and no opportunity democratic costs

Tables 42 and 43 below compare the usage of agency mechanisms (frequency of internal audits, Table 42; and frequency of external audits, Table 43) across the two groups of cooperatives.

Table 42 - Opportunity democratic costs at the board of directors (underrepresentation) and usage of mechanisms (frequency of internal audits) to reduce exposure to agency problems of cooperatives with high/low levels of member participation at the board of directors

\begin{tabular}{c|c|c|c}
\hline Cooperative & $\begin{array}{c}\text { Level of member } \\
\text { participation at the } \\
\text { board of directors } \\
\text { (board size) }\end{array}$ & $\begin{array}{c}\text { Opportunity democratic costs at } \\
\text { the board of directors, } \\
\text { underrepresentation (number of } \\
\text { products underrepresented) }\end{array}$ & $\begin{array}{c}\text { Usage of mechanisms to reduce } \\
\text { exposure to agency problems } \\
\text { (frequency of internal audits) }\end{array}$ \\
\hline COOP-K & High & 0 & 30 \\
COOP-B & Low & 0 & 30 \\
\hline COOP-G & & 7 & 10 \\
COOP-E & 2 & 10 \\
COOP-I & 2 & 30 \\
COOP-F & & & 30 \\
\hline
\end{tabular}

Table 43 - Opportunity democratic costs at the board of directors (underrepresentation) and usage of mechanisms (frequency of external audits) to reduce exposure to agency problems of cooperatives with high/low levels of member participation at the board of directors

\begin{tabular}{c|c|c|c}
\hline \multirow{2}{*}{$\begin{array}{c}\text { Cooperative } \\
\text { COOP-K }\end{array}$} & $\begin{array}{c}\text { Level of member } \\
\text { participation at the } \\
\text { board of directors } \\
\text { (board size) }\end{array}$ & $\begin{array}{c}\text { Opportunity democratic costs at } \\
\text { the board of directors, } \\
\text { underrepresentation (number of } \\
\text { products underrepresented) }\end{array}$ & $\begin{array}{c}\text { Usage of mechanisms to reduce } \\
\text { exposure to agency problems } \\
\text { (frequency of external audits) }\end{array}$ \\
\hline COOP-B & High & 0 & 360 \\
COOP-G & Low & 0 & 30 \\
COOP-E & & 7 & 90 \\
COOP-I & 2 & 90 \\
\hline
\end{tabular}

\footnotetext{
${ }^{36}$ This cooperative has not external audits. Because of this, it is not analyzed in Table 48 and Figure 40.
} 
These relations are also depicted in Figures 38 (considering frequency of internal audits) and 39 (considering frequency of external audits) below.

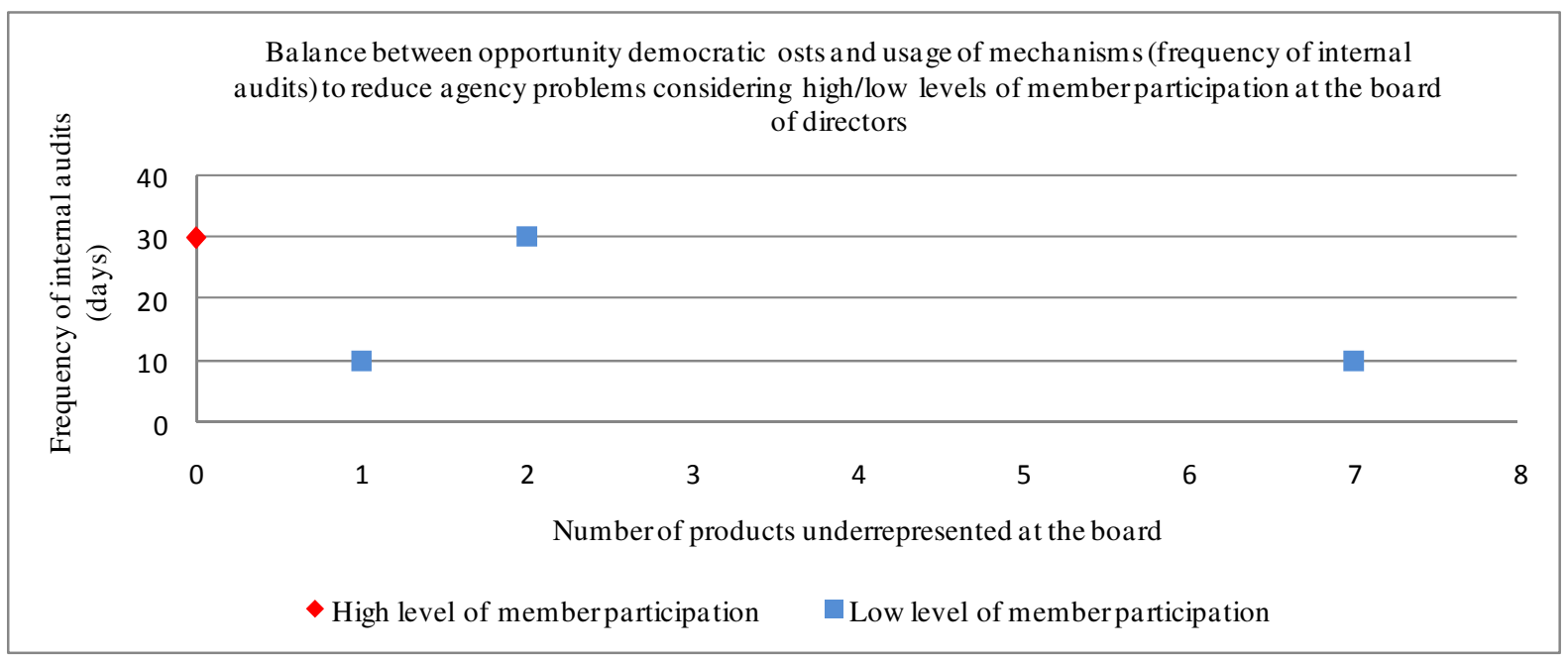

Figure 38 - Balance between opportunity democratic costs and usage of mechanisms (frequency of internal audits) to reduce agency problems considering high/low levels of member participation at the board of directors

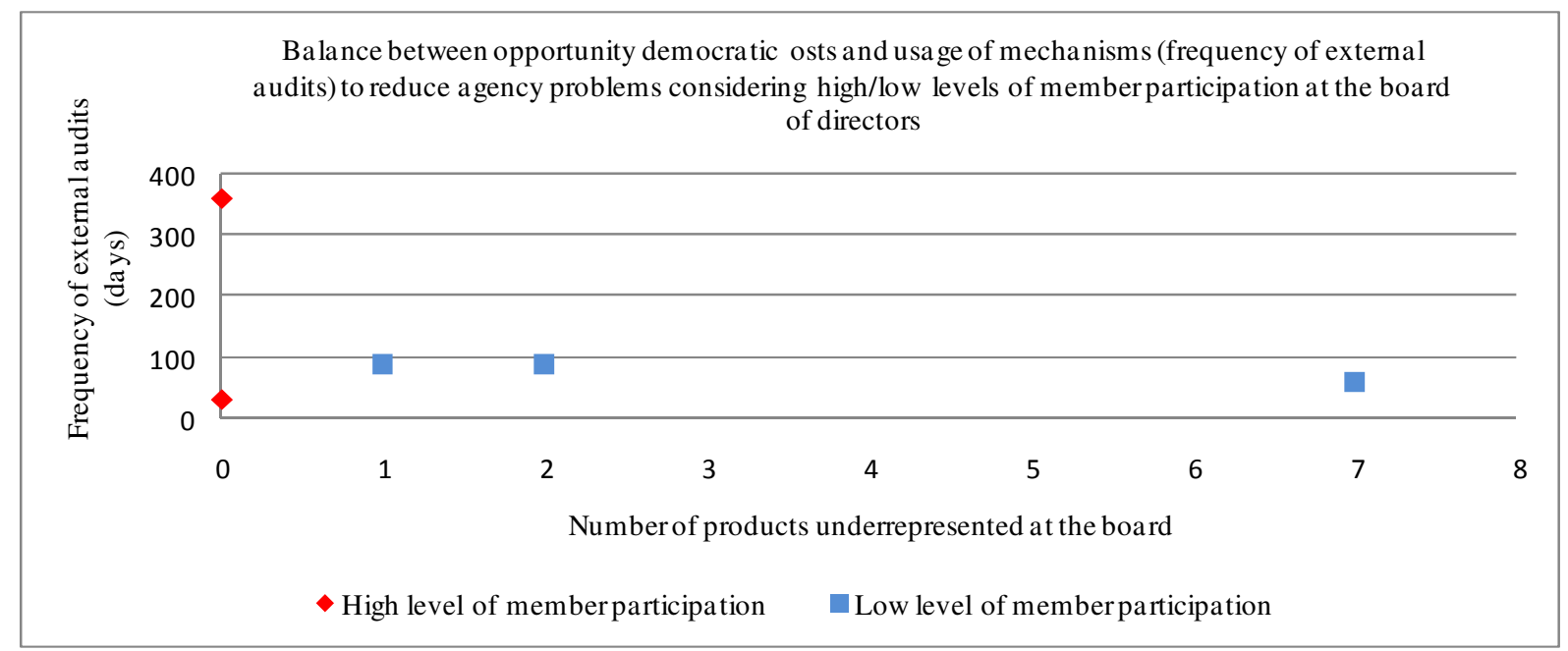

Figure 39 - Balance between opportunity democratic and usage of mechanisms (frequency of external audits) to reduce agency problems considering high/low levels of member participation at the board of directors

Figure 38 shows that cooperatives that have lower level of member participation at the board of directors, COOP-G, COOP-E, COOP-I, COOP-F have higher frequency of internal audits, in accordance with the proposition 4. Cooperatives such as COOP-K and COOP-B that have higher level of member participation and a higher frequency of internal audits may incur unnecessary (direct) agency costs. Of course, to the extent that these audits prevent agency problems, their costs may not be an issue. However, some of the cooperatives may be exaggerating with the 
frequency of their internal audits. Too frequent audits may not only lead to unnecessary costs, it may also reduce the quality of the audits.

Particular troubling are those cooperatives which incur high democratic costs besides agency costs. In this regard, COOP-B is an example worth mentioning: despite a large board, it has a very high frequency of both internal and external audits (once every 30 days) which increase (direct) agency costs. This may be an excessive number of audits for a cooperative that also have a large board that should monitor management.

With regard to external auditing (Figure 39), cooperatives with low member participation at the board have frequent audits (once ever 90 days or more frequently). And, cooperatives with high level of member participation have less frequent external audits.

Results for proposition 6: Cooperatives with high member participation and high opportunity democratic costs VS. Cooperatives with low member participation and low opportunity democratic costs

Figure 40 shows the two groups of cooperatives which are compared. Cooperatives are regarded as having low member participation at the board, when their board size has less than 12 members (note that those which have 12 or more are considered with higher member participation). Cooperatives are regarded as having high opportunity democratic costs at the board when they have either 2 or more products overrepresented at the board. ${ }^{37}$

\footnotetext{
${ }^{37}$ In chapter 3 we considered cooperatives regarded as having high opportunity democratic costs at the board when they had more than one product overrepresented at the board. In the present chapter we extend it to 2 products because otherwise there would have not enough cooperatives to be compared.
} 


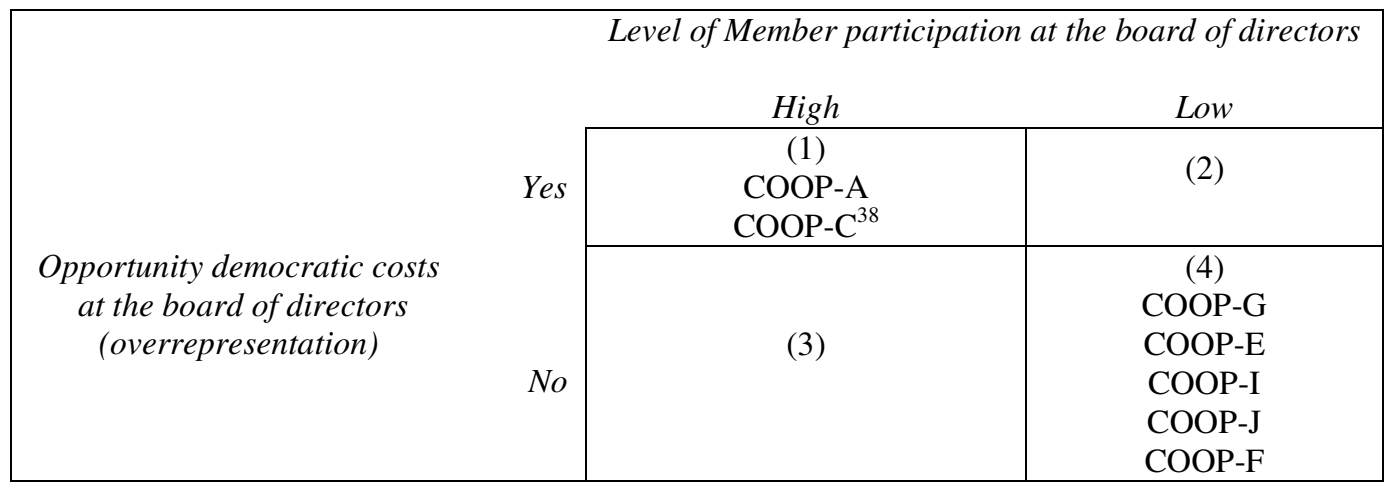

Figure 40 - Two groups of cooperatives: high member participation and opportunity democratic costs Vs. low member participation and no opportunity democratic costs

Tables 44 and 45 below compare the usage of agency mechanisms (frequency of internal audits, Table 44; and frequency of external audits, Table 45) across the two groups of cooperatives.

Table 44 - Opportunity democratic costs at the board of directors (overrepresentation) and usage of mechanisms (frequency of internal audits) to reduce exposure to agency problems of cooperatives with high/low levels of member participation at the board of directors

\begin{tabular}{c|c|c|c}
\hline Cooperative & $\begin{array}{c}\text { Level of member } \\
\text { participation at the } \\
\text { board of directors } \\
\text { (board size) }\end{array}$ & $\begin{array}{c}\text { Opportunity democratic costs at } \\
\text { the board of directors, } \\
\text { overrepresentation (number of } \\
\text { products overrepresented) }\end{array}$ & $\begin{array}{c}\text { Usage of mechanisms to reduce } \\
\text { exposure to agency problems } \\
\text { (frequency of internal audits) }\end{array}$ \\
\hline COOP-A & High & 3 & 7 \\
COOP-C & Low & 2 & 15 \\
\hline COOP-G & & 1 & 10 \\
COOP-E & 1 & 10 \\
COOP-I & 1 & 30 \\
COOP-J & & 1 & 30 \\
COOP-F & & & \\
\hline
\end{tabular}

Table 45 - Opportunity democratic costs at the board of directors (overrepresentation) and usage of mechanisms (frequency of internal audits) to reduce exposure to agency problems of cooperatives with high/low levels of member participation at the board of directors

\begin{tabular}{c|c|c|c}
\hline Cooperative & $\begin{array}{c}\text { Level of member } \\
\text { participation at the } \\
\text { board of directors } \\
\text { (board size) }\end{array}$ & $\begin{array}{c}\text { Opportunity democratic costs at } \\
\text { the board of directors, } \\
\text { overrepresentation (number of } \\
\text { products overrepresented) }\end{array}$ & $\begin{array}{c}\text { Usage of mechanisms to reduce } \\
\text { exposure to agency problems } \\
\text { (frequency of external audits) }\end{array}$ \\
\hline COOP-A & High & 3 & 60 \\
COOP-G & Low & 1 & 90 \\
COOP-E & & 1 & 60 \\
COOP-I & 1 & 90 \\
COOP-J & 1 & 360 \\
\hline
\end{tabular}

${ }^{38}$ This cooperative has not external audits. Because of this, it is not analyzed in Table 49 and Figure 43. 
This relation is also depicted in Figures 41 (considering frequency of internal audits) and 42 (considering frequency of external audits) below.

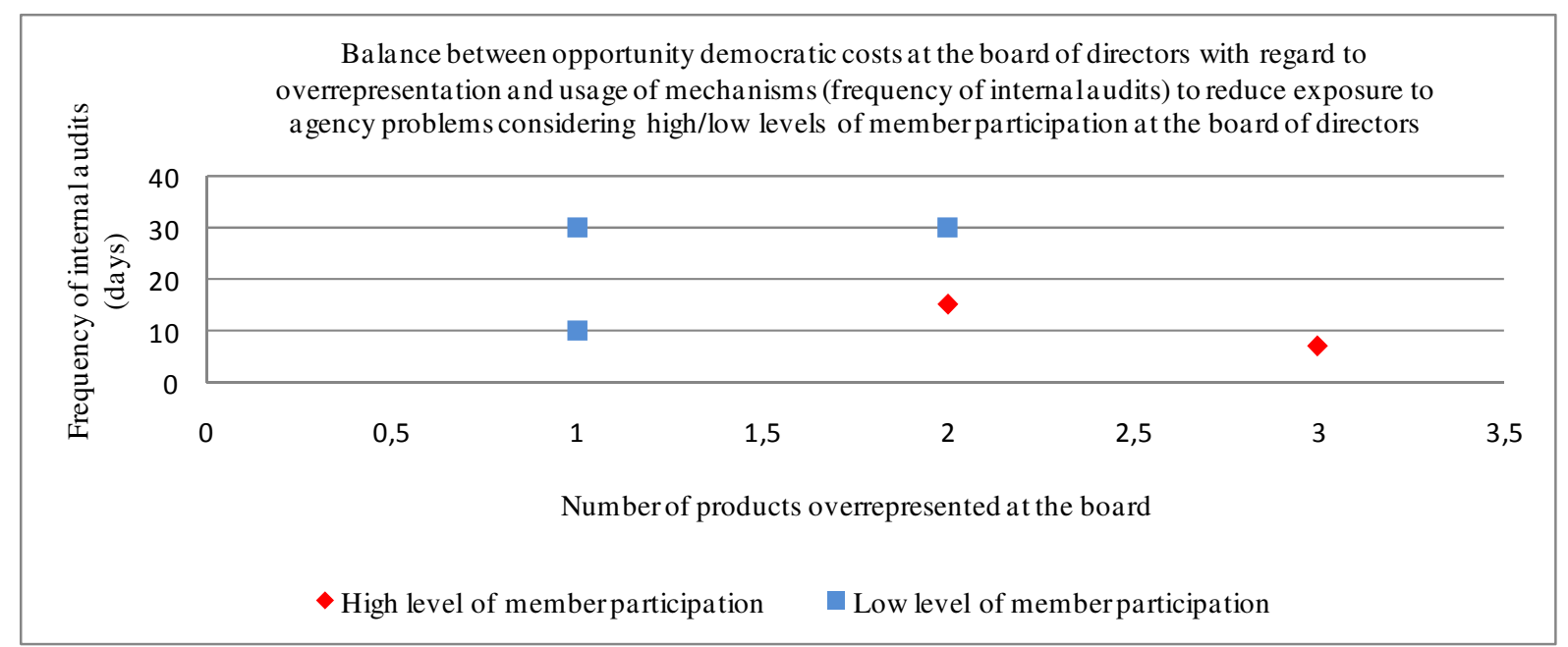

Figure 41 - Balance between opportunity democratic costs at the board of directors with regard to overrepresentation and usage of mechanisms (frequency of internal audits) to reduce exposure to agency problems considering high/low levels of member participation at the board of directors

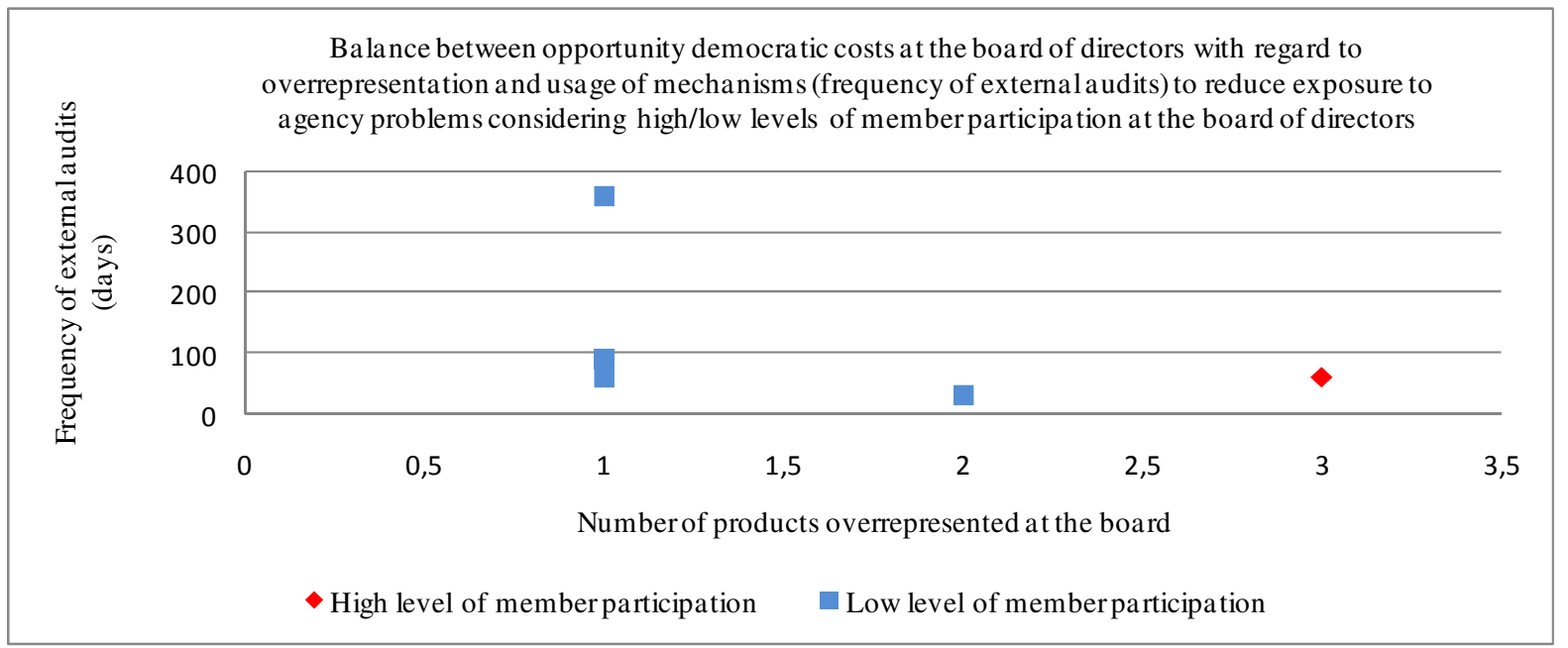

Figure 42 - Balance between opportunity democratic costs at the board of directors with regard to overrepresentation and usage of mechanisms (frequency of external audits) to reduce exposure to agency problems considering high/low levels of member participation at the board of directors

Figure 41 shows that some of the cooperatives (COOP-I, COOP-J, COOP-F) that have lower level of member participation at the board of directors (i.e., the small board size) have the lowest frequency of internal audit. According to the proposition, they would be expected to have higher frequency of internal audits (i.e., higher usage of mechanisms to reduce exposure to agency problems), since they have smaller board (i.e., fewer members monitoring management), that is 
the case of COOP-G and COOP-E. The figure shows also that cooperatives that have high level of member participation at the board of directors have higher frequency of internal audits. As a result, they are incurring in democratic costs and unnecessary (direct) agency costs.

In addition, Figure 42 shows that although COOP-K (the cooperative has low level of member participation and also infrequent external audits) those cooperatives that have lower member participation at the board of directors do have external audits more frequently. However, they are not more frequently than do cooperatives that have higher member participation at the board of directors. Once more, cooperatives that have higher level of member participation and a higher frequency of external audits may incur unnecessary (direct) agency costs. In summary, COOP-K is incurring in high democratic costs and high exposure to agency problems; the rest of the group of cooperatives with low member participation is balancing their low democratic costs with usage of frequent external audits; and the group of cooperatives with high member participation has high democratic costs and high direct agency costs but low exposure to agency opportunity costs.

\subsection{Conclusion}

This study has examined how cooperatives can control both democratic and agency costs considering different levels of member participation. It is a key issue for cooperatives since, at the same time, member-democratic control makes decision making process slower and more costly in cooperatives in contrast with investor-owned firms and cooperatives lack some of the mechanisms which investor-owned firms use to control agency costs. This is the main theme of the present thesis. Insufficient research has examined both democratic and agency costs in agricultural cooperatives.

Delegating more control to the management team may reduce democratic costs, since decision making processes require less input or participation of the members. However, with lower level of member participation, agency costs are likely to increase, as fewer members will monitor management. In such situations, cooperatives should use more agency 'mechanisms' (which will increase direct agency costs), such as increase the frequency of internal and external audits, in 
order to avoid a high risk of exposure to agency problems (and thus avoid a increase in opportunity agency costs). The research question that led the present study has been the following: How does the ability of cooperatives to control both democratic and agency costs is related to the level of member participation? In order to answer this question, we have developed six propositions. We have examined the relationships suggested by the propositions by means of the scatter plot.

The first proposition compared the use of agency mechanisms across two different groups: (1), cooperatives with high member participation and high direct democratic costs; (2), cooperatives with low member participation and low direct democratic costs. Proposition 1 predicted that cooperatives from the first group would use less agency mechanisms than cooperatives from the second group. The results validated this proposition, as cooperatives from this group have fewer audits than cooperatives from the second group. Cooperatives from the second group compensate the lack of participation of its members in cooperative governance, by increased audits of the management team, i.e., the auditors monitor on behalf of the members. Low member participation for these cooperatives may reduce direct democratic costs, but it also increases direct agency costs as increased audits of management is necessary to prevent agency problems and thus an increase in opportunity agency costs.

The second proposition compared the use of agency mechanisms across two groups: (1), low level of member participation and high opportunity democratic costs with regard to underrepresentation; (2) high level of member participation and high opportunity democratic costs with regard to underrepresentation. The proposition predicted that cooperatives from the first group use more agency mechanisms than cooperatives from the second group. This proposition could not be tested because underrepresentation at the general assembly was not an issue for almost all researched cooperatives.

The third proposition compared the use of agency mechanisms across two groups: (1), high level of member participation and high opportunity democratic costs with regard to overrepresentation; (2) low level of member participation and low opportunity democratic costs with regard to overrepresentation. The proposition predicted that cooperatives from the first group use less agency mechanisms than cooperatives from the second group. This proposition also could not be 
tested because almost all researched cooperatives with high member participation incur opportunity costs of overrepresentation at the general assembly.

The fourth proposition compared the use of agency mechanisms across two groups: (1), high level of member participation and high direct democratic costs; (2) low level of member participation and low direct democratic costs. The proposition predicted that cooperatives from the first group use less agency mechanisms than cooperatives from the second group. No significant differences could be found between the two groups with regard to both types of agency mechanisms.

The fifth proposition compared the use of agency mechanisms across two groups: (1), those cooperatives with low member participation and high opportunity costs of underrepresentation; (2) those cooperatives with high member participation and low opportunity costs of underrepresentation. The proposition predicted that cooperatives from the first group use more agency mechanisms than cooperatives from the second group. This was supported by the results, as cooperatives from this group have more frequent audits, in particular internal audits. On the one hand, this result is positive, as these cooperatives seem to take agency problems seriously. On the other hand, some of the cooperatives may be exaggerating with regard to the frequency of internal audits (e.g., once every 10 days), which may reduce the quality of the audits. Furthermore, some cooperatives have both large boards (which should already monitor management) as well as an additional high frequency of audits. In other words, these cooperatives incur both high direct democratic costs (i.e., in terms of board salary) as well as high direct agency costs (in terms of high auditing costs). Some of these cooperatives, however, have high opportunity costs of underrepresentation. It could be that the additional audits take place to protect the interests of the underrepresented groups.

The sixth proposition compared the usage of agency mechanisms across two groups: (1) high level of member participation and high opportunity costs of overrepresentation; (2), low level of member participation and low opportunity costs of overrepresentation. The proposition predicted that cooperatives from the first group use less agency mechanisms than cooperatives from the second group. The proposition was supported with regard to use of external mechanisms, but not with regard to use of internal mechanisms. With regard to the usage of internal mechanisms, no 
difference could be found between the two groups. As is explained above, it could be that cooperatives from the first group need additional agency mechanisms because underrepresented producer groups in these cooperatives want additional audits of management, to prevent that management colludes with the board which does not represent the interests of the whole cooperative.

By and large, the results show that some cooperatives indeed face difficulties in minimizing both democratic costs and agency costs. At the general assembly, cooperatives with low member participation and low direct democratic costs generally do have more audits, both internal and external, than cooperatives with high member participation and high direct democratic costs. Cooperatives from the former group seem to compensate the lack of member participation with more frequent auditing. At the board of directors, some cooperatives use frequent agency mechanism (external audits), even though they already have a large board. At the one hand, this may be regard as positive: the cooperatives take agency problems seriously. At the other, considering the high level of member participation at board of these cooperatives, which primary task is to monitor management, the frequency by which they use additional mechanisms to monitor management may be excessive. For example, some cooperatives undertake internal audits once a week. This may prevent management from focusing on the actual management of the cooperative. Furthermore, the results have shown that cooperatives are more oriented towards minimizing opportunity agency costs than opportunity democratic costs. Opportunity democratic costs arise, amongst others, when cooperative decision makers make decisions which benefit some member groups at the expense of other groups. Opportunity agency costs arise when cooperative decision makers make decisions which benefit themselves rather than the members. Therefore, although cooperative decision makers are unlikely to make decisions which benefit themselves (because they are frequently audited etc.), they may make decisions which benefit certain interest groups within the cooperative. This is because some interest groups are underrepresented at board level.

The present study provided contributions to various segments, such as the literature on transaction costs, corporate governance, and cooperative management. The sections outlined below summarize the theoretical, methodological and managerial implications of these findings. Limitations of the research and directions for further research are given further in chapter 5. 


\section{Theoretical contributions}

The present study has examined a much broader range of decision making costs than most studies. Additionally, the study distinguished between the various (i.e., horizontal, vertical and diagonal) conflicts of interests which form the sources of these costs. Horizontal conflicts of

interest can lead to direct and opportunity democratic costs; diagonal conflicts of interests to opportunity democratic costs of over-and underrepresentation; while vertical conflicts of interests can lead to both direct and opportunity agency costs. Previous studies do not distinguish between these different sources of conflicts of interests. In particular, often diagonal conflicts of interests are often lumped together with either horizontal or vertical conflicts of interests. Without examining the sources of decision making costs, it is difficult for studies to examine what types of mechanisms are necessary for controlling these costs.

Moreover, the present study has shown the differences in weighs between direct and opportunity agency costs. In other words, it has shown that direct agency cost should be a smaller concern for cooperatives comparing to the risk of exposure to high opportunity agency costs.

Mainly, the present study has shown the difficulties cooperative face in minimizing both democratic and agency costs. This topic has received insufficient attention in the literature, with most studies examining only certain types of democratic costs or agency costs, but not examining these costs jointly. The present study has shown that with lower level of member participation, direct democratic costs may be reduced, but opportunity agency costs may rise as fewer members monitor management. In this case, cooperatives should increase either member participation or use additional agency mechanisms (e.g., audits) to reduce exposure to agency problems.

\section{Managerial implications}

The present study has drawn attention to some of the trade-offs cooperatives face in reducing decision making costs: e.g., between reducing agency or democratic costs; or between reducing direct or opportunity costs. The study has revealed that, rather than increasing member participation, cooperatives could consider other strategies for improving cooperative governance. For example, cooperatives could implement more representative boards and skilled management 
teams as well as increased use of agency mechanisms to control management (e.g., frequent audits). As members are apparently unwilling to get involved in cooperative governance, other mechanisms are required to monitor and control the cooperative. 
The motivation for this thesis was the observed loss of competitiveness of cooperatives compared to investor-owned firms. One of the main explanations of this, given in the literature, are the higher decision making costs which cooperatives face when compared to investor-owned firms. On the one hand, cooperatives may face costs related to the collective democratic control (i.e., democratic costs). Control is likely more decentralized in cooperatives, as each member has one vote, unlike investor-owned firms where large blocks of shareholders may control the organization. On the other hand, cooperatives may also face additional costs in monitoring the management, when compared to investor-owned firms (i.e., agency costs). Because no individual member has a large stake in the cooperative, there may be little incentive for members to monitor how the cooperative is managed.

The focus of the present thesis was on how cooperatives can control both democratic and agency costs, and on the factors that affect the ability of cooperatives to control these costs. In particular, two factors are important in this regard: the level of heterogeneity and the level of member participation in cooperative governance. The level of heterogeneity affects the level of member participation in cooperative governance, while the level of member participation in turn affects decision making costs (democratic and agency costs). The thesis has examined how cooperatives can control both democratic and agency costs considering different levels of heterogeneity and member participation. The relationships amongst the key variables of the studies have been examined from three different angles, resulting in three research questions.

RQ1: What is the relation between level of heterogeneity and level of member participation in the governance of agricultural cooperatives?

RQ2: What is the relation between level of member participation and democratic costs in agricultural cooperatives?

RQ3: How is the ability of cooperatives to control both democratic and agency costs related to the level of member participation? 
To answer these questions, data was collected in 12 cooperatives from Rio Grande do Sul. To generate the data, multiple methods were employed, such as: two interviews per cooperative, including the elected manager and the hired executive; cooperatives' records analysis such as reports, minutes, balance sheets; observations at cooperatives' websites.

These questions have been addressed in Chapters 2-4. The sections outlined below summarize the findings presented in these chapters. Subsequently, the theoretical, methodological and managerial implications of these findings are discussed. Also, the limitations of the current study are discussed and areas for further research are highlighted.

\subsection{Heterogeneity and level of member participation in cooperative governance}

A challenge cooperatives face is to minimize decision making costs. This chapter has examined the relationship between two aspects of cooperatives that affect the ability with which they can minimize these costs: the level of heterogeneity and the level of member participation in cooperative governance. The more heterogeneous a cooperative is, the more the interests of the various member groups of the cooperative are likely to differ, resulting in additional decision making costs. In the first part of the chapter, a model was developed which ranks cooperatives from homogenous to heterogeneous with regard to member characteristics (farm size) and cooperative characteristics (share of each type of product delivered by members in the annual revenues of the cooperative and the number of members which deliver each type of product). In the second part of the chapter, this ranking of cooperatives was used to test the relation between heterogeneity and member participation by means of a logistic regression model.

In the first part of the chapter, a proposed measurement of heterogeneity based on grouping, with the aim of showing the presence (absence) of a dominant group and the size of the minority group(s) has been developed. Measuring heterogeneity based on grouping means that the cooperatives are placed into various groups based on certain criteria, for example, the size of the largest producer group (e.g., the rice produces) and the size of the second largest producer group 
in the cooperative (e.g., soybeans producers). In total, five different categories have been distinguished, which rank cooperatives from homogeneous to more heterogeneous:

- (1), one dominant party: the cooperative's largest group of producers (e.g., rice producers) is responsible for over $50 \%$ of the total revenues and the second largest group (e.g., soya producers, pig producers) is responsible for no more than $20 \%$ of the total revenues;

- (2), one majority party and one small minority: the cooperative's largest group is responsible for over $50 \%$ of the total revenues and the second largest group is responsible for $21-30 \%$ of the total revenues;

- (3), one majority party and one significant minority: the cooperative's largest group is responsible for over $50 \%$ of the total revenues and the second largest group is responsible for $31-40 \%$ of the total revenues;

- (4), one majority party and one large minority: the cooperative's largest group is responsible for over $50 \%$ of the total revenues and none of the other groups is responsible for $41-50 \%$ of the total revenues;

- (5), no majority groups: either more than one group is responsible for more than $50 \%$ of the total revenues, or none of the producer groups is responsible for more than $50 \%$ of the total revenues.

An alternative way of measuring heterogeneity is to rank the cooperatives based on the coefficient of variation (CV). This measure, frequently used by biological scientists to assess heterogeneity, was compared to the developed model (i.e., grouping measurement of heterogeneity). However, $\mathrm{CV}$ as a heterogeneity measurement model was not found useful to assess cooperative's heterogeneity because, in determining which cooperatives are more heterogeneous, it did not take into account the importance of dominant groups in the cooperatives (i.e., those groups responsible for the majority of the revenues) which can (informally) control the cooperative, even if there were a lot of small groups besides it.

In the second part of the chapter, differences in the level of member participation across these categories have been examined. Two types of member participation have been distinguished in the study: (1), at the general assembly; and (2), at the board of the directors. The relation between 
heterogeneity and member participation at the general assembly has been examined by means of scatter plots. The relation between heterogeneity and member participation at the board has been examined by means of logistic regression.

The results of the scatter plots showed that member participation increases with higher levels of heterogeneity until heterogeneity reaches a certain level where the cooperative lacks a dominant group. Cooperatives placed into category 1-4 show increased member participation when one shifts from one category to the next; i.e., a cooperative in category 3 has higher member participation than a cooperative in category 2 , and a cooperative in category 4 has higher member participation than either group. However, the member participation starts to fall again in the cooperatives in category 5 , where no single producer group has a dominant share in the total revenues.

These results are in line with the theoretical model developed in the chapter which postulates that there is a non-linear relation between member participation and level of heterogeneity (Figure 43). The model predicted that members have a stronger incentive to participate when heterogeneity increases, as long as there is a dominant group. When there is a dominant group and the cooperative is homogenous (category 1 cooperative), there is less incentive for members to participate as the interests of the members are aligned. When there is a dominant group and the cooperative is heterogeneous (category 4 cooperative), members have a strong incentive to participate to protect their interest: members from the dominant group to protect its interest and the large minority groups because they want to prevent the dominant group from taking control over the cooperative. Without a dominant group (category 5 cooperative) there is less incentive to participate because there is less threat of exploitation by the majority group, and member participation starts to fall again. 


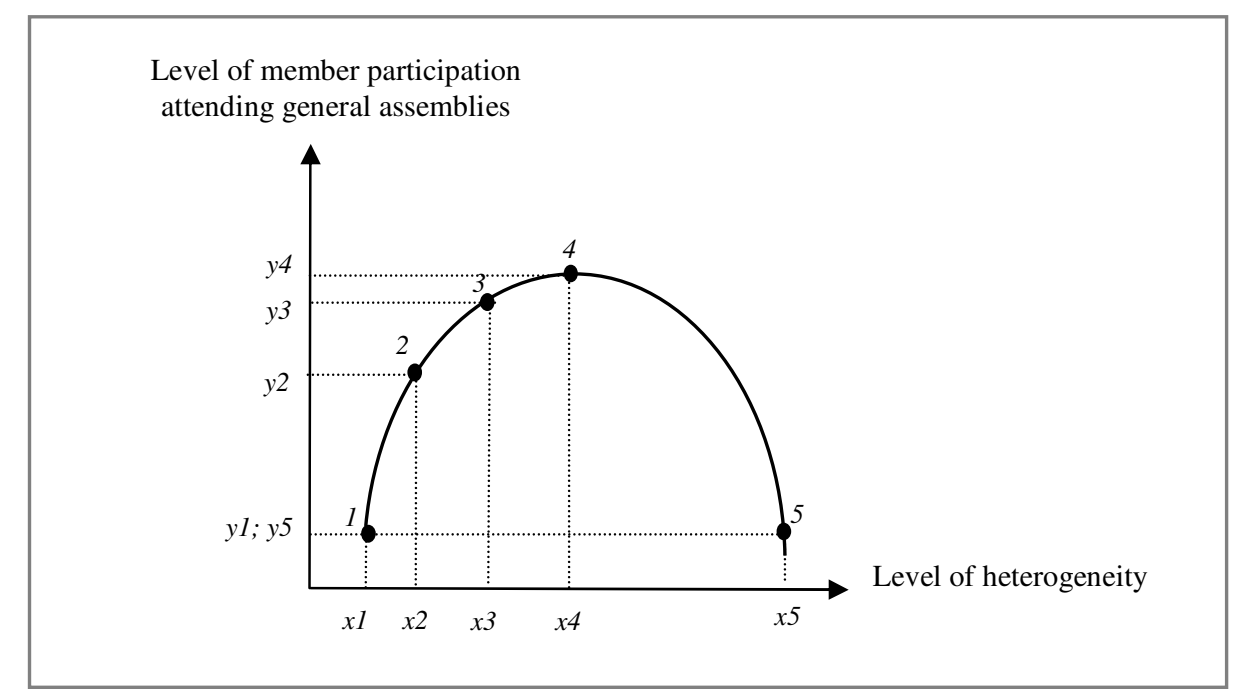

Figure 43 - Relation between level of heterogeneity and level of member participation at the general assembly

To test the relation between heterogeneity and member participation at the board of directors, 7 logistic regressions have been examined. The purpose of the regressions was to examine whether larger farmers participate more in the board of directors when the cooperative is more heterogeneous. The underlying logic is that larger farmers, who are a minority in the cooperative and thus have limited voting power at the general assembly, try to protect their interest by means of board participation. We expected that probability that larger farmers participate in the board is highest for the most heterogeneous cooperatives that still have a dominant group (category 4).

The results more significantly supported the proposition for two variables (one related to cooperatives' characteristics and another related to members' characteristics): (1), levels of cooperative heterogeneity with regard to the size of the largest group of producers $\left(\mathrm{PG}_{1}\right)$ in relation to the size of the minorities $\left(\mathrm{PG}_{2}\right)$ (i.e., the variable PERCMEMB) and also the variable CV_PERCMEMB (i.e., variability of the weights of all groups of members who deliver each product); and (2), variability of the percentages of groups of members who deliver large, medium and small volume of products to the cooperative (i.e., the variable CV_PERCVOL). 


\subsection{The costs of democratic control}

This chapter has developed the concept of democratic costs. Furthermore, it has examined the relation between member participation and democratic costs at both the general assembly and the board of directors. Two types of democratic costs have been distinguished: direct and opportunity costs. Direct democratic costs are the costs associated with members' time, board and executives' time, and salary costs. Opportunity democratic costs are those costs associated with delayed decisions (which can result in lost opportunities) or failure to achieve decisions which maximize the benefit of all members. Table 46 shows the propositions which have been developed to examine the relation between democratic costs and member participation.

Table 46 - Propositions on the relation between member participation in cooperative governance and democratic costs

Propositions

1: The higher is the level of member participation at the general assembly, the higher are the direct democratic costs.

2: When the level of member participation at the general assembly is low, the more likely the cooperative is to incur opportunity costs of underrepresentation. When the level of member participation at the general assembly increases until all (groups of) members are (proportionally) represented, opportunity democratic costs are likely to decrease. When the level of member participation at the general assembly is high, the more likely the cooperative is to incur opportunity costs of overrepresentation.

3: The larger is the board of directors, the higher are the direct democratic costs at the board of directors.

4: Smaller boards are more likely than larger boards to incur opportunity costs of underrepresentation.

5: Larger boards are more likely than smaller boards to incur opportunity costs of overrepresentation.

Two propositions have been developed in this chapter about the relation between member participation and the direct costs of democratic control. These propositions are based on the theoretical model developed in the chapter which postulated that direct democratic costs rises with increased member participation (see Figure 24 in Chapter 3). Based on the theoretical model, also 3 propositions have been developed in the chapter about the relation between member participation and the opportunity costs of democratic control (Figure 44). 


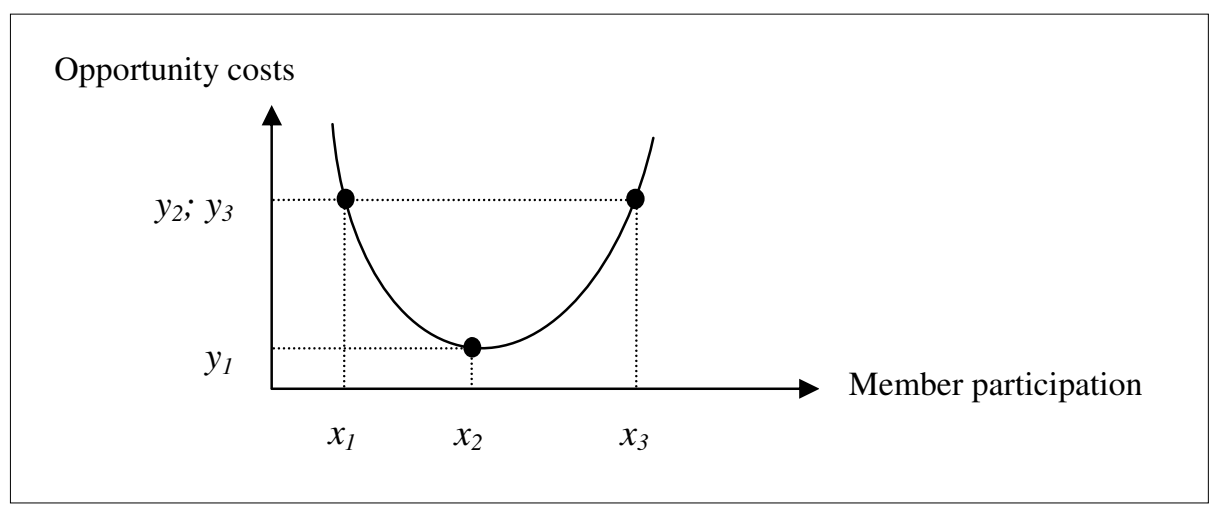

Figure 44 - Hypothetical relation between member participation and opportunity costs of democratic control

In order to examine the propositions of the study, data was used from the twelve cooperatives, as is explained in the previous sections. Various new measurements have been developed for examining democratic costs (see Table 23 in Chapter 3 for an overview).

With regard to direct democratic costs, the results not (completely) supported Propositions 1 and supported Proposition 3, and thus the theoretical model visualized in Figure 24 (i.e., direct democratic costs increase with increased member participation). With regard to Proposition 1, the results showed that on the one hand, there are some cooperatives in which the level of member participation is high and the number of members per nucleus is low (what did support the proposition). On the other hand, there are some cooperatives which have a low number of members per nucleus, and a low level of member participation; and also other cooperatives which have a high number of members per nucleus, and a high level of member participation at the general assembly (what did not support the proposition). With regard to Propositions 3, the results showed that cooperatives with large boards incur higher board salary cost, which was used as proxy for direct costs at the board. The results showed also that the cooperatives with the smallest boards have the lowest average salary costs per board member.

With regard to opportunity democratic costs a more complex picture emerges: some cooperatives operate according to the logic of the proposition, some do not. However, the cooperatives which do operate according to the logic of the propositions incur the lowest opportunity democratic costs. With regard to opportunity costs at the general assembly (Proposition 2), the results showed that opportunity costs related to underrepresentation at the general assembly is hardly an 
issue for the cooperatives: most cooperatives offer sufficient locations to their members for holding nucleus meetings. Overrepresentation is an issue, however, as a lot of cooperatives offer multiple locations per city for holding nucleus meetings. Overrepresentation is not related to member participation, as particularly cooperatives with low member participation have multiple nucleus locations per city. These cooperatives spend a lot of resources on organization meetings, but unsuccessfully, considering the low member participation achieved.

With regard to opportunity costs at the board, the results showed underrepresentation at the board occurs frequently. 8 out of 12 cooperatives have underrepresented boards in the sense that not all products the cooperative receives are represented at the board by members that produce these products. Underrepresentation is not related to board size however, as also large boards have products which are not represented at the board. It is questionable if underrepresentation should be an important concern for cooperatives, as almost all products which are underrepresented at the board, are products which contribute only marginally to the products revenues (e.g., less than $3 \%$ per product).

Overrepresentation at the board of directors (Proposition 5) also occurs frequently at cooperatives: 11 out of 12 cooperatives incur opportunity costs related to overrepresentation. It is not surprising that cooperatives can incur opportunity costs related to both over- and underrepresentation. Overrepresentation means that some products have a higher proportional representation at the board than their contribution to revenues justifies. The additional board seats taken-up by the groups which are overrepresented, 'crowd-out' board members from other groups; i.e., insufficient board seats are available for other groups. Overrepresented groups most of the time are from the groups which contribute the most to the revenues of the cooperative. Overrepresentation should be a concern for cooperatives because they could lead to conflicts of interests, as the board is 'captured' by certain groups in the cooperative. Overrepresentation is not related to board size, as both small and large boards have overrepresented products. 


\subsection{Balancing democratic and agency costs in cooperative governance}

This study has examined how cooperatives can control both democratic and agency costs considering different levels of member participation. Delegating more control to the management team may reduce democratic costs, since decision making processes require less input or participation of the members. However, with lower level of member participation, agency costs are likely to increase, as fewer members will monitor management. In such situations, cooperatives should use more 'agency mechanisms' (which will increase direct agency costs), such as increase the frequency of internal and external audits, in order to avoid a high risk of exposure to agency problems (and thus avoid an increase in opportunity agency costs). The research question that led the present study has been the following: How is the ability of cooperatives to control both democratic and agency costs related to the level of member participation? In order to answer this question, we have developed six propositions (Table 47). The propositions have been examined by comparing the use of agency mechanisms across various groups of cooperatives.

Table 47 - Propositions on the relation amongst level of member participation, democratic and agency costs in cooperative governance

Propositions

P1: The lower the level of member participation at the general assembly, the lower the direct democratic costs at the general assembly and the higher the usage of mechanisms to reduce exposure to agency problems.

P2: The lower the level of member participation at the general assembly, the higher the opportunity democratic costs at the general assembly with regard to underrepresentation and the higher the usage of mechanisms to reduce exposure to agency problems.

P3: The higher the level of member participation at the general assembly, the higher the opportunity democratic costs at the general assembly with regard to overrepresentation and the lower the usage of mechanisms to reduce exposure to agency problems.

P4: The lower the level of member participation at the board of directors (i.e., the smaller the board size), the lower the direct democratic costs at the board of directors and the higher the usage of mechanisms to reduce exposure to agency problems.

P5: The lower the level of member participation at the board of directors, the higher the opportunity democratic costs at the board of directors with regard to underrepresentation and the higher the usage of mechanisms to reduce exposure to agency problems.

P6: The higher the level of member participation at the board of directors, the higher the opportunity democratic costs at the board of directors with regard to overrepresentation at the board of directors and the lower the usage of mechanisms to reduce exposure to agency problems. 
With regard to the propositions (1-3) which relate member participation at the general assembly to decision making costs, only the first proposition could be examined. Proposition 2-3 could not be examined because there were not sufficient cooperatives in the groups to make a meaningful comparison possible. Proposition 1 compared the use of agency mechanisms across two different groups: (1), cooperatives with high member participation and high direct democratic costs; (2), cooperatives with low member participation and low direct democratic costs. Proposition 1 predicted that cooperatives from the first group would use less agency mechanisms than cooperatives from the second group. The results validated this proposition, as cooperatives from this group have fewer audits than cooperatives from the second group. Cooperatives from the second group compensate the lack of participation of its members in cooperative governance, by increased audits of the management team, i.e., the auditors monitor on behalf of the members. Low member participation for these cooperatives may reduce direct democratic costs, but it also increases direct agency costs as increased audits of management is necessary to prevent agency problems and thus an increase in opportunity agency costs.

With regard to the propositions (4-6) which related member participation at the board to decision making costs, only proposition 5 was validated by the results. Proposition 5 compared the use of agency mechanisms across two groups: (1), those cooperatives with low member participation and high opportunity costs of underrepresentation; (2) those cooperatives with high member participation and low opportunity costs of underrepresentation. The proposition predicted that cooperatives from the first group use more agency mechanisms than cooperatives from the second group. This was supported by the results, as cooperatives from this group have more frequent audits, in particular internal audits. On the one hand, this result is positive, as these cooperatives seem to take agency problems seriously. On the other hand, some of the cooperatives may be exaggerating with regard to the frequency of internal audits (e.g., once every 10 days), which may reduce the quality of the audits. Furthermore, some cooperatives have both large boards (which should already monitor management) as well as an additional high frequency of audits. In other words, these cooperatives incur both high direct democratic costs (i.e., in terms of board salary) as well as high direct agency costs (in terms of high auditing costs). Some of these cooperatives, however, have high opportunity costs of underrepresentation. It could be that the additional audits take place to protect the interests of the underrepresented groups. 
Proposition 4 compared the use of agency mechanisms across two groups: (1), high level of member participation and high direct democratic costs; (2) low level of member participation and low direct democratic costs. The proposition predicted that cooperatives from the first group use less agency mechanisms than cooperatives from the second group. No significant differences could be found between the two groups with regard to both types of agency mechanisms.

Proposition 6 compared the usage of agency mechanisms across two groups: (1) high level of member participation and high opportunity costs of overrepresentation; (2), low level of member participation and low opportunity costs of overrepresentation. The proposition predicted that cooperatives from the first group use less agency mechanisms than cooperatives from the second group. The proposition was supported with regard to use of external mechanisms, but not with regard to use of internal mechanisms. With regard to the usage of internal mechanisms, no difference could be found between the two groups. As is explained above, it could be that cooperatives from the first group need additional agency mechanisms because underrepresented producer groups in these cooperatives want additional audits of management, to prevent that management colludes with the board which does not represent the interests of the whole cooperative.

Overall, the results have shown that cooperatives are more oriented towards minimizing opportunity agency costs than opportunity democratic costs. Opportunity democratic costs arise, amongst others, when cooperative decision makers make decisions which benefit some member groups at the expense of other groups. Opportunity agency costs arise when cooperative decision makers make decisions which benefit themselves rather than the members. Therefore, although cooperative decision makers are unlikely to make decisions which benefit themselves (because they are frequently audited etc.), they may make decisions which benefit certain interest groups within the cooperative. This is because some interest groups are underrepresented at board level. 


\section{$5.4 \quad$ Theoretical and methodological implications}

This thesis is one of the first studies to empirically examine how cooperatives manage their decision making costs. In doing so, it has made a number of important contributions to cooperative literature in general and (cooperative) governance literature in particular.

First, the present thesis has developed a method, called grouping, for measuring the level of heterogeneity in cooperatives. It is important to measure heterogeneity, because it is a significant source of conflict of interests between members. No previous studies have been identified which have operationalized the concept of heterogeneity. The grouping method categorizes cooperatives into different types of groups, ranking from least heterogeneous to most heterogeneous. The ranking is based on the size of the dominant groups within the cooperative and the size of minority groups. Three types of heterogeneity were distinguished at two different levels: member characteristics (farm size) and cooperative characteristics (share of each type of product delivered by members in the annual revenues of the cooperative and number of members who deliver each type of product). The grouping method was validated by examining the heterogeneity by means of the case studies conducted in 12 cooperatives.

Second, the present thesis has contributed to insights about how cooperative heterogeneity and level of member of member participation at the general assembly are related. Gaining an accurate picture of this relation is important, because both heterogeneity and member participation are sources of decision making costs. Some studies assume that there is a positive linear relation between member participation and heterogeneity (HANSMANN, 1996; HENDRIKSE; BIJMAN, 2002; KALOGERAS et al, 2009): when heterogeneity increases, members have more incentive to actively participate in the governance of the cooperative. However, other studies (ÖSTERBERG; NILSSON, 2009) state that member participation may decrease as heterogeneity increases, because the cooperative becomes to complex to manage. The present thesis postulates that both streams of literature are partially right. A model (see Figure 43) was developed which predicts a non-linear relation between member participation and heterogeneity. The model assumes that members have a stronger incentive to participate when heterogeneity increases, as long as there is a dominant group within the cooperative. Without a dominant group there is less 
incentive to participate because there is less threat of exploitation by the majority group, and member participation starts to fall, even as heterogeneity increases. The model's assumptions have been validated by means of the case study results.

Third, the present thesis has examined a much broader range of decision making costs than most studies. The present thesis examined both democratic and agency costs. Additionally, the thesis distinguished between both direct and opportunity costs for both types of decision making costs. With regard to opportunity costs, a further distinction has been made between costs associated to over-and underrepresentation. Furthermore, these costs have been examined both at the general assembly and at the board of directors. Moreover, the thesis distinguished between the various conflicts of interests which form the sources of these costs. A clear distinction was made between horizontal, vertical and diagonal conflicts of interests (Figure 45). Horizontal conflicts of interest can lead to direct and opportunity democratic costs; diagonal conflicts of interests to opportunity democratic costs of over-and underrepresentation; while vertical conflicts of interests can lead to both direct and opportunity agency costs. Previous studies do not distinguish between these different sources of conflicts of interests. In particular, often diagonal conflicts of interests are often lumped together with either horizontal or vertical conflicts of interests. Without examining the sources of decision making costs, it is difficult for studies to examine what types of mechanisms are necessary for controlling these costs.

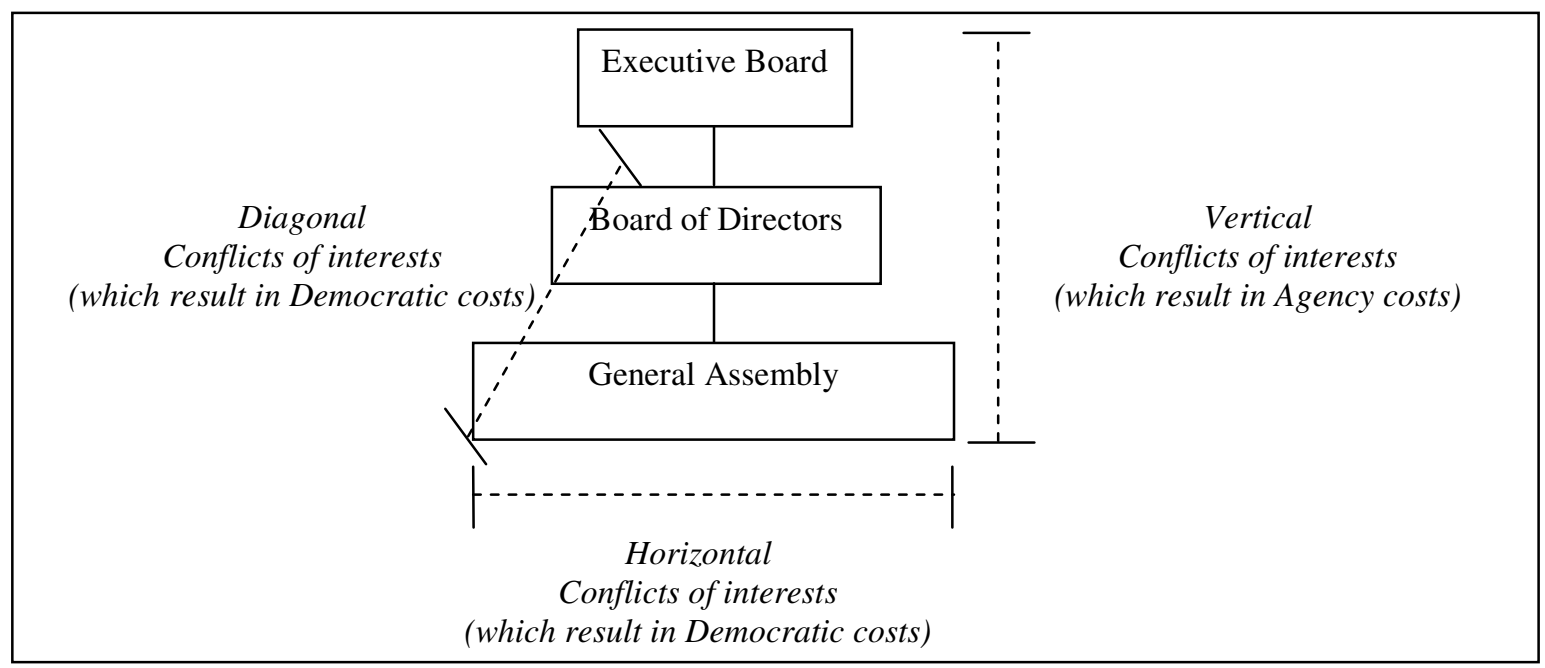

Figure 45 - Horizontal, diagonal and vertical conflicts of interests in cooperative decision makings

Fourth, the present thesis has conceptualized the relation between member participation and democratic costs at the general assembly in greater detail. By distinguishing between direct and 
opportunity democratic costs, the thesis has drawn attention to the fact that the mechanisms to increase member participation are not without costs. Frequently, studies focus mainly on the benefits of increased member participation, disregarding some of the costs associated with it. These costs include both direct costs, as when more resources are spent on holding meetings, and opportunity costs, as the decision making process becomes slower because more people are involved in cooperative governance.

Fifth, the present thesis has shown that the relation between member participation at the board of directors and democratic costs is more complex than often assumed in the literature. Compared to previous studies, this thesis focused not only on board size, but also on board composition; i.e., which member groups the board represents. Board composition, with regard to internal stakeholder groups, is important topic to study because a board which misrepresents the cooperative is a likely source for opportunity democratic costs, as the board will make uniformed decisions or decisions which benefit some member groups, rather than the cooperative as a whole. The empirical results of the study show that most of the examined cooperatives have boards that are both under- and overrepresented; i.e., some producer groups have more seats on the board than their contribution to cooperative revenues justifies, while other groups are underrepresented. Furthermore, the study developed theoretical models (Figure 46) which show that members should take the relative costs of both direct and opportunity costs in total democratic costs into account when determining the optimal size and composition of their board. If direct democratic costs have more weight, members should focus on minimizing direct costs; i.e., they should not attempt to increase board size as it is unlikely to bring much benefit in terms of reduced opportunity costs. If opportunity democratic costs have more weight, members should focus on minimizing opportunity costs; i.e., they can attempt to increase board size and particularly board representativeness as direct costs are relatively insignificant. Increasing board representativeness can also be achieved without increasing the size of the board though, for example by having members at the board who produce multiple products and thus represent multiple producer groups. 


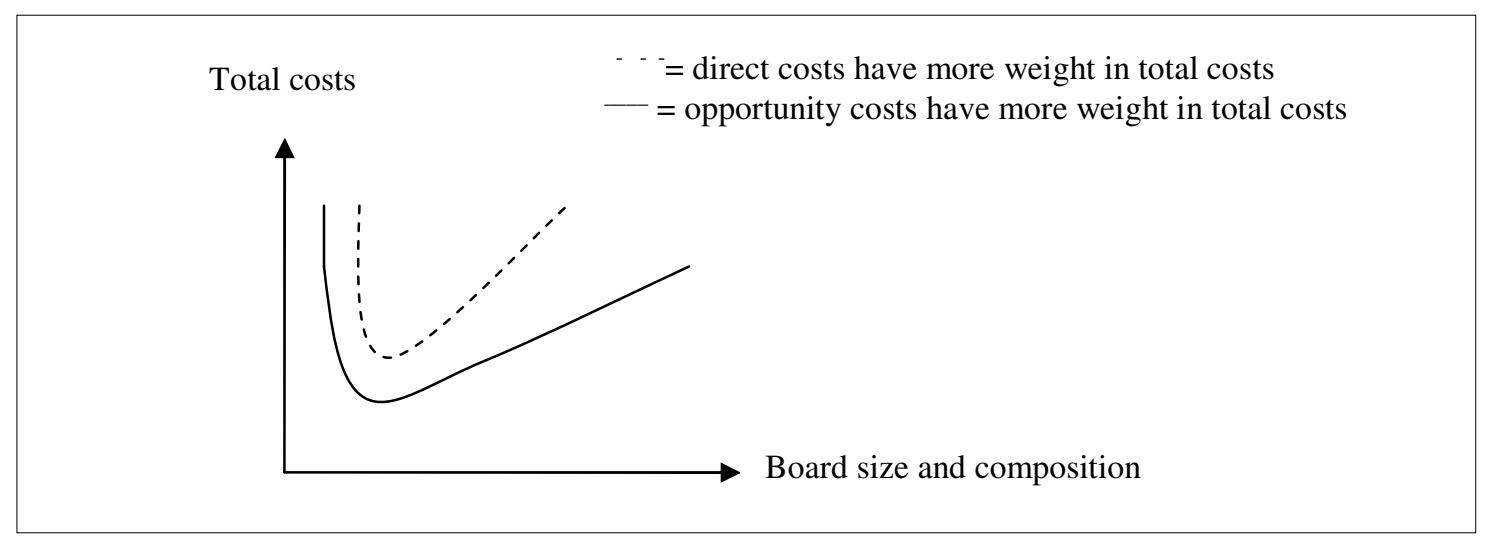

Figure 46 - Hypothetical relations between member participation at the board of directors and total costs of democratic control

Six, the present thesis has shown the difficulties cooperative face in minimizing both democratic and agency costs. This topic has received insufficient attention in the literature, with most studies examining only certain types of democratic costs or agency costs, but not examining these costs jointly. The present thesis has shown that with lower level of member participation, direct democratic costs may be reduced, but opportunity agency costs may rise as fewer members monitor management. In this case, cooperatives should increase either member participation or use additional agency mechanisms (e.g., audits) to reduce exposure to agency problems.

\subsection{Managerial implications}

Various implications from the thesis for cooperative managers, board members and members can be drawn.

First, the grouping method described in Chapter 2 gives to cooperatives a tool to examine how heterogeneous they are with regard to members' characteristics; how the relative distribution of (economic) power is settle amongst the producer groups; and what potential conflicts of interests exist amongst the groups as a result. Cooperatives should take heterogeneity with regard to members' characteristics into account when designing board composition. Potential conflicts of interest at member level could be mitigated at board of directors' level. 
Second, the present thesis has shown that member participation at the general assembly is low for most cooperatives, even though some of them spend a lot of resources attempting to improve member participation. Clearly, this strategy has not worked. Cooperatives should consider that increased heterogeneity and complexity of cooperatives might form an unsurpassable barrier to increasing member participation. Rather than increasing member participation, cooperatives could consider other strategies for improving cooperative governance, for example, more representative boards and skilled management teams, and increased use of agency mechanisms to control management (e.g., frequent audits). As members are apparently unwilling to get involved in cooperative governance, other mechanisms are necessary to monitor and control the cooperative.

Third, the present thesis has shown that most of the studied cooperatives have underrepresented boards; i.e., board in which some producer groups are not represented. However, most of the products which are underrepresented at the board contribute only marginally to the cooperatives' revenues. Cooperatives need to consider whether they want to continue to receive products that contribute little to their revenues and potentially increase the complexity of cooperative management (as a more diverse portfolio of products need to be managed, and a more diverse set of producer groups can also increase conflicts of interests). If cooperatives want to continue to receive a wide set of products, they should consider increasing their representation at board level. If minority producer are better represented at the board, a more informed board could perhaps increase their contribution to cooperative revenues. A potential benefit of the cooperative of increasing the revenues of the smaller products is that the cooperative is more diversified, and thus less exposed to volatility in the market price of individual products.

Fourth, and related to the previous point, cooperatives also have to be aware of overrepresented boards. The results showed that most of the examined cooperatives have producer groups which dominate the board to a larger extent than their contribution to the revenues of the cooperative justifies. This 'crowd-outs' board representatives of some of the other producer groups. Cooperatives should attempt to increase product representation at the board in order to align the economic interests groups have in the cooperative better with their control rights. Amongst others, this can be achieved by allocating some of the board seats of the overrepresented groups to that of the underrepresented seats. An alternative strategy is to obtain board members who 
produce multiple products; e.g., a board member who produces marginal products of the cooperative (i.e., products which contribute little to cooperative revenues) besides one of the main products. Another approach is that cooperatives could allocate a board seat to a 'minorityrepresentative'; i.e., a board member which represents various minority products. The point is that board representativeness can be increased without increasing board.

Fifth, the present thesis has drawn attention to some of the trade-offs cooperatives face in reducing decision making costs: e.g., between reducing agency or democratic costs; or between reducing direct or opportunity costs. Cooperative boards and managers who are aware of these potential trade-offs could examine whether these trade-offs apply to their cooperatives, and if so, what type of costs are most important for them to reduce. For example, should board representativeness be improved to accommodate underrepresented groups at the board, or is the cooperative so homogenous that (diagonal) conflicts of interests between producer groups are unlikely to emerge?

Six, more generally, the cooperatives can use the present thesis to compare their level of heterogeneity, level of member participation, and decision making process and costs to that of the cooperatives examined in the study. Although the results are not representative for (Brazilian) cooperatives in general, the study did examine most of the largest cooperatives from the various regions in Rio Grande do Sul. Cooperatives could look whether for example their number of nucleuses, number of members per nucleus, board size, board salary costs, frequency of audits is comparable to that of the cooperatives sampled in this study.

\subsection{Limitations of the study and direction for further research}

Twelve cooperatives have been deeply researched on various aspects outlined below. Data has been generated through multiple methods (e.g., two interviews per cooperative, including the elected manager and the hired executive; cooperatives' records analysis such as reports, minutes, balance sheets; observations at cooperatives' websites). The research which has been conducted is more qualitative than quantitative in nature. It is because we wanted to have in-depth insights, 
which could not have been obtained otherwise, on the following aspects of cooperative decision making:

(1), into a broad range of both cooperative (e.g., percentage of each product in the total annual revenues, percentage of members who deliver each product) and members' characteristics (e.g., volume of products that cooperative members deliver) which are likely to bring conflicts of interests to the decision making process.

(2), into numerous incentives (e.g., number of nucleus per city) cooperatives provide for members to participate in the decision making process;

(3), into the level of member participation, not only at the general assembly, but at all levels of the cooperative decision making process (i.e., at the general, pre-general assemblies and board of directors);

(4), into not only board size (which can be examined quantitatively), but also board composition (i.e., an analysis of the characteristics of each board member), for which a more qualitative approach is required.

Further research should examine these measures and relationships on more large scale. Of these various measures, in particular the grouping-method can be applicable in many contexts, including in investor-owned firms (to examine the level of heterogeneity amongst shareholders).

Furthermore, further research should examine how decision making costs differ across different types of cooperative models (i.e., also non-traditional cooperatives). Chaddad and Cook (2004) distinguish between 5 types of new cooperatives models (i.e., proportional investment cooperatives, member investor cooperatives, new generation cooperatives, cooperatives with capital seeking entities, investor-share cooperatives). However, not all of these new types may be efficient. For example, Itambé, a large dairy cooperative from Brazil and, Danish Crown, a large meat cooperative from Denmark, are willing to sell part of the cooperative to an investor-owned firm. This may increase the cooperatives access to capital, but it may also increase agency problems as the members may have less control over the decision making process. A comparison 
of the decision making costs across these cooperatives could yield important insights into which of these new generation models is most suitable for cooperatives in order to remain competitive with investor-owned firm. 


\section{REFERENCES}

AGHION, Philippe; TIROLE, Jean. Formal and real authority in organizations. Journal of Political Economy, v. 105, n. 1, p. 1-29. 1997.

AIZSILNIEKS, Arnolds P. Farmer cooperatives and economic welfare: a reply. Journal of Farm Economics, v. 34, n. 4, p. 563-566, Nov. 1952.

ALCHIAN, Armen A.; DEMSETZ, Harold. Production, information costs, and economic organization. American Economic Review, v. 62, p. 77-95, 1972.

ANG, James S.; COLE, Rebel A.; LIN, James W. Agency costs and ownership structure. The Journal of Finance, v. LV, n. 1, p. 81-106, February, 2000.

ARESVIK, Oddvar. Comments on "economic nature of the cooperative association". Journal of Farm Economics, v. 37, n. 1, p. 140-44, Feb. 1955.

ARROW, Kenneth J. Social choice and individual values. New York: John Wiley and Sons, 1951.

BANERJEE, Abhijit; MOOKHERJEE, Dilip; MUNSHI, Kaivan; RAY, Debraj. Inequality, control rights, and rent seeking: sugar cooperatives in Maharashtra. The Journal of Political Economy, v. 109, n. 1, p. 138-190, Feb. 2001.

BAUMOL, William. Business behavior, value and growth. New York: Macmillan co., 1959.

BERLE, Adolf; MEANS, Gardiner. The modern corporation and private property. New York: Macmillan, 1932.

BHUYAN, Sanjib. The "people” factor in cooperatives: an analysis of members' attitudes and behavior. Canadian Journal of Agricultural Economics, v. 55, p. 275-298, 2007.

BIALOSKORSKI NETO. Sigismundo. Member participation and relational contracts in agribusiness cooperatives in Brazil. International Journal of Cooperative Management, v. 3, n. 1, Dec. 2006.

BIJMAN, Jos. Essays on agricultural cooperatives: governance structures in fruit and vegetable chains. ERIM Ph.D. Series Research in Management. Erasmus University of Rotterdam. Rotterdam, 2002. 
BIRCHALL, Johnston. Some theoretical and practical implications of the attempted takeover of a consumer cooperative society. Annals of Public and Cooperative Economics. 71, 1, 29-54. 2000.

BIRCHALL, Johnston; SIMMONS, Richard. A theoretical model of what motivates public service users to participate. Final report to the Economic and Social Research Council. June, 2002.

BIRCHALL, Johnston; SIMMONS, Richard. The involvement of members in the governance of large-scale cooperative and mutual businesses: a formative evaluation of the cooperative group. Review of Social Economy, V. LXII, n. 4, Dec. 2004a.

BIRCHALL, Johnston; SIMMONS, Richard. What motivates members to participate in cooperative and mutual businesses? a theoretical model and some findings. Annals of Public and Cooperative Economics, 75:3 pp. 465-495. 2004b.

BIRCHALL, Johnston; SIMMONS, Richard. What motivates members to participate in the governance of consumer cooperatives? a study of the cooperative group. Research Report No.2. Economic and Social Research Council. 26pp, January 2004c.

BOGETOFT, Peter; OLESEN, Henrik B. Design of production contracts: lessons from theory and agriculture. Copenhagen Business School Press, 2004.

BOGETOFT, Peter; OLESEN, Henrik B. Influence costs in heterogeneous cooperatives: a formal model of sales distortion. Agricultural and Applied Economics Association Annual Meeting, July, Montreal, Canada, 2003.

BRASIL. LEI N ${ }^{\circ}$ 5.764, DE 16 DE DEZEMBRO DE 1971.

$<$ http://legislacao.planalto.gov.br/legisla/legislacao.nsf/Viw_Identificacao/lei\%205.7641971? OpenDocument>. 1971

BUTLER, Gillian. Designing membership structures for large agricultural cooperatives. Research Report, n. 75, Washington, D. C.: U.S. Department of Agriculture, Agricultural Cooperative Service, Aug. 1988.

CHITHELEN, Ignatius. Origins of cooperative sugar industry in Maharashtra. Economical and Political, Weekly 20, p. 604-12, April 6, 1985.

CHRISTIANO; Thomas. Philosophy and democracy: an anthology. Oxford University Press, 2003.

CLARK, Eugene. Farmer cooperatives and economic welfare. Journal of Farm Economics, v. 34, p. 35-51, 1952. 
COASE, Ronald H. The nature of the firm. Economica, 4, p. 386-405. 1937.

CONDON, Andrew M. The methodology and requirements of a theory of modern cooperative enterprise. In: ROYER, Jeffrey S. Cooperative theory: new approaches. USDA/ACS, Cooperative Management Division, p. 1-32, 1987.

COOK, Michael L. The future of U.S. agricultural cooperatives: a neo-institutional approach. American Journal of Agricultural Economics, v. 77, p. 1153-59, Dec. 1995.

COOK, Michael L. The role of management behavior in agricultural cooperatives. Journal of Agricultural Cooperation, p. 42-58, 1994.

COSTA, Davi Rogério de Mora. Propriedade e decisões de gestão em organizações cooperativas agropecuárias Brasileiras. Tese (doutorado). Fundação Getúlio Vargas. 133p. São Paulo, 2010.

COSTA, Davi Rogério de Mora; AZEVEDO, Paulo Furquim. Determinantes da delegação do direito de controle formal nas cooperativas agropecuárias Brasileiras. Annals of the 48th Congresso SOBER Sociedade Brasileira de Economia, Administração e Sociologia Rural. Campo Grande, 25-28th July, 2010.

COSTA, Davi Rogério de Mora; CHADDAD, Fabio Ribas; AZEVEDO, Paulo Furquim. Separação entre propriedade e decisão de gestão nas cooperativas agropecuárias Brasileiras. Annals of the 48th Congresso SOBER Sociedade Brasileira de Economia, Administração e Sociologia Rural. Campo Grande, 25-28th July, 2010.

COTTERILL, R. Agricultural cooperatives: a unified theory of pricing, finance, and investment. In: ROYER, Jeffrey S. Cooperative theory: new approaches. USDA/ACS, Cooperative Management Division, 1987.

CROPP, B.; TRECHTER, D.; COTTINGHAM, J.; BERENDS, P. Equity redemption practices: a study of Wisconsin cooperatives. Center for Cooperatives, University of Wisconsin, Madison. 1998.

DANISH CROW. Articles of association of Danish Crown AmbA. Copenhagen, 2006.

EISENHARDT, Kathleen M. Building theories from case study research. The Academy of Management Review, v. 14, n. 4 (Oct.), pp. 532-550, 1989.

EMELIANOFF, O. Economic theory of cooperation: economic structure of cooperative organizations. Washington, D.C.: Ivan V. Emelianoff. 1948.

FAMA, Eugene F. Agency problems, and the theory of the firm. Journal of Political Economy, v. 88 , p. $288-307,1980$. 
FAMA, Eugene F.; JENSEN, Michael C. Separation of ownership and control. Journal of Law and Economics. v. 26, 1983a.

FAMA, Eugene; JENSEN; Michael. Agency problems and residual claims. Journal of Law and Economics, v. 26, p. 327-49, 1983b.

FORCADELL, Francisco Javier. Democracy, cooperation and business success: the case of Mondragón corporación cooperative. Journal of Business Ethics, 56, p. 255-274, 2005.

FULTON, Murray. 2004

FULTON, Murray. New generation cooperatives. Unpublished Working Paper. 12 p. November, 2000.

FULTON, Murray. Traditional versus new generation cooperatives. Unpublished Working Paper. 24p. 1999.

FUROBOTN, E. G.; RICHTER, R. Institutions and economic theory. the contribution of the new institutional economics. Ann Arbor: University of Michigan Press, 1998.

GAVIOUS, A.; MIZRAHI, S. Two-level collective action and group identity. Journal of Theoretical Politics, v. 11, p. 497 - 517, 1999.

GORROÑOGOITIA, Alfonso. La organización interna de una cooperativa. Textos Básicos de Otalora, Capitulo III (s. d), 38 p.

GORTON, Gary; SCHMID, Frank. Corporate governance, ownership dispersion and efficiency: empirical evidence from Austrian cooperative banking. Journal of Corporate Finance, v. 5, p. 119-140, 1999.

GRAY Thomas W.; KRAENZLE, Charles A. Member participation in agricultural cooperatives: a regression and scale analysis. Research Report, n. 165, Washington, D. C.: U.S. Department of Agriculture, Rural Business Cooperative Service, Dec. 1998.

GRAY, Thomas W. Structuring for member control in large cooperatives: a case study in dairy, Research Report, n. 72, Washington, D. C.: U.S. Department of Agriculture, Agricultural Cooperative Service, July 1988.

GRAY, Thomas W.; BUTLER, Gillian. Membership structural design: a pilot test on DHI cooperatives. Research Report, n. 131, Washington, D. C.: U.S. Department of Agriculture, Cooperative Service, Nov. 1994. 
GRAY, Thomas W.; DUFFEY, P. Listen and learn: understanding member complaints can help build commitment. Rural Cooperatives, pp. 8-10. May-June. 1996.

GRIPSRUD, Geir; LENVIK, Gaute Homb; OLSEN, Nina Veflen. Influence activities in agricultural cooperatives: the impact of heterogeneity. The Food Sector in Transition - Nordic Research, Oslo, Norway, June 14-15, 2000.

GROSSMAN, Sanford. J.; HART, Oliver D. The costs and benefits of ownership: a theory of vertical and lateral integration. Journal of Political Economy, v. 94, n. 4. pp. 691-719, 1986.

HAIR, Joseph F.; BLACK, William C.; BABIN, Barry J.; ANDERSON, Rolph E.; TATHAM, Ronald L. Multivariate data analysis. 6 ed. New Jersey: Pearson Education, 2006.

HANSMANN, Henry. Cooperative firms in theory and practice. The Finnish Journal of Business Economics, v. 4, p. 387-403, 1999.

HANSMANN, Henry. Ownership of firm. Journal of Law, Economics and Organizations, v. 4, n. 2, p. 267-304, Fall 1988.

HANSMANN, Henry. The ownership of enterprise. Cambridge, MA: Harvard University Press. 1996.

HART, Oliver; MOORE, John. Property rights and the nature of the firm. Journal of Political Economy. v. 98, n.6. pp. 1119-1158, 1990.

HART, Oliver; MOORE, John. The governance of exchanges: members' cooperatives versus outside ownership. Oxford Review of Economic Policy, v. 12, n. 4, p. 53-69. 1996

HECKATHORN, Douglas D. Collective action and group heterogeneity: voluntary provision versus selective incentives. American Sociological Review, v. 58, n. 3, Jun., pp. 329-350, 1993.

HECKATHORN, Douglas D. Collective sanctions and compliance norms: a formal theory of group-mediated social control. American Sociological Review, v. 55, p. 366-84. 1990.

HECKATHORN, Douglas D. Collective sanctions and group heterogeneity: cohesion and polarization in normative systems. Advances in Group Process, v. 9, p. 41-63. 1992.

HELMBERGER, Peter; HOOS, Sidney. Cooperative enterprise and organization theory. Journal of Farm Economics, v. 44, p. 275-90, 1962.

HENDRIKSE, George W. J. Screening, competition and the choice of the cooperative as an organizational form. Journal of Agricultural Economics, v. 49, n. 2, p. 202-217, Spring, 1998. 
HENDRIKSE, George W. J.; OIJEN, Aswin A.C.J. Diversification and corporate governance. In: HENDRIKSE, George W. J. Restructuring agricultural cooperatives. p. 51-64. Rotterdam: Erasmus University Rotterdam, Rotterdam School of Management, 2004.

HENDRIKSE, George W.J.; BIJMAN, Jos. Ownership structure in agrifood chains: the marketing cooperative. American Journal of Agricultural Economics, v. 84, n. 1, February, p 104-119, 2002.

HENDRIKSE, George W.J.; VEERMAN, Cees P. Marketing cooperatives and financial structure: a transaction costs analysis. Agricultural Economics, v. 26, p. 205-216, 2001.

HENEHAN, B. How to attain and retain member loyalty. American Cooperation. Washington, D.C.: National Council of Farmer Cooperatives, p. 189-94. 1992.

HENR $\ddot{Y}$, Hagen. Guidelines for cooperative legislation. $2^{\text {nd }}$. revised ed., Geneva, International Labour Office, 2005.

HIRSHMAN, A. Exit, voice and loyalty: response to decline in firms, organizations and states. Cambridge, MA: Harvard University Press. 1970.

HOGELAND, J. A. The economic culture of U.S. agricultural cooperatives. Culture \& Agriculture, v. 28, n. 2, p. 67-79. 2006.

HVIID, Morten. Incentive payments in Danish cooperative creameries. School of Economic and Social Studies and Centre for Competition and Regulation University of East Anglia, 2001, 27-p.

ILIOPOULOS, Constantine. Manager compensation and influence costs in agribusiness cooperatives. s. d. $16 p$.

ILIOPOULOS, Constantine; COOK, Michael L. The efficiency of internal resource allocation in decisions in costumer-owned-firms: the influence costs problem. Paper presented at the $3^{\text {rd }}$ annual conference of the International Society for New Institutional Economics. Washington, DC, Sep. 1999.

ILIOPOULOS, Constantine; HENDRIKSE, George W. J. Influence costs in agribusiness cooperatives: evidence from case studies. ERIM Report Series Research in Management. Erasmus University of Rotterdam. Rotterdam, July, 2008.

JENSEN, Michael C. MECKLING, William H. Rights and production functions: application to labor-managed firms and codetermination. Journal of Business, v. 52, p. 469-506. 1979a. 
JENSEN, Michael C. MECKLING, William H. Theory of the firm: managerial behavior, agency costs, and ownership structure. In: BRUNNER, Karl (ed.), Economics and Social Institutions, p. 305-60. Boston: Martinus Nijhoff Publishing, 1979b.

JENSEN, Michael C.; MECKLING, William H. Theory of the firm: managerial behavior, agency costs and ownership structure. Journal of Financial Economics, v. 3, p. 305-360. 1976.

KAARLEHTO, Paavo. Cooperation as a form of economic i integration. Acta Agriculturae Scandinavica, 5 p. 85-97, 1955.

KAARLEHTO, Paavo. On the economic nature of cooperation. Acta Agriculturae Scandinavica, 6, p. 243-352, 1956.

KALOGERAS, Nikos; PENNINGS, Joost M.E.; van der LANS, Ivo A.; GARCIA, Philip; van DIJK, Gert. Understanding heterogeneous preferences of cooperative members. Agribusiness, v. 25, n. 9, p. 90-111, 2009.

KARANTININIS, Kostas; ZAGO, Angelo. Endogenous membership in mixed duopsonies. American Journal of Agricultural Economics, v. 83, n. 5, Proceedings Issue, p. 1266-1272, Dec. 2001.

KIRKMAN, C. H. Cooperative member responsibilities and control. Cooperative Information Report, 1, Section 7, Washington, D. C.: U.S. Department of Agriculture, Agricultural Cooperative Service, Sep. 1993.

KLEIN, Benjamin; CRAWFORD, Robert G.; ALCHIAN, Armen A. Vertical integration, appropriable rents, and the competitive contracting process. The Journal of Law and Economics, p. 297-326. 1978.

KRAENZLE, Charles et al., Cooperative historical statistics. Cooperative Information Report, 1, Section 26, Washington, D. C.: U.S. Department of Agriculture, Agricultural Cooperative Service, Aug. 2004.

LAURSEN, Christina; KARANTININIS, Kostas; BHUYAN, Sanjib. Organizational characteristics and member participation in agricultural cooperatives: evidence from modern Danish cooperatives. Paper submitted to the Seminar the Role of the Cooperatives in the European Agro-food System, Bologna, May, 2008.

MACHADO FILHO, Claudio Antonio Pinheiro. Corporate governance and corporate responsibility. In: ZYLBERSZTAJN, Decio; OMTA, Onno. (eds.), Advances in supply chain analysis in agri-food systems. p. 231-246. São Paulo: Singular, 2009. 
MARRIS, Robin. A model of managerial enterprise. Quarterly Journal of Economics, v. 77, p. 185-209, 1963.

MAYER, Tammy M. Understanding cooperatives: who runs the cooperative business? board of directors. Cooperative Information Report, 45, Section 5, Washington, D. C.: U.S. Department of Agriculture, Rural Business Cooperative Service, Oct. 1994.

McCLAVE, James T.; SINCICH, Terry. Statistics. 9. ed. New Jersey: Prentice Hall, 2003.

MIELE, Marcelo; ZYLBERSZTAJN, Decio. Coordenação e desempenho da transação entre viticultores e vinícolas na serra Gaúcha. RAUSP. Revista de Administração, São Paulo, v. 40, n. 4, p. 330-341, 2005.

MILGROM, Paul. R. Employment contracts, influence activities, and efficient organization design. Journal of Political Economy, v. 96, n. 1, p 42-59, 1988 b.

MILGROM, Paul. R.; ROBERTS, John. An economic approach to influence activities in organizations. American Journal of Sociology, v. 94 Supplement: S154-S179. 1988a.

MILGROM, Paul. R.; ROBERTS, John. Bargaining Costs, influence costs, and the organization of economic activity. In James E. Alt and Kenneth A. Shepsle (eds.), Perspectives on Positive Political Economy, pp. 57 - 89. Cambridge: Cambridge University Press, 1990.

MILGROM, Paul. R.; ROBERTS, John. Economics, organization \& management. Englewood Cliffs, NJ: Prentice-Hall. 1992.

MUELLER, Dennis. C. Public choice II. Cambridge: Cambridge University Press, 1989.

NOURSE, Edwin G. The economic philosophy of cooperation. American Economic Review, v. 12, p. 577-97. 1922.

NOURSE, Edwin G. The place of the cooperative in our national economy. In: American

Cooperation 1942-45. Washington, D.C.: American Institute of Cooperation, p. 33-39. 1945.

OCB - Organização das Cooperativas Brasileiras. Dados Consolidados de 2008. Março de 2009.

OCB - Organização das Cooperativas Brasileiras. www.brasilcooperativo.org.br . Accessed on March, $27^{\text {th }}, 2010$.

OHM, Hans. Member behavior and optimal pricing in marketing cooperatives. Journal of Farm Economics, 38, No.2, p. 613-21, May 1956. 
OLIVER, Pamela E. Rewards and punishments as selective incentives for collective action: theoretical investigations. American Journal of Sociology, v. 85, pp. 1356-75, 1980.

OLSON, Mancur. The logic of collective action: public goods and the theory of groups. Cambridge: Harvard University Press, 1965.

ÖSTERBERG, Peter; NILSSON, Jerker. Members' perception of their participation in the governance of cooperatives: the key to trust and commitment in agricultural cooperatives. Agribusiness, v. 25, n. 2, p. 181-197, 2009.

PERRAUT, Ellis Edward. A comparison of managerial behavior in cooperatives and investor owned firms serving farmers. Master's Plan B paper, Michigan State University, 1983.

PHILLIPS, Richard. Economic nature of the cooperative association. Journal of Farm Economics, v. 35, p. 74-87, 1953.

PORTER, Philip. K.; SCULLY, G. H. Economic efficiency in cooperatives. Journal of Law and Economics, V. 30, October, p. 489-512. 1987.

POZZOBON, Daniela Maria; MACHADO FILHO, Claudio Antonio Pinheiro. In search of cooperative governance: a Brazilian agricultural co-op case study. In: International PENSA Conference, Ribeirão Preto, 2007.

REYNOLDS, Bruce J. Decision-making in cooperatives with diverse member interests.

Research Report, n. 155, Washington, D. C.: U.S. Department of Agriculture, Rural Business Cooperative Service, Apr. 1997.

REYNOLDS, Bruce J.; GRAY, Thomas W.; KRAENZLE, Charles A. Voting and representation systems in agricultural cooperatives. Research Report, n. 156, Washington, D. C.: U.S. Department of Agriculture, Rural Business Cooperative Service, Jun. 1997.

ROBOTKA, Frank. A theory of cooperation. In: ABRAHAMSEN, Martin; SCROGGS, Claud (Ed.) Agricultural Cooperation, pp. 121-42. Minneapolis: University of Minnesota Press, 1957.

RODHES, James V. Large agricultural cooperatives: on the road to where? In: ROYER, Jeffrey S. Cooperative theory: new approaches. USDA/ACS, Cooperative Management Division, p. 155-170, 1987.

ROTH, Roland R. Spatial heterogeneity and bird species diversity. Ecology, v. 57, n. 4, July, p. 773-782, 1976.

SAVAGE, Job. Comments on economic nature of the cooperative association. Journal of Farm Economics, v. 36, p. 529-54, 1954. 
SHAPIRO, C. Premiums for high quality products as returns to reputations. Quarterly Journal of Economics. November 1983.

STAATZ, John M. A game theoretic a game-theoretic analysis of decision making in farmer cooperatives. In: ROYER, Jeffrey S. Cooperative theory: new approaches. USDA/ACS, Cooperative Management Division, p. 117-147, 1987a.

STAATZ, John M. Farmer cooperative theory: recent developments. Research Report, n. 84. Washington, D. C.:, Agricultural Cooperative Services, 1987b. http://purl.umn.edu/52017

STAATZ, John M. Farmers' incentives to take collective action via cooperatives: a transaction cost approach. In: ROYER, Jeffrey S. Cooperative theory: new approaches. USDA/ACS, Cooperative Management Division, p. 87-107, 1987c.

STAATZ, John M. The structural characteristics of farmer cooperatives and their behavioral consequences. In: ROYER, Jeffrey S. Cooperative theory: new approaches. USDA/ACS, Cooperative Management Division, p. 33-59, 1987d.

STAATZ, John M. Towards a model of decision making in farmer cooperatives. Working paper, n. 6, Michigan State University, Department of Agricultural Economics. 1983.

SVENDSEN, Søren V. Lock-in of farmers in agricultural cooperatives: reviving the effect of exit by means of constitutional amendments. In: KARANTININIS, Kostas; NILSSON, Jerker. Vertical markets and cooperative hierarchies, Springer, p. 115-135. 2007.

TRIFON, Raphael. The economics of cooperative ventures: further comments. Journal of Farm Economics, v. 43, p. 215-35, 1961.

VITALIANO, Peter. Cooperative enterprise: an alternative conceptual basis for analyzing a complex institution. American Agricultural Economics Association, p. 1078-1083, Dec. 1983.

WADSWORTH, James J. Assessing performance and needs of cooperative boards of directors. Cooperative Information Report, 58, Washington, D. C.: U.S. Department of Agriculture, Rural Business Cooperative Service, Oct. 2000

WADSWORTH, James J. Keep the co-op candle burning. Rural Cooperatives, v. 68, n. 2, p. 19-20, 30. 2001.

WILLIAMSON, Oliver E. Economic organization: firms, markets and policy control. Brighton: Wheatsheaf Books, 1986.

WILLIAMSON, Oliver E. Markets and hierarchies: analysis and antitrust implications. New York: The free press, 1975. 
WILLIAMSON, Oliver E. Profit, growth, and sales maximization. Economica, v. 33, p. 1-16, 1966.

WILLIAMSON, Oliver E. The economic institutions of capitalism. New York: The Free Press, 1985.

WILLIAMSON, Oliver E. The economics of discretionary behavior: managerial objectives in a theory of the firm. New Jersey: Prentice Hall, 1964.

WILLIAMSON, Oliver E. The mechanisms of governance. Oxford: Oxford University Press, 1996.

ZUSMAN, Pinhas. Group choice in an agricultural marketing cooperative. The Canadian Journal of Economics / Revue Canadienne d'Economique, v. 15, n. 2, p. 220-234, May. 1982.

ZYLBERSZTAJN, Decio. Organização de cooperativas: desafios e tendências. Revista de Administração, v. 29, n. 3, p. 23-32, Jul/Set., 1994.

ZYLBERSZTAJN, Decio. Quatro estratégias fundamentais para cooperativas agrícolas. In: BRAGA; Marcelo José; REIS, Brício dos Santos (Orgs.) Agronegócio Cooperativo:

Reestruturação e Estratégias. Viçosa: Suprema, p. 55-75. 2002.

ZYLBERSZTAJN, Decio; MIELE, Marcelo. Stability of contracts in the Brazilian wine industry. Revista de Economia e Sociologia Rural, Brasília, v. 43, n. 2, p. 353-371, 2005. 
APPENDIX 


\section{Appendix 1 - Case Studies' Instrument (in Portuguese)}

\section{1 - DADOS GERAIS}

1.1 Nome da cooperativa:

1.2 Sede da cooperativa (cidade):

1.3 Data de fundação:

1.3 Número de membros ativos:

1.4 Número e nome das cidades atendidas: 
1 - HETEROGENEIDADE

\section{CARACTERÍSTICAS DAS COOPERATIVAS}

\begin{tabular}{|c|c|c|}
\hline PRODUTOS & $\begin{array}{l}\text { 1.1 Qual é o \% que cada } \\
\text { produto representa nas } \\
\text { vendas anuais da } \\
\text { cooperativa? }\end{array}$ & $\begin{array}{l}1.2 \text { Qual é o \% de membros } \\
\text { ativos que entrega cada } \\
\text { produto? }\end{array}$ \\
\hline \multicolumn{3}{|l|}{ ARROZ } \\
\hline \multicolumn{3}{|l|}{ FEIJÃO } \\
\hline \multicolumn{3}{|l|}{ SORGO } \\
\hline \multicolumn{3}{|l|}{ TRIGO } \\
\hline \multicolumn{3}{|l|}{ MILHO } \\
\hline \multicolumn{3}{|l|}{ MANDIOCA } \\
\hline \multicolumn{3}{|c|}{ CANA-DE-AÇUCAR } \\
\hline \multicolumn{3}{|c|}{ SOJA } \\
\hline \multicolumn{3}{|l|}{ GIRASSOL } \\
\hline \multicolumn{3}{|l|}{ CANOLA } \\
\hline \multicolumn{3}{|l|}{ AVEIA } \\
\hline \multicolumn{3}{|l|}{ TRITICALE } \\
\hline \multicolumn{3}{|l|}{ CENTEIO } \\
\hline \multicolumn{3}{|l|}{ CEVADA } \\
\hline \multicolumn{3}{|l|}{ LEITE } \\
\hline \multicolumn{3}{|l|}{ CITRUS } \\
\hline \multicolumn{3}{|l|}{ UVA } \\
\hline \multicolumn{3}{|l|}{ FRUTAS } \\
\hline \multicolumn{3}{|c|}{ VEGETAIS/BATATAS } \\
\hline \multicolumn{3}{|c|}{ SUÍNOS } \\
\hline \multicolumn{3}{|l|}{ AVES } \\
\hline \multicolumn{3}{|l|}{ BOVINOS } \\
\hline \multicolumn{3}{|l|}{ CAPRINOS } \\
\hline \multicolumn{3}{|l|}{ OVINOS } \\
\hline \multicolumn{3}{|l|}{ L $\tilde{A}$} \\
\hline \multicolumn{3}{|l|}{ ALGODÃO } \\
\hline \multicolumn{3}{|l|}{ EUCALIPTO } \\
\hline \multicolumn{3}{|l|}{ CAFÉ } \\
\hline \multicolumn{3}{|l|}{ OUTRO (Citar) } \\
\hline Total & $\mathbf{R} \$($ & \\
\hline
\end{tabular}

\section{CHARACTERISTICAS DAS PROPRIEDADES RURAIS}

\begin{tabular}{l||l|l|l}
\hline \hline $\begin{array}{l}1.3 \text { Qual é o \% de membros que } \\
\text { entregam grande, médio e } \\
\text { pequeno volume* de produtos à } \\
\text { cooperativa? }\end{array}$ & $\left(\begin{array}{l}\text { ) GRANDE } \\
\hline\end{array}\right.$
\end{tabular}

*De acordo com a classificação de cada cooperativa 


\section{2 - PARTICIPAÇÃO DOS MEMBROS NA GOVERNANÇA}

2.1 Quantos membros participam da assembléia geral da cooperativa em 2010?

2.2 Quantos membros participaram de cada reunião de núcleo em 2010 (pré-assembléias gerais)? Observação: excluem-se

reuniões técnicas (pré-plantio), dia de campo, reuniões de jovens, reuniões de comitês em geral, reuniões de mulheres

\section{3 - IMPACTO DA HETEROGENEIDADE NA PARTICIPAÇÃO DOS MEMBROS NA GOVERNANÇA}

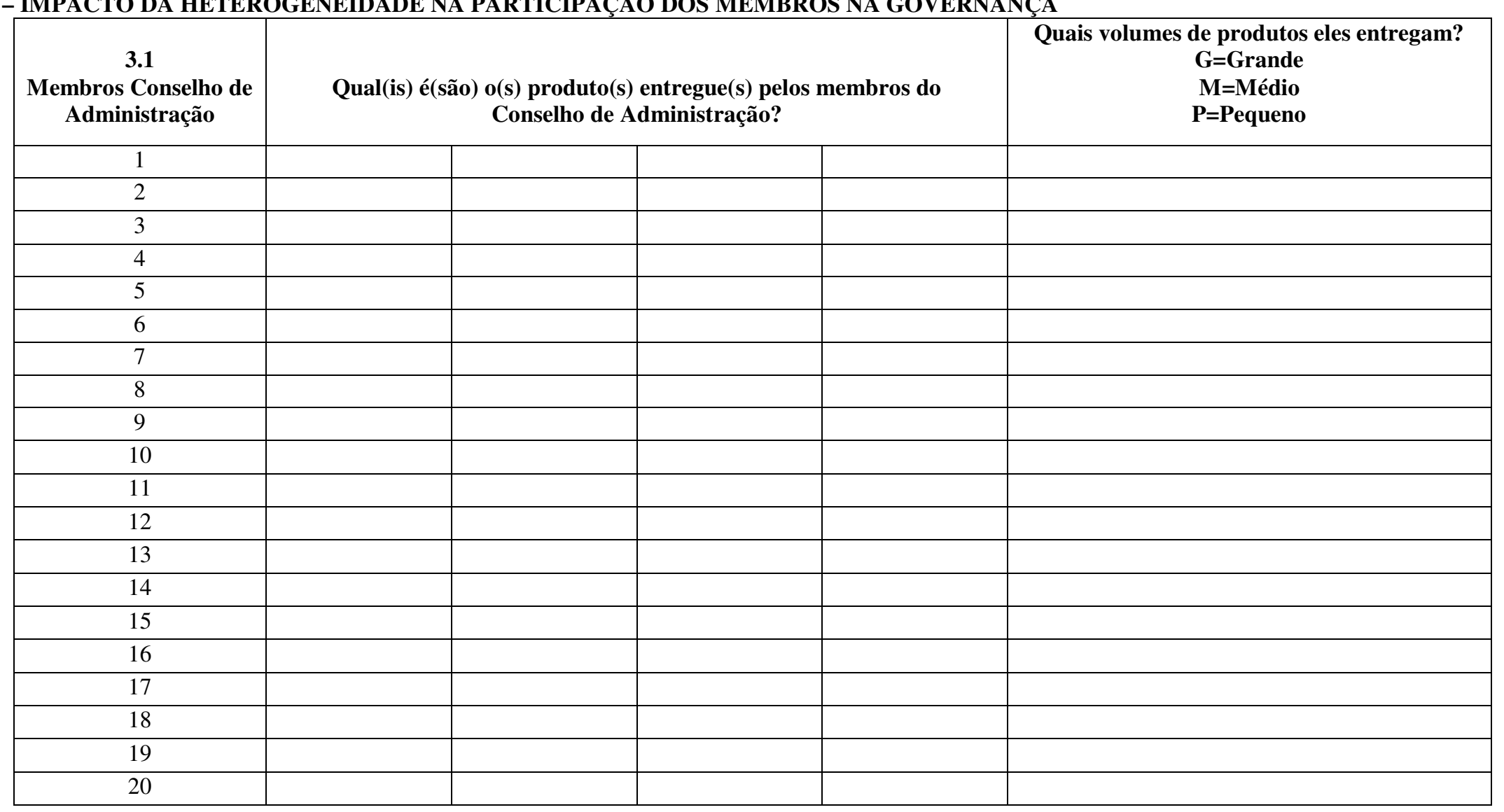




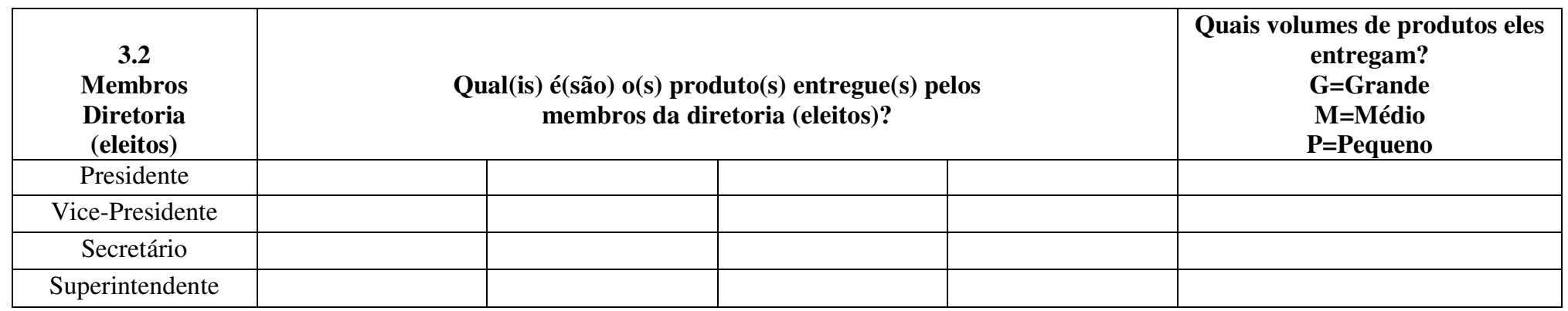

\section{4 - CUSTOS DEMOCRÁTICOS}

Nota: Reuniões de Núcleos são aquelas reuniões utilizadas por algumas cooperativas a fim de aproximar os associados das decisões da cooperativa. Núcleos são diferentes de comitês. Algumas das questões abaixo se referem aos Núcleos, e não aos comitês. Estes últimos não são estudados nesta tese.

\begin{tabular}{|l|l|}
\hline A cooperativa tem Núcleos? & ( ) Sim ( ) Não \\
\hline 4.1 Quantos Núcleos têm a cooperativa? & \\
\hline 4.2 Qual o total dos honorários dos Representantes, em R\$/ano? & \\
\hline 4.3 Qual o total dos honorários do Conselho de Administração, em R\$/ano? & \\
\hline
\end{tabular}

\section{5 - MECANISMOS UTILIZADOS PARA REDUZIR CUSTOS DE AGÊNCIA}

5.1 Com qual freqüência o conselho fiscal fiscaliza?

( )

5.2 Com qual freqüência a auditoria externa fiscaliza?

( )

5.3 Qual a freqüência de reuniões entre diretoria eleita e conselho de administração?

( ) 
Appendix 2 - Calculations for variables of heterogeneity using CV as a measurement model

\begin{tabular}{|c|c|c|}
\hline COOPERATIVE & PERCPROD (\%) & $C V \_P E R C P R O D$ \\
\hline \multirow{8}{*}{ COOP-E } & 72.00 & \multirow{8}{*}{190.61} \\
\hline & 24.49 & \\
\hline & 2.69 & \\
\hline & 0.68 & \\
\hline & 0.06 & \\
\hline & 0.04 & \\
\hline & 0.03 & \\
\hline & 0.01 & \\
\hline \multirow{9}{*}{ COOP-D } & 69.05 & \multirow{9}{*}{187.41} \\
\hline & 13.00 & \\
\hline & 6.00 & \\
\hline & 6.00 & \\
\hline & 2.00 & \\
\hline & 2.00 & \\
\hline & 1.00 & \\
\hline & 0.60 & \\
\hline & 0.40 & \\
\hline \multirow{6}{*}{ COOP-I } & 63.40 & \multirow{6}{*}{131.56} \\
\hline & 21.60 & \\
\hline & 6.00 & \\
\hline & 4.00 & \\
\hline & 3.00 & \\
\hline & 2.00 & \\
\hline \multirow{7}{*}{$\mathrm{COOP}-\mathrm{C}$} & 57.00 & \multirow{7}{*}{127.04} \\
\hline & 16.00 & \\
\hline & 13.00 & \\
\hline & 5.00 & \\
\hline & 5.00 & \\
\hline & 3.00 & \\
\hline & 1.00 & \\
\hline \multirow{5}{*}{$\mathrm{COOP}-\mathrm{H}$} & 52.30 & \multirow{5}{*}{100.36} \\
\hline & 34.70 & \\
\hline & 7.00 & \\
\hline & 5.00 & \\
\hline & 1.00 & \\
\hline \multirow{6}{*}{ COOP-F } & 55.72 & \multirow{6}{*}{112.95} \\
\hline & 21.28 & \\
\hline & 13.00 & \\
\hline & 8.00 & \\
\hline & 1.00 & \\
\hline & 1.00 & \\
\hline \multirow{5}{*}{$C O O P-B$} & 60.34 & \multirow{5}{*}{104.29} \\
\hline & 17.66 & \\
\hline & 13.00 & \\
\hline & 7.00 & \\
\hline & 2.00 & \\
\hline
\end{tabular}


Continuation Table 48 - Calculations for CV_PERCPROD

\begin{tabular}{|c|c|c|}
\hline COOPERATIVE & PERCPROD (\%) & $C V_{-} P E R C P R O D$ \\
\hline \multirow{5}{*}{$C O O P-G$} & 54.54 & \multirow{5}{*}{99.64} \\
\hline & 28.46 & \\
\hline & 14.00 & \\
\hline & 2.00 & \\
\hline & 1.00 & \\
\hline \multirow{4}{*}{$C O O P-L$} & 65.00 & \multirow{4}{*}{98.02} \\
\hline & 24.00 & \\
\hline & 10.00 & \\
\hline & 1.00 & \\
\hline \multirow{9}{*}{ COOP-A } & 24.00 & \multirow{9}{*}{75.79} \\
\hline & 19.00 & \\
\hline & 19.00 & \\
\hline & 17.00 & \\
\hline & 9.00 & \\
\hline & 9.00 & \\
\hline & 1.70 & \\
\hline & 0.80 & \\
\hline & 0.60 & \\
\hline \multirow{4}{*}{ COOP-J } & 45.00 & \multirow{4}{*}{54.77} \\
\hline & 30.00 & \\
\hline & 15.00 & \\
\hline & 10.00 & \\
\hline \multirow{2}{*}{ COOP-K } & 53.00 & \multirow{2}{*}{6.69} \\
\hline & 47.00 & \\
\hline
\end{tabular}


Table 49 - Calculations for CV_PERCMEMB

\begin{tabular}{|c|c|c|}
\hline COOPERATIVE & PERCMEMB (\%) & $C V \_P E R C M E M B$ \\
\hline \multirow{9}{*}{ COOP-E } & 54.08 & \multirow{9}{*}{181.50} \\
\hline & 26.86 & \\
\hline & 3.19 & \\
\hline & 1.50 & \\
\hline & 0.85 & \\
\hline & 0.52 & \\
\hline & 0.35 & \\
\hline & 0.17 & \\
\hline & 0.06 & \\
\hline \multirow{6}{*}{$C O O P-F$} & 95.00 & \multirow{6}{*}{127.78} \\
\hline & 28.50 & \\
\hline & 10.00 & \\
\hline & 10 & \\
\hline & 5.00 & \\
\hline & 3 & \\
\hline \multirow{10}{*}{ COOP-A } & 44.44 & \multirow{10}{*}{119.43} \\
\hline & 37.57 & \\
\hline & 16.36 & \\
\hline & 12.65 & \\
\hline & 5.13 & \\
\hline & 4.25 & \\
\hline & 3.04 & \\
\hline & 2.25 & \\
\hline & 0.39 & \\
\hline & 0.26 & \\
\hline \multirow{7}{*}{$\mathrm{COOP}-\mathrm{C}$} & 95.00 & \multirow{7}{*}{113.89} \\
\hline & 30.00 & \\
\hline & 20.00 & \\
\hline & 15.00 & \\
\hline & 10.00 & \\
\hline & 10.00 & \\
\hline & 1.00 & \\
\hline \multirow{9}{*}{$C O O P-D$} & 44.46 & \multirow{9}{*}{113.25} \\
\hline & 24.38 & \\
\hline & 13.53 & \\
\hline & 12.13 & \\
\hline & 6.63 & \\
\hline & 5.29 & \\
\hline & 1.04 & \\
\hline & 0.62 & \\
\hline & 0.22 & \\
\hline \multirow{6}{*}{ COOP-I } & 69.18 & \multirow{6}{*}{93.12} \\
\hline & 46.77 & \\
\hline & 18.78 & \\
\hline & 13.06 & \\
\hline & 4.64 & \\
\hline & 3.10 & \\
\hline
\end{tabular}


Continuation Table 49 - Calculations for CV_PERCMEMB

\begin{tabular}{|c|c|c|}
\hline COOPERATIVE & PERCMEMB (\%) & CV_PERCMEMB \\
\hline \multirow{5}{*}{$C O O P-B$} & 90.00 & \multirow{5}{*}{85.90} \\
\hline & 40.00 & \\
\hline & 30.00 & \\
\hline & 15.00 & \\
\hline & 1.50 & \\
\hline \multirow{6}{*}{ СOOP-H } & 90.00 & \multirow{6}{*}{83.96} \\
\hline & 70.00 & \\
\hline & 50.00 & \\
\hline & 15.00 & \\
\hline & 10.00 & \\
\hline & 1.00 & \\
\hline \multirow{5}{*}{$C O O P-G$} & 53.33 & \multirow{5}{*}{80.82} \\
\hline & 32.00 & \\
\hline & 21.33 & \\
\hline & 8.00 & \\
\hline & 0.53 & \\
\hline \multirow{4}{*}{$C O O P-L$} & 57.14 & \multirow{4}{*}{75.21} \\
\hline & 48.05 & \\
\hline & 10.39 & \\
\hline & 5.19 & \\
\hline \multirow{4}{*}{ COOP-J } & 76.00 & \multirow{4}{*}{55.44} \\
\hline & 32.00 & \\
\hline & 25.00 & \\
\hline & 23.00 & \\
\hline \multirow{3}{*}{ СOOP-K } & 94.06 & \multirow{3}{*}{23.52} \\
\hline & 58.24 & \\
\hline & & \\
\hline
\end{tabular}


Table 50 - Calculations for CV_PERCVOL

\begin{tabular}{|c|c|c|}
\hline COOPERATIVE & $\begin{array}{c}\text { VOLUME } \\
(\text { LARGE, MEDIUM, AND SMALL } \\
\text { FARMERS' GROUPS } \\
\text { RESPECTIVELY)(\%) }\end{array}$ & $C V \_P E R C V O L$ \\
\hline \multirow{3}{*}{ COOP-E } & 0.50 & \multirow{3}{*}{130.91} \\
\hline & 4.50 & \\
\hline & 95.00 & \\
\hline \multirow{3}{*}{$C O O P-B$} & 1.00 & \multirow{3}{*}{130.87} \\
\hline & 4.00 & \\
\hline & 95.00 & \\
\hline \multirow{3}{*}{$C O O P-G$} & 0.50 & \multirow{3}{*}{121.71} \\
\hline & 9.00 & \\
\hline & 90.50 & \\
\hline \multirow{3}{*}{$C O O P-F$} & 0.00 & \multirow{3}{*}{111.13} \\
\hline & 15.00 & \\
\hline & 85.00 & \\
\hline \multirow{3}{*}{$\mathrm{COOP}-\mathrm{H}$} & 5.00 & \multirow{3}{*}{90.28} \\
\hline & 20.00 & \\
\hline & 75.00 & \\
\hline \multirow{3}{*}{ COOP-A } & 10.00 & \multirow{3}{*}{78.74} \\
\hline & 20.00 & \\
\hline & 70.00 & \\
\hline \multirow{3}{*}{$C O O P-L$} & 20.00 & \multirow{3}{*}{78.74} \\
\hline & 70.00 & \\
\hline & 10.00 & \\
\hline \multirow{3}{*}{$C O O P-D$} & 30.00 & \multirow{3}{*}{73.82} \\
\hline & 65.00 & \\
\hline & 5.00 & \\
\hline \multirow{3}{*}{ COOP-I } & 65.00 & \multirow{3}{*}{68.51} \\
\hline & 23.00 & \\
\hline & 12.00 & \\
\hline \multirow{3}{*}{ COOP-K } & 9.00 & \multirow{3}{*}{62.66} \\
\hline & 31.00 & \\
\hline & 60.00 & \\
\hline \multirow{3}{*}{$\mathrm{COOP}-\mathrm{C}$} & 60.00 & \multirow{3}{*}{56.57} \\
\hline & 20.00 & \\
\hline & 20.00 & \\
\hline \multirow{3}{*}{ COOP-J } & 40.00 & \multirow{3}{*}{14.14} \\
\hline & 30.00 & \\
\hline & 30.00 & \\
\hline
\end{tabular}


Appendix 3 - Calculations for variables of heterogeneity using grouping as a measurement model

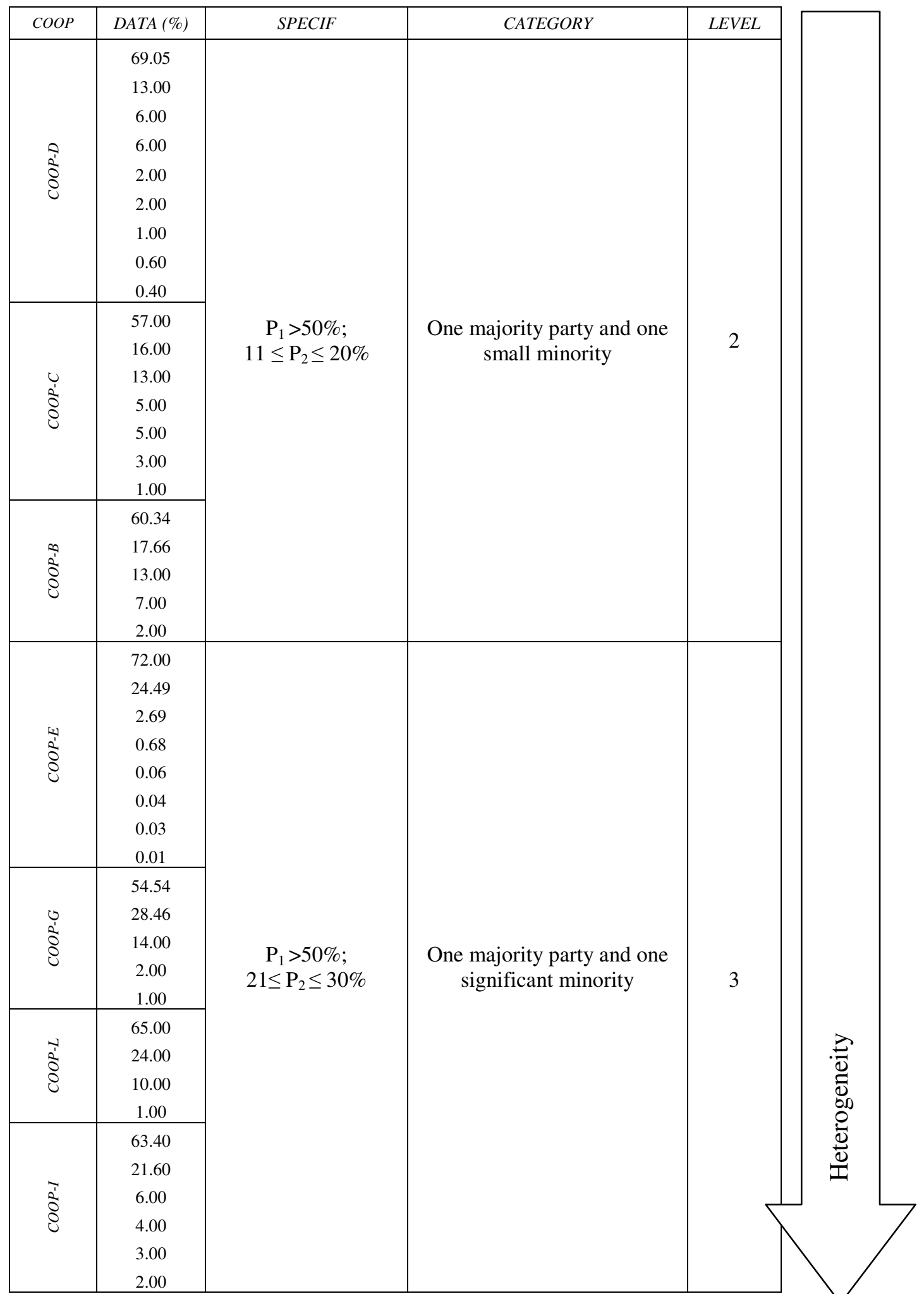

Figure 47 - Homogeneity-heterogeneity for PERCPROD using grouping heterogeneity measurement model

Continued 


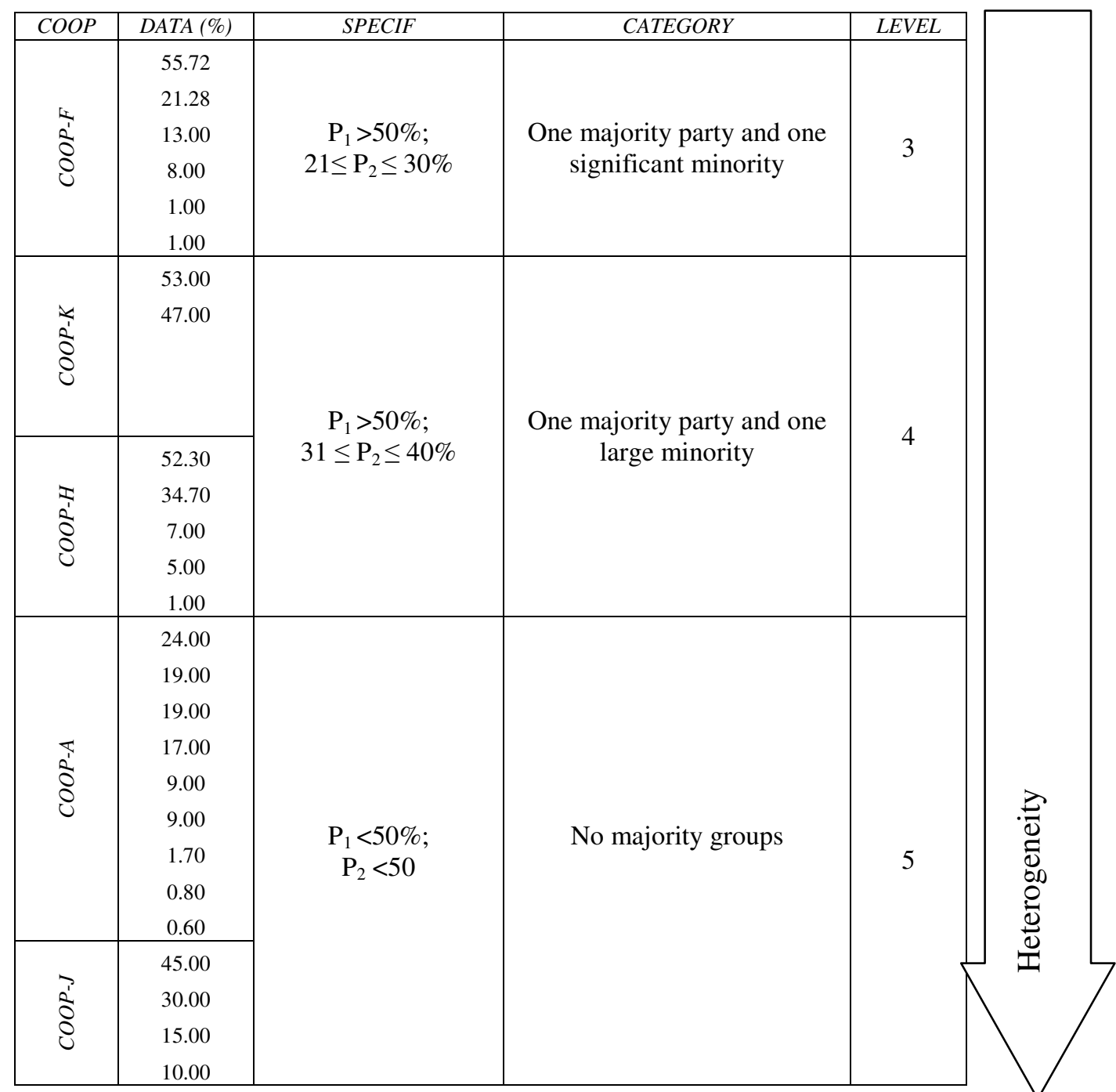

Continuation Figure 47 -Homogeneity-heterogeneity for PERCPROD using grouping heterogeneity measurement model 


\begin{tabular}{|c|c|c|c|c|}
\hline $\mathrm{COOP}$ & DATA $(\%)$ & SPECIF & CLASSIF & LEVEL \\
\hline \multirow{9}{*}{$\begin{array}{l}1 \\
\vdots \\
0 \\
0 \\
0\end{array}$} & 54.08 & \multirow{22}{*}{$\begin{array}{c}\mathrm{PG}_{1}>50 \% \\
21 \leq \mathrm{PG}_{2} \leq 30 \%\end{array}$} & \multirow{22}{*}{$\begin{array}{l}\text { One majority party and } \\
\text { one small minority }\end{array}$} & \multirow{22}{*}{2} \\
\hline & 26.86 & & & \\
\hline & 3.19 & & & \\
\hline & 1.50 & & & \\
\hline & 0.85 & & & \\
\hline & 0.52 & & & \\
\hline & 0.35 & & & \\
\hline & 0.17 & & & \\
\hline & 0.06 & & & \\
\hline \multirow{6}{*}{$\begin{array}{l}4 \\
\vdots \\
8 \\
8 \\
0\end{array}$} & 95.00 & & & \\
\hline & 28.50 & & & \\
\hline & 10.00 & & & \\
\hline & 10.00 & & & \\
\hline & 5.00 & & & \\
\hline & 3.00 & & & \\
\hline \multirow{7}{*}{$\begin{array}{l}u \\
\delta^{\prime} \\
8 \\
0\end{array}$} & 95.00 & & & \\
\hline & 30.00 & & & \\
\hline & 20.00 & & & \\
\hline & 15.00 & & & \\
\hline & 10.00 & & & \\
\hline & 10.00 & & & \\
\hline & 1.00 & & & \\
\hline \multirow{4}{*}{$\begin{array}{l}\frac{1}{8} \\
8 \\
0\end{array}$} & 76.00 & \multirow{14}{*}{$\begin{array}{c}\mathrm{PG}_{1}>50 \% \\
31 \leq \mathrm{PG}_{2} \leq 40 \%\end{array}$} & \multirow{14}{*}{$\begin{array}{l}\text { One majority party and } \\
\text { one significant minority }\end{array}$} & \multirow{14}{*}{3} \\
\hline & 32.00 & & & \\
\hline & 25.00 & & & \\
\hline & 23.00 & & & \\
\hline \multirow{5}{*}{$\begin{array}{l}\text { i } \\
\vdots \\
\vdots \\
0\end{array}$} & 53.33 & & & \\
\hline & 32.00 & & & \\
\hline & 21.33 & & & \\
\hline & 8.00 & & & \\
\hline & 0.53 & & & \\
\hline \multirow{5}{*}{$\begin{array}{l}0 \\
\text { iे } \\
8\end{array}$} & 90.00 & & & \\
\hline & 40.00 & & & \\
\hline & 30.00 & & & \\
\hline & 15.00 & & & \\
\hline & 1.50 & & & \\
\hline
\end{tabular}

Figure 48 - Homogeneity-heterogeneity for PERCMEMB using grouping heterogeneity measurement model

Continued 


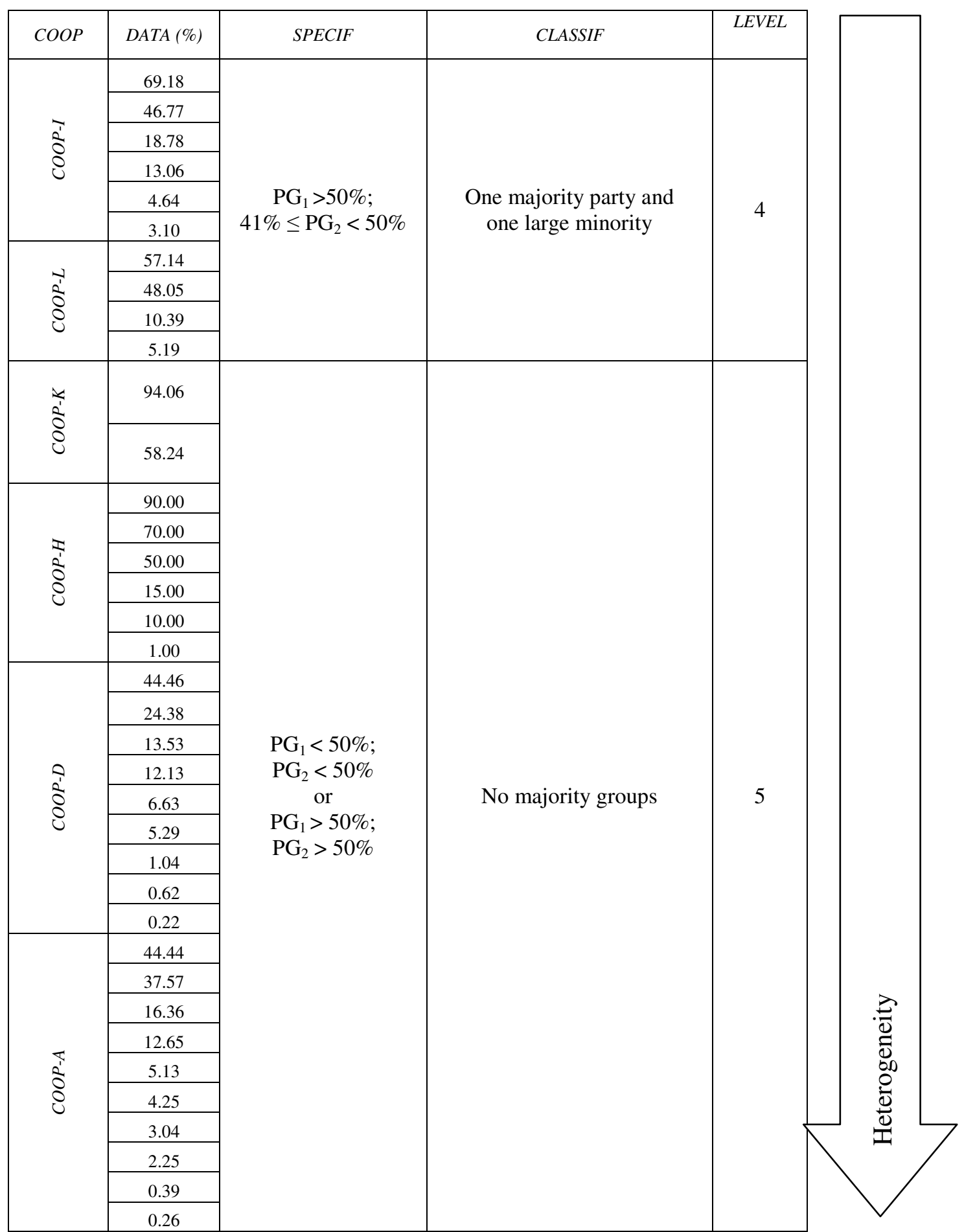

Continuation Figure 48 -Homogeneity-heterogeneity for PERCMEMB using grouping heterogeneity measurement model 
Table 51 - Homogeneity-heterogeneity for PERCVOL using grouping heterogeneity measurement model

\begin{tabular}{|c|c|c|c|c|}
\hline COOPERATIVE & $\begin{array}{c}\text { VOLUME } \\
\text { (LARGE, MEDIUM, AND } \\
\text { SMALL FARMERS' } \\
\text { GROUPS } \\
\text { RESPECTIVELY) }\end{array}$ & SPECIF & CATEGORY & LEVEL \\
\hline $\mathrm{COOP}-\mathrm{C}$ & $\begin{array}{r}\mathbf{6 0 \%} \\
20 \% \\
20 \% \\
\end{array}$ & $\begin{array}{c}\mathrm{LF}>50 \% \text { or } \\
\mathrm{LF}<50 \% ; \mathrm{MF}> \\
50,1 \%\end{array}$ & One dominant group & 1 \\
\hline COOP-I & $\begin{array}{l}\mathbf{6 5 \%} \\
23 \% \\
12 \% \\
\end{array}$ & $\begin{array}{c}\mathrm{LF}>50 \% \text { or } \\
\mathrm{LF}<50 \% ; \mathrm{MF}> \\
50,1 \%\end{array}$ & One dominant group & 1 \\
\hline$C O O P-L$ & $\begin{array}{l}\mathbf{2 0 \%} \\
70 \% \\
10 \% \\
\end{array}$ & $\begin{array}{c}\mathrm{LF}>50 \% \text { or } \\
\mathrm{LF}<50 \% ; \mathrm{MF}> \\
50,1 \%\end{array}$ & One dominant group & 1 \\
\hline$C O O P-D$ & $\begin{array}{l}30 \% \\
65 \% \\
05 \% \\
\end{array}$ & $\begin{array}{c}\mathrm{LF}>50 \% \text { or } \\
\mathrm{LF}<50 \% ; \mathrm{MF}> \\
50,1 \%\end{array}$ & One dominant group & 1 \\
\hline COOP-E & $\begin{array}{l}\mathbf{0 . 5} \% \\
4.5 \% \\
95 \%\end{array}$ & $\begin{array}{c}\mathrm{LF}<50 \% ; 0 \% \leq \mathrm{MF} \leq \\
12.4 \%\end{array}$ & $\begin{array}{l}\text { One bargaining group and one } \\
\text { small minority }\end{array}$ & 2 \\
\hline$C O O P-G$ & $\begin{array}{c}\mathbf{0 . 5 \%} \\
9 \% \\
90.5 \% \\
\end{array}$ & $\begin{array}{c}\mathrm{LF}<50 \% ; 0 \% \leq \mathrm{MF} \leq \\
12.4 \%\end{array}$ & $\begin{array}{l}\text { One bargaining group and one } \\
\text { small minority }\end{array}$ & 2 \\
\hline$C O O P-B$ & $\begin{array}{r}1 \% \\
4 \% \\
95 \% \\
\end{array}$ & $\begin{array}{c}\mathrm{LF}<50 \% ; 0 \% \leq \mathrm{MF} \leq \\
12.4 \%\end{array}$ & $\begin{array}{l}\text { One bargaining group and one } \\
\text { small minority }\end{array}$ & 2 \\
\hline COOP-H & $\begin{array}{l}\mathbf{5 \%} \\
20 \% \\
75 \% \\
\end{array}$ & $\begin{array}{c}\mathrm{LF}<50 \% ; 12.5 \% \leq \mathrm{MF} \\
\leq 25 \%\end{array}$ & $\begin{array}{l}\text { One bargaining group and one } \\
\text { significant minority }\end{array}$ & 3 \\
\hline COOP-A & $\begin{array}{l}10 \% \\
20 \% \\
70 \% \\
\end{array}$ & $\begin{array}{c}\mathrm{LF}<50 \% ; 12.5 \% \leq \mathrm{MF} \\
\leq 25 \%\end{array}$ & $\begin{array}{l}\text { One bargaining group and one } \\
\text { significant minority }\end{array}$ & 3 \\
\hline$C O O P-F$ & $\begin{array}{r}0 \% \\
15 \% \\
85 \% \\
\end{array}$ & $\begin{array}{c}\mathrm{LF}<50 \% ; 12.5 \% \leq \mathrm{MF} \\
\leq 25 \%\end{array}$ & $\begin{array}{l}\text { One bargaining group and one } \\
\text { significant minority }\end{array}$ & 3 \\
\hline COOP-K & $\begin{array}{l}\mathbf{9 \%} \\
31 \% \\
60 \% \\
\end{array}$ & $\begin{array}{c}\mathrm{LF}<50 \% ; 25.1 \% \leq \mathrm{MF} \\
\leq 37.5 \%\end{array}$ & $\begin{array}{l}\text { One bargaining group and one } \\
\text { large minority }\end{array}$ & 4 \\
\hline COOP-J & $\begin{array}{l}\mathbf{4 0 \%} \\
30 \% \\
30 \% \\
\end{array}$ & $\begin{array}{c}\mathrm{LF}<50 \% ; 25.1 \% \leq \mathrm{MF} \\
\leq 37.5 \%\end{array}$ & $\begin{array}{l}\text { One bargaining group and one } \\
\text { large minority }\end{array}$ & 4 \\
\hline
\end{tabular}


226 
Appendix 4 - Transformation of the CV heterogeneity data from low to high

Table 52 - Negative correlation between CV_PERCPROD and level of member participation

\begin{tabular}{c|c|c}
\hline Cooperative & (CV PERCPROD) & LEVEL OF MP \\
\hline COOP $-E$ & 204.73 & 4 \\
\hline COOP $-D$ & 187.13 & 7 \\
\hline COOP $-I$ & 132.67 & 12 \\
\hline COOP $-C$ & 128.86 & 3 \\
\hline COOP $-H$ & 118.58 & 8 \\
\hline COOP $-F$ & 112.66 & 3 \\
\hline COOP $-B$ & 104.28 & 17 \\
\hline COOP $-G$ & 99.5 & 4 \\
\hline COOP $-L$ & 97.55 & 5 \\
\hline COOP $-A$ & 86.63 & 41 \\
\hline COOP $-J$ & 54.77 & 40 \\
\hline COOP $-K$ & 6.69 & \\
\hline NEGATIVE CORRELATION & & $\mathbf{- 0 . 6 8}$ \\
\hline
\end{tabular}

Table 53 - Positive correlation between CV_PERCPROD and level of member participation

\begin{tabular}{c|c|c}
\hline Cooperative & $($ CV PERCPROD $)$ & LEVEL OF MP \\
\hline COOP $-E$ & 0.01 & 4 \\
\hline COOP $-D$ & 17.6 & 7 \\
\hline COOP $-I$ & 72.06 & 12 \\
\hline COOP $-C$ & 75.87 & 3 \\
\hline COOP $-H$ & 86.15 & 8 \\
\hline COOP $-F$ & 92.07 & 3 \\
\hline COOP $-B$ & 100.45 & 2 \\
\hline COOP $-G$ & 105.23 & 4 \\
\hline COOP $-L$ & 107.18 & 5 \\
\hline COOP $-A$ & 118.1 & 40 \\
\hline COOP $-J$ & 149.96 & \\
\hline COOP $-K$ & 198.04 & $\mathbf{0 . 6 8}$ \\
\hline POSITIVE CORRELATION & \multicolumn{2}{|}{} \\
\hline
\end{tabular}


Table 54 - Negative correlation between CV_PERCMEMB and level of member participation

\begin{tabular}{c|c|c}
\hline Cooperative & $($ CV PERCMEMB $)$ & LEVEL OF MP \\
\hline COOP $-E$ & 181.5 & 4 \\
\hline$C O O P-F$ & 127.78 & 3 \\
\hline$C O O P-A$ & 119.43 & 5 \\
\hline$C O O P-C$ & 113.89 & 3 \\
\hline$C O O P-D$ & 113.25 & 7 \\
\hline$C O O P-I$ & 93.12 & 12 \\
\hline$C O O P-B$ & 85.9 & 8 \\
\hline$C O O P-H$ & 83.96 & 2 \\
\hline$C O O P-G$ & 80.82 & 4 \\
\hline$C O O P-L$ & 75.21 & 41 \\
\hline$C O O P-J$ & 55.44 & 40 \\
\hline$C O O P-K$ & 23.52 & \\
\hline NEGATIVE CORRELATION & & $\mathbf{- 0 . 7 0}$ \\
\hline
\end{tabular}

Table 55 - Positive correlation between CV_PERCMEMB and level of member participation

\begin{tabular}{c|c|c}
\hline Cooperative & $($ CV PERCMEMB $)$ & LEVEL OF MP \\
\hline COOP $-E$ & 0.01 & 4 \\
\hline COOP $-F$ & 53.72 & 3 \\
\hline COOP $-A$ & 62.07 & 5 \\
\hline COOP $-C$ & 67.61 & 3 \\
\hline COOP $-D$ & 68.25 & 7 \\
\hline COOP-I & 88.38 & 12 \\
\hline COOP $-B$ & 95.6 & 8 \\
\hline COOP $-H$ & 97.54 & 2 \\
\hline COOP $-G$ & 100.68 & 4 \\
\hline COOP $-L$ & 106.29 & 41 \\
\hline COOP $-J$ & 126.06 & 40 \\
\hline COOP $-K$ & 157.98 & \\
\hline POSITIVE CORRELATION & & $\mathbf{0 . 7 0}$ \\
\hline
\end{tabular}


Table 56 - Negative correlation between CV_PERCVOL and level of member participation

\begin{tabular}{c|c|c}
\hline Cooperative & $($ CV PERCVOL $)$ & LEVEL OF MP \\
\hline COOP $-E$ & 130.91 & 4 \\
\hline COOP $-B$ & 130.87 & 17 \\
\hline COOP $-G$ & 121.71 & 2 \\
\hline COOP $-F$ & 111.13 & 3 \\
\hline COOP $-H$ & 90.28 & 8 \\
\hline COOP $-A$ & 78.74 & 5 \\
\hline COOP $-L$ & 78.74 & 7 \\
\hline COOP $-D$ & 73.82 & 12 \\
\hline COOP $-I$ & 68.51 & 40 \\
\hline COOP $-K$ & 62.66 & 3 \\
\hline COOP-C & 56.57 & 41 \\
\hline COOP $-J$ & 14.14 & \\
\hline NEGATIVE CORRELATION & & $\mathbf{- 0 . 5 7}$ \\
\hline
\end{tabular}

Table 57 - Positive correlation between CV_PERCVOL and level of member participation

\begin{tabular}{c|c|c}
\hline Cooperative & $($ CV PERCVOL $)$ & LEVEL OF MP \\
\hline COOP $-E$ & 0.01 & 4 \\
\hline COOP $-B$ & 0.04 & 17 \\
\hline COOP $-G$ & 9.2 & 2 \\
\hline COOP $-F$ & 19.78 & 3 \\
\hline COOP $-H$ & 40.63 & 8 \\
\hline COOP $-A$ & 52.17 & 5 \\
\hline COOP $-L$ & 52.17 & 7 \\
\hline COOP $-D$ & 57.09 & 12 \\
\hline$C O O P-I$ & 62.4 & 40 \\
\hline COOP $-K$ & 68.25 & 3 \\
\hline$C O O P-C$ & 74.34 & 41 \\
\hline$C O O P-J$ & 116.77 & \\
\hline POSITIVE CORRELATION & & $\mathbf{0 . 5 7}$ \\
\hline
\end{tabular}


Table 58 - Negative correlation between CV_AVERAGE and level of member participation

\begin{tabular}{c|c|c}
\hline Cooperative & CV_AVERAGE & LEVEL OF MP \\
\hline COOP $-E$ & 172.38 & 4 \\
\hline COOP-D & 124.73 & 7 \\
\hline COOP $-F$ & 117.19 & 3 \\
\hline COOP $-B$ & 107.02 & 17 \\
\hline COOP $-G$ & 100.68 & 2 \\
\hline COOP $-C$ & 99.77 & 3 \\
\hline COOP-I & 98.1 & 12 \\
\hline COOP $-H$ & 97.61 & 5 \\
\hline COOP- $A$ & 94.93 & 4 \\
\hline COOP-L & 83.83 & 41 \\
\hline COOP-J & 41.45 & 40 \\
\hline COOP $-K$ & 30.96 & \\
\hline NEGATIVE CORRELATION & & $\mathbf{- 0 . 7 6}$ \\
\hline
\end{tabular}

Table 59 - Positive correlation between CV_AVERAGE and level of member participation

\begin{tabular}{|c|c|c|}
\hline Cooperative & CV_AVERAGE & LEVEL OF MP \\
\hline COOP-E & 0.01 & 4 \\
\hline$C O O P-D$ & 47.65 & 7 \\
\hline$C O O P-F$ & 55.19 & 3 \\
\hline$C O O P-B$ & 65.36 & 17 \\
\hline$C O O P-G$ & 71.7 & 2 \\
\hline $\mathrm{COOP}-\mathrm{C}$ & 72.61 & 3 \\
\hline COOP-I & 74.28 & 12 \\
\hline $\mathrm{COOP}-\mathrm{H}$ & 74.77 & 8 \\
\hline COOP-A & 77.45 & 5 \\
\hline COOP-L & 88.55 & 4 \\
\hline COOP-J & 130.93 & 41 \\
\hline COOP-K & 141.42 & 40 \\
\hline POSITIVE CORRELATION & \multicolumn{2}{|c|}{0.76} \\
\hline
\end{tabular}


Appendix 5 - Placing cooperatives into groups based on two dimensions: (1), level of member participation; (2), level of (direct or opportunity) democratic cost

Table 60 - Two groups of cooperatives: high member participation and high direct democratic costs Vs. low member participation and low direct democratic costs

\begin{tabular}{c|c|c|c|c}
\hline Cooperative & $\begin{array}{c}\text { Level (\%) of member } \\
\text { participation } \\
\text { at general assembly }\end{array}$ & Classification & $\begin{array}{c}\text { Direct democratic costs at } \\
\text { the general assembly } \\
\text { (Number of members per } \\
\text { nucleus) }\end{array}$ & Classification \\
\hline$C O O P-B$ & 17 & High & 48 & High \\
\hline$C O O P-K$ & 40 & High & 51 & High \\
\hline$C O O P-A$ & 5 & Low & 53 & High \\
\hline$C O O P-F$ & 3 & Low & 60 & High \\
\hline$C O O P-C$ & 3 & Low & 101 & High \\
\hline$C O O P-I$ & 12 & High & 121 & Low \\
\hline$C O O P-L$ & 4 & Low & 167 & Low \\
\hline$C O O P-D$ & 7 & Low & 199 & Low \\
\hline$C O O P-E$ & 4 & Low & 201 & Low \\
\hline$C O O P-H$ & 8 & Low & 266 & - \\
\hline$C O O P-G$ & 2 & Low & 374 & - \\
\hline
\end{tabular}

Table 61 - Two groups of cooperatives: high member participation and high direct democratic costs Vs. low member participation and low direct democratic costs

\begin{tabular}{c|c|c|c|c}
\hline Cooperative & $\begin{array}{c}\text { Level of member } \\
\text { participation at the } \\
\text { board of directors } \\
\text { (Board Size) }\end{array}$ & Classification & $\begin{array}{c}\text { Direct democratic costs at } \\
\text { the board of directors } \\
\text { Board Total Salary/year) } \\
(R \$)\end{array}$ & Classification \\
\hline$C O O P-B$ & 19 & High & 109,200 & High \\
\hline$C O O P-K$ & 20 & High & 106,827 & High \\
\hline$C O O P-A$ & 20 & High & 91,780 & High \\
\hline$C O O P-J$ & 9 & Low & 72,000 & High \\
\hline$C O O P-D$ & 12 & High & 66,000 & Low \\
\hline$C O O P-E$ & 9 & Low & 65,988 & Low \\
\hline$C O O P-C$ & 15 & High & 65,126 & Low \\
\hline$C O O P-I$ & 9 & Low & 65,124 & Low \\
\hline$C O O P-G$ & 10 & Low & 61,380 & Low \\
\hline$C O O P-H$ & 12 & High & 56,880 & Low \\
\hline$C O O P-F$ & 8 & Low & 29,376 & 15,000 \\
\hline
\end{tabular}


Table 62 - Two groups of cooperatives: low member participation and opportunity democratic costs Vs. high member participation and no opportunity democratic costs

\begin{tabular}{|c|c|c|c|c|}
\hline Cooperative & $\begin{array}{l}\text { Level of member } \\
\text { participation at the } \\
\text { board of directors } \\
\text { (Board Size) }\end{array}$ & Classification & $\begin{array}{l}\text { Opportunity democratic } \\
\text { costs at the board of } \\
\text { directors (Number of } \\
\text { products } \\
\text { underrepresented at the } \\
\text { board) }\end{array}$ & Classification \\
\hline COOP-E & 9 & Low & 7 & Yes \\
\hline$C O O P-D$ & 12 & High & 3 & Yes \\
\hline $\mathrm{COOP}-\mathrm{C}$ & 15 & High & 3 & Yes \\
\hline COOP-A & 20 & High & 3 & Yes \\
\hline COOP-F & 8 & Low & 2 & Yes \\
\hline COOP-I & 9 & Low & 2 & Yes \\
\hline COOP-H & 12 & High & 2 & Yes \\
\hline$C O O P-G$ & 10 & Low & 1 & Yes \\
\hline COOP-L & 6 & Low & 0 & No \\
\hline COOP-J & 9 & Low & 0 & No \\
\hline$C O O P-B$ & 19 & High & 0 & No \\
\hline COOP-K & 20 & High & 0 & No \\
\hline
\end{tabular}

Table 63 - Two groups of cooperatives: high member participation and opportunity democratic costs Vs. low member participation and no opportunity democratic costs

\begin{tabular}{|c|c|c|c|c|}
\hline Cooperative & $\begin{array}{l}\text { Level of member } \\
\text { participation at the } \\
\text { board of directors } \\
\text { (Board Size) }\end{array}$ & Classification & $\begin{array}{l}\text { Opportunity democratic } \\
\text { costs at the board of } \\
\text { directors (Number of } \\
\text { products overrepresented } \\
\text { at the board) }\end{array}$ & Classification \\
\hline COOP-G & 10 & Low & 1 & No \\
\hline COOP-E & 9 & Low & 1 & No \\
\hline COOP-I & 9 & Low & 1 & No \\
\hline COOP-J & 9 & Low & 1 & No \\
\hline COOP-F & 8 & Low & 1 & No \\
\hline COOP-L & 6 & Low & 2 & Yes \\
\hline COOP-A & 20 & High & 3 & Yes \\
\hline COOP-K & 20 & High & 1 & No \\
\hline$C O O P-B$ & 19 & High & 1 & No \\
\hline $\mathrm{COOP}-\mathrm{C}$ & 15 & High & 2 & Yes \\
\hline$C O O P-D$ & 12 & High & 1 & No \\
\hline COOP-H & 12 & High & 0 & No \\
\hline
\end{tabular}




\section{Annex 1 - The role of Rio Grande do Sul in the Brazilian's and World's agricultural production, selected commodities}

Table 64 - Largest rice producers in the world, 2008

\begin{tabular}{llr}
\hline Rank & Country & $(\boldsymbol{t})$ \\
\hline $\mathbf{1}$ & China & 193.354 .175 \\
$\mathbf{2}$ & India & 148.260 .000 \\
$\mathbf{3}$ & Indonesia & 60.251 .072 \\
$\mathbf{4}$ & Bangladesh & 46.905 .000 \\
$\mathbf{5}$ & Viet Nam & 38.725 .100 \\
$\mathbf{6}$ & Thailand & 31.650 .632 \\
$\mathbf{7}$ & Myanmar & 30.500 .000 \\
$\mathbf{8}$ & Philippines & 16.815 .548 \\
$\mathbf{9}$ & Brazil & 12.061 .465 \\
$\mathbf{1 0}$ & Japan & 11.028 .750 \\
$\mathbf{1 1}$ & Pakistan & 10.428 .000 \\
$\mathbf{1 2}$ & United States of America & 9.241 .173 \\
$\mathbf{1 3}$ & Egypt & 7.253 .373 \\
$\mathbf{1 5}$ & Cambodia & 7.175 .473 \\
$\mathbf{1 4}$ & Republic of Korea & 6.919 .250 \\
$\mathbf{1 7}$ & Nepal & 4.299 .264 \\
$\mathbf{1 6}$ & Nigeria & 4.179 .000 \\
$\mathbf{1 8}$ & Sri Lanka & 3.875 .000 \\
$\mathbf{1 9}$ & Madagascar & 3.000 .000 \\
$\mathbf{2 0}$ & Peru & 2.775 .800 \\
\hline
\end{tabular}

SOURCE: Author, with data from FAO http://faostat.fao.org accessed in September, $17^{\text {th }}, 2010$

\section{Brazilian RICE's Production (t), per Province, 2008}

Mato Grosso do Sul

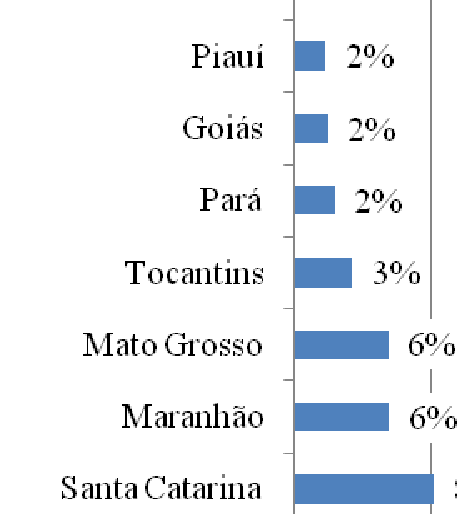

Rio Grande do Sul 
Table 65 - Largest Tobacco Producers in the world, 2008 (t)

\begin{tabular}{llr}
\hline Rank & Country & $(\boldsymbol{t})$ \\
\hline $\mathbf{1}$ & China & 2.836 .725 \\
$\mathbf{2}$ & Brazil & 851.058 \\
$\mathbf{3}$ & India & 520.000 \\
$\mathbf{4}$ & United States of America & 363.103 \\
$\mathbf{5}$ & Argentina & 170.000 \\
$\mathbf{6}$ & Indonesia & 169.668 \\
$\mathbf{7}$ & Malawi & 160.238 \\
$\mathbf{8}$ & Italy & 110.000 \\
$\mathbf{9}$ & Pakistan & 107.765 \\
$\mathbf{1 0}$ & Turkey & 93.403 \\
$\mathbf{1 1}$ & Zimbabwe & 79.000 \\
$\mathbf{1 2}$ & Thailand & 70.000 \\
$\mathbf{1 3}$ & Mozambique & 64.342 \\
$\mathbf{1 4}$ & Democratic People's Republic of Korea & 63.000 \\
$\mathbf{1 5}$ & United Republic of Tanzania & 50.800 \\
$\mathbf{1 6}$ & Lao People's Democratic Republic & 49.830 \\
$\mathbf{1 7}$ & Zambia & 48.000 \\
$\mathbf{1 8}$ & Canada & 44.000 \\
$\mathbf{1 9}$ & Bulgaria & 42.162 \\
$\mathbf{2 0}$ & Poland & 41.200 \\
\hline $\mathbf{1}$ & & \\
\hline
\end{tabular}

SOURCE: Author, with data from FAO http://faostat.fao.org accessed in September, $17^{\text {th }}, 2010$

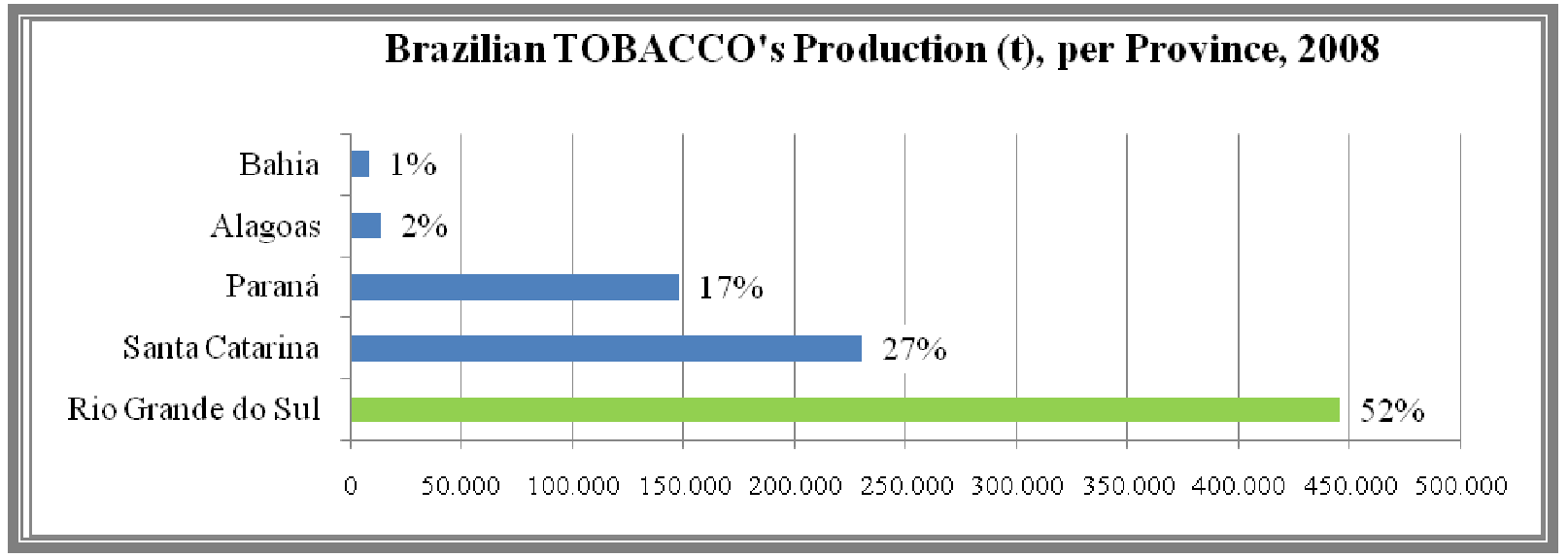

Figure 50 - Brazilian tobacco's production (t), per province, 2008

SOURCE: Author, with data from IBGE http://www.sidra.ibge.gov.br accessed in September, $17^{\text {th }}, 2010$ 
Table 66 - Largest Oats Producers in the world, 2008

\begin{tabular}{clr}
\hline Rank & Country & $(\boldsymbol{t})$ \\
\hline $\mathbf{1}$ & Russian Federation & 5.834 .910 \\
$\mathbf{2}$ & Finland & 1.213 .400 \\
$\mathbf{3}$ & Australia & 1.160 .028 \\
\hline $\mathbf{4}$ & Ukraine & 944.400 \\
$\mathbf{5}$ & Sweden & 820.000 \\
$\mathbf{6}$ & Germany & 793.188 \\
\hline $\mathbf{7}$ & United Kingdom & 783.574 \\
$\mathbf{8}$ & Belarus & 605.441 \\
$\mathbf{9}$ & France & 471.960 \\
$\mathbf{1 0}$ & Chile & 384.224 \\
$\mathbf{1 1}$ & Norway & 327.800 \\
$\mathbf{1 2}$ & Brazil & 238.516 \\
$\mathbf{1 3}$ & Turkey & 196.099 \\
$\mathbf{1 4}$ & Hungary & 181.792 \\
$\mathbf{1 5}$ & Ireland & 176.600 \\
\hline $\mathbf{1 6}$ & Czech Republic & 155.868 \\
\hline $\mathbf{1 7}$ & Latvia & 141.500 \\
\hline $\mathbf{1 8}$ & Estonia & 77.500 \\
\hline $\mathbf{1 9}$ & South Africa & 45.000 \\
\hline $\mathbf{2 0}$ & Ethiopia & 30.558 \\
\hline
\end{tabular}

SOURCE: Author, with data from FAO http://faostat.fao.org accessed in September, $17^{\text {th }}, 2010$

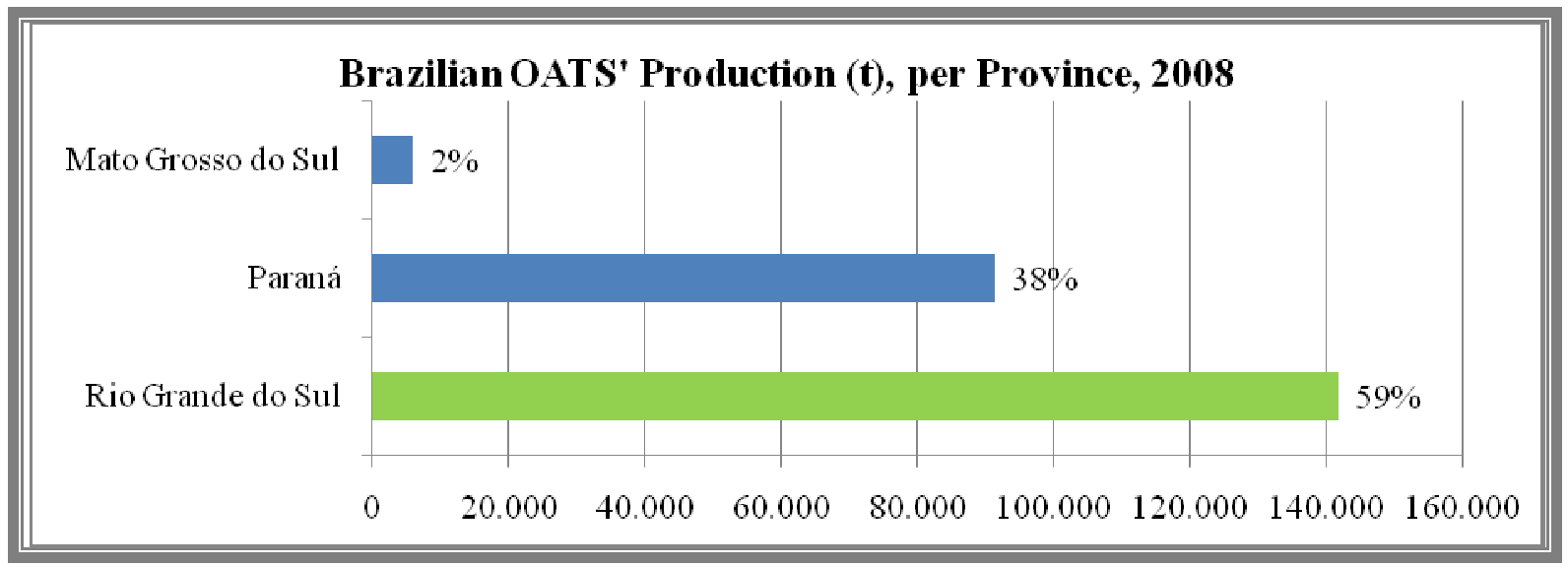

Figure 51 - Brazilian oats' production (t), per province, 2008

SOURCE: Author, with data from IBGE http://www.sidra.ibge.gov.br accessed in September, $17^{\text {th }}, 2010$ 
Table 67 - Largest Grapes Producers in the world, 2008

\begin{tabular}{clr}
\hline Rank & Country & $(\boldsymbol{t})$ \\
\hline $\mathbf{1}$ & Italy & 7.793 .301 \\
$\mathbf{2}$ & China & 7.235 .656 \\
$\mathbf{3}$ & United States of America & 6.639 .920 \\
$\mathbf{4}$ & Spain & 6.020 .000 \\
$\mathbf{5}$ & France & 5.664 .195 \\
$\mathbf{6}$ & Turkey & 3.918 .440 \\
$\mathbf{7}$ & Argentina & 2.900 .000 \\
$\mathbf{8}$ & Chile & 2.400 .000 \\
$\mathbf{9}$ & Australia & 1.956 .790 \\
$\mathbf{1 0}$ & South Africa & 1.791 .643 \\
$\mathbf{1 1}$ & Iran (Islamic Republic of) & 1.739 .503 \\
$\mathbf{1 2}$ & India & 1.735 .000 \\
$\mathbf{1 3}$ & Egypt & 1.531 .418 \\
$\mathbf{1 4}$ & Germany & 1.428 .776 \\
$\mathbf{1 5}$ & Brazil & 1.421 .431 \\
$\mathbf{1 6}$ & Romania & 996.023 \\
$\mathbf{1 7}$ & Greece & 852.900 \\
$\mathbf{1 8}$ & Uzbekistan & 791.000 \\
$\mathbf{1 9}$ & Portugal & 763.000 \\
$\mathbf{2 0}$ & Republic of Moldova & 635.513 \\
\hline $\mathbf{A}$ & & \\
\hline
\end{tabular}

SOURCE: Author, with data from FAO http://faostat.fao.org accessed in September, $17^{\text {th }}, 2010$

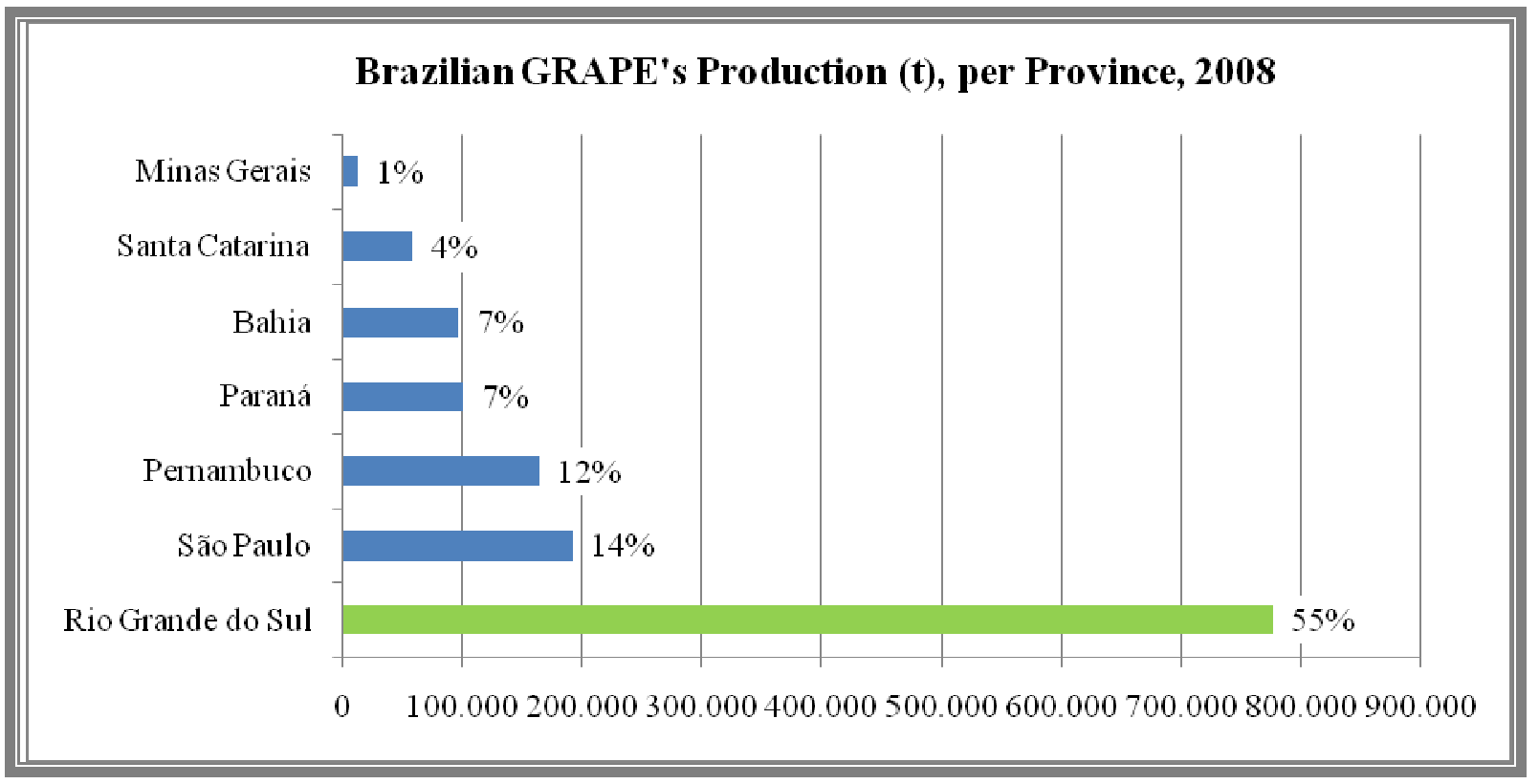

Figure 52 - Brazilian grape's production (t), per province, 2008

SOURCE: Author, with data from IBGE http://www.sidra.ibge.gov.br accessed in September, $17^{\text {th }}, 2010$ 
Brazilian WOOL's Production (t), per Province, 2008

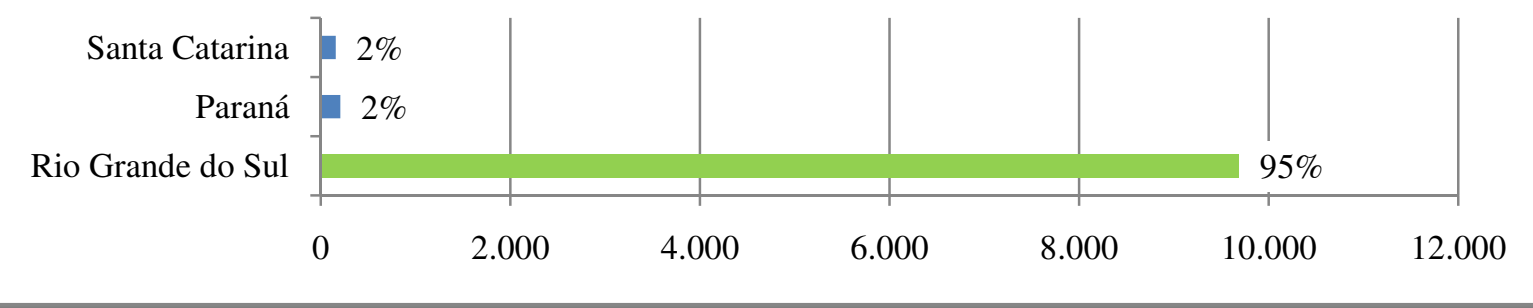

Figure 53 - Brazilian wool's production (t), per province, 2008

SOURCE: Author, with data from IBGE http://www.sidra.ibge.gov.br accessed in September, $17^{\text {th }}, 2010$ 
Table 68 - Largest Dairy Producers in the world, 2008

\begin{tabular}{clr}
\hline Rank & Country & $(\boldsymbol{t})$ \\
\hline $\mathbf{1}$ & United States of America & 86.159 .637 \\
$\mathbf{2}$ & India & 44.100 .000 \\
$\mathbf{3}$ & China & 35.853 .665 \\
\hline $\mathbf{4}$ & Russian Federation & 32.099 .658 \\
$\mathbf{5}$ & Germany & 28.656 .256 \\
$\mathbf{6}$ & Brazil & 27.579 .383 \\
$\mathbf{7}$ & France & 24.516 .320 \\
$\mathbf{8}$ & New Zealand & 15.216 .840 \\
$\mathbf{9}$ & United Kingdom & 13.719 .000 \\
$\mathbf{1 0}$ & Poland & 12.425 .300 \\
\hline $\mathbf{1 4}$ & Pakistan & 11.550 .000 \\
\hline $\mathbf{1 7}$ & Ukraine & 11.523 .800 \\
\hline $\mathbf{1 1}$ & Netherlands & 11.285 .910 \\
$\mathbf{1 2}$ & Italy & 11.285 .910 \\
$\mathbf{1 3}$ & Turkey & 11.255 .200 \\
\hline $\mathbf{1 5}$ & Mexico & 10.765 .827 \\
\hline $\mathbf{1 6}$ & Argentina & 10.325 .465 \\
\hline $\mathbf{1 8}$ & Australia & 9.223 .000 \\
\hline $\mathbf{1 9}$ & Canada & 8.140 .000 \\
\hline $\mathbf{2 0}$ & Japan & 7.982 .030 \\
\hline $\mathbf{A}$ & A & \\
\hline
\end{tabular}

SOURCE: Author, with data from FAO http://faostat.fao.org accessed in September, $17^{\text {th }}, 2010$

Brazilian COW MILK's Production (thousand liters), per Province, 2006

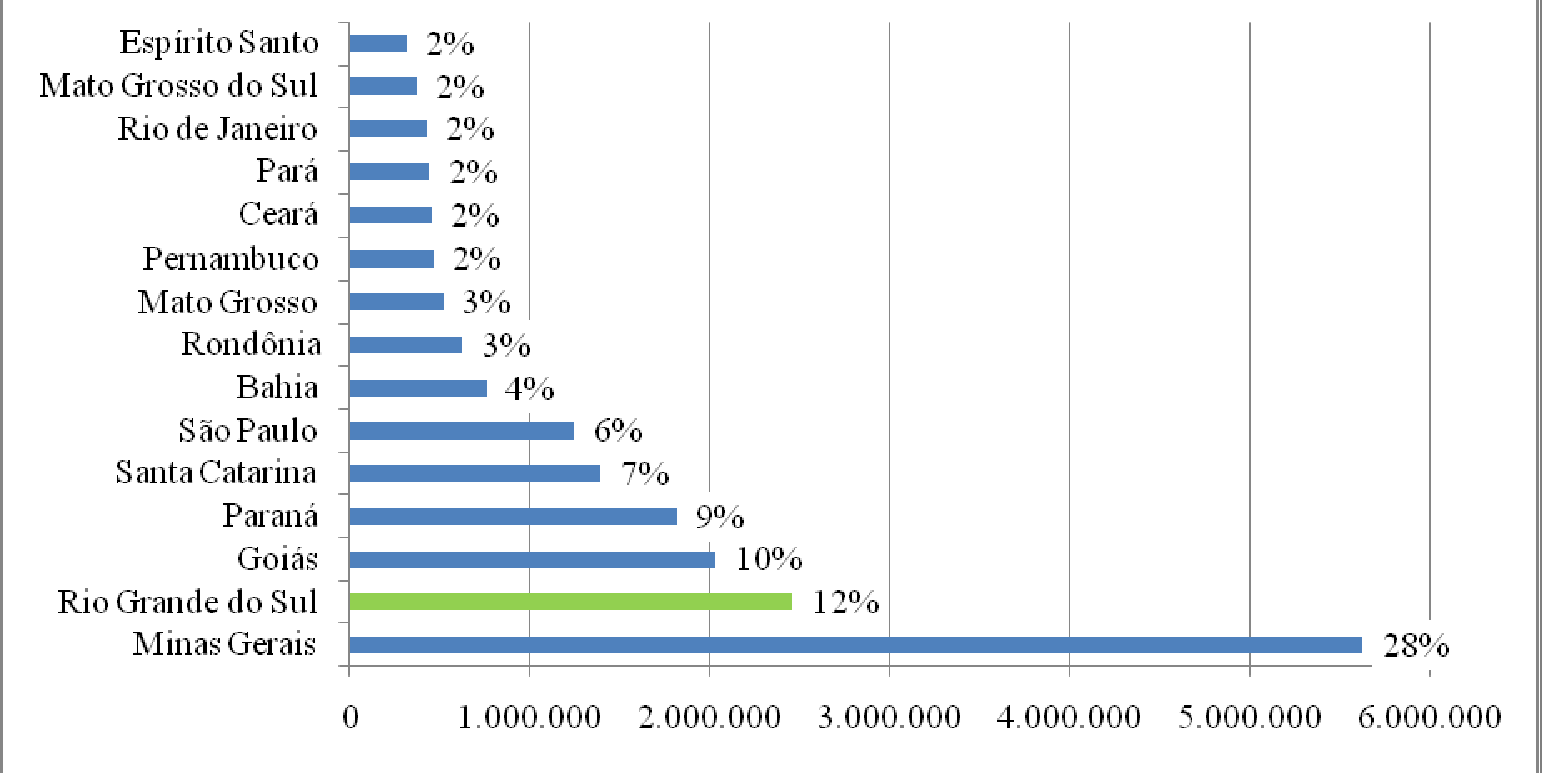

Figure 54 - Brazilian dairy production (t), per province, 2008

SOURCE: Author, with data from IBGE http://www.sidra.ibge.gov.br accessed in September, $17^{\text {th }}, 2010$ 
Table 69 - Largest Wheat Producers in the world, 2008

\begin{tabular}{clr}
\hline Rank & Country & $(\boldsymbol{t})$ \\
\hline $\mathbf{1}$ & China & 112.463 .296 \\
$\mathbf{2}$ & India & 78.570 .200 \\
$\mathbf{3}$ & United States of America & 68.016 .100 \\
$\mathbf{4}$ & Russian Federation & 63.765 .140 \\
$\mathbf{5}$ & France & 39.001 .700 \\
$\mathbf{6}$ & Canada & 28.611 .100 \\
$\mathbf{7}$ & Germany & 25.988 .565 \\
$\mathbf{8}$ & Ukraine & 25.885 .400 \\
$\mathbf{9}$ & Australia & 21.420 .177 \\
\hline $\mathbf{1 0}$ & Pakistan & 20.958 .800 \\
$\mathbf{1 1}$ & Turkey & 17.782 .000 \\
\hline $\mathbf{1 2}$ & United Kingdom & 17.227 .000 \\
$\mathbf{1 3}$ & Kazakhstan & 12.538 .200 \\
\hline $\mathbf{1 4}$ & Poland & 9.274 .920 \\
$\mathbf{1 5}$ & Italy & 8.855 .440 \\
\hline $\mathbf{1 6}$ & Argentina & 8.508 .156 \\
$\mathbf{1 7}$ & Egypt & 7.977 .051 \\
$\mathbf{1 8}$ & Iran (Islamic Republic of) & 7.956 .647 \\
$\mathbf{1 9}$ & Romania & 7.180 .980 \\
$\mathbf{2 0}$ & Brazil & 6.027 .131 \\
\hline
\end{tabular}

SOURCE: Author, with data from FAO http://faostat.fao.org accessed in September, $17^{\text {th }}, 2010$

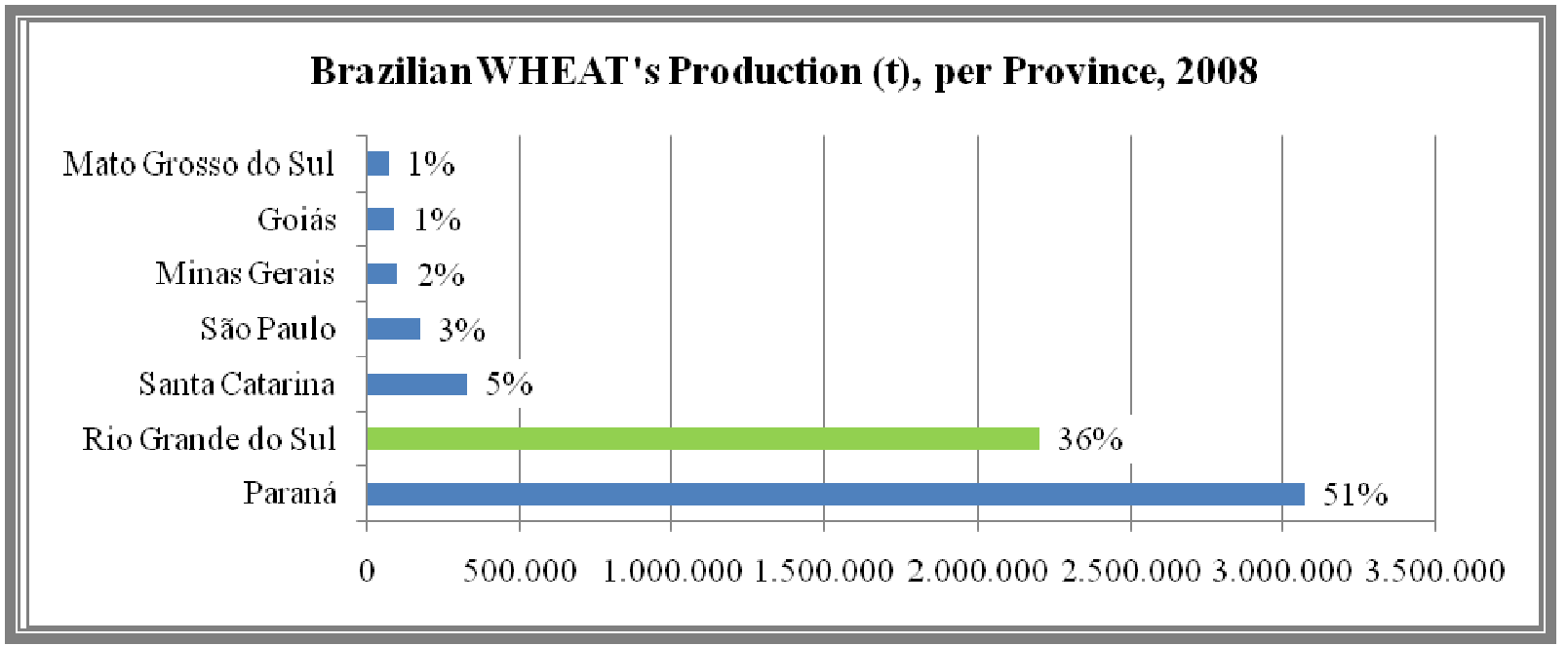

Figure 55 - Brazilian wheat's production (t), per province, 2008

SOURCE: Author, with data from IBGE http://www.sidra.ibge.gov.br accessed in September, $17^{\text {th }}, 2010$ 
Table 70 - Largest Pig Herds in the world, 2009

\begin{tabular}{llr}
\hline Rank & Country & Heads \\
\hline $\mathbf{1}$ & China & 451.177 .581 \\
\hline $\mathbf{2}$ & United States of America & 67.148 .000 \\
$\mathbf{3}$ & Brazil & 37.000 .000 \\
$\mathbf{4}$ & Viet Nam & 27.627 .700 \\
$\mathbf{5}$ & Germany & 26.886 .500 \\
$\mathbf{6}$ & Spain & 26.289 .600 \\
$\mathbf{7}$ & Russian Federation & 16.161 .860 \\
$\mathbf{8}$ & Mexico & 16.100 .000 \\
$\mathbf{9}$ & France & 14.810 .000 \\
$\mathbf{1 0}$ & Poland & 14.278 .647 \\
$\mathbf{1 1}$ & India & 13.840 .000 \\
$\mathbf{1 2}$ & Philippines & 13.596 .000 \\
$\mathbf{1 3}$ & Canada & 12.400 .000 \\
\hline $\mathbf{1 4}$ & Denmark & 12.369 .145 \\
$\mathbf{1 5}$ & Netherlands & 12.108 .000 \\
\hline $\mathbf{1 6}$ & Japan & 9.899 .000 \\
$\mathbf{1 7}$ & Italy & 9.252 .400 \\
$\mathbf{1 8}$ & Thailand & 7.480 .530 \\
$\mathbf{1 9}$ & Indonesia & 6.922 .261 \\
$\mathbf{2 0}$ & Ukraine & 6.526 .000 \\
\hline
\end{tabular}

SOURCE: Author, with data from FAO http://faostat.fao.org accessed in September, $17^{\text {th }}, 2010$

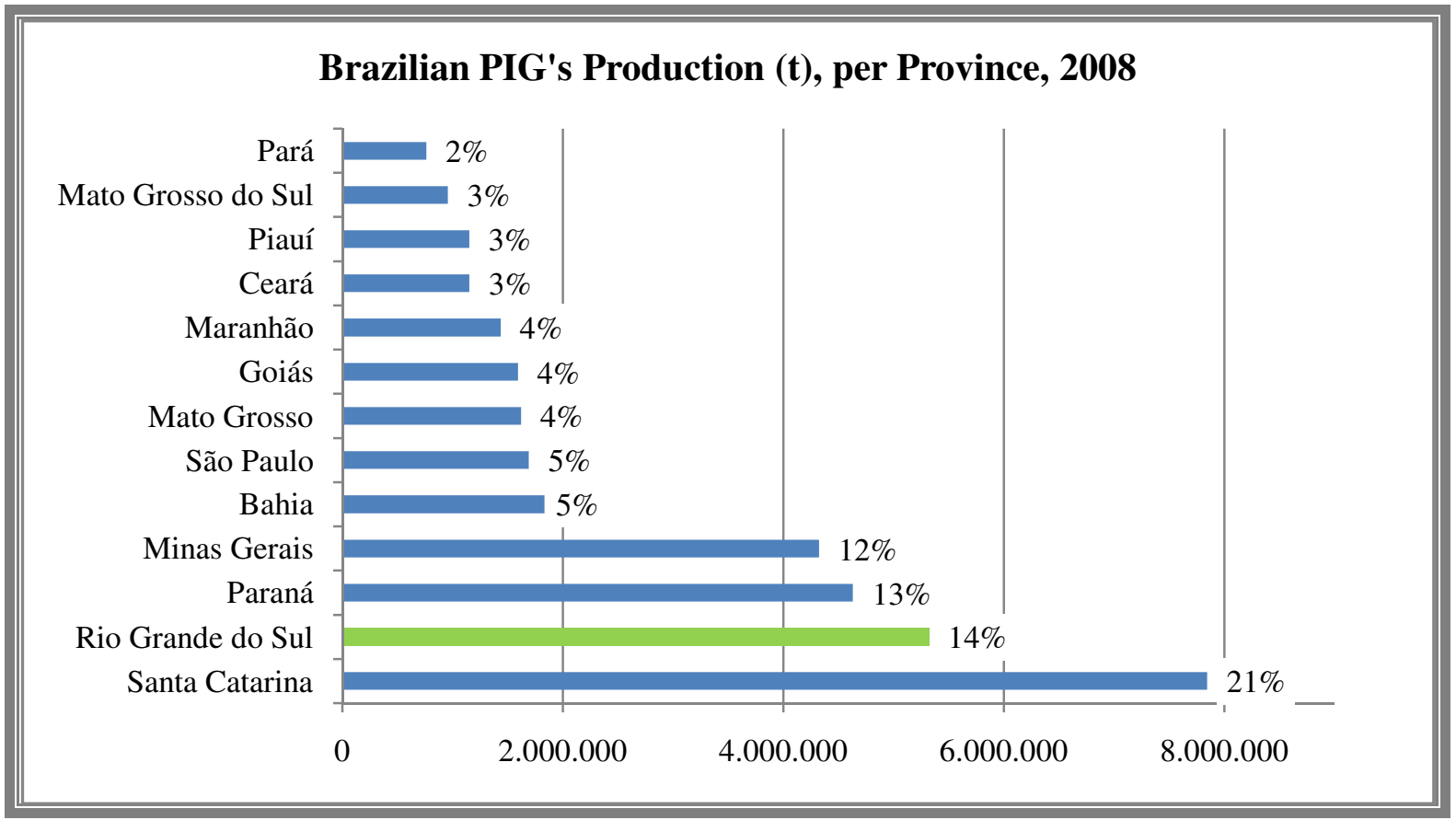

Figure 56 - Brazilian pig's production (t), per province, 2008

SOURCE: Author, with data from IBGE http://www.sidra.ibge.gov.br accessed in September, $17^{\text {th }}, 2010$ 
Table 71 - Largest Soybeans (dry) Producers in the world, 2008

\begin{tabular}{clr}
\hline Rank & Country & $(\boldsymbol{t})$ \\
\hline $\mathbf{1}$ & United States of America & 80.748 .700 \\
$\mathbf{2}$ & Brazil & 59.242 .480 \\
$\mathbf{3}$ & Argentina & 46.238 .087 \\
$\mathbf{4}$ & China & 15.545 .141 \\
$\mathbf{5}$ & India & 9.905 .000 \\
\hline $\mathbf{6}$ & Paraguay & 6.311 .794 \\
$\mathbf{7}$ & Canada & 3.335 .900 \\
$\mathbf{8}$ & Bolivia (Plurinational State of) & 1.259 .676 \\
$\mathbf{9}$ & Uruguay & 880.000 \\
$\mathbf{1 0}$ & Ukraine & 812.800 \\
$\mathbf{1 1}$ & Indonesia & 776.491 \\
$\mathbf{1 2}$ & Russian Federation & 745.990 \\
$\mathbf{1 3}$ & Nigeria & 591.000 \\
\hline $\mathbf{1 4}$ & Serbia & 350.946 \\
$\mathbf{1 5}$ & Italy & 346.245 \\
\hline $\mathbf{1 6}$ & Democratic People's Republic of Korea & 345.000 \\
$\mathbf{1 7}$ & South Africa & 282.000 \\
$\mathbf{1 8}$ & Viet Nam & 268.600 \\
$\mathbf{1 9}$ & Iran (Islamic Republic of) & 197.246 \\
$\mathbf{2 0}$ & Thailand & 186.598 \\
\hline
\end{tabular}

SOURCE: Author, with data from FAO http://faostat.fao.org accessed in September, $17^{\text {th }}, 2010$

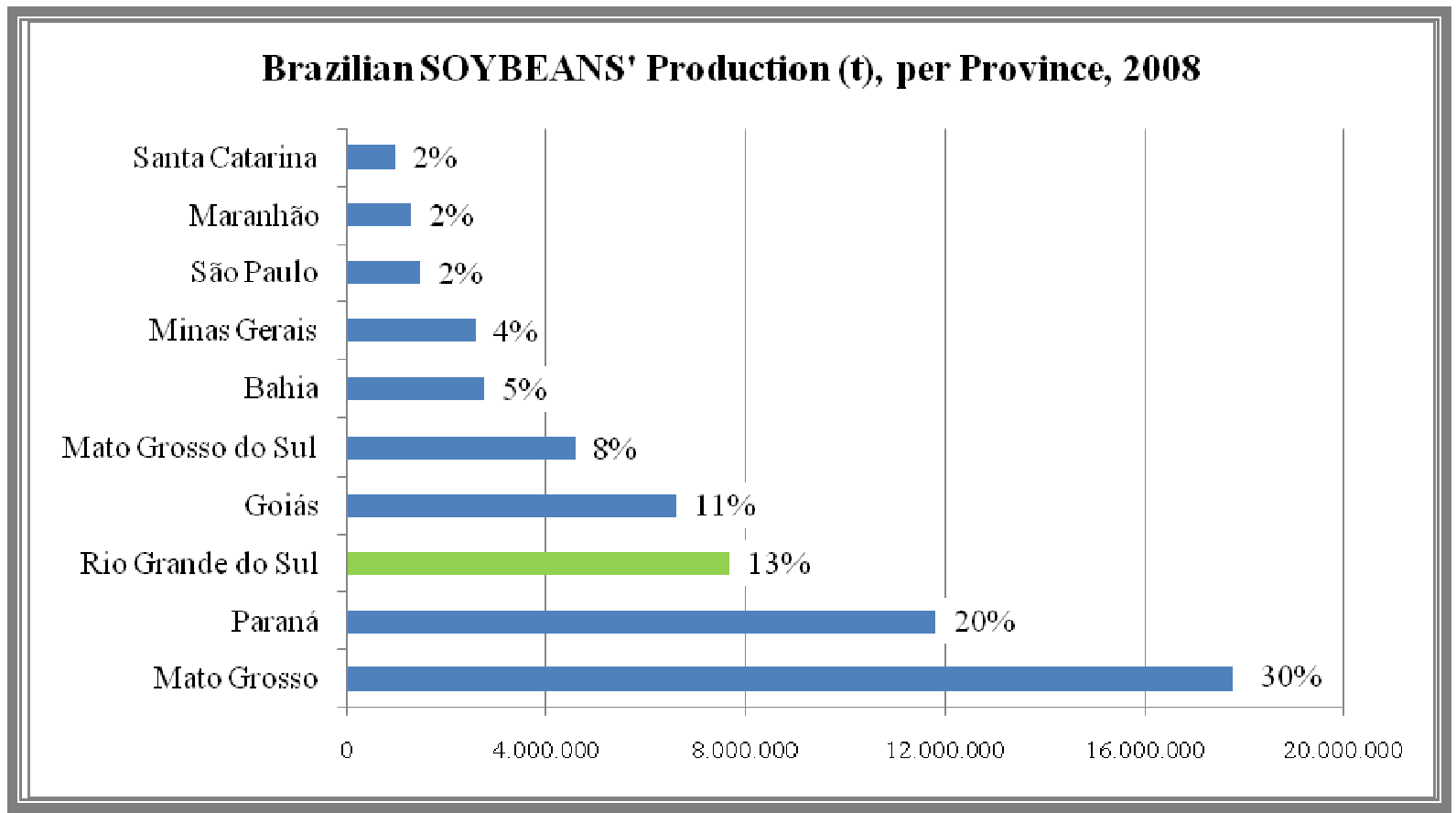

Figure 57 - Brazilian soybeans (dry)' production (t), per province, 2008

SOURCE: Author, with data from IBGE http://www.sidra.ibge.gov.br accessed in September, $17^{\text {th }}, 2010$ 
Table 72 - Largest Maize (Green) Producers in the world, 2008

\begin{tabular}{clr}
\hline $\boldsymbol{R a n} \boldsymbol{k}$ & Country & $\boldsymbol{( t )}$ \\
\hline $\mathbf{1}$ & United States of America & 307.142 .010 \\
$\mathbf{2}$ & China & 166.032 .097 \\
$\mathbf{3}$ & Brazil & 58.933 .347 \\
$\mathbf{4}$ & Mexico & 24.320 .100 \\
$\mathbf{5}$ & Argentina & 22.016 .926 \\
$\mathbf{6}$ & India & 19.730 .000 \\
$\mathbf{7}$ & Indonesia & 16.323 .922 \\
$\mathbf{8}$ & France & 15.818 .500 \\
$\mathbf{9}$ & South Africa & 12.700 .000 \\
$\mathbf{1 0}$ & Ukraine & 11.446 .800 \\
$\mathbf{1 1}$ & Canada & 10.592 .000 \\
$\mathbf{1 2}$ & Hungary & 8.897 .138 \\
$\mathbf{1 3}$ & Romania & 7.849 .080 \\
$\mathbf{1 4}$ & Nigeria & 7.525 .000 \\
$\mathbf{1 5}$ & Philippines & 6.928 .220 \\
$\mathbf{1 6}$ & Ethiopia & 3.776 .440 \\
$\mathbf{1 7}$ & United Republic of Tanzania & 3.659 .000 \\
$\mathbf{1 8}$ & Pakistan & 3.593 .000 \\
$\mathbf{1 9}$ & Malawi & 2.634 .701 \\
$\mathbf{2 0}$ & Kenya & 2.367 .237 \\
\hline
\end{tabular}

SOURCE: Author, with data from FAO http://faostat.fao.org accessed in September, $17^{\text {th }}, 2010$

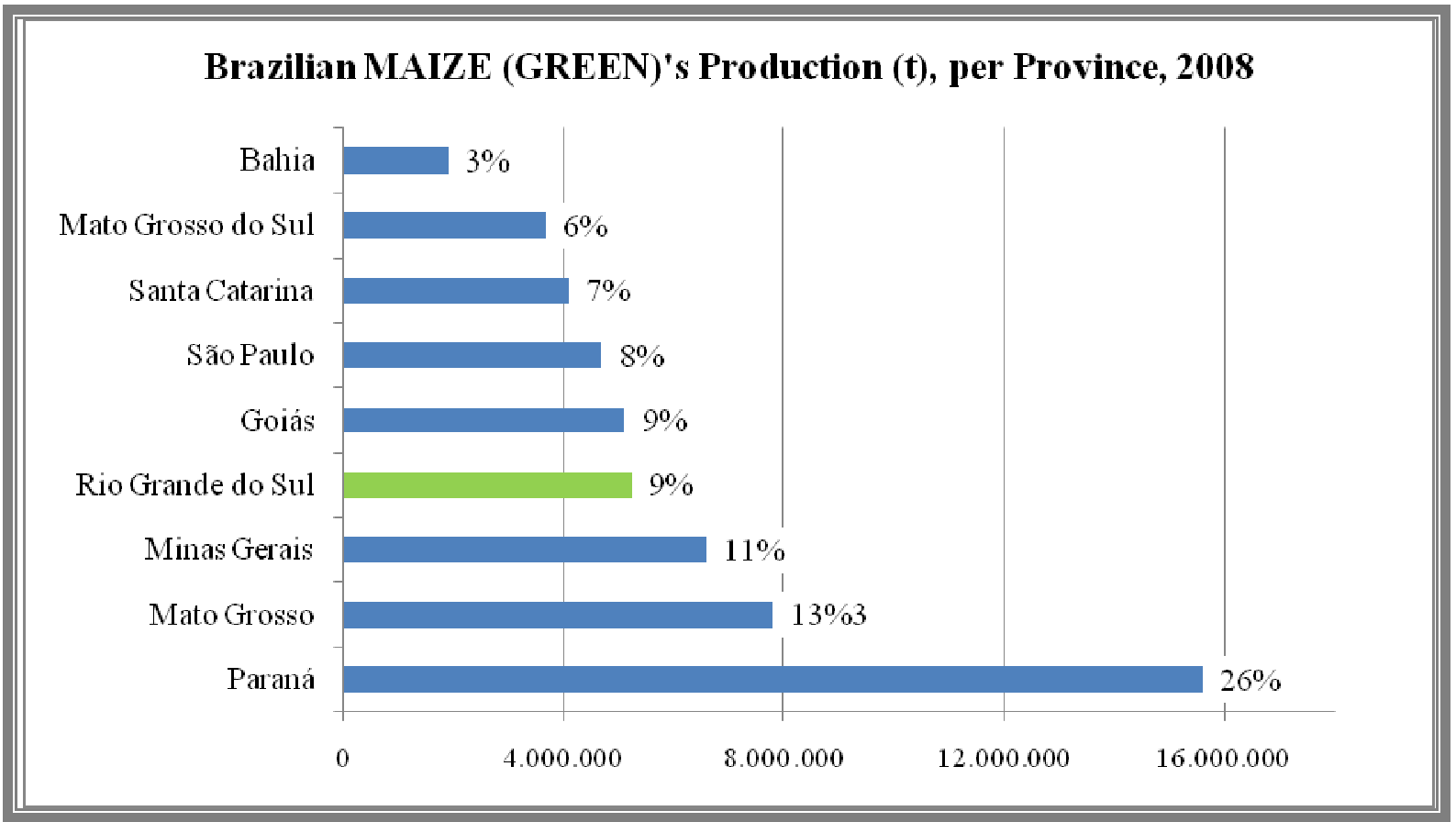

Figure 58 - Brazilian Maize (Green)'s production (t), per province, 2008

SOURCE: Author, with data from IBGE http://www.sidra.ibge.gov.br accessed in September, $17^{\text {th }}, 2010$ 
Table 73 - Largest Chicken Herds in the world, 2009

\begin{tabular}{|c|c|c|}
\hline Rank & Country & 1000 Heads \\
\hline 1 & China & 4.702 .278 \\
\hline 2 & Indonesia & 1.341 .784 \\
\hline 3 & Brazil & 1.205 .000 \\
\hline 4 & India & 613.000 \\
\hline 5 & Iran (Islamic Republic of) & 513.000 \\
\hline 6 & Mexico & 506.000 \\
\hline 7 & Russian Federation & 366.282 \\
\hline 8 & Pakistan & 296.000 \\
\hline 9 & Japan & 285.349 \\
\hline 10 & Turkey & 244.280 \\
\hline 11 & Thailand & 228.207 \\
\hline 12 & Bangladesh & 221.300 \\
\hline 13 & Viet Nam & 196.140 \\
\hline 14 & France & 176.000 \\
\hline 15 & United Kingdom & 170.000 \\
\hline 16 & Morocco & 165.000 \\
\hline 17 & Ukraine & 158.800 \\
\hline 18 & Philippines & 158.372 \\
\hline 19 & Colombia & 157.000 \\
\hline 20 & Spain & 138.000 \\
\hline
\end{tabular}

SOURCE: Author, with data from FAO http://faostat.fao.org accessed in September, $17^{\text {th }}, 2010$

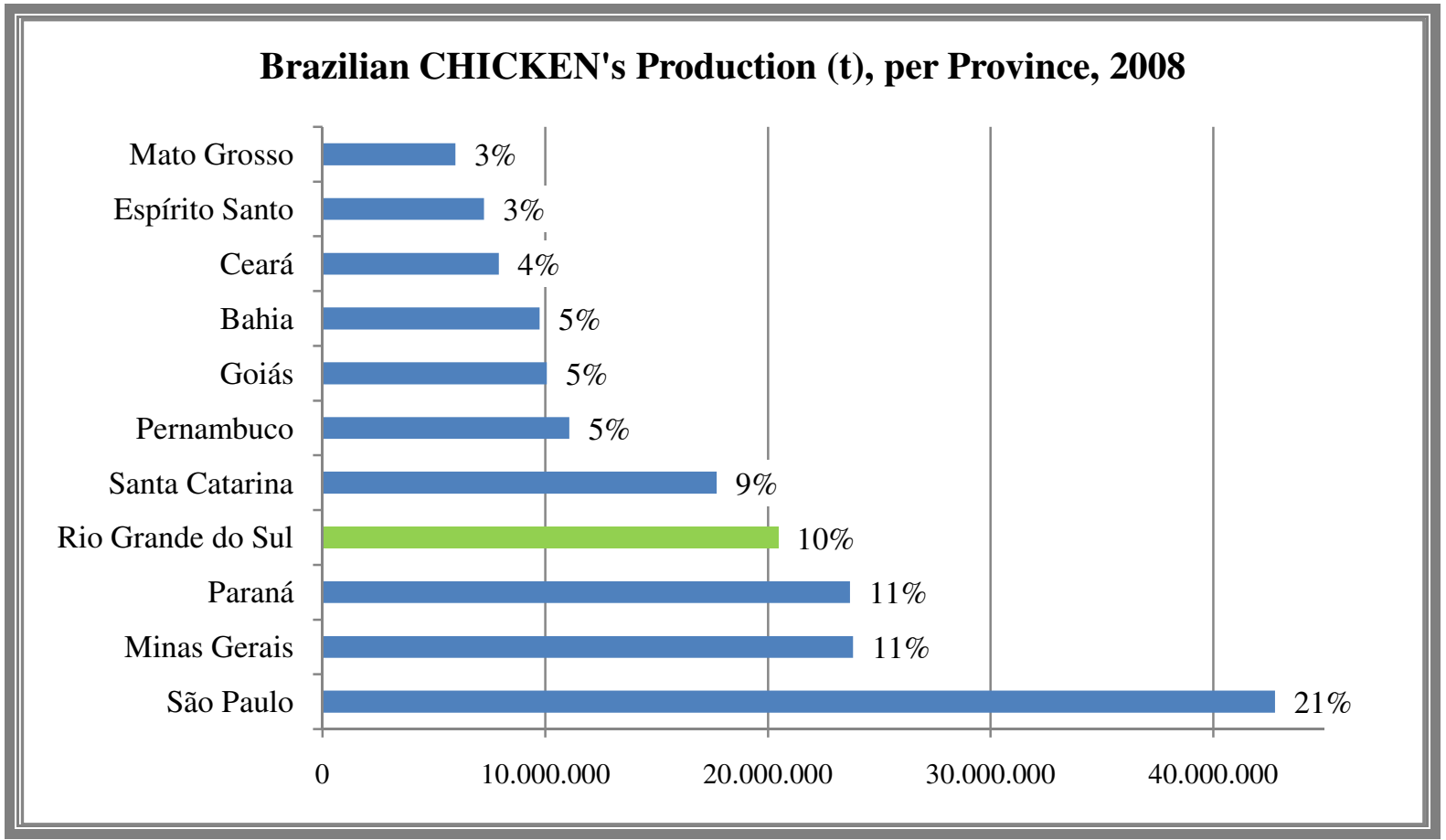

Figure 59 - Brazilian chicken's production $(t)$, per province, 2008

SOURCE: Author, with data from IBGE http://www.sidra.ibge.gov.br accessed in September, $17^{\text {th }}, 2010$ 


\section{Brazilian ROOSTERS, PULLETS AND CHICK's Production}

(t), per Province, 2008

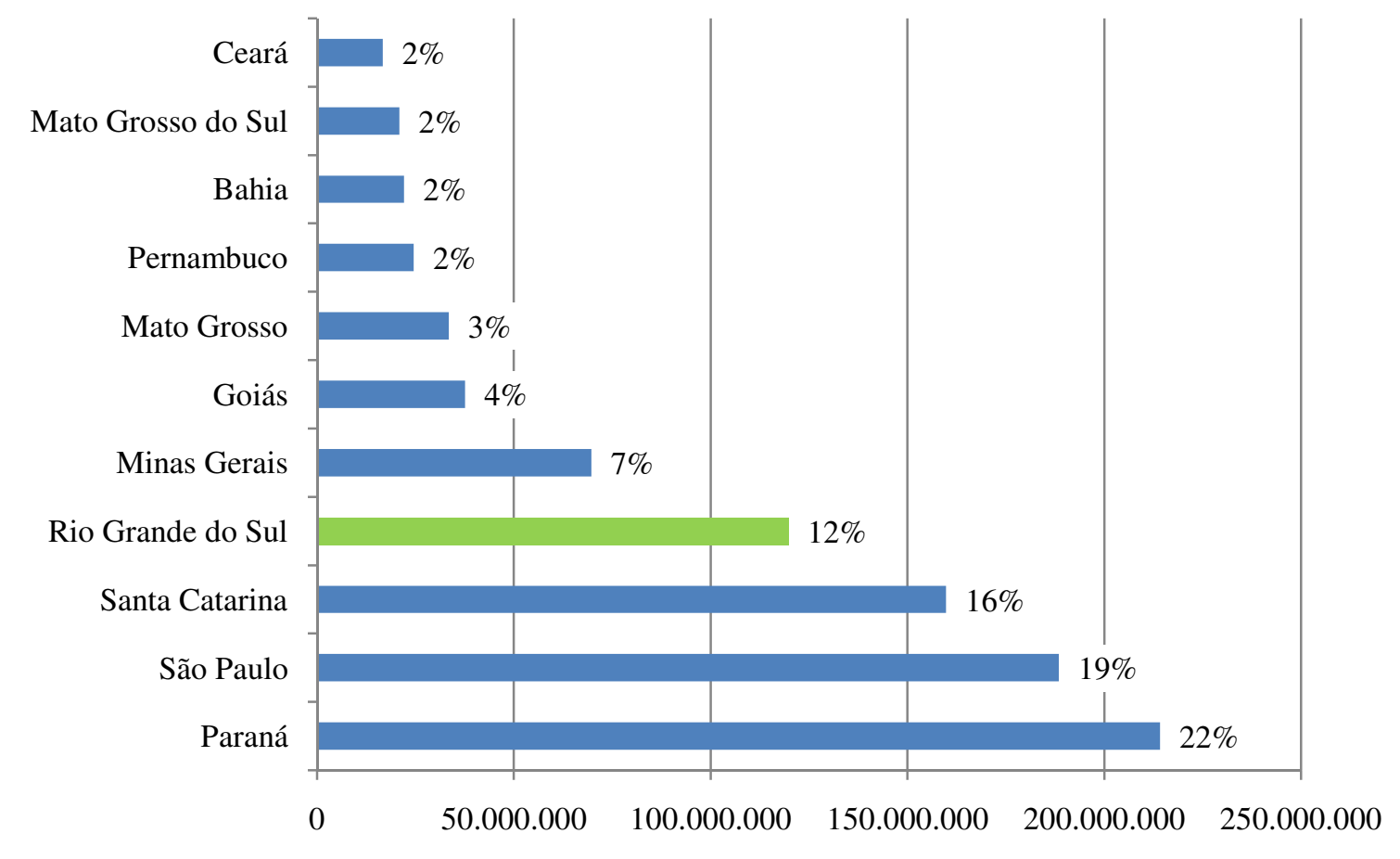

Figure 60 - Brazilian roosters, pullets and chick's production (t), per province, 2008

SOURCE: Author, with data from IBGE http://www.sidra.ibge.gov.br accessed in September, $17^{\text {th }}, 2010$ 
Table 74 - Largest Cattle Herds in the world, 2009

\begin{tabular}{|clr|}
\hline Rank & Country & Heads \\
\hline $\mathbf{1}$ & Brazil & 204.500 .000 \\
$\mathbf{2}$ & India & 172.451 .000 \\
$\mathbf{3}$ & United States of America & 94.521 .000 \\
\hline $\mathbf{4}$ & China & 92.131 .951 \\
$\mathbf{5}$ & Ethiopia & 50.884 .005 \\
\hline $\mathbf{6}$ & Argentina & 50.750 .000 \\
\hline $\mathbf{7}$ & Sudan & 41.563 .000 \\
\hline $\mathbf{8}$ & Pakistan & 33.000 .000 \\
$\mathbf{9}$ & Australia & 27.906 .765 \\
\hline $\mathbf{1 0}$ & Colombia & 27.359 .290 \\
\hline $\mathbf{1 1}$ & Bangladesh & 22.970 .000 \\
\hline $\mathbf{1 2}$ & Russian Federation & 21.038 .029 \\
\hline $\mathbf{1 3}$ & France & 18.591 .000 \\
\hline $\mathbf{1 4}$ & Nigeria & 16.400 .000 \\
\hline $\mathbf{1 5}$ & South Africa & 13.761 .161 \\
\hline $\mathbf{1 6}$ & Canada & 13.180 .000 \\
\hline $\mathbf{1 7}$ & Germany & 12.944 .903 \\
\hline $\mathbf{1 8}$ & Indonesia & 12.859 .037 \\
\hline $\mathbf{1 9}$ & Kenya & 12.490 .130 \\
\hline $\mathbf{2 0}$ & Paraguay & 11.643 .386 \\
\hline
\end{tabular}

SOURCE: Author, with data from FAO http://faostat.fao.org accessed in September, $17^{\text {th }}, 2010$

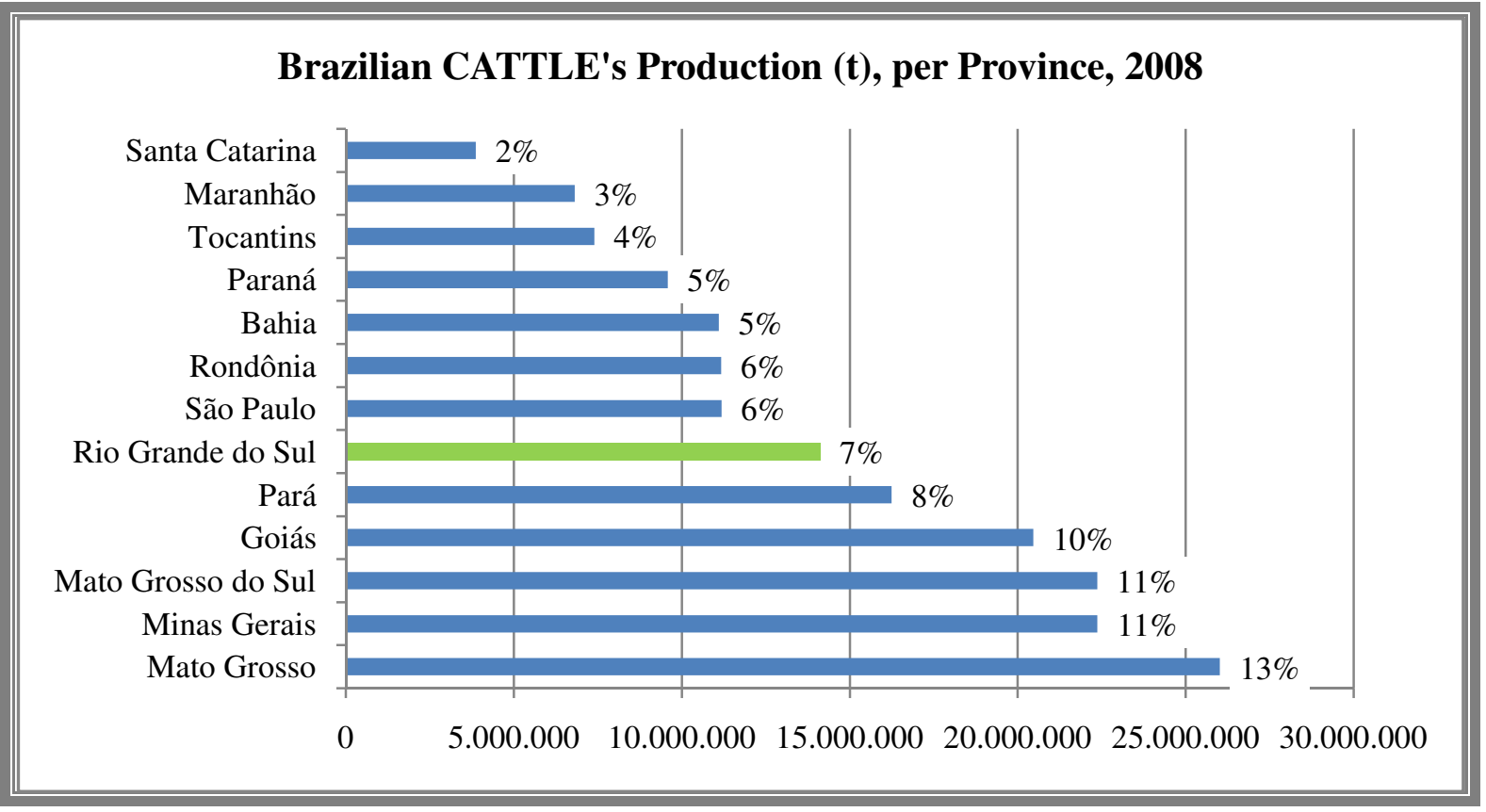

Figure 61 - Brazilian cattle's production (t), per province, 2008

SOURCE: Author, with data from IBGE http://www.sidra.ibge.gov.br accessed in September, 17 th $^{\text {th }}, 2010$ 


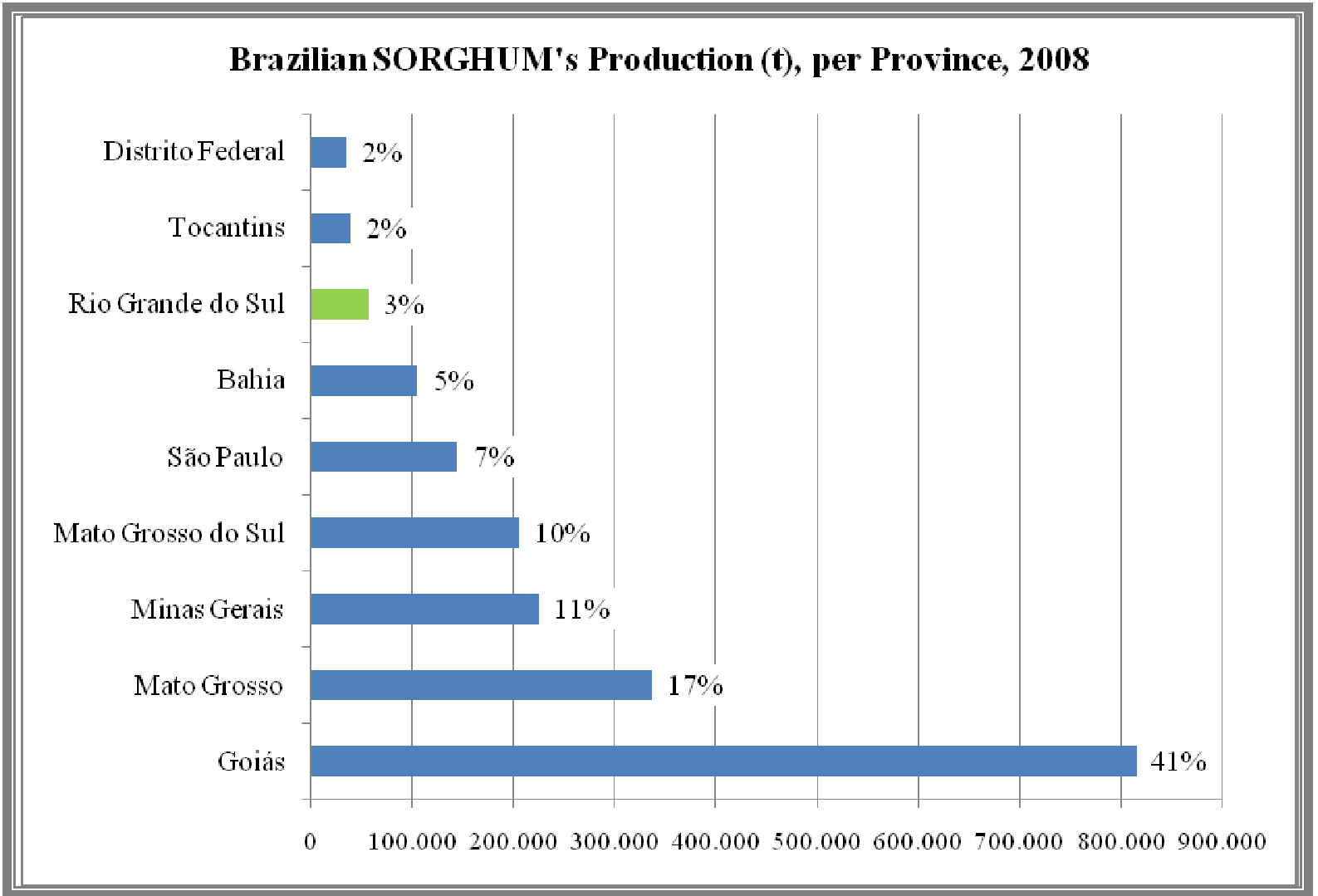

Figure 62 - Brazilian sorghum's production $(t)$, per province, 2008

SOURCE: Author, with data from IBGE http://www.sidra.ibge.gov.br accessed in September, $17^{\text {th }}, 2010$ 
Table 75 - Largest Beans (dry) (Dry) Producers in the world, 2008

\begin{tabular}{crr}
\hline Rank & Country & $(\boldsymbol{t})$ \\
$\mathbf{1}$ & Brazil & 3.461 .194 \\
$\mathbf{2}$ & India & 3.010 .000 \\
$\mathbf{3}$ & Myanmar & 2.500 .000 \\
$\mathbf{4}$ & China & 1.709 .151 \\
$\mathbf{5}$ & United States of America & 1.159 .290 \\
\hline $\mathbf{6}$ & Mexico & 1.122 .720 \\
$\mathbf{7}$ & United Republic of Tanzania & 850.000 \\
$\mathbf{8}$ & Uganda & 440.000 \\
$\mathbf{9}$ & Argentina & 336.779 \\
\hline $\mathbf{1 0}$ & Indonesia & 325.000 \\
$\mathbf{1 1}$ & Rwanda & 308.000 \\
$\mathbf{1 2}$ & Democratic People's Republic of Korea & 300.000 \\
$\mathbf{1 3}$ & Canada & 266.200 \\
\hline $\mathbf{1 4}$ & Kenya & 265.006 \\
\hline $\mathbf{1 5}$ & Cameroon & 250.000 \\
$\mathbf{1 6}$ & Ethiopia & 241.418 \\
$\mathbf{1 7}$ & Burundi & 205.196 \\
$\mathbf{1 8}$ & Iran (Islamic Republic of) & 183.073 \\
$\mathbf{1 9}$ & Nicaragua & 176.655 \\
$\mathbf{2 0}$ & Pakistan & 171.100 \\
\hline
\end{tabular}

SOURCE: Author, with data from FAO http://faostat.fao.org accessed in September, $17^{\text {th }}, 2010$

Brazilian BEANS (Dry)'s Production (t), per Province, 2008

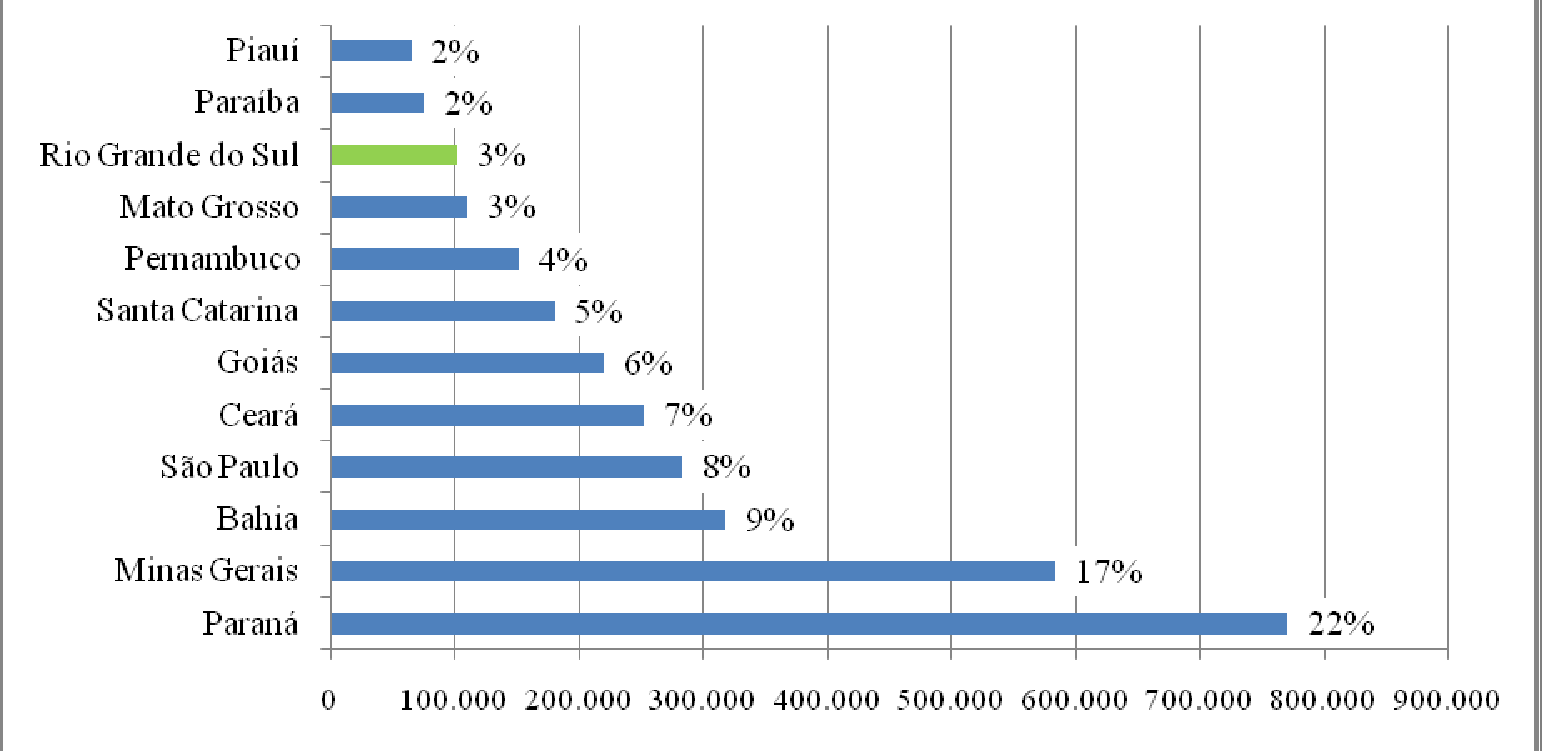

Figure 63 - Brazilian beans (dry)'s production (t), per province, 2008

SOURCE: Author, with data from IBGE http://www.sidra.ibge.gov.br accessed in September, $17^{\text {th }}, 2010$ 